\author{
UNIVERSIDADE DE SÃO PAULO \\ FACULDADE DE FILOSOFIA, LETRAS E CIÊNCIAS HUMANAS \\ DEPARTAMENTO DE GEOGRAFIA \\ PROGRAMA DE PÓS-GRADUAÇÃO EM GEOGRAFIA FíSICA
}

LUZIA MATOS DE SOUZA

Vulnerabilidade da População e os

Processos de Corridas de Detritos e Inundações Bruscas

(Versão corrigida) 


\author{
UNIVERSIDADE DE SÃO PAULO \\ FACULDADE DE FILOSOFIA, LETRAS E CIÊNCIAS HUMANAS \\ DEPARTAMENTO DE GEOGRAFIA \\ PROGRAMA DE PÓS-GRADUAÇÃO EM GEOGRAFIA FÍSICA
}

LUZIA MATOS DE SOUZA

\title{
Vulnerabilidade da População e os \\ Processos de Corridas de Detritos e Inundações Bruscas
}

(Versão corrigida)

Tese apresentada ao Programa de PósGraduação em Geografia Física da Faculdade de Filosofia, Letras e Ciências Humanas da Universidade de São Paulo para a obtenção do título de Doutor.

Área de Concentração: Geografia Física.

Linha de Pesquisa: Estudos interdisciplinares em pedologia e geomorfologia

Agência de Fomento: Coordenação de Aperfeiçoamento de Pessoal de Nível Superior (CAPES)

Orientadora: Prof ${ }^{a}$. Dr ${ }^{\mathrm{a}}$. Bianca Carvalho Vieira.

Supervisor Estágio-Sanduiche: Prof. Dr. Carlos Valdir M. Bateira Universidade do Porto (Portugal) Processo CAPES (PDSE): 88881-190037/2018-01

São Paulo 


\section{ENTREGA DO EXEMPLAR CORRIGIDO DA TESE}

\section{$\underline{\text { Termo de Ciência e Concordância da orientadora }}$}

Nome do (a) aluno (a): Luzia Matos de Souza

Data da defesa: __11_/_01_/_2021_

Nome do Prof. (a) orientador (a): Bianca Carvalho Vieira

Nos termos da legislação vigente, declaro ESTAR CIENTE do conteúdo deste EXEMPLAR CORRIGIDO elaborado em atenção às sugestões dos membros da comissão Julgadora na sessão de defesa do trabalho, manifestando-me plenamente favorável ao seu encaminhamento e publicação no Portal Digital de Teses da USP.

São Paulo, _11___03__2021_ 
Autorizo a reprodução e divulgação total ou parcial deste trabalho, por qualquer meio convencional ou eletrônico, para fins de estudo e pesquisa, desde que citada a fonte.

Catalogação na Publicação

Serviço de Biblioteca e Documentação

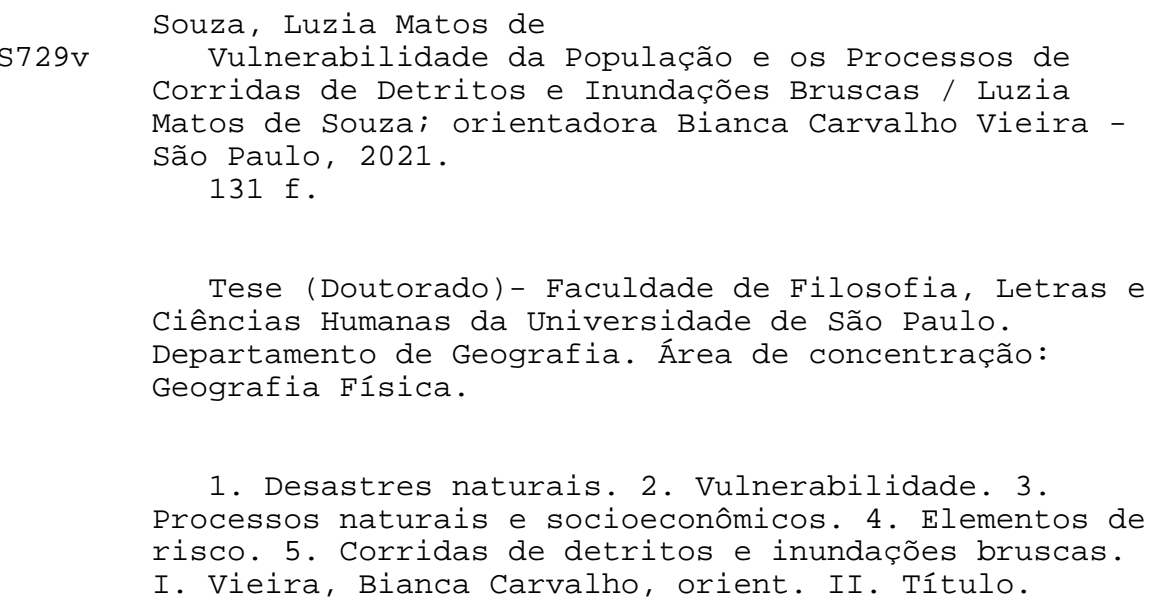




\title{
FACULDADE DE FILOSOFIA, LETRAS E CIÊNCIAS HUMANAS DEPARTAMENTO DE GEOGRAFIA PROGRAMA DE PÓS-GRADUAÇÃO EM GEOGRAFIA FÍSICA
}

\author{
Luzia Matos de Souza \\ Vulnerabilidade da População e os Processos de \\ Corridas de Detritos e Inundações Bruscas \\ (Versão corrigida) \\ Tese apresentada ao Programa de Pós-Graduação em \\ Geografia Física da Faculdade de Filosofia, Letras e \\ Ciências Humanas da Universidade de São Paulo para \\ a obtenção do título de Doutor (a).
}

Banca examinadora:

Profa. Dra. Bianca Carvalho Vieira (orientadora)

Programa de Pós-Graduação em Geografia Física da Faculdade de Filosofia, Letras

e Ciências Humanas da Universidade de São Paulo

Prof. Dr. Carlos Valdir M. Bateira

Departamento de Geografia Universidade do Porto

Profa. Dra. Camila Cunico

Departamento de Geociências Universidade Federal da Paraíba

Dr. Claudio José Ferreira

Instituto Geológico/SMA 


\section{AGRADECIMENTOS}

Interessante pensar que esta é a última página que escrevo; curiosamente os agradecimentos que aqui faço, me levam de volta aos anos de pesquisa e não me deixam esquecer o que aprendi e com quem pude contar. Seguem:

Agradeço a professora Bianca Carvalho Vieira pelos anos de convívio e estudo; agradeço pelo aceite em orientar a pesquisa voltada a vulnerabilidade e a redução de risco, temas que sempre me envolveram e que agora parecem envolver a nós duas.

Sinceramente, Obrigada.

Ao professor Carlos V. de Meneses Bateira, que supervisionou etapa importante deste estudo na Faculdade de Letras (FLUP) - Universidade do Porto.

Aos professores Cláudio J. Ferreira pela colaboração com estes estudos, desde a etapa de qualificação do mestrado, defendido em 2014 e Ligia V. Barrozo pelo auxílio na etapa inicial da pesquisa com o reconhecimento da base de dados do IBGE, 2010.

À Universidade de São Paulo (Programa de Pós Graduação em Geografia Física) e a CAPES, na pessoa da professora Bianca C. Vieira pelas bolsas de estudo e estágio no exterior.

Á Universidade do Porto e laboratório de geografia física nas pessoas do professor Carlos Bateira e do Técnico de laboratório Antônio Costa.

Ao grupo de pesquisa GPMorfo, nas pessoas dos professores: Bianca C. Vieira, Tiago D. Martins, Carlos V. de Meneses Bateira, Marcelo F. Gramani e dos colegas Vivian Dias e Evandro Daniel pelos estudos e os ótimos trabalhos de campo com os quais aprendemos juntos.

Às queridas Thalita (UNICAMP) e Thamires (UNIFESP) também pelos trabalhos de campo e partilha de um pouco da vivência no alto vale do Ribeira.

A prefeitura de Itaoca na pessoa do Júnior Mendes, que de maneira bastante ativa e amigável, colaborou com a realização dessa pesquisa.

A população dos municípios estudados, sobretudo a de Itaoca que viveu a vulnerabilidade que conheço apenas pelos livros.

Termino estas lembranças no ponto em que tudo começou, em um tempo e um espaço em que fui acreditada; no seio da minha família. 
(...) Basta eu embarcar no afluente e chegarei ao rio, e daí ao mar.

A - D. Sertillanges. 
MATOS, J. L. (2020) Vulnerabilidade da população e os processos de corridas de detritos e inundações bruscas. Tese de Doutorado. Programa de Pós-Graduação em Geografia Física, Universidade de São Paulo.

\section{RESUMO}

A recorrência dos cenários críticos em estudos voltados a redução de risco ressalta os limites do conhecimento, no que tange a interdependência entre as variáveis do perigo às corridas de detritos e a vulnerabilidade alcançada pelos elementos atingidos. No Brasil, as corridas de detritos estão sempre associadas aos níveis de catástrofe, diante dos elevados registros que contabilizam os danos e as perdas decorrentes, sem o aproveitamento, contudo, de estudos voltados a vulnerabilidade. Nesse contexto, o objetivo central da pesquisa foi avaliar a condição de vulnerabilidade da população aos processos de corridas de detritos e inundações bruscas. Para tanto, adotou-se o método SAVE (Spatial Approach to Vulnerability Assessment) estabelecendo os fatores e dimensões de análise pertinentes ao processo por meio 5 etapas: 1) Mapeamento dos processos de corridas de detritos e inundações bruscas, 2) Seleção e cálculo dos índices de vulnerabilidade, 3) Elaboração de seus indicadores, tendo em base as dimensões de análise: sensibilidade, exposição e déficit de resiliência. 4) Construção da vulnerabilidade final e 5) Avaliação da vulnerabilidade obtida e os eventos de 2014. Foram mapeados 70 setores censitários, sendo 42 urbanos e 28 rurais, abrangendo os municípios de Apiaí, Itaoca e Ribeira. A condição da vulnerabilidade alcançada variou desde as classes muito alta a baixa, principalmente pela ação da exposição populacional, que ao se aproximar da sensibilidade alcançou a vulnerabilidade máxima em $2,85 \%$ dos setores de estudo. Nos casos em que ela se aproximou do déficit de resiliência a vulnerabilidade variou entre baixa, 24,28\%; média $38,57 \%$ e alta $34,28 \%$. Destacando os setores atingidos, verificou-se que os 5 dos 7 casos, incluindo o acometido por corridas de detritos, aplicam-se ao segundo caso com vulnerabilidades altas e médias.

Palavras-chave: Risco, Exposição, SAVE, Vale do Ribeira, Setores Demográficos 
MATOS, J. L. Vulnerability of the population and the processes of debris flows and flash floods (Thesis). PhD. Graduate Program in Physical Geography. University of São Paulo.

\section{ABSTRACT}

The recurrence of critical scenarios in studies aimed at risk reduction highlights the limits of knowledge regarding the interdependence between the variables of hazards to debris flows and the vulnerability reached by the risk elements hit. In Brazil, debris flows are always associated with catastrophe levels, given the high records that account for the resulting damage and loss, without, monitoring the vulnerability studies. In this context, the main objective of the research was to assess the condition of the population's vulnerability to the debris flow and flash flood processes. Thus, the SAVE method (Spatial Approach to Vulnerability Assessment) was applied, establishing the factors and dimensions of analysis relevant to the process through 5 steps: 1) Mapping the debris flow and flash flood processes, 2) Selection and calculation of the vulnerability indices, 3) Elaboration of its indicators, based on the following dimensions of analysis: sensitivity, exposure, and the deficit of resilience. 4) Construction of the final vulnerability and 5) Assessment of the vulnerability obtained and the events triggered in 2014. Thus, 70 demographic sectors were mapped, 42 urban and 28 rural, covering the municipalities of Apiaí, Itaoca, and Ribeira. The condition of the vulnerability achieved varied between the very high, high, médium and low levels, mainly due to the action of population exposure, which, when approaching the sensitivity, reached the maximum vulnerability in $2,85 \%$ of the study sectors. In cases where it got closer to the resilience deficit, the vulnerability varied between low level with 24,28\%; medium, 38,57\%, and high 34,28\%. Highlighting the sectors affected, it was found that 5 out of 7 cases, including the one affected by debris flows, apply to the second case with high and medium vulnerabilities.

Keywords: Risk, Exposure, SAVE, Ribeira Valley, Demographic Sectors 


\section{LISTA DE FIGURAS}

Figura 1: Zona de deposição da massa detrítica sobre áreas ocupadas. A) Perfil esquemático. Fonte: Yi Wu, (2003); A1) Caso das corridas de detritos em Vargas, Caraballeda, Venezuela em 1999. Fonte: Larsen et al. (2001); A2) Illgraben, Suiça em 2011. Fonte: Haas et al. (2018); A3) Santa Tereza, Peru, 1998. Fonte: Jornal El comércio".

Figura 2: Corridas de detritos no Brasil e perdas humanas relacionadas. A) Depósitos das corridas de detritos de 1967 em Caraguatatuba, litoral norte de São Paulo, atingindo o andar térreo do hospital, Santa Casa de misericórdia. Fonte: Arquivo Público de Caraguatatuba, 1967. B) Zona de deposição da corrida de detritos em área ocupada de Teresópolis, Rio de Janeiro em 2011. Fonte: Bianca C. Vieira (2011). C) Inundações bruscas, decorrentes de corridas de detritos, atingindo o centro da cidade de Itaoca em 2014. Fonte: Prefeitura Municipal de Itaoca.

Figura 3: Etapas de movimentação de uma corrida de detritos, onde: (1) corresponde a área de colapso, deflagração das corridas de detritos, (2) área cujo processo predominante é a erosão e (3) fluxo e deposição da massa. Fotografia: Cadeia de montanhas do complexo Monte Unzen no Japão, Japonese Sediment Division, (1991). Perfil: Adaptado de Yi Wu, (2003).

Figura 4: Feições morfológicas das corridas de detritos. (A) Porção do cordão lateral "levees" de uma corrida de detritos pretérita em pequeno curso d'água (Vandine, 1996). (B) Transporte de bloco de rocha com aproximadamente 6 metros de diâmetro, durante a movimentação da massa; (C) Represamentos naturais formados pela massa detrítica transportada (Welsh, 2007).

Figura 5: Concentração de depósitos transportados pelas Corridas de detritos de 1967 em Caraguatatuba, SP. Observa-se a acomodação dos blocos em cordões laterais, indicando o caminho traçado pelo rio. Fonte: Cruz (1974).

Figura 6: Corridas de detritos em Teresópolis (RJ). Percurso da corrida de detritos no córrego Vieira em (2011). Destaque para a natureza da massa detrítica na zona de transporte e deposição. Fonte: Bianca C. Vieira, (2011)

Figura 7: (a) Cenário crítico de risco envolvendo a vulnerabilidade das construções ao perigo dos Deslizamentos rasos em Lichtenstein (Alemanha). Fonte: Papatmoma-Khöle et al. 2007. Em (b): Cenário crítico de risco envolvendo a vulnerabilidade das construções ao perigo das corridas de detritos na bacia de Barcelonnette (França) Fonte: Kappes et al. 2012.

Figura 8: Área de estudo com destaque para os municípios de Itaoca, Apiaí e Ribeira. .....23

Figura 9: Municípios de estudo e os aspectos de sua localização. No caso de Apiaí destacase o perímetro da estrutura urbana adjacentes ao morro do ouro. Quanto ao Ribeira e Itaoca, localizam-se nas planícies fluviais do rio Ribeira

Figura 10: Município de Ribeira nos anos de 2019 e 1997. No primeiro destaca-se a área atual do campo de futebol que fora inundado em janeiro de 1997. O segundo exibe registro da enchente do rio Ribeira neste local. Fonte: Fotografia de moradores publicada em formato de vídeo e observada aos 0:58s. na plataforma do YouTube. Propriedade de Batatal - Enchente do Rio Ribeira 1997.

Figura 11: Corridas de detritos deflagradas nas bacias do rio Guarda-Mão e rio Gurutuba em janeiro de 2014. Em A) destaca-se a etapa de colapso da corrida e em c) a deposição dos blocos de rocha, a exemplo do cordão lateral, ambos na bacia do rio Guarda-Mão. Em B) 
observa-se a paisagem deflagrada por deslizamentos rasos e corridas de detritos (destacadas com as setas vermelhas) na bacia do rio Gurutuba.

Figura 12: Área de estudo e os setores demográficos urbanos, urbanos isolados e rurais. . 29

Figura 13: Etapas metodológicas desenvolvidas

Figura 14: Observações realizadas em trabalho de campo na bacia do Rio Guarda-Mão em abril de 2017. (A) medição da altura da casa soterrada; (B) observação de blocos de tamanhos intermediários. (C) barramento natural ao longo do curso principal e (d) depósito de corridas de detritos de 2014.

Figura 15: Demonstração de como a delimitação das feições de corridas de detritos foram aplicadas. Em (A) observa-se a localização do processo na bacia deflagrada, enquanto que nas figuras (B) e (C) buscou-se registrar as feições da corrida de detritos, conforme suas etapas de desenvolvimento.

Figura 16: Características das Inundações bruscas e indicação de alguns pontos de sua delimitação, na altura dos cursos alto e médio do rio Palmital. Em (A) destaca-se o alargamento do canal durante o processo, com a deposição de detritos. Em (B) buscou-se observar a baixa ordenação dos depósitos transportados, bem como a presença do aporte vegetal. (C) Indica a direção das inundações bruscas que arrastaram a ponte do bairro do Lageado.

Figura 17: (A) e (B) Corridas de detritos na bacia do rio Guarda- Mão. (C) e (D) Corridas de detritos e inundações bruscas na bacia do rio Gurutuba. Fonte: Marcelo F. Gramani e Prefeitura de Itaoca (2014).

Figura 18: Corridas de Detritos no Município de Itaoca. A) Corridas de detritos atingindo a bacia hidrográfica do rio Guarda-Mão em um setor rural do município de Itaoca A1) Delimitação das corridas de detritos na bacia do rio Guarda-Mão. B) Corridas de detritos atingindo a bacia hidrográfica do rio Gurutuba no mesmo setor demográfico. B1) Delimitação das corridas de detritos na bacia do rio Gurutuba. Fonte: Imagens históricas; Google Earth (agosto, 2014).

Figura 19: A) Paisagem com deflagrações de corridas de detritos no setor Palmital. Em A1) destaca-se a delimitação das inundações bruscas que atingiram o alto Palmital no município de Apiaí. Fonte: Google Earth, imagens históricas (agosto, 2014). Em B, C e D, observa-se algumas se suas características, como: acomodação de sedimentos, afora do curso do rio, além do aporte vegetal. Fotografias: Prefeitura do Município de Itaoca/Acervo, 2014. 56

Figura 20: Em (A) e (B) observa-se o aspecto das inundações bruscas neste bairro. Em (C) e (D) destaca-se, respectivamente, a destruição da ponte na paisagem ainda recoberta por detritos e a construção da nova ponte. Fonte: A1: Google Earth, imagens históricas (agosto, 2014). Fotografias (A) e (C) Prefeitura do município de Itaoca/Acervo, 2014; (B) e (D) Picanço/UNICAMP, 2014.

Figura 21: Impacto das inundações no centro da cidade de Itaoca. Em (A) observa-se a obstrução da ponte central principalmente por detrito vegetal e lama. Em (B) nota-se a altura a que o rio subiu depositando o material flutuante nas casas e construções próximas. Em (C) percebe-se a força da água e material transportado através do dano à estrutura construtiva. Fonte: Google Earth, imagens históricas (agosto, 2014). Fotografias: Prefeitura do município de Itaoca/Acervo, 2014. 58 
Figura 22: Distribuição e áreas atingidas pelas corridas de detritos e inundações bruscas, em cada setor demográfico.

Figura 23: Observa-se os valores extremos alcançados por cada um dos cinco índices de análise aplicados. Nota-se que a densidade demográfica corresponde ao índice de maior valor, no caso, 1; ao passo que a população infanto-juvenil representa os índices mais baixos com valor máximo alcançado de 0,34 . No caso dos valores mínimos nota-se a densidade demográfica como sendo a menor com 0,000153 e a população feminina como a maior apresentando 0,42 .

Figura 24: Localização dos índices extremos de densidade demográfica. Na Figura 2 observase o índice mais baixo encontrado, enquanto que na Figura 3 destaca-se o mais elevado.. 61

Figura 25: Correlação entre os índices de análise das populações idosa e analfabeta. Destaque para os valores extremos alcançados. 62

Figura 26: Distribuição espacial dos índices: População idosa, analfabeta, feminina e infantojuvenil. Nas Figuras 2, 3 e 4 observa-se a localização dos índices de análise da população idosa e analfabeta. No caso da Figura 2, destaca-se que os índices mais elevados se estabelecem no mesmo setor. Nas figuras 5 e 7 observa-se os índices mais elevados das populações feminina e infanto-juvenil, enquanto que as Figuras 6 e 8 apresentam os índices menos elevados. Nota-se ainda que a população infanto-juvenil mais baixa da Figura 8 localiza-se no mesmo setor em que as populações idosa e analfabeta mais elevadas se estabelecem.

Figura 27: Comparação entre os índices da População Feminina e Infanto-juvenil nos setores de análise. Destaque para os índices extremos.

Figura 28: A população total e o percentual da população permanentemente exposta. 65

Figura 29: Observa-se a distribuição da população ao longo dos setores, por meio das variáveis população total e perfis da exposição permanente, ressaltando os índices extremos.

Figura 30: Distribuição espacial dos perfis de exposição permanente. Na Figura 2 observa-se que os índices urbanos são, relativamente, mais baixos, enquanto que na Figura 3, onde predominam os setores rurais, reúnem-se alguns dos índices mais elevados.

Figura 31: Distribuição dos perfis de exposição permanente da população. Destaque para os índices extremos alcançados em cada perfil de análise.

Figura 32:Localização dos perfis de exposição permanente da população na área de estudo. Destaque para os setores com índices extremos alcançados.

Figura 33:Observa-se os índices alcançados pelas variáveis de análise que compõem o déficit de resiliência.

Figura 34: Articulação entre os índices da PEA e da Situação da Renda em função do déficit de resiliência......

Figura 35: Destaca-se os fatores de análise que compõem a variável, situação da renda. No caso do índice mais baixo, 0,4850, observa-se a ausência de uma população atingida e os baixos valores dos perfis, população com renda e sem renda. Quanto ao setor com o indicador mais elevado, 1,7103, nota-se, novamente a ausência da população atingida, contudo o perfil da renda populacional foi bastante elevado. 
Figura 36: Distribuição dos índices da PEA e da Situação da Renda. Nota-se tendência de aumento dos índices da PEA nos setores urbanos e os da Situação da Renda nos setores rurais, destacando os setores com os índices extremos dessas variáveis de análise. .71

Figura 37:Observa-se que o setor com a condição de moradia mais alta, apresentou distribuição semelhante entre os fatores de análise. No setor com a condição de moradia mais baixa destaca-se a ausência da população atingida e dos domicílios sem serviços, diminuindo o déficit de resiliência.

Figura 38: Distribuição dos setores com índices da Condição de Moradia. Destaque para os setores com índices extremos, como o "0" concentrado em 12 setores urbanos em Apiaí e 1,235 em um setor rural, propriamente, no Guarda-Mão e Gurutuba. 73

Figura 39:Observa-se o quanto os índices da dimensão de sensibilidade variaram, destacando os setores com indicadores extremos nos setores de análise.

Figura 40: Registros dos indicadores de sensibilidade nos setores urbanos e rurais, com destaque para os valores extremos alcançados nas Figuras. 2 e 3.

Figura 41: Setores com a sensibilidade máxima (1) e mínima $(0,00070)$ alcançadas. Entre elas, destaca-se a ampla variação no índice, densidade demográfica. A população analfabeta e infanto-juvenil variou pouco.

Figura 42: Mapa da Sensibilidade final da população. Nota-se a ausência de setores com sensibilidade muito baixa, predomínio de sensibilidade baixa em setores rurais e concentração dos setores com sensibilidade média e alta nos centros urbanos.

Figura 43: Variação da exposição populacional nos setores demográficos. Destaque para os índices extremos.

Figura 44: Nota-se que o aumento da população total, no setor com a exposição mais baixa, é acompanhado da diminuição do perfil populacional mais exposto. Da mesma maneira, a diminuição da população total, no setor em que a exposição é mais alta, o perfil populacional com exposição permanente aumenta.

Figura 45: Distribuição espacial da população com exposição permanente 80

Figura 46: Variação dos indicadores do déficit de resiliência. Destaca-se os setores com os indicadores extremados, além das variações mais acintosas ao longo dos 70 setores aplicados.

Figura 47: Distribuição dos indicadores do déficit de resiliência em meio as infraestruturas urbanas e rurais, destacando os setores com indicadores extremos.

Figura 48: Observação das variáveis de análise nos setores com indicadores finais extremos. No setor com o indicador do déficit de resiliência mais baixo 0,3419, o índice da condição de moradia, foi determinante. No caso do setor com o indicador mais elevado (1), tratou-se da condição de moradia, seguida da situação da renda.

Figura 49: Classificação dos indicadores de análise na dimensão do déficit de resiliência. . 83

Figura 50: Variação dos indicadores da vulnerabilidade final. 84

Figura 51: Distribuição das classes da vulnerabilidade final nos setores demográficos. 85 
Figura 52: Localização do setor demográfico com a maior vulnerabilidade alcançada em Apiaí.

Figura 53: Indicadores do setor demográfico com a maior vulnerabilidade alcançada......... 86

Figura 54: Localização do setor demográfico com a menor vulnerabilidade alcançada. ...... 87

Figura 55: Indicadores do setor demográfico com a menor vulnerabilidade alcançada........87

Figura 56: "Setores não atingidos" e a "vulnerabilidade final" destes setores...................... 88

Figura 57: "Setores atingidos" e a "vulnerabilidade final" destes setores............................. 88

Figura 58: Elementos de risco atingidos e processos naturais deflagrados .......................91

Figura 59: Observa-se o impacto nos domicílios e população atingida na dimensão do déficit de resiliência. Legenda: (PEA) População Economicamente Ativa, (PA) População Atingida (DA) Domicílios Atingidos; (CM) Condição de Moradia e (SR) Situação da Renda.............. 92

Figura 60: Organograma esquemático demonstrando a ação combinada entre as dimensões de análise em função da vulnerabilidade final.

Figura 61: Movimentos da dimensão de exposição e seu impacto na vulnerabilidade final . 96

Figura 62: A paleta de cores no centro da figura representa a primeira classificação aplicada, indicando $3 \%$ da área com vulnerabilidade muito alta, 50\% alta e 47\% média. Em seu entorno observa-se as extensões e indicadores máximos e mínimos de cada uma das 6 associações que interferiram na vulnerabilidade final.................................................................... 99

Figura 63: Mapa da estrutura que embasa a vulnerabilidade final. ................................ 100 


\section{LISTA DE TABELAS}

Tabela 1: Organização socio demográfica dos municípios estudados ............................................... 28

Tabela 2: Fórmulas para obtenção dos indicadores de sensibilidade a partir dos MODELOS 1 e 2... 33

Tabela 3: Fórmulas para obtenção dos indicadores de exposição a partir dos MODELOS 1 e 2. ...... 35

Tabela 4: Fórmulas para obtenção dos indicadores do déficit de resiliência. ..................................... 37

Tabela 5: Construções e Domicílios Atingidos pelos Processos de 2014 ........................................... 46

Tabela 6: Modelos de Classificação para a vulnerabilidade Final ...................................................... 49

Tabela 7: Classes de Vulnerabilidade e os Processos Naturais em Apiaí e Itaoca. ............................ 89 


\section{Sumário}

RESUMO

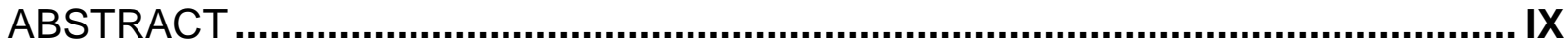

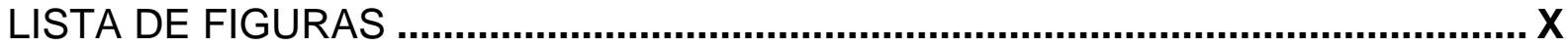

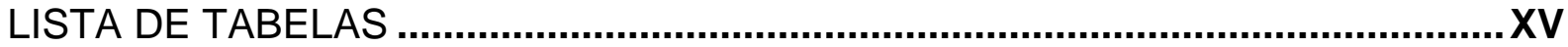

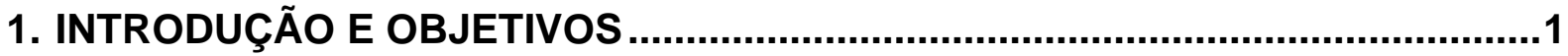

2. EMBASAMENTO TEÓRICO-METODOLÓGICO..................................................

2.1 Corridas de Detritos: Principais Características.............................................................................. 5

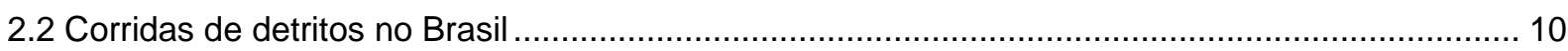

2.3 Cenários de Risco: Conceitos e Abordagens de Análise ............................................................ 15

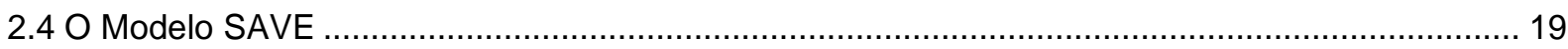

3. ÁREA DE ESTUDO

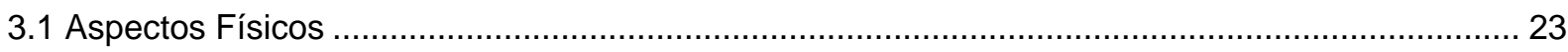

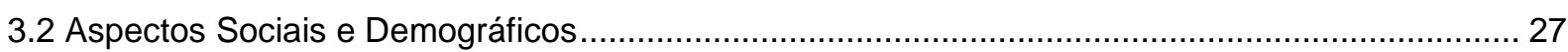

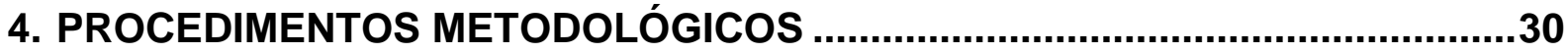

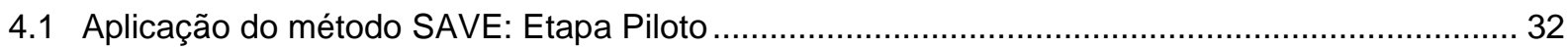

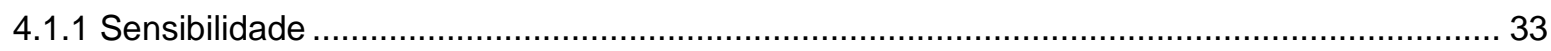

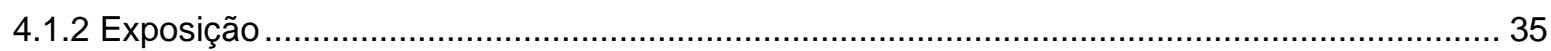

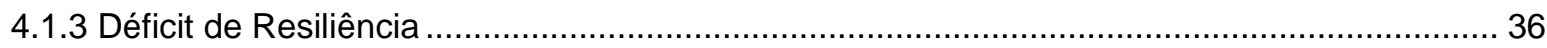

4.2 Aplicação do método SAVE: Limitações e Redefinição da Área ...................................................... 38

4.2.1 Mapeamento das Corridas de Detritos e Inundações Bruscas................................................ 38

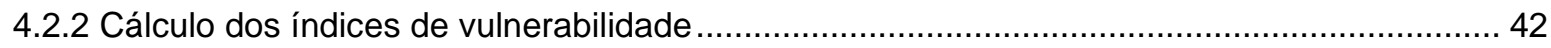

4.2.3 Elaboração dos Indicadores de Vulnerabilidade por Dimensão de Análise ........................... 47

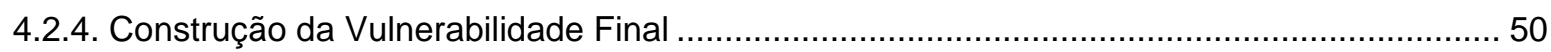

4.2.5. Vulnerabilidade Final e o Evento de 2014 ..................................................................... 51

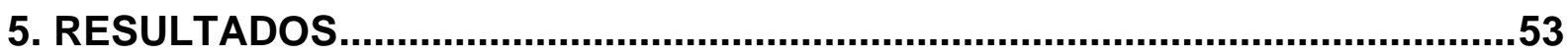

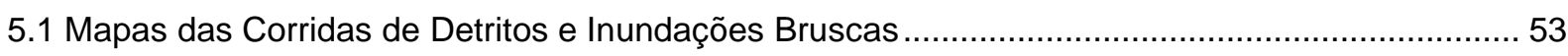

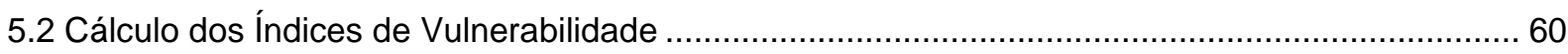

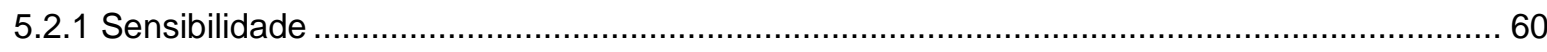

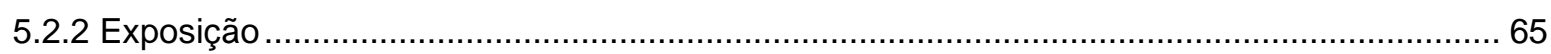

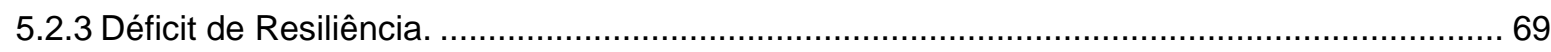

5.3 Elaboração dos Indicadores de Vulnerabilidade por Dimensão de Análise .................................. 74

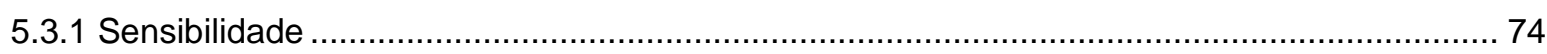

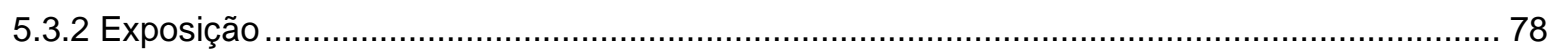

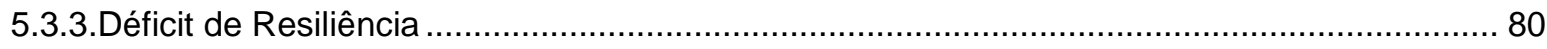

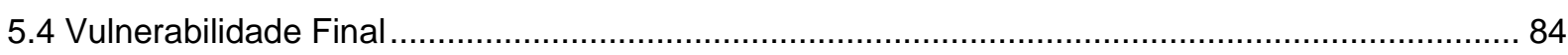

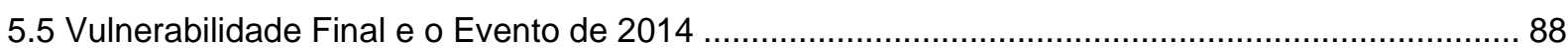


6. DISCUSSÕES

.93

7. CONSIDERAÇÕES FINAIS....................................................................101

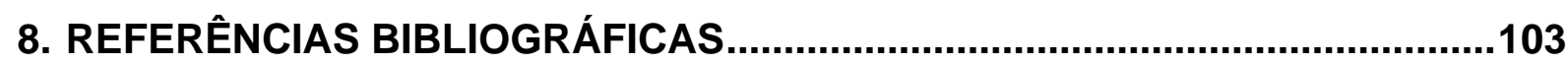

ANEXO 1: DENSIDADE DA POPULAÇÃO (DIMENSÃO DE SENSIBILIDADE) ....107 ANEXO 2: POPULAÇÃO FEMININA (DIMENSÃO DE SENSIBILIDADE) ..............108 ANEXO 3: POPULAÇÃO INFANTO-JUVENIL (DIMENSÃO DE SENSIBILIDADE) 109 ANEXO 4: POPULAÇÃO IDOSA (DIMENSÃO DE SENSIBILIDADE). .110 ANEXO 5: EXPOSIÇÃO FINAL DA POPULAÇÃO - MODELO 1 111 


\section{INTRODUÇÃO E OBJETIVOS}

As corridas de detritos e seus mecanismos caracterizam-se por sua dinamicidade, tipificando suas zonas de movimento e dirigindo seu percurso, conforme a densidade detrítica e o fluxo de água. Da mesma maneira, a vulnerabilidade configura-se como um processo dinâmico, no espaço e no tempo (AUBRECHT et al. 2013), condicionado, sobretudo pela exposição dos elementos de risco ao perigo e reforçado por sua fragilidade (CARDONA, 2004). Dessa maneira, a combinação entre estes dois processos, favorece o desenvolvimento dos cenários de risco, tornando bastante complexo o campo de pesquisa voltado as suas análises.

Propriamente sobre as corridas de detritos, Guidicini e Nieble (1976) as definem como movimentos rápidos nos quais os materiais se comportam como fluídos altamente viscosos e conforme o tipo predominante de material podendo ser classificados como corridas de lama, de terra ou de detritos. Em Wolle e Carvalho, (1994) as corridas de detritos caracterizam-se em escoamentos rápidos de água e materiais sólidos de diversos tamanhos e constituições, que demandam elevadas energias e apenas ocorrem em condições excepcionais, em que o fluxo de água ou de materiais sólidos é suficientemente elevado para produzi-las. Dessa maneira, a deflagração destes processos se manifesta como as mais expressivas na paisagem, por mobilizarem alto volume de material e alcançarem grandes distâncias (AUGUSTO FILHO, 1993; IPT, 2002).

Diante dessa capacidade de alcance das corridas de detritos, destaca-se a deposição de seus detritos em altitudes mais baixas, caracterizadas como as zonas de transporte e acomodação do material mobilizado. Nesta zona afere-se a vulnerabilidade dos sistemas socioeconômicos, físicos ou populacionais, culturais e ambientais (BIRKMANN et al. 2013) (Figura 1). Dessa maneira, observa-se que a situação da vulnerabilidade de um sistema ou elemento de risco atingido corresponde essencialmente a sua capacidade em lidar com os efeitos adversos do processo perigoso, podendo tomar a dimensão de desastres ou catástrofes (CANNON 2008; ONU/ISDR, 2009; AUBRECHT et al. 2013). 

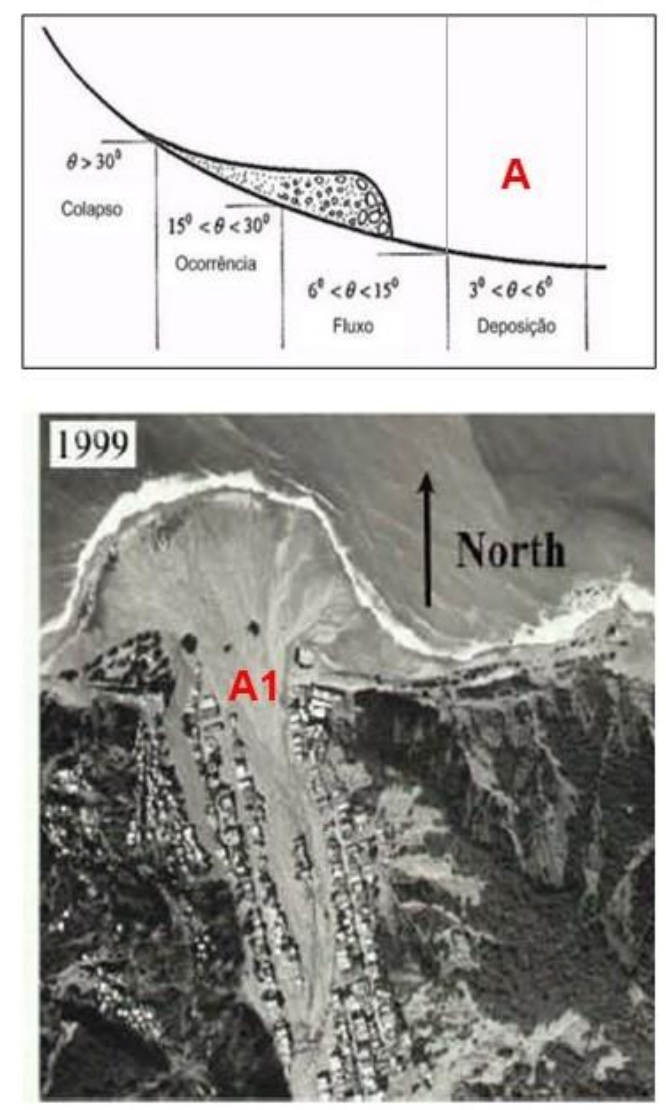

Figura 1: Zona de deposição da massa detrítica sobre áreas ocupadas. A) Perfil esquemático. Fonte: Yi Wu, (2003); A1) Caso das corridas de detritos em Vargas, Caraballeda, Venezuela em 1999. Fonte: Larsen et al. (2001); A2) Illgraben, Suiça em 2011. Fonte: Haas et al. (2018); A3) Santa Tereza, Peru, 1998. Fonte: Jornal El comércio".

Em diferentes regiões do mundo, a combinação desses processos, tem resultado diferentes graus de perdas e danos às sociedades atingidas, gerando consequências que variam desde níveis administráveis até catastróficos. Contudo, os eventos amplamente divulgados na literatura correspondem, em sua maioria, aqueles que impulsionaram grandes desastres (MARCHI e TECCA, 2006; SANTI et al. 2011). Dessa forma, muitos trabalhos voltados a redução de risco, envolvendo as corridas de detritos deparam-se com um banco de dados polarizado no que tange as forças de impacto e criação dos índices de corridas de detritos (JAKOB et al. 2012).

No caso do Brasil, estes processos merecem destaque, ainda que sua recorrência seja menos frequente, quando comparadas aos deslizamentos rasos (EMDAT, 2016), por suscitar a formação de cenários catastróficos (Figura 2). Contudo, ressalta-se a necessidade de registros voltados as deflagrações de baixa magnitude, tendo em vista sua contribuição à maior lucidez acerca da relação entre o processo e 
suas consequências. Somente na Serra do Mar há registros sistemáticos de deflagrações desde 1960; mesmo assim, elas ainda estão desacompanhadas de avaliações condizentes à vulnerabilidade dos elementos de risco atingidos.
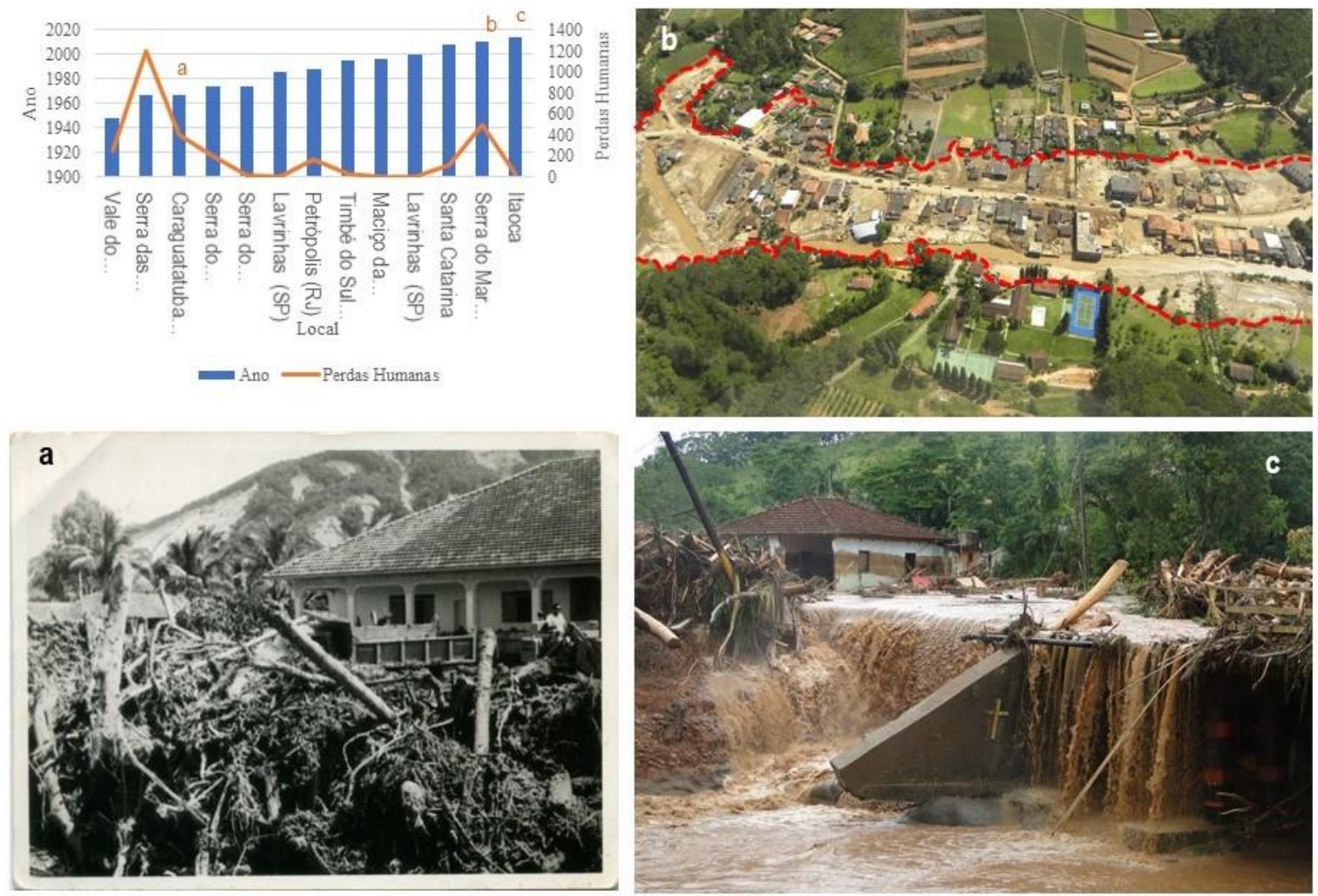

Figura 2: Corridas de detritos no Brasil e perdas humanas relacionadas. A) Depósitos das corridas de detritos de 1967 em Caraguatatuba, litoral norte de São Paulo, atingindo o andar térreo do hospital, Santa Casa de misericórdia. Fonte: Arquivo Público de Caraguatatuba, 1967. B) Zona de deposição da corrida de detritos em área ocupada de Teresópolis, Rio de Janeiro em 2011. Fonte: Bianca C. Vieira (2011). C) Inundações bruscas, decorrentes de corridas de detritos, atingindo o centro da cidade de Itaoca em 2014. Fonte: Prefeitura Municipal de Itaoca.

O caso do vale do Ribeira, no interior de São Paulo, cujas deflagrações ocorreram em janeiro de 2014 não destoa dessa realidade. A este exemplo, destacase, principalmente o município de Itaoca, por ter sido intensamente atingido por corridas de detritos e inundações bruscas, sem, contudo, apresentar intervenções mitigatórias posteriores capazes de diminuir objetivamente a vulnerabilidade alcançada em 2014. De maneira geral, todo esse contexto desponta amplas incertezas e pouco conhecimento acerca da vulnerabilidade as corridas de detritos nas paisagens brasileiras. 
Diante do exposto, destacam-se duas questões estruturais justificando o presente estudo. A primeira justificativa ressalta a escassez de estudos voltados às corridas de detritos no Brasil, na perspectiva da redução de riscos dificultando a avaliação da vulnerabilidade dos elementos de risco a este processo. Atualmente, muitas paisagens com recorrentes deflagrações de corridas de detritos encontram-se ocupadas, sem restrição ou planejamento de risco para as moradias próximas aos canais ou em zonas de deposição destes processos (MATOS et al., 2017). Esforços na literatura nacional predominam na tentativa do reconhecimento físico e classificações do processo perigoso como se observa em: Meis e Silva (1968); Augusto Filho (1993), Kanji e Gramani (2001) e Ferreira et al. (2016). A segunda se formula diante da recorrência dos cenários críticos, nas regiões brasileiras, posto que podem estar associados a elevação dos danos e das perdas diante das corridas de detritos, atingindo bairros, cidades, paralisando serviços e acabando por classificar o Brasil como uma sociedade de baixa resiliência. A este exemplo observa-se a relação entre corridas de detritos e as consequências alcançadas nos anos do impacto em Gramani, (2001); Kanji, Massad e Cruz (2003) e ABGE, (2014).

A partir das premissas e justificativas descritas, a presente pesquisa destaca as deflagrações das corridas de detritos nos municípios de Itaoca e Apiaí, atingidos em 2014 e Ribeira, por sua proximidade e experiência com desastres naturais anteriores, afim de responder a pergunta central: Qual a vulnerabilidade da população às corridas de detritos no período compreendido entre 2010 - 2014, nos municípios de Apiaí, Itaoca e Ribeira?; em outras palavras: Qual a capacidade de resposta da população as corridas de detritos neste período? Dessa maneira, o objetivo central da pesquisa foi avaliar a condição de vulnerabilidade da população aos processos de corridas de detritos e inundações bruscas. Para tanto, alguns objetivos específicos foram delimitados: I) Identificar como os fatores e dimensões de análise conformaram a vulnerabilidade alcançada neste período; II) Avaliar a aplicabilidade do SAVE nos municípios de Apiaí, Itaoca e Ribeira, Vale do Ribeira (SP); III) Analisar grau de assertividade da vulnerabilidade final. 


\section{EMBASAMENTO TEÓRICO-METODOLÓGICO}

\subsection{Corridas de Detritos: Principais Características}

As corridas de detritos são processos que marcadamente correspondem a uma massa contínua composta por partículas sólidas com diferentes diâmetros, podendo ser transportadas, inicialmente pela gravidade do terreno e alcançando maior mobilidade, conforme a quantidade de água ou lama envolvida (TAKAHASHI, 2007).

A deflagração dos processos de corridas de detritos caracteriza-se por grande impulso erosivo gerando intensa força de impacto ao longo de seu percurso (IPT, 2002). Seu desenvolvimento é acentuado ao longo de drenagens nos vales encaixados das encostas até que, ao atingir vales mais abertos ou planícies, com declividades mais baixas, ocorre um espraiamento, cessando a corrida (STINY, 1997) (Figura 3).

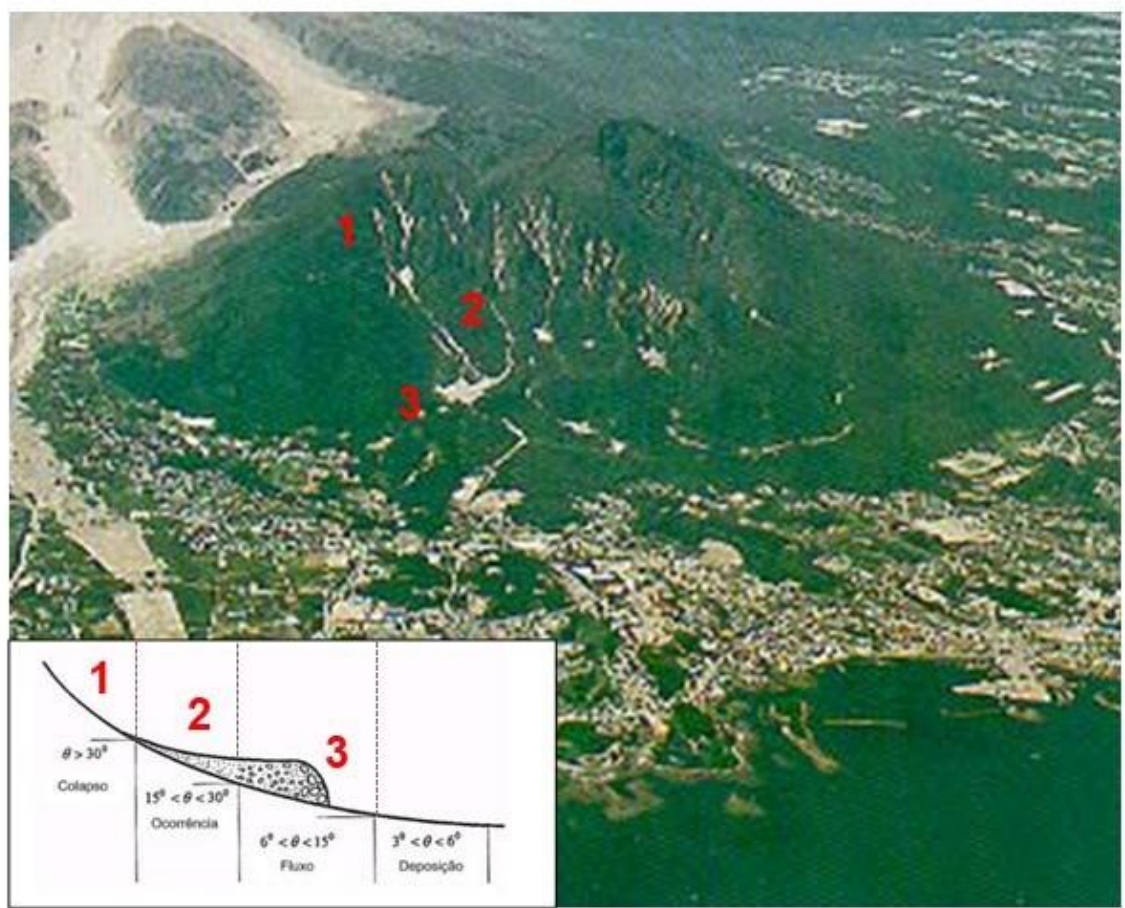

Figura 3: Etapas de movimentação de uma corrida de detritos, onde: (1) corresponde a área de colapso, deflagração das corridas de detritos, (2) área cujo processo predominante é a erosão e (3) fluxo e deposição da massa. Fotografia: Cadeia de montanhas do complexo Monte Unzen no Japão, Japonese Sediment Division, (1991). Perfil: Adaptado de Yi Wu, (2003). 
Nesse contexto, o mecanismo de transporte das corridas de detritos varia, conforme a composição da massa sólida, que pode apresentar camadas espessas de partículas mais finas, arenosas e até cascalhentas, conferindo à massa detrítica uma dinâmica mais fluida e menos veloz ao movimento (TAKAHASHI, 2007).

Para os detritos maiores, como os fragmentos de rocha que podem apresentar a partir de 1 metro de diâmetro, acabam por condicionar, juntamente às inclinações da bacia, o transporte gravitacional com velocidades mais altas (STINY, 1997; TAKAHASHI, 2007). Neste processo, feições morfológicas características das corridas de detritos como as levees, a inversão granulométrica e o imbricamento dos blocos são formados, além de represamentos e deflagração de inundações bruscas, flash floods, comumente presentes nestes cenários (Figura 4).

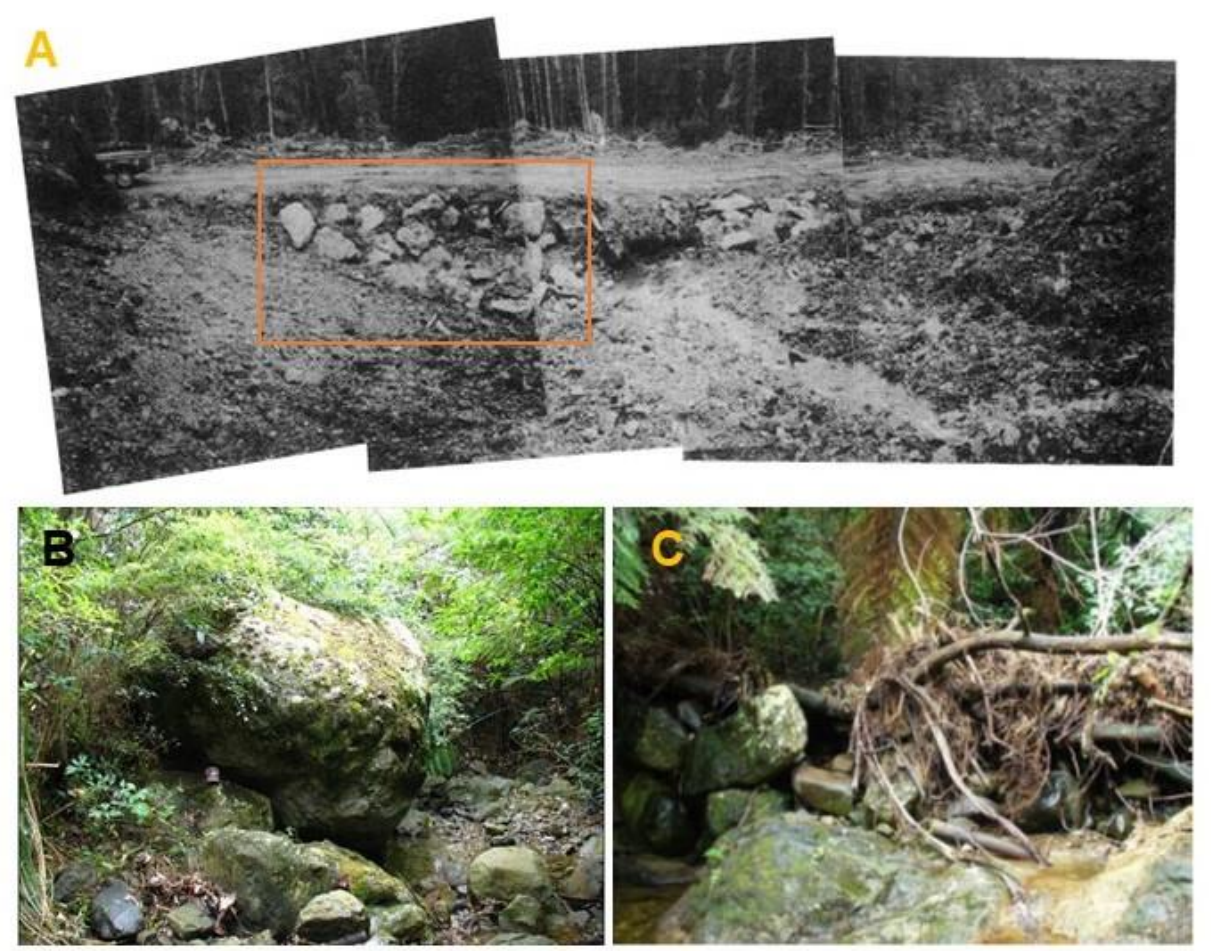

Figura 4: Feições morfológicas das corridas de detritos. (A) Porção do cordão lateral "levees" de uma corrida de detritos pretérita em pequeno curso d'água (Vandine, 1996). (B) Transporte de bloco de rocha com aproximadamente 6 metros de diâmetro, durante a movimentação da massa; (C) Represamentos naturais formados pela massa detrítica transportada (Welsh, 2007). 
De maneira geral, a disponibilidade de material inconsolidado em uma paisagem poderá conduzir os mecanismos do fluxo. No caso de ambientes onde a quantidade de material é baixa, o escoamento do fluxo tende a erodir o canal, aumentando sua concentração, na mesma medida em que, quando sua disponibilidade é alta, o fluxo promove seu depósito, diminuindo-o (TAKAHASHI, 2007).

Neste contexto, os termos Earth flow (corridas de terra), Mud flow (fluxos de lama) e Debris flow (corridas de detritos) são usados para distinguir as três classes de material que, misturados aos diferentes volumes de água, definem o fluxo do processo (SELBY, 1993); podendo ser classificados em três tipos de corridas de detritos, no caso, Stony (Fluxo de Blocos), Muddy (Fluxo de Lama) ou Viscous (Fluxo Viscoso) (TAKAHASHI, 2007).

Contudo, a classificação das corridas de detritos não se limita a seus mecanismos, abarcando também as causas de sua deflagração (TAKAHASHI, 2007). Neste contexto, destaca-se o rápido derretimento de camadas de gelo e neve, durante a primavera e verão nas zonas climáticas temperadas do globo, bem como a precipitação pluvial nas zonas intertropicais, como agentes deflagradores em inúmeros estudos. Nestes casos, as corridas de detritos podem ser deflagradas diretamente, conforme o volume e duração das chuvas, ou ainda como um processo secundário, a exemplo das deflagrações dos deslizamentos de terra antecedendo a formação das corridas de detritos ou em função de um impacto externo em bacias suscetíveis como os incêndios florestais.

Há ainda os fatores endógenos como os abalos sísmicos, vulcanismos e terremotos que podem induzir à deflagração de corridas de detritos. Em paisagens como estas a recorrência das corridas de detritos é ainda mais antiga, surgindo em resposta às forças orogênicas formadoras de montanhas, ao mobilizarem grandes fluxos detríticos na direção dos vales (STINY, 1997).

A exemplo das deflagrações em ambientes impactados pelos incêndios florestais, destaca-se o caso das corridas de detritos iniciadas em setembro de 1994, nas encostas de Storm King, Colorado, Estados Unidos. Seu mecanismo descreveu como os incêndios no Sul do Canyon em julho do mesmo ano conduziram-na, em meio aos dias chuvosos. Neste processo, Cannon et al. (2001) notaram, que as 
cicatrizes de infiltração, comumente observadas no topo das encostas, demarcando o início de uma corrida de detritos, foram reduzidas, enquanto o escoamento superficial da massa foi dominante no processo. Diante desse mecanismo, os autores compreendem que a escassez de incisões nos canais indicam que significativo volume da massa mobilizada, não foi proveniente dos canais, já que o escoamento superficial dominante no processo limitou a formação das áreas de contribuição nas linhas de drenagem e seu gradiente, tornando crítica a iniciação das corridas de detritos. O volume pluviométrico foi o agente deflagrador dessas corridas de detritos, ainda que seu volume exato não tenha sido registrado. A massa detrítica resultante caracterizou-se como uma mistura de lama com detritos vegetais queimados e pequenos fragmentos de rochas (CANNON et al, 2001).

No caso das corridas de detritos deflagradas diretamente nos canais de drenagem ou ainda as decorrentes dos deslizamentos de terra, destaca-se os estudos de Portilla, Chevalier e Hürlimann (2010) aplicados à cadeia de montanhas dos Pirineus orientais na Espanha, por seu histórico de recorrentes corridas de detritos. Nesta pesquisa discute-se as deflagrações ocorridas durante o ano de 2008, iniciadas com as chuvas convectivas de verão, caracterizadas, portanto, por sua intensa e curta duração.

No caso das corridas de detritos iniciadas diretamente nos canais de drenagem destaca-se as bacias dos rios Runer e Portainé, pelas deflagrações nos meses de agosto e setembro de 2008 , sem apresentar rastros de deslizamentos de terra em sua paisagem. Na bacia do rio Runer, sob as chuvas de $57.0 \mathrm{~mm} / \mathrm{h}$ e inclinação de aproximadamente $15^{\circ}$ observou-se uma progressiva incorporação da massa sólida ao fluxo culminando em uma alta descarga detrítica, ao longo do canal. A magnitude do processo foi de $14.000 \mathrm{~m}^{3}$ e envolveu a formação das levees com poucos blocos com diâmetro de 1 e 2 metros, mas ampla quantidade de material vegetal, volumes de areia, pedregulhos e partículas mais finas. Na Portainé, com chuvas de 14,6 mm/h, a magnitude foi bem maior, totalizando o transporte de uma massa com aproximadamente $26.000 \mathrm{~m}^{3}$. Nela, não houve uma definição muito clara sobre o ponto inicial da corrida; seus autores sugerem que o início se deu por um pequeno processo erosivo que foi amadurecendo ao longo das seções declivosas, erodindo as laterais dos riachos e aumentando o volume do material transportado. 
Quanto às corridas de detritos deflagradas em decorrência dos deslizamentos de terra, vale ressaltar que se tratou dos deslizamentos rasos, nas bacias de Fontanals Del Pui, Andreuet Torrent e Sant Nicolau. A primeira teve início com valores similares do rio Runer em agosto, embora seu pico tenha sido de $14.6 \mathrm{~mm} / \mathrm{h}$. A deflagração das corridas de detritos nesta bacia se deu por meio de pequenas falhas ocupadas por seixos que foram sendo mobilizados, ao longo da encosta, em um processo que alternava entre os impulsos erosivos, sem, contudo, apresentar evidências de deposição. $O$ tamanho das partículas mobilizadas foi menor, quando comparadas as transportadas pelo rio Runer, incluindo pedregulhos e material vegetal que não alcançaram mais que $50-70 \mathrm{~cm}$ de diâmetro, conformando a baixa magnitude de $1.500 \mathrm{~m}^{3}$.

Em Saint Nicolau e Andreuet torrent as chuvas de 13.0 e $13.6 \mathrm{~mm} / \mathrm{h}$ deram início a deflagração dos deslizamentos rasos, nos meses de maio e junho, respectivamente, resultando em corridas de detritos de baixa magnitude. A massa dominante foi composta por detritos vegetais e sedimentação mais fina, apresentando também a formação dos cordões laterais, levees, ainda que os volumes depositados tenham sido de 1.800 e $1.000 \mathrm{~m}^{3}$, respectivamente.

De maneira geral, os volumes totais de chuva que deflagraram as cinco corridas de detritos estudadas em Portilla, Chevalier e Hürlimann (2010) foi de 31 e 65 mm com intensidade de 13 a $57 \mathrm{~mm} / \mathrm{h}$, reforçando o papel das chuvas convectivas de verão. Nestas bacias não houve registro de chuvas nos 8 dias que antecederam as tempestades intensas deflagrando os deslizamentos e corridas de detritos na região, exceto o caso de Saint Nicolas que apresentou $70.8 \mathrm{~mm}$ quatro dias antes das corridas de detritos em 25 de maio de 2008.

Neste contexto, observa-se que a relação entre os volumes pluviométricos e a deflagração de corridas de detritos não é óbvia, sobressaltando os casos em que as corridas de detritos decorrem dos deslizamentos de terra, pois que há necessidade de maior tempo para que o solo seja saturado (TAKAHASHI, 2007). Este autor sugere ainda que, salvo as condições do abastecimento de água nas bacias, são as espessura e propriedades dos solos, características da encosta e condições dos leitos da bacia que afetam significativamente o início das corridas de detritos. 


\subsection{Corridas de detritos no Brasil}

As corridas de detritos são recorrentes nas paisagens brasileiras, sobretudo nos ambientes tropical e subtropical, com vários registros na Serra do Mar (SP e RJ), Serra da Mantiqueira (SP e MG), Serra Geral (SC e RS) e Serra de Maranguape (CE), abrangendo estados das regiões sudeste, sul e nordeste (GRAMANI, 2001). Historicamente, muitos desses registros demonstram que as deflagrações das corridas de detritos no Brasil são decorrentes dos deslizamentos de terra, durante as estações chuvosas nos meses de dezembro a março.

De maneira geral estas deflagrações resultam de chuvas orográficas em encostas com altitudes entre 600 e $1.300 \mathrm{~m}$, sobre bacias hidrográficas isoladas ou em sequência (GRAMANI, 2001). Neste ambiente, a deflagração das corridas de detritos no Brasil, tem ocorrido sob um volume pluviométrico aproximado de 60 a $70 \mathrm{~mm} / \mathrm{h}$ em bacias relativamente pequenas com inclinações médias de 15 e $20^{\circ}$ e em vertentes com declividades, normalmente acima dos 25 (AUGUSTO FILHO, 1993; KANJI e GRAMANI, 2001). Caracteriza-se também como um fator recorrente registrado nas corridas de detritos observadas, o papel dos solos residuais e coluvionares, bastante presentes no ambiente serrano em função do intenso processo intempérico (KANJI, MASSAD e CRUZ, 2003).

Na região da Serra do Mar, paisagens vizinhas e sua extensão sobre as regiões sul e sudeste, concentra-se o maior número de casos registrados das corridas de detritos no Brasil e consequentemente o maior volume de trabalhos tais como: os eventos de 1966 e 1967 no Rio de Janeiro e São Paulo (Meis e Silva,1968; Petri e Suguio,1971, Cruz, 1974) - Cubatão (SP) em 1985 (IPT, 1987) - Petrópolis (RJ) 1988 (Nakazawa e Cerri 1990) - Cubatão (SP) em 1994 e 1996; Ubatuba (SP) em 1996; Quitite e Papagaio (RJ) em 1996 (Vieira et al, 1996) e Via Anchieta (SP) em 1999 registrados principalmente em Gramani (2001) e Gramani e Kanji (2001).

Quanto as corridas de detritos deflagradas recentemente na Serra do Mar, destacam-se aquelas ocorridas na região serrana do Rio de Janeiro em 2011 (Avelar et al, 2011); e no Vale do Ribeira (SP) em 2014 (Gramani e Arduin, 2015; Ferreira et al. 2016). 
Destacando estes registros, seguem algumas características das corridas deflagradas durante os verões de 1966 e 1967 no Rio de Janeiro e em São Paulo, já que os volumes pluviométricos alcançados nestes anos foram excepcionais, resultando na deflagração de diferentes movimentos de massa.

No caso do Rio de Janeiro, observa-se a deflagração das corridas de detritos em 23 de janeiro de 1966 com índice pluviométrico mensal total de 617,6 mm, concentrado em $472,0 \mathrm{~mm}$ em 72 horas. Vertentes com declividade acima de $25^{\circ}$ foram atingidas e apresentaram cobertura coluvial com espessuras de até 3 metros em alguns pontos das cicatrizes que deram início aos processos; o material mobilizado exibiu alguns blocos espaçados, mas caracterizou-se, sobretudo por material grosseiro, envolvido por densa matriz de partículas finas (MEIS e SILVA, 1968).

A alta plasticidade também caracterizou o material mobilizado no verão de 1967 no estado do Rio de Janeiro, Serra das Araras, diante de novas deflagrações de movimentos de massa, incluindo os deslizamentos rasos e as corridas de detritos. Estas ocorreram em 19 e 20 de fevereiro, sob os registros de $432 \mathrm{~mm}$ de chuva durante o mês, concentradas em 299,5 mm em 48 horas. Neste caso, a massa apresentou-se mais homogenia, exibindo também árvores com deslocamento por mais de 100 metros. Em seu mecanismo, as corridas exibiram um movimento regressivo nas cabeceiras e alargamento dos canais, em um processo de acomodação das paredes íngremes e desiquilibradas pela corrida do material (MEIS e SILVA, 1968).

Em Caraguatatuba, no litoral norte do estado de São Paulo, chuvas fortes de verão culminaram na deflagração generalizada de enchentes, deslizamentos de terra e corridas de detritos (Figura 5). Estes processos tiveram início em 18 de março, sob concentrações pluviométricas de 195,5 mm e volume mensal de 324,8 mm (CRUZ, 1974). Totalizando as áreas atingidas, propriamente pelos deslizamentos e corridas de detritos, a exemplo do vale do Rio Santo Antônio, verificou-se que muitas das vertentes deflagradas apresentaram declividade superior a 22ำ (CRUZ, 1974). Estas corridas de detritos mobilizaram um fluxo detrítico heterogêneo desde as escarpas com blocos de rocha, pedregulhos e material galhoso até a baixada com sedimentação mais fina; no caso deste último, constatou-se um volume aproximado de 2 milhões de toneladas (PETRI e SUGUIO, 1971) 


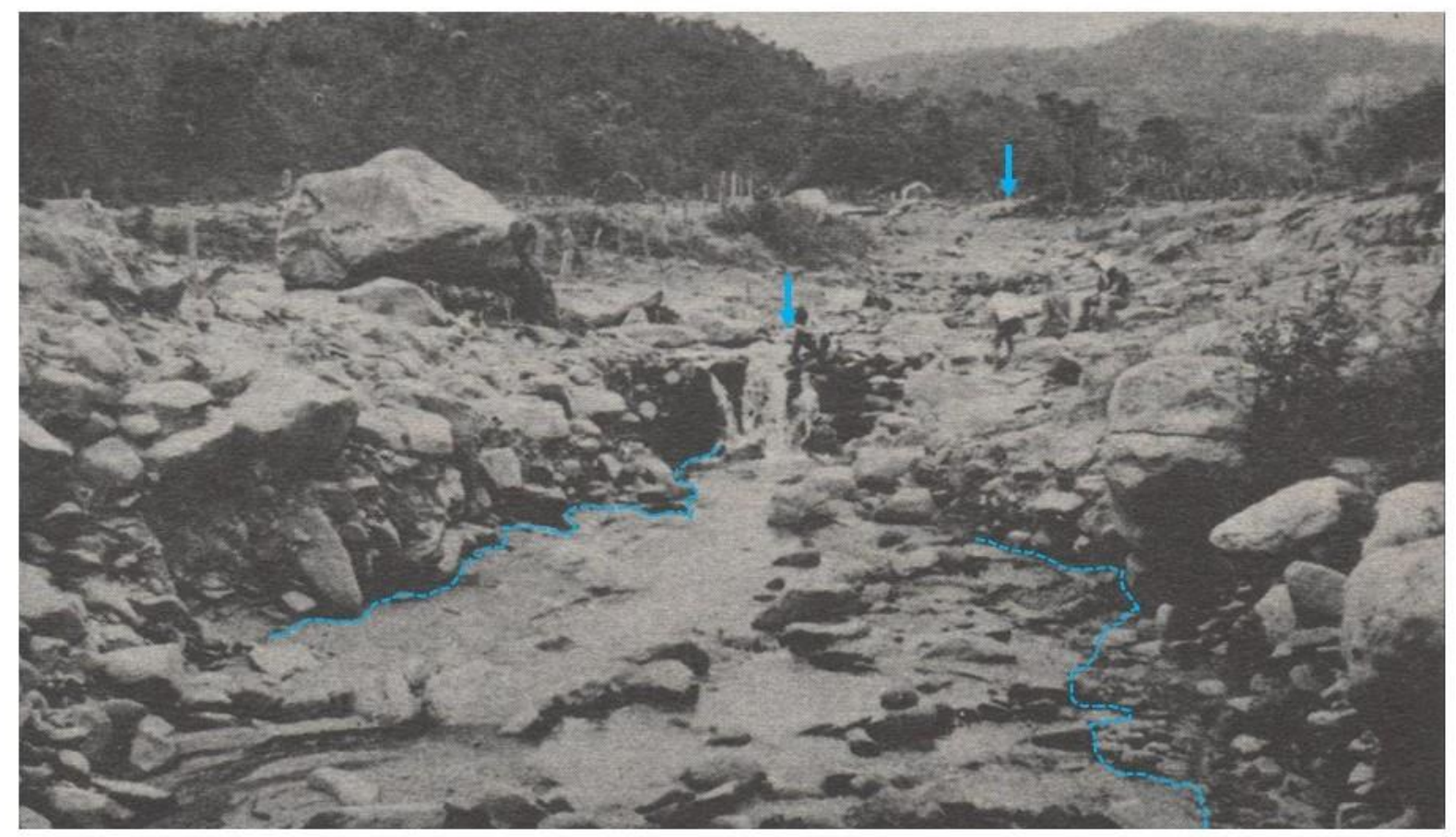

Figura 5: Concentração de depósitos transportados pelas Corridas de detritos de 1967 em Caraguatatuba, SP. Observa-se a acomodação dos blocos em cordões laterais, indicando o caminho traçado pelo rio. Fonte: Cruz (1974).

Nas décadas de 1980 e 1990 novas corridas de detritos foram deflagradas em diferentes regiões da Serra do Mar, envolvendo chuvas de verão que deram início aos processos dos movimentos de massa. Destaca-se aqui o caso da refinaria Presidente Bernardes em Cubatão, atingida por recorrentes corridas de detritos na bacia do córrego das Pedras (2,64 km²), litoral norte de São Paulo. Em 1985 os deslizamentos rasos tiveram início em vertentes com $800 \mathrm{~m}$ de altura situadas logo atrás da refinaria de Cubatão. A formação da massa detrítica se deu por meio das cicatrizes de deslizamento, agregando um enorme volume de lama, madeira e blocos de rocha que chegaram a atingir a face norte da refinaria.

Em 1994 a precipitação pluviométrica de $214 \mathrm{~mm}$ em 24 horas nesta mesma paisagem deflagrou corridas de detritos com velocidade de $10 \mathrm{~m} / \mathrm{s}$ e magnitude de $300.000 \mathrm{~m}^{3}$ distribuídos em lama, areia, pedregulhos, blocos de rocha e grandes quantidades de areia e madeira. Neste processo, a massa detrítica atingiu não apenas a face norte da refinaria, mas também a leste e a oeste. Em 1996 novas corridas de detritos foram deflagradas, embora tenham apresentado magnitude na ordem de $16.000 \mathrm{~m}^{3}$ (KANJI, MASSAD e CRUZ, 2003). 
Dentre as corridas de detritos mais recentes, destaca-se o caso da região serrana do Rio de Janeiro em 2011 (Figura 6) cujas paisagens atingidas em 11 e 12 de janeiro, se estenderam por vários municípios. Neles, as corridas de detritos apresentaram massa heterogênea com blocos de rocha, solo residual, lama e grandes quantidades de água

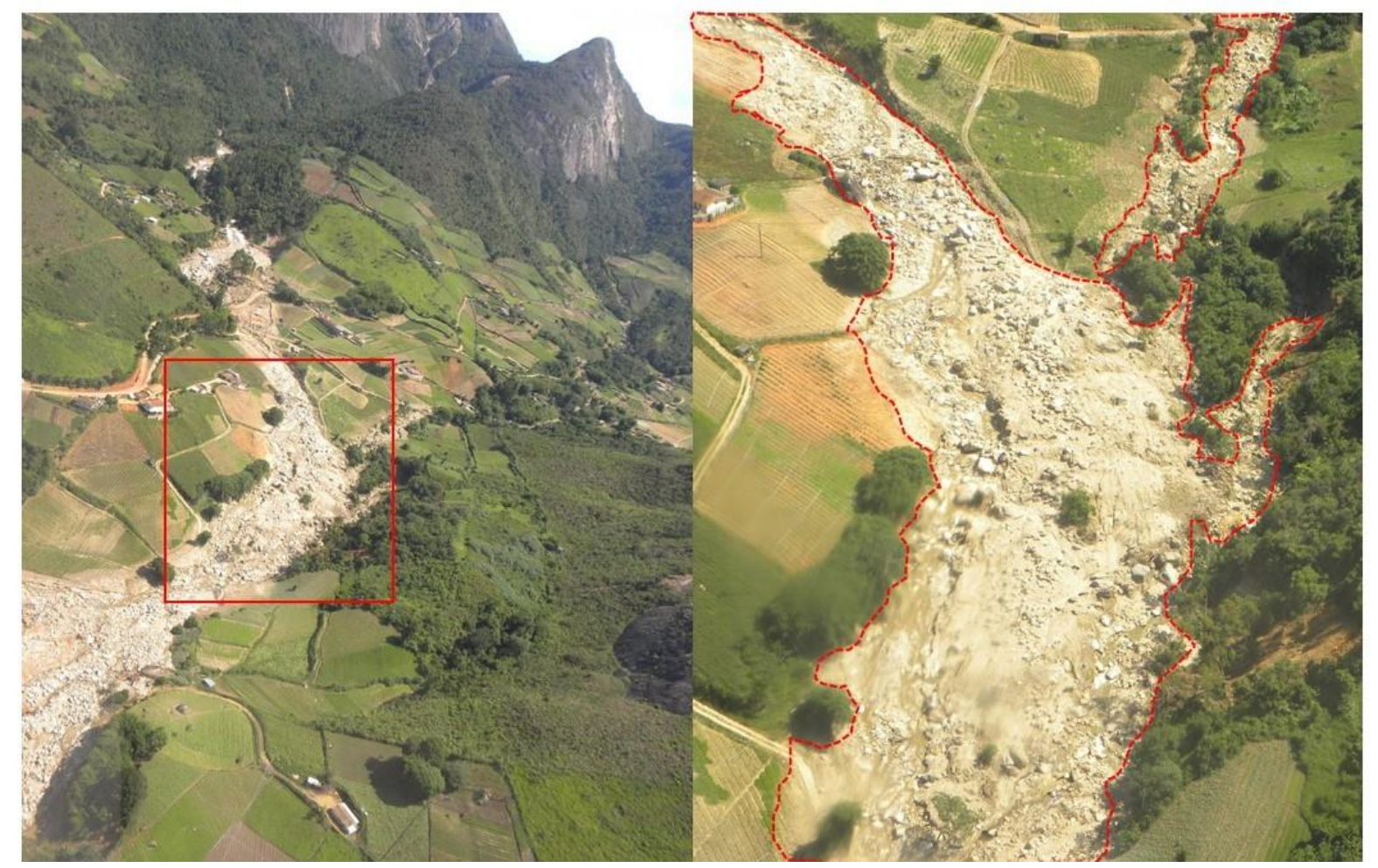

Figura 6: Corridas de detritos em Teresópolis (RJ). Percurso da corrida de detritos no córrego Vieira em (2011). Destaque para a natureza da massa detrítica na zona de transporte e deposição. Fonte: Bianca C. Vieira, (2011)

De maneira geral, os registros pluviométricos diários apontaram $100 \mathrm{~mm}$ para o dia 11 e 150mm para do dia 12 com o início das deflagrações em Petrópolis no vale do rio Cuiabá, por onde a massa detrítica percorreu $9 \mathrm{~km}$ de comprimento e variou entre 20 e 40 metros de largura (AVELAR et al. 2011; LIMA et al. 2020). Nesse contexto, as corridas de detritos deflagradas em Nova Friburgo, bacia do córrego D'antas alcançaram a maior extensão com $11 \mathrm{~km}$ de comprimento e largura de 100 metros (LIMA et al. 2020). Nessa região, observou-se que as corridas de detritos resultaram da conformação dos deslizamentos de terra rasos e planares; ao todo, foram mais de 3000 cicatrizes dos deslizamentos de terra, em vertentes com inclinação variada, atendendo um ângulo de encosta desde $11^{\circ}$ a mais de $30^{\circ}$ 
(AVELAR et al. 2011). Propriamente, os escorregamentos rasos que se conformaram em corridas de detritos, apresentaram cicatrizes em encostas com $45^{\circ}$ de inclinação (LIMA et al. 2020).

Quanto aos registros das corridas de detritos deflagradas na Serra Geral, destaca-se os estudos de Bigarella e Becker, (1975) sobre as deflagrações em Tubarão, (SC), 1974 e Pellerin et al. (1997) em Timbé do Sul (SC), 1997. No caso da primeira, propriamente sobre a região de Tubarão em Santa Catarina as precipitações pluviais também impulsionaram a deflagração de enchentes, deslizamentos e corridas de detritos. Trata-se do verão de 1974 no qual as bacias dos rios Tubarão e Araranguá registraram $742 \mathrm{~mm}$ em 16 dias de chuva, dos quais $251,7 \mathrm{~mm}$ caíram nas 24 horas no dia 25 de março. Os movimentos de massa resultantes nesta região afetaram a porção superior da vertente, mobilizando, portanto, uma camada mais fina do manto de intemperismo, ocasionando grandes quedas de blocos; em seguida, o mecanismo de transporte, dos desmoronamentos, atingiu as porções média e inferior da vertente, abrangendo maior volume de material intemperizado (BIGARELLA e BECKER, 1975). Chama a atenção, as descargas fluviais nos rios da bacia de Tubarão que registraram cheias incomuns; sua planície de inundação sofreu considerável agradação de sedimentos com espessura irregular (BIGARELLA e BECKER, 1975 p. 1062).

Em 1995, no sul do estado de Santa Catarina, novas deflagrações de corridas de detritos ocorreram com percursos distribuídos pelos rios Figueira em Timbé do Sul, Pinheirinho e São Bento (PELLERIN et al. 1997). O registro do início das deflagrações se deu em 23 de dezembro de 1995 com precipitações intensas sobre vertentes bastante íngremes (entre 800 e 900 m), após várias semanas de seca. As precipitações duraram 4 horas e chegaram a aproximadamente $500 \mathrm{~mm}$ em $24 \mathrm{hs}$, originando o fluxo de detritos, que embora tenham exibido troncos de árvores, blocos rochosos, concentrou, sobretudo uma massa detrítica mais fina (PELLERIN et al. 1997) 


\subsection{Cenários de Risco: Conceitos e Abordagens de Análise}

No contexto dos desastres naturais, o risco está ligado a deflagração e as características de um processo geomorfológico perigoso, gerando perdas e danos nos elementos de risco atingidos (HOLLETEIN, 2005).

O Risco é definido como a expectativa de perdas em função da intensidade do processo por determinado tempo abrangendo os conceitos de suscetibilidade, perigo e vulnerabilidade (CARDONA, 2004). No âmbito das ciências naturais, essa relação é expressa em uma equação de risco (Equação 1) que quantifica a formação desse cenário a partir da probabilidade de ocorrência do evento e suas consequências nos elementos de risco (AUBRECHT, 2013).

$$
R=P \times C \quad \text { (Equação 1) }
$$

$(\mathrm{R})$ risco, resulta da $(\mathrm{P})$ probabilidade de ocorrência de determinado processo natural e suas $(C)$ consequências socioeconômicas.

De maneira mais precisa, a Probabilidade $(P)$ de deflagração de um processo natural está associada à compreensão dos conceitos de susceptibilidade e de perigo. O primeiro expressa as condições de ocorrência do processo, conforme análise de um conjunto de fatores físicos em uma área específica, sem considerar, entretanto, os fatores deflagradores como precipitação ou sismicidade (SOETERS e VAN WESTEN, 1996).

A fim de avaliar a suscetibilidade de uma área aos processos geodinâmicos, as técnicas mais utilizadas são as heurísticas ou empíricas, determinísticas e estatísticas, conforme a qualidade de dados disponíveis e o tempo de aplicação necessário (SOUZA e SOBREIRA, 2014).

Lopes (2006) aplicou técnicas determinísticas criando os modelos dinâmico e estático, respectivamente, a fim de simular as condições físicas que levaram a deflagração das corridas de detritos na Serra do Mar nos anos de 1985, 1994 e 1996 e de compreender a fisiografia de áreas com potencial de evolução dos escorregamentos translacionais rasos para as corridas de detritos. A partir de métodos com base estatística 
No caso do perigo, sua correlação com a suscetibilidade está na ação de agentes dinâmicos como a pluviosidade, sismicidade ou "antropização" potencializando ou mesmo deflagrando, efetivamente o processo natural. Trata-se, portanto, de uma variável dinâmica diretamente capaz de atingir pessoas e bens (AUBRECHT, 2013). Neste contexto, muitos trabalhos voltados às avaliações de perigo sobre os movimentos de massa acabam por concentrar-se na definição de zoneamentos que abrangem a área deflagrada (CONWAY et al., 2010) ou ainda, voltados a formação de cenários perigosos com experimentos que alteram as condições do fator deflagrador (Chen et al., 2010) e por fim, na apresentação dos métodos de contenção do processo de modo a diminuir as perdas e os danos (WEINMEISTER, 2007).

Ainda no âmbito da equação de risco, as consequências (C), associam-se a compreensão do conceito de vulnerabilidade, definida nas ciências naturais sendo o grau de perda a um dado elemento ou grupo de elementos de risco diante do processo perigoso, expressando o valor do dano em 0 (sem danos) e 1 (com danos) (UNDRO, 1984).

Sabe-se, entretanto, que o conceito de vulnerabilidade não é universal abrangendo aplicação em diferentes áreas do conhecimento (BIRKMANN, 2006). Nesse sentido, as abordagens conceituais que envolvem diretamente as expectativas desta pesquisa compreendem seu caráter dinâmico, multidimensional e escalar diante de um processo natural perigoso. Abrange, portanto, a concepção do potencial de perda (MICHELL, 1989); as adversidades inerentes às áreas de risco a processos naturais (ALEXANDER, 1993); a exposição e fragilidades das múltiplas dimensões dos elementos em risco ao processo natural perigoso ou antropogênico (CARDONA, 2004) envolvendo, ainda, a capacidade de resposta e absorção do dano durante e depois da deflagração do processo (BIRKMANN, 2006).

Nesse contexto, sua abordagem de análise resulta em pesquisas de face qualitativa, semi-qualitativa ou quantitativa, na medida em que relaciona a intensidade do fenômeno com os níveis de dano estimados a partir dos cenários com potencial de perda (CARDONA, 2004). A interface real entre estas variáveis de análise descreve a interação das dinâmicas natural e social oferecendo respostas mais realísticas do cenário integrado, melhorando o desenvolvimento de estratégias no gerenciamento da redução de risco (AUBRECHT et al. 2013). Nesse contexto, destacam-se 3 
abordagens metodológicas: as curvas de vulnerabilidades, as matrizes de danos e os indicadores de vulnerabilidade.

As curvas de vulnerabilidade expressam o potencial de dano em graus utilizando apenas um parâmetro de vulnerabilidade (Ex: Construções), avaliando as perdas de cenários futuros, já que traduz as perdas em valores monetários (FUCHS et al., 2007; WEN-CHUN LO et al., 2012 e CIUREAN et al. 2016).

Nos trabalhos realizados por Ciurean et al. (2016), por exemplo, foram avaliadas a vulnerabilidade e os graus de perda das construções expostas às corridas de detritos a partir do volume de sedimentos e detritos registrados nas construções do nordeste da Itália em escalas local e regional. Seus resultados foram comparados com outros estudos envolvendo o mesmo método, indicando que a vulnerabilidade local simulou melhor os danos observados devido ao uso de dados empíricos.

As matrizes de danos caracterizam-se como uma abordagem mais flexível, baseada, sobretudo nas avaliações de perdas e danos a partir de dados empíricos e análises subjetivas (por especialistas), gerando resultados de face qualitativa (PAPATHOMA E DOMINEY- HOWES, 2003; PAPATHOMA- KHÖLE et al., 2007; JAKOB et al., 2012).

Jakob et al. (2012), embora apliquem essa abordagem, ao elaborarem a vulnerabilidade das construções e seu potencial de dano com maior detalhamento, recorrem aos índices de probabilidade de seus parâmetros de análise, apresentando os resultados finais em valores quantitativos. Dentre suas conclusões, sugerem que a vulnerabilidade das construções, diante do impacto das corridas de detritos, talvez sejam a variável de risco menos quantificável, já que também envolve muitas perdas humanas associadas aos danos nas construções.

Outro exemplo se refere ao método Papathoma Tsunami Vulnerability Assessment (PTVA) que por meio da "Matrizes de Danos" permite a inserção de parâmetros de análise variados, conforme os diferentes eventos perigosos. Inicialmente pensado para a avaliação da vulnerabilidade aos tsunamis, em Papathoma e Dominey- Howes (2003) e posteriormente avaliando os deslizamentos em Papathoma- Khöle et al. (2007) o PTVA desenvolveu-se também por meio dos indicadores de vulnerabilidade (VRI) em Kappes et al., 2012 registrando os casos de perigos múltiplos na França (Figura 7). Contudo, as lacunas que envolvem a formação 
dos cenários críticos na interface entre o perigo e a vulnerabilidade se mostram presentes denotando construções altamente vulneráveis sobre áreas em que o evento apresenta baixa intensidade e seu contrário.

A identificação recorrente desses cenários críticos em estudos voltados ao risco, ressalta os limites do conhecimento atual no que tange a interdependência entre as variáveis de perigo e de vulnerabilidade, ainda investigando questões como: Por que a vulnerabilidade nem sempre estará em conformidade com a intensidade do perigo deflagrado? Qual o nível de dependência entre estas variáveis? Ou ainda, sua relação é realmente linear? Ou seja, quanto maior a intensidade do evento, necessariamente serão as perdas e os danos, desenvolvendo os cenários de desastres?

Por fim, ainda em ascensão nas pesquisas voltadas a vulnerabilidade física, mas amplamente utilizados nas ciências aplicadas (PAPATHOMA et al. 2017), os indicadores de vulnerabilidade correspondem aos métodos que melhor possibilitam a inserção de parâmetros favorecendo maior integração entre eles (CARDONA, 2004).
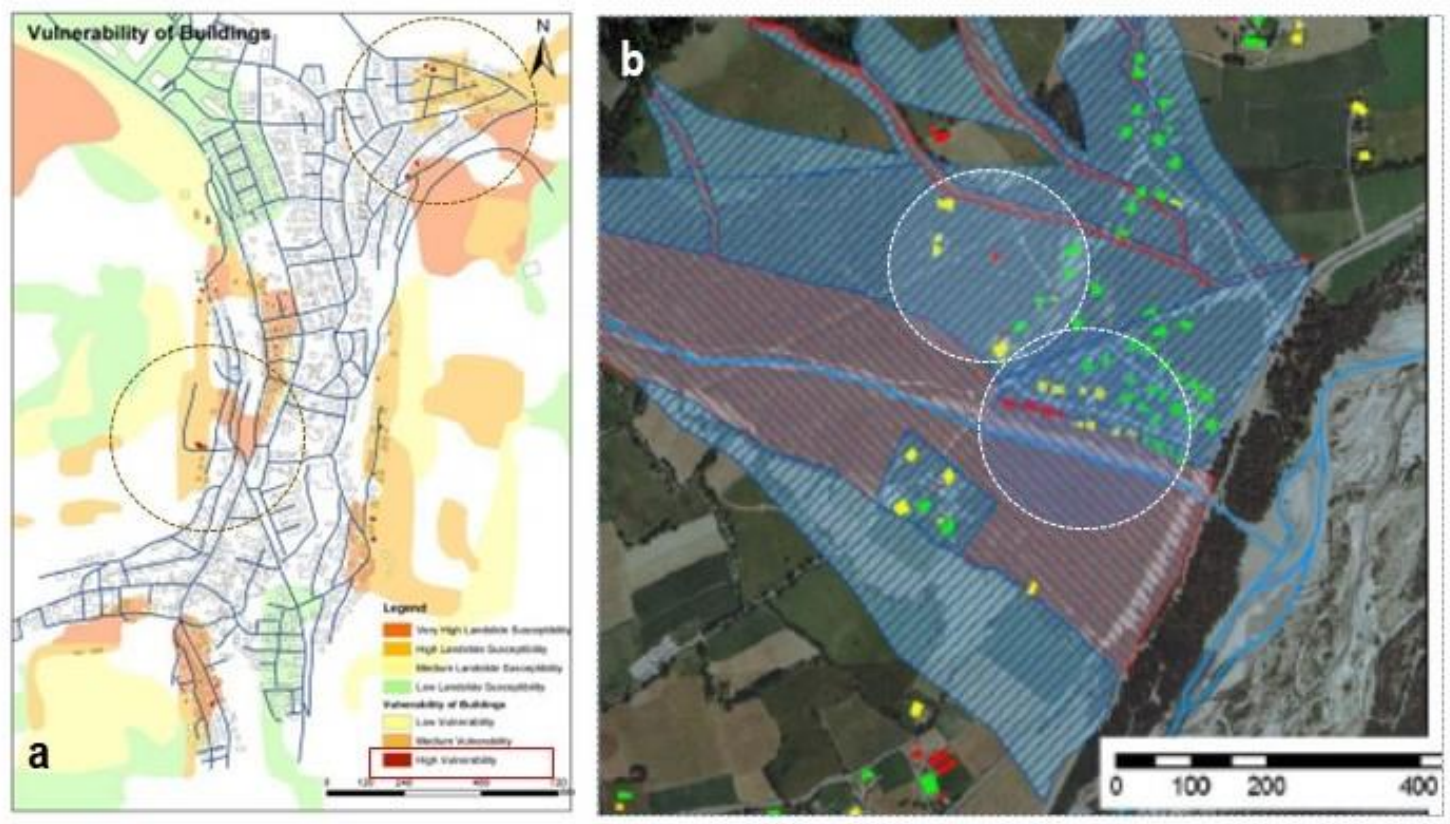

Figura 7: (a) Cenário crítico de risco envolvendo a vulnerabilidade das construções ao perigo dos Deslizamentos rasos em Lichtenstein (Alemanha). Fonte: Papatmoma-Khöle et al. 2007. Em (b): Cenário crítico de risco envolvendo a vulnerabilidade das construções ao perigo das corridas de detritos na bacia de Barcelonnette (França) Fonte: Kappes et al. 2012. 
Dado o caráter dinâmico da vulnerabilidade, a elaboração de indicadores de vulnerabilidade torna-se bastante relevante oferecendo maior compreensão tempoespacial do cenário de risco (WEICHSELGARTNER, 2001; BIRKMANN, 2007; KAPPES et al., 2012). Birkmann (2007), apresenta a construção de índices e indicadores de risco e vulnerabilidade para preencher as lacunas existentes entre a concepção teórica e a prática dos tomadores de decisão, tornando mais tangível o seu dia-a-dia profissional.

Weichselgartner (2001) desenvolve cinco indicadores de vulnerabilidade, elaborando, cinco mapas de aplicação direta e indireta ao fenômeno analisando-os. São eles; o próprio evento (Ex:, Intensidade, inventário, condições físicas que favorecem a deflagração, etc); a exposição dos elementos em risco (Ex; Identificação da infraestrutura exposta; uso e ocupação do solo, etc); a eficiência (Ex; analisar as condições e medidas de precaução capazes de dar respostas rápidas e efetivas diante do evento perigoso); a prevenção (Ex; analise das atividades e medidas voltadas a prevenção do impacto); a resposta (Ex; análise das atividades e medidas voltadas a redução das perdas e dos danos; capacidade de recuperação e reconstrução da área afetada). Ao final, o mapa de vulnerabilidade, soma dos cinco mapas base, identifica não apenas os graus de vulnerabilidade, mas também suas razões, podendo responder algumas das questões levantadas.

\subsection{O Modelo SAVE}

Integrada aos Métodos de Melhorias nas Avaliações de Vulnerabilidade da Europa (MOVE), a Abordagem Espacial das Avaliações de Vulnerabilidade (SAVE) corresponde a um modelo de avaliação da vulnerabilidade que integra diferentes dimensões de análise tempo-espaciais, tornando-a mais acurada e realística.

Caracterizado por sua abordagem heurística, o MOVE se desenvolve na direção da redução de risco, destacando como a complexidade e condições de emergência de uma sociedade, frente a ameaça de deflagração dos processos perigosos, pode ser integrada e promover adaptação dos afetados (BIRKMANN et al, 2013). Neste contexto, os aspectos que envolvem a exposição e a susceptibilidade dos elementos em risco, podem ser adequadamente compreendidos como uma interação. Sob esta 
perspectiva, é lícito avaliar a vulnerabilidade e os desastres como uma explanação integrada do risco (CARDONA, 2004), já que a complexidade do primeiro, demanda em consequências para a formação do segundo.

O risco e a vulnerabilidade são compreendidos como processos dinâmicos e dependem de decisões, na ordem de políticas públicas, para obterem diferentes condições de impacto frente a ocorrência de processos naturais que ofereçam perigo. Dessa maneira, a compreensão da vulnerabilidade deve analisar o impacto do processo como uma função das dimensões de exposição, da sensibilidade e da capacidade adaptativa do elemento ameaçado ou afetado (TURNER et al. 2003). Nesse processo, o reconhecimento da vulnerabilidade e seu potencial de retorno direciona o uso das ferramentas de intervenção já existentes ou que podem ser desenvolvidas, com o propósito de reduzir o risco (BIRKMANN, 2006).

A abordagem de análise do SAVE baseia-se na construção de indicadores aplicados aos aspectos da sensibilidade, exposição e resiliência descritos para uma avaliação mais acurada da vulnerabilidade.

No âmbito das dimensões de análise, ressalta-se o papel da sensibilidade interagindo com diferentes aspectos da vulnerabilidade. Reconhecida também pelas definições de susceptibilidade ou fragilidade do elemento em risco (social ou ecológico), é descrita por sua predisposição em sofrer prejuízos (BIRKMANN, 2013).

No caso das análises de pesquisas que envolvem a sensibilidade da população, reconhece-se como parâmetros amplamente utilizados para sua aplicação, a própria concentração demográfica. Nela, as aglomerações favorecem o reconhecimento de seus aspectos, exibindo indicadores sociais, que podem ressaltar a predominância de um baixo padrão construtivo ou sua condição de alto impacto com o evento (RUFAT et al. 2015).

Ainda sobre o aspecto demográfico, Rufat et al. (2015) ressaltam que os perfis populacionais como a Idade, Gênero e a Instrucão se destacam por serem recorrentes em pesquisas que buscam avaliar a vulnerabilidade social. No caso da primeira, trata-se das populações mais dependentes de socorro nos cenários de risco, seja pelas limitações físicas, seja pela ausência de autonomia nas tomadas de decisão (RUFAT et al. 2015). 
Especificamente no caso da população feminina convém observar que em países com direitos desiguais entre os gêneros, o número de mortes em cenários de risco é maior (NEUMAYER e PLÜMPER, 2007). Quanto ao grau de instrução, grupos de pessoas iletradas, alfabéticas ou até mesmo estrangeiras, nos cenários podem apresentar dificuldade em compreender os alertas, símbolos e orientações das equipes especializadas em situações de risco (DEMUTH et al. 2016).

A dimensão de exposição corresponde a relação entre os elementos de risco e o processo perigoso de uma forma mais direta (FUCHS et al. 2011). Na construção de suas variáveis de análise é comum utilizar parâmetros que envolvem as características sociais da área, como a distribuição da população ou de suas construções e condições de transporte (RUFAT et al. 2015), como a integração de estradas e rodovias. A questão tempo-espaço também é comumente aplicada nesta dimensão de análise, indicando os períodos de maior permanência das pessoas em áreas de risco (FREIRE, AUBRECHT e WEGSCHEIDER, 2011).

Por fim a dimensão de análise da resiliência corresponde a capacidade do elemento em risco (um sistema, comunidade ou sociedade Ex;.) resistir, absorver, adaptar-se e recuperar-se de sua exposição às ameaças externas e seus efeitos, em tempo hábil e de forma eficiente (ONU/ISDR, 2009).

Birkmann (2013) descreve dois componentes de resiliência. O primeiro se refere a capacidade do elemento em risco lidar ou se recuperar do agente estressante em face das consequências, nomeado como déficit de resiliência; enquanto que o segundo se aplica a melhoria da resiliência, indicando, portanto, características de sua adaptação.

Possíveis maneiras de quantificar a resiliência residem em parâmetros que revelem qual é a capacidade de enfrentamento do elemento em risco, frente aos desastres, podendo ser indicado por variáveis econômicas como o número de pessoas empregadas, renda ou ainda, seu acesso a seguros que indenizem as perdas e os danos relacionadas (FUCHS, 2009).

Mesmo diante da importância das dimensões descritas para a avaliação da vulnerabilidade, muitos trabalhos visitados cuja base de aplicação dos indicadores reside no SAVE, não reúnem as três abordagens de análise, muitas vezes estimulada 
pela falta de dados ou mesmo para explorar melhor uma dimensão de análise em função de seus objetivos.

Guillard-Gonçalves e Zêzere (2018) aplicaram as dimensões de sensibilidade e resiliência, estabelecendo uma vulnerabilidade social, embora tenham correlacionado posteriormente com os mapeamentos de deslizamentos em Lisboa, Portugal, avaliando o seu risco. Em Freire, Aubrecht e Wegscheider (2011), o foco de análise foi produzir mapas que determinassem os diferentes períodos de evacuação da população exposta a tsunamis em Lisboa, Portugal.

Murilo-Garcia et al. (2017) buscaram analisar a vulnerabilidade da população na direção das avaliações de risco a deslizamentos no município de Pahuatlán no México. Para tanto, as dimensões de análise propostas pelo SAVE foram relacionadas por meio de exponenciação e multiplicações gerando os índices e indicadores de cada uma. No total os autores avaliaram uma população de 19.559 habitantes e um total de 316 unidades espaciais, obtidos por censo demográfico do ano de 2010. Estas últimas foram relacionadas com as unidades de relevo, conforme sua inclinação.

Guillard-Gonçalves e Zêzere (2018) basearam-se em Murilo-Garcia et al. (2017), buscando combinar as vulnerabilidades física (construções) e social (população) para analisar o risco a deslizamentos no município de Lisboa, Portugal. Contudo, os dados aplicados nesta pesquisa se desenvolveram a partir de médias aritméticas, além da dimensão de exposição populacional não ter sido diretamente agregada a composição da vulnerabilidade. No total, 205,054 pessoas residentes em 18 unidades espaciais tiveram sua condição de vulnerabilidade estudadas. 


\section{3. ÁREA DE ESTUDO}

\subsection{Aspectos Físicos}

A área de estudo é composta por três municípios localizados na região do vale do Rio Ribeira, a sudoeste do estado de São Paulo. Trata-se, propriamente da subregião denominada Alto Vale do Ribeira, com os municípios de Apiaí, Itaoca e Ribeira (Figura 8). A escolha dessa região e municípios, se deu sobretudo por suas características físicas, envolvendo a recorrência de processos naturais hidrológicos, ao longo do tempo, bem como a condição social em que vive seus moradores.

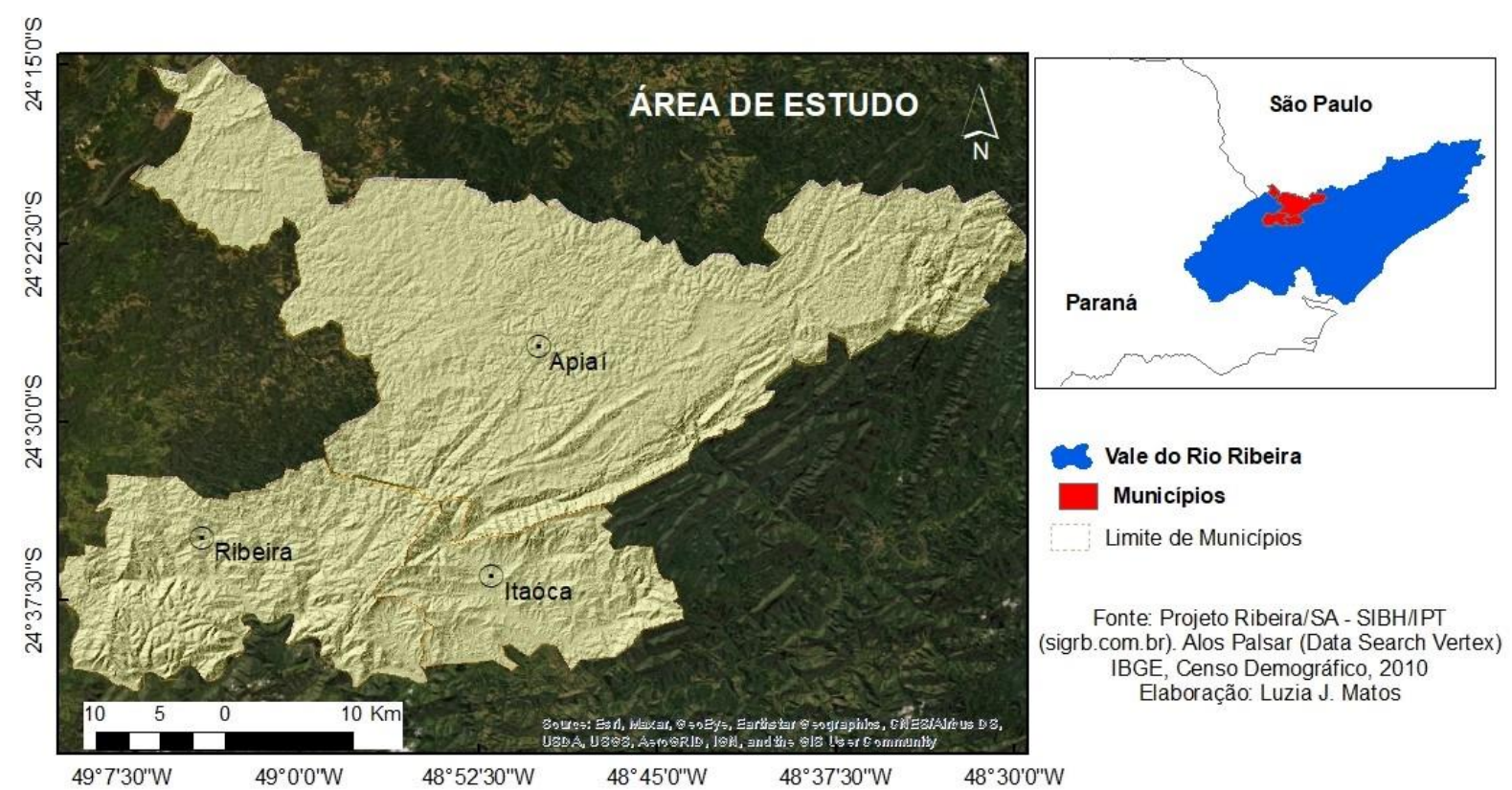

Figura 8: Área de estudo com destaque para os municípios de Itaoca, Apiaí e Ribeira.

No que se refere as características físicas, verifica-se sua localização sobre uma das unidades de planalto do Cinturão Orogenético do Atlântico brasileiro, correspondendo aos Planaltos e Serras do Atlântico Leste Sudeste. Neste ínterim, o Vale do Ribeira apresenta vasta e complexa formação litológica dominada, sobretudo, pela presença dos granitos (migmatitos e micaxistos) (ROSS e MOROZ, 1997; MELLO e BITTENCOURT, 1998) e distintos compartimentos de relevo como os morros de superfície cimeira regional; morros bastante dissecados; terras da depressão tectônica e planície costeira marinha e fluvial (ROSS, 2002). 
Propriamente, sobre o Alto Ribeira, prevalecem formas em morros de topos convexos com vales estreitos, profundos e vertentes muito inclinadas (30 e 60\%) (ROSS, 2002); em menor extensão, o relevo é alongado e mais alto com topos montanhosos que variam entre 900 e 1100 metros (ROSS, Op. cit).

Sua rede hidrográfica apresenta intensa densidade com rios encaixados, formando uma paisagem hidro geomorfológica favorável a formação de processos erosivos e movimentos de massa. Dessa forma, cidades como Apiaí, cuja altitude corresponde a 900 metros nas proximidades do Morro do Ouro, estão mais expostas aos materiais inconsolidados trazidos por escoamento superficial mais intenso, durante as estações chuvosas (Figura 9). Em cidades com altitudes entre 145 e 170m, encravados no meio dos morros, como Ribeira e Itaoca, a exposição é ainda maior às inundações periódicas, através do rio Ribeira (ROSS, 2002).

Aliada a paisagem descrita, o clima e a vegetação predominantes consolidam as precipitações pluviais prolongadas, além da característica e persistente garoa e neblina na região (MANCEBO, 2001). Trata-se das chuvas convectivas de verão características do Clima Tropical Úmido, tornando a região bastante úmida com índices pluviométricos anuais que variam de $1000 \mathrm{~mm} / \mathrm{a}$ para os anos menos chuvosos, podendo em pontos isolados, chegar a $4000 \mathrm{~mm} / \mathrm{a}$ em anos mais chuvosos (ROSS, 2002). Propriamente sobre a bacia do Ribeira, verifica-se precipitações pluviométricas que variam entre 1.215 a 1.880 mm (TERASSI e GALVANI, 2017).

Quanto a formação florestal da região, destaca-se tratar de resíduos da Floresta Latifoliada Tropical de Mata Atlântica com áreas de transição para a Floresta Aciculifoliada de Araucárias (ROMARIS, 1996). Nessa região, uma área contínua de Mata é preservada pelo Parque Estadual Turístico do Alto do Ribeira (PETAR), ocupando 25\% do município de Apiaí (MANCEBO, 2001). Contudo, descreve-se também, as ocupações intensas na região, em função de atividades econômicas como as pastagens, silvicultura de pinus e produção de resinas (ROSS, 2002). Neste processo, nota-se alguns de seus impactos, a exemplo dos incêndios florestais que atingiram o Morro do Ouro em Apiaí em julho 1994 (MANCEBO, 2001). 

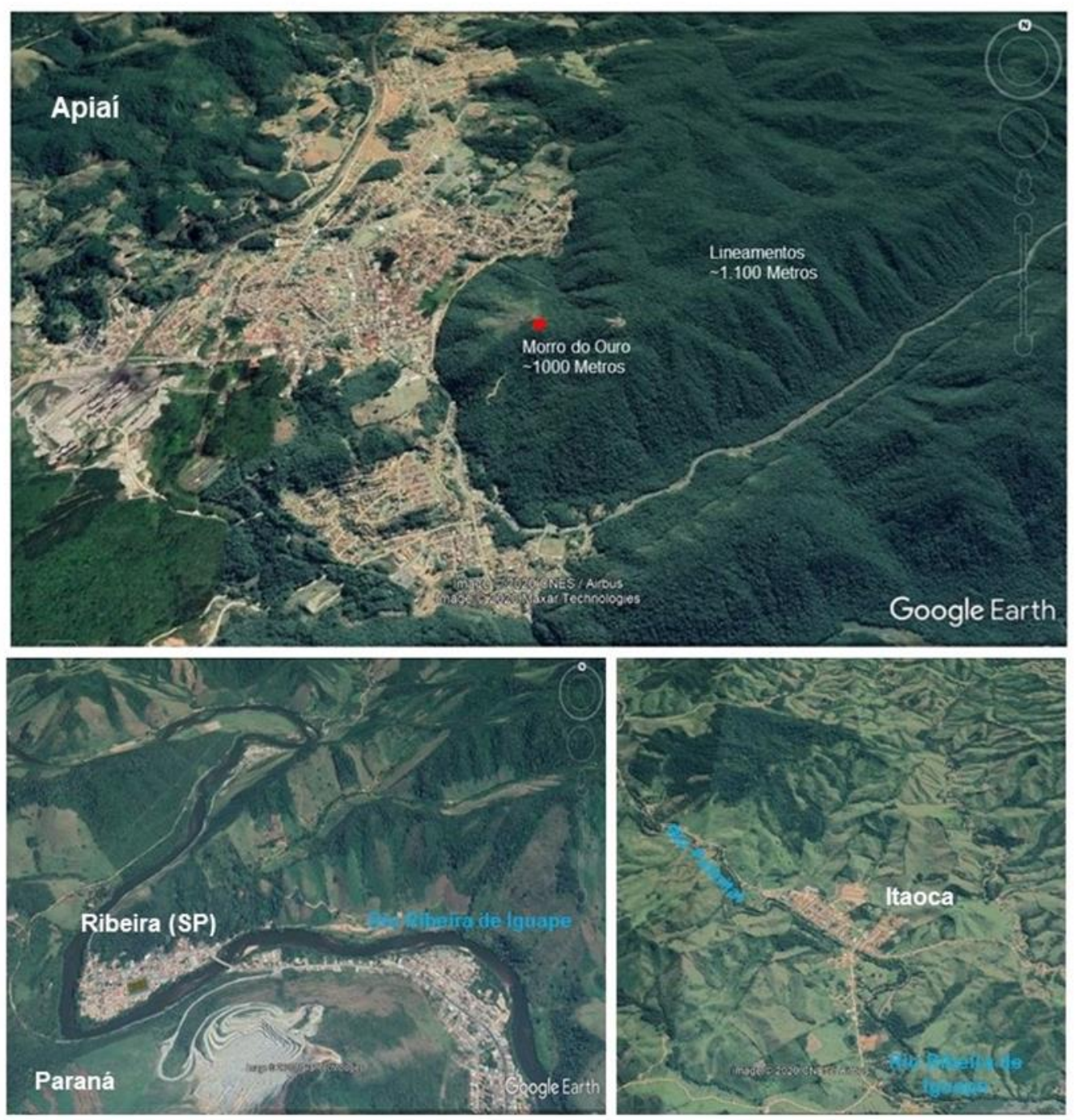

Figura 9: Municípios de estudo e os aspectos de sua localização. No caso de Apiaí destacase o perímetro da estrutura urbana adjacentes ao morro do ouro. Quanto ao Ribeira e Itaoca, localizam-se nas planícies fluviais do rio Ribeira

Diante do exposto, as deflagrações de processos naturais como os de cunho hidrológico são recorrentes (Figura 10), apresentando registros de cinco eventos críticos nos últimos 23 anos (BROLLO et al. 2015). Dentre eles destaca-se as inundações de 21 de janeiro de 1997, com as quais, a ponte de ligação dos municípios de Ribeira (SP) e Adrianópolis (PR) foi arrastada pelo volume de água que perpassou também o município de Eldorado, desabrigando mais de 1.000 pessoas (VALE DO RIBEIRA, Jornal Regional, 2011). Neste processo, a ponte de Iporanga também foi danificada, sendo interditada. Foram chuvas ininterruptas alcançando as cabeceiras do vale, por mais de uma semana (MANCEBO, 2001). 


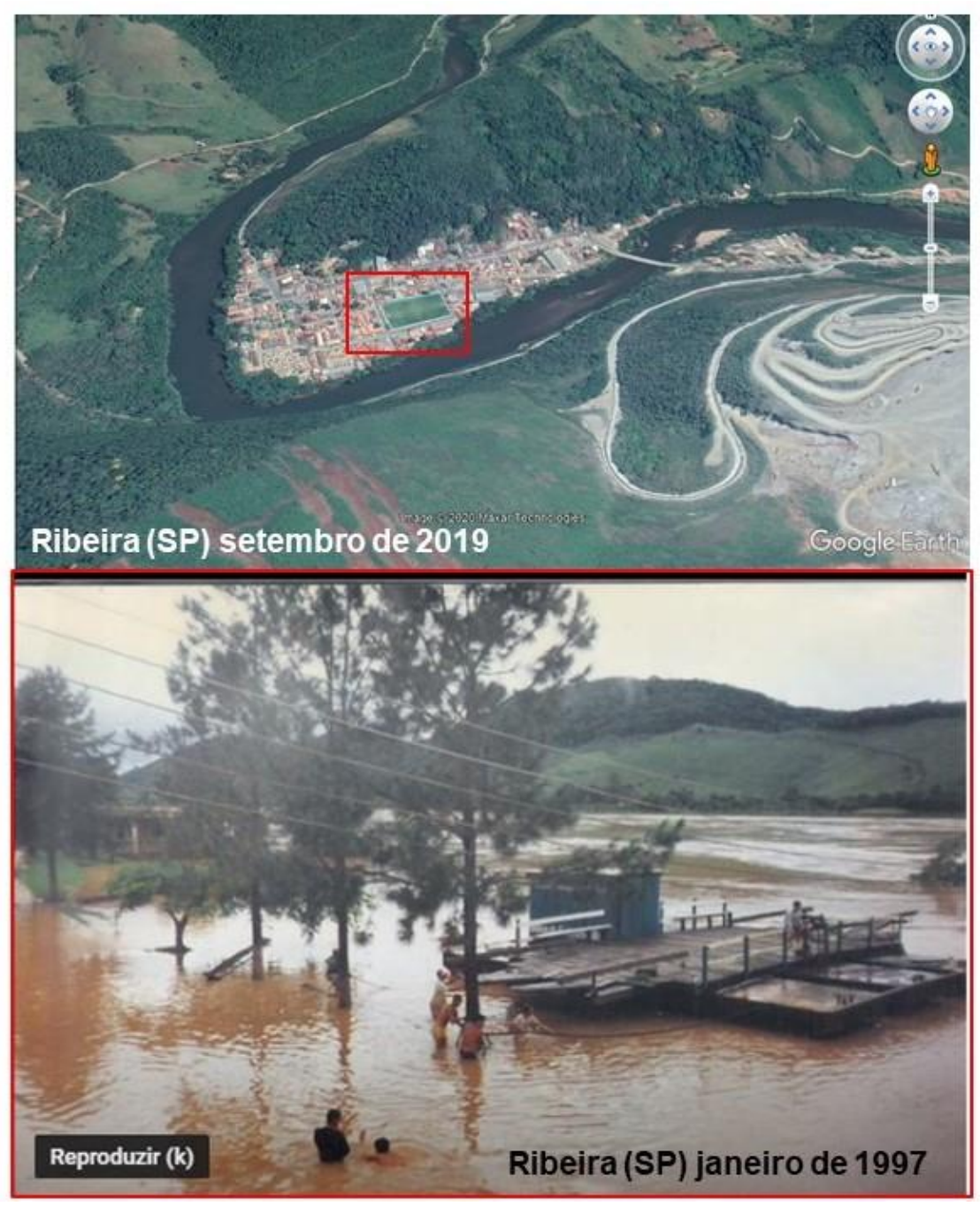

Figura 10: Município de Ribeira nos anos de 2019 e 1997. No primeiro destaca-se a área atual do campo de futebol que fora inundado em janeiro de 1997. O segundo exibe registro da enchente do rio Ribeira neste local. Fonte: Fotografia de moradores publicada em formato de vídeo e observada aos 0:58s. na plataforma do YouTube. Propriedade de Batatal Enchente do Rio Ribeira 1997.

Ainda sobre estas deflagrações, o autor destaca que grandes barreiras com pedaços de rochas, de grande dimensão rolaram, interrompendo estradas e em muitos locais as pessoas ficaram isoladas, sendo alcançadas apenas por helicópteros do governo do estado (MANCEBO, 2001, p. 231). Propriamente na cidade de Ribeira muitas pessoas foram desabrigadas com 40 casas interditadas, a exceção das que foram desmoronadas. 
Em 12 janeiro de 2014, escorregamentos, corridas de lama e detritos explanaram um cenário de desastres, resultando em 25 mortes (DEFESA CIVIL, 2015; GRAMANI e MIRANDOLA, 2014); 300 pessoas desabrigadas e aproximadamente 100 construções destruídas (SANTORO, 2014; GRAMANI e ARDUIN, 2015). Foram 200 $\mathrm{mm}$ de chuvas concentradas em 2 horas ocasionando barramentos e a elevação no volume d'água do rio Palmital, rompendo pontes (GRAMANI e ARDUIN, 2015) e redefinindo os caminhos de atuação do processo com diferentes raios de alcance nas áreas inundadas (Figura 11).
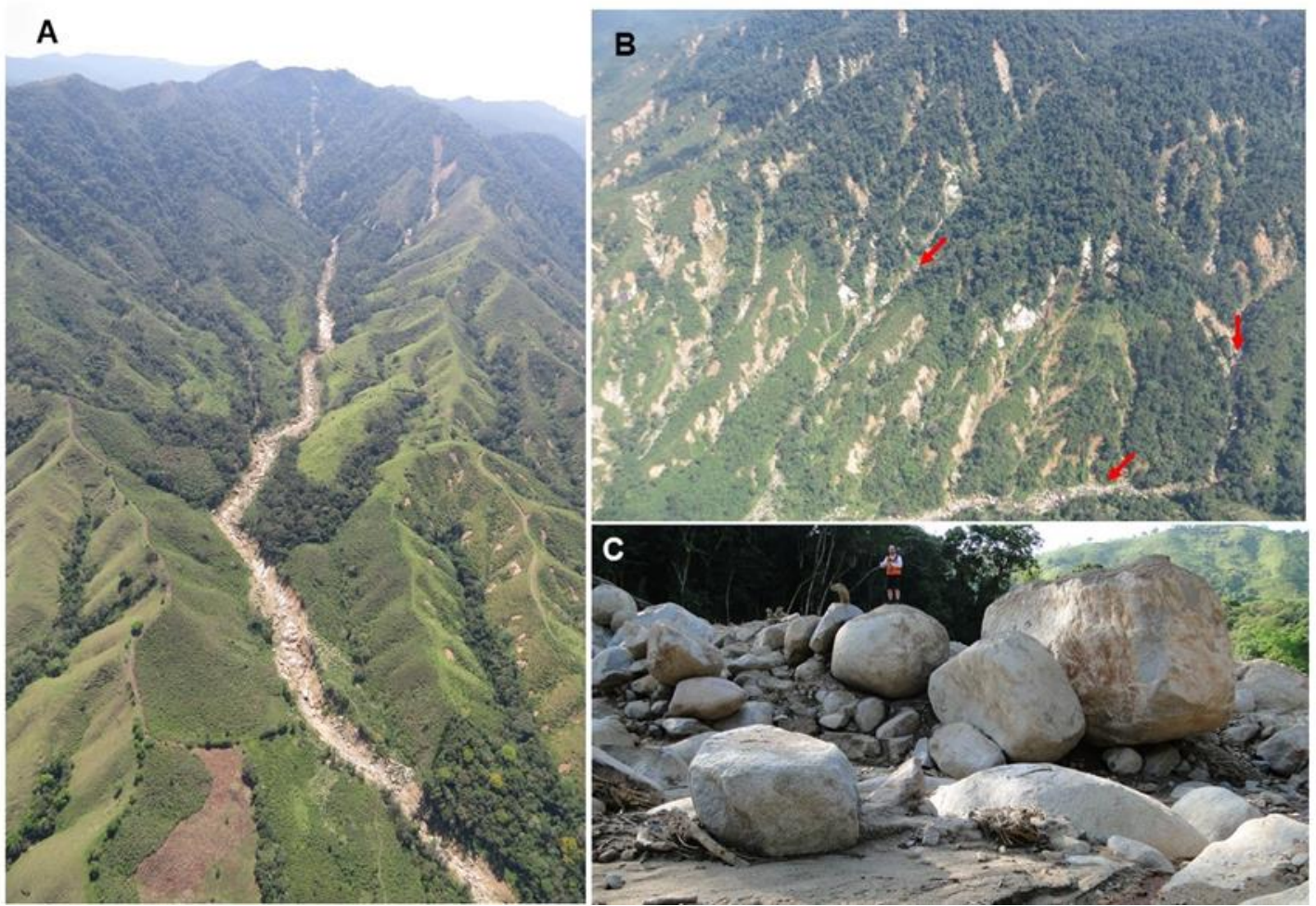

Figura 11: Corridas de detritos deflagradas nas bacias do rio Guarda-Mão e rio Gurutuba em janeiro de 2014. Em A) destaca-se a etapa de colapso da corrida e em c) a deposição dos blocos de rocha, a exemplo do cordão lateral, ambos na bacia do rio Guarda-Mão. Em B) observa-se a paisagem deflagrada por deslizamentos rasos e corridas de detritos (destacadas com as setas vermelhas) na bacia do rio Gurutuba.

\subsection{Aspectos Sociais e Demográficos}

Os municípios estudados ocupam juntos uma área aproximada de 1.486,365 $\mathrm{Km}^{2}$ com uma população absoluta de 31,777 habitantes, das quais, mais de 10.000 encontram-se em zonas rurais (IBGE, 2010). Nesse contexto, destaca-se que nos três municípios os índices de desenvolvimento humano (IDH) correspondem a alguns dos mais baixos do estado de São Paulo, com destaque para Itaoca com 0,68 e Ribeira 
com 0,698 (PNUD, 2010) (Tabela 1). Em todos estes municípios a variável renda configura-se no fator com os índices mais baixos

Tabela 1: Organização socio demográfica dos municípios estudados

\begin{tabular}{|l|l|l|l|l|c|c|}
\hline \multirow{2}{*}{ Municípios } & \multicolumn{2}{|c|}{ Área Km2 } & \multicolumn{2}{c|}{$\begin{array}{c}\text { População } \\
\text { Absoluta }\end{array}$} & \multirow{2}{*}{$\begin{array}{c}\text { População } \\
\text { hab/Km }\end{array}$} & \multirow{2}{*}{ IDHM } \\
\cline { 2 - 5 } & Urbana & Rural & Urbana & Rural & & \\
\hline Apiaí & 10,980 & 954,018 & 18.218 & 6.973 & 25,85 & 0,71 \\
\hline Itaoca & 3,874 & 179,910 & 1.760 & 1.468 & 17,64 & 0,68 \\
\hline Ribeira & 0,630 & 335,176 & 1.236 & 2.122 & 10,00 & 0,69 \\
\hline Total & $15.151^{*}$ & 1366.139 & 21.214 & 10.563 & & \\
\hline
\end{tabular}

Fonte: IBGE, 2010 e SEADE, 2015

Para compreender, com maior detalhe, a realidade socioeconômica destes municípios, o presente estudo utilizou-se da maior escala de análise disponível para o interior de sua extensão territorial. Trata-se da aplicação dos setores demográficos, desenvolvidos pelo IBGE (2010), totalizando 72 malhas espaciais sobre os municípios estudados.

Destacadamente os setores rurais apresentam maior extensão territorial, quando comparados aos setores urbanos. Contudo, 42 correspondem aos setores urbanos e apenas 30 aos rurais. No caso das malhas urbanas o IBGE (2010) distingue sua condição, conforme a presença de uma infraestrutura central, totalizando 37 malhas, nesta condição e 5, como sendo de estrutura urbana isolada. 


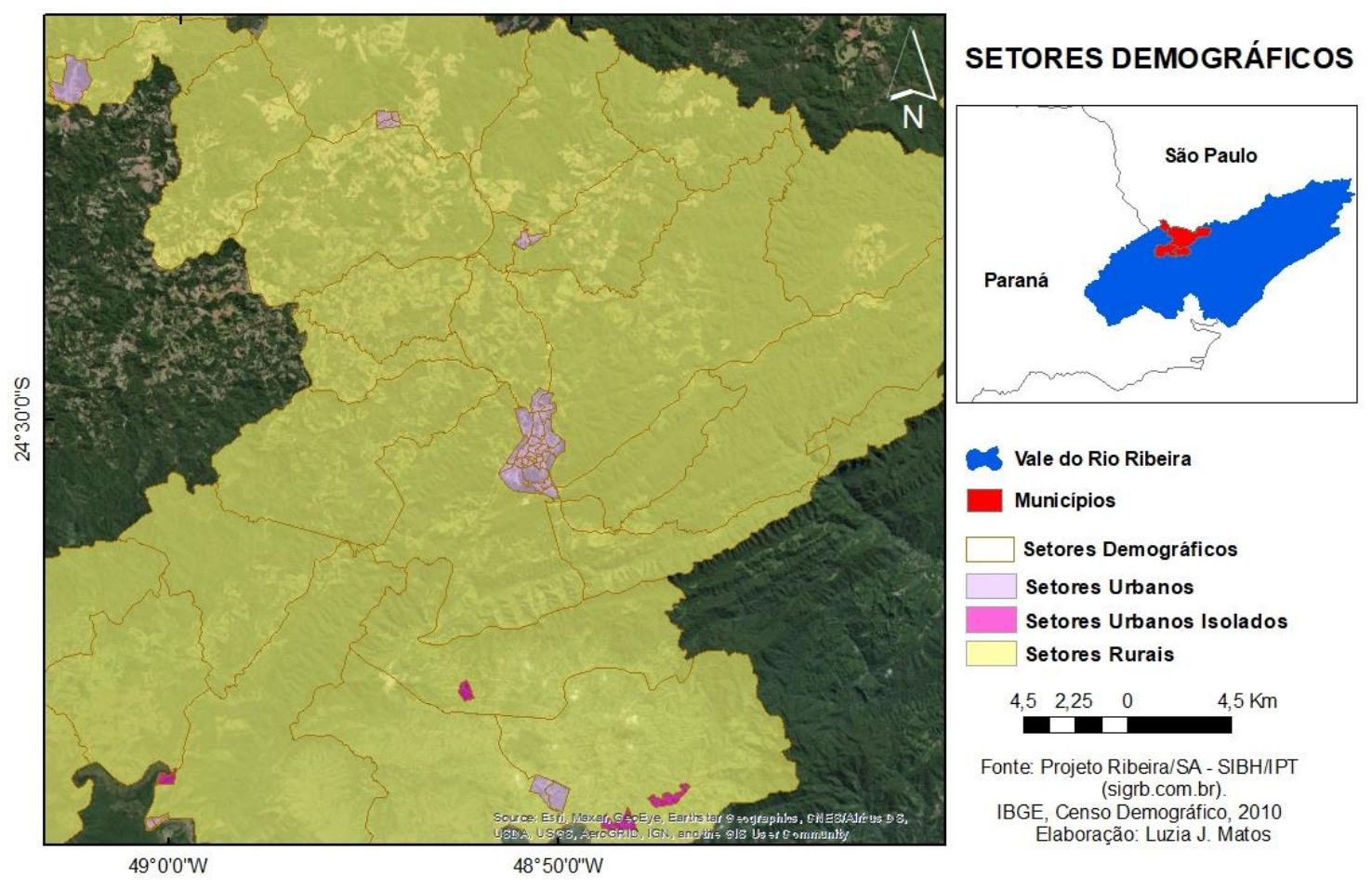

Figura 12: Área de estudo e os setores demográficos urbanos, urbanos isolados e rurais. 


\section{PROCEDIMENTOS METODOLÓGICOS}

A pesquisa foi dividida em duas grandes etapas de trabalho (Figura 13) que aqui foram nomeadas como "etapa piloto" (4.1) e "etapa final" (4.2).

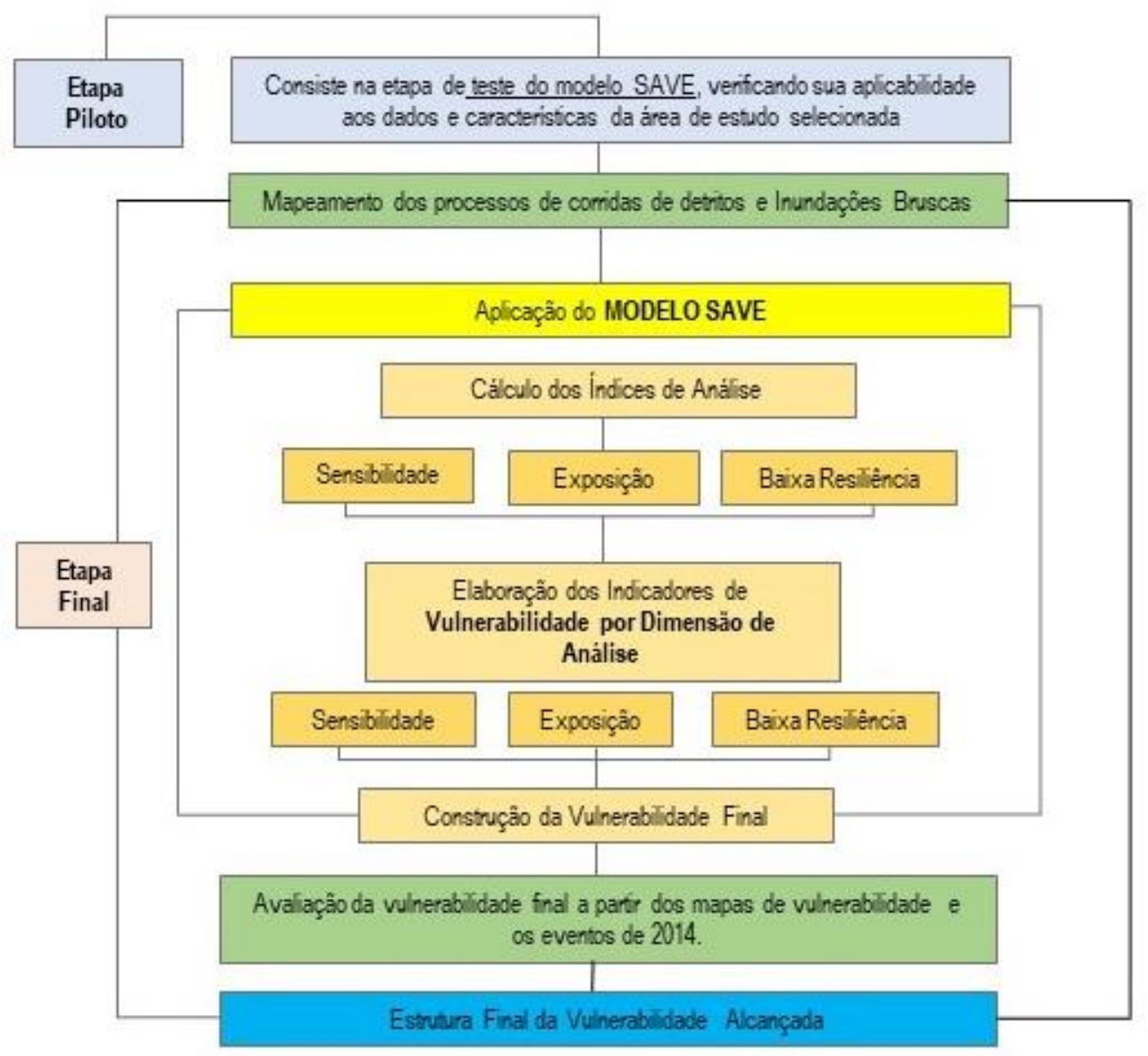

Figura 13: Etapas metodológicas desenvolvidas

A primeira consiste na avaliação do modelo SAVE, verificando sua aplicabilidade diante dos dados disponíveis à pesquisa. Trata-se da base de dados do IBGE, (2010) e da Emplasa, 2010/2011 para a elaboração dos dados socioeconômicos da população, além das ferramentas de análise com registros dos processos naturais de janeiro de 2014, como a plataforma Google Earth e a ferramenta das imagens históricas. Diante do acesso a esses recursos e da escala temporal de análise que envolve tanto a concepção da vulnerabilidade, como um processo, quanto o modelo 
tempo-espacial do SAVE, destaca-se como período de análise da presente pesquisa, os anos entre 2010 e 2014.

Estabelecida a etapa de teste do modelo, a segunda consiste na obtenção da vulnerabilidade da população nos municípios, por setores censitários. Para tanto, foram necessárias mais 5 etapas: (4.2.1) Mapeamento dos processos de corridas de detritos e Inundações Bruscas; (4.2.2) Cálculo dos Índices de vulnerabilidade; (4.2.3) Elaboração dos Indicadores por dimensão de análise (sensibilidade, exposição e déficit de resiliência; (4.2.4) Construção da vulnerabilidade final e (4.2.5) Avaliação da vulnerabilidade final a partir dos mapas de vulnerabilidade gerados e os eventos de 2014.

Na etapa 4.2.1 (Mapeamento das Corridas de detritos e Inundações Bruscas) buscou-se identificar seus registros ao longo da área de estudo, distinguindo suas feições e visualizando-as em cada setor demográfico. Na etapa 4.2.2 (Cálculo dos Índices de vulnerabilidade) os índices de vulnerabilidade foram construídos, por meio de equações simples, elaboradas, conforme o MODELO 2 e testados na etapa 3.1, para as três dimensões de análise do método SAVE.

$\mathrm{Na}$ etapa 4.2.3 (Elaboração dos Indicadores por dimensão: sensibilidade, exposição e déficit de resiliência) a elaboração dos indicadores de vulnerabilidade baseou-se nas Tabelas 2, 3 e 4 do MODELO 2, avaliado na etapa 3.1 e envolveu os índices calculados na etapa 4.2.2, resultando em grupos de indicadores de vulnerabilidade, conforme as características de cada dimensão de análise. Em seguida, na etapa 4.2.4 (Construção da vulnerabilidade final) a vulnerabilidade por dimensão de análise embasou o realinhamento dos cálculos, combinando-os na vulnerabilidade final.

Por fim, a etapa 4.2.5 (Avaliação da vulnerabilidade Final com o Evento de 2014), buscou avaliar o potencial do modelo SAVE apurando/explicando a vulnerabilidade alcançada. Nela os setores atingidos e não atingidos foram analisados de forma comparativa. 


\subsection{Aplicação do método SAVE: Etapa Piloto}

A presente pesquisa utilizou as abordagens de Murilo-Garcia et al. (2017) e Guillard-Gonçalves e Zêzere (2018) para a aplicação inicial do SAVE. Embora ambas tenham a mesma base metodológica, os primeiros autores utilizaram expressões logarítmicas e exponenciais, enquanto que o segundo estudo se baseia nos cálculos aritméticos, na construção da vulnerabilidade final. Para a presente pesquisa os respectivos cálculos são nomeados como MODELO 1 (base logarítmica e exponencial) e MODELO 2 (base aritmética). Os dois modelos aplicados quantificaram os parâmetros de vulnerabilidade de modo que pudessem ser analisados com valores mínimos de zero (0) a máximos de um (1), como são amplamente identificados na literatura.

Nesta etapa da pesquisa, buscou-se compreender o funcionamento da base de dados disponível, aplicando-os por meio dos MODELOS 1 e 2. Trata-se, principalmente dos dados do censo demográfico do Instituto Brasileiro de Geografia e Estatística IBGE, (2010) para o interior do estado de São Paulo, propriamente no vale do Ribeira.

Pontualmente, os MODELOS 1 e 2 caracterizam-se como estruturas do SAVE para uma aplicação piloto dos dados disponíveis, envolvendo, naturalmente as três dimensões de análise: sensibilidade, exposição e resiliência das populações.

De maneira geral, a aplicação dos MODELOS considerou os índices de interesse conforme a qualidade e a viabilidade encontrada nesta primeira etapa, chamada etapa piloto. Assim, os índices selecionados, foram aplicados em uma ou duas fórmulas, conforme os MODELOS utilizados, resultando em indicadores para cada dimensão estudada. 


\subsubsection{Sensibilidade}

A Tabela 2 apresenta os cinco índices aplicados (Densidade Demográfica; População Infanto-Juvenil; População Idosa; População Feminina e População Analfabeta) nos Modelos 1 e 2; as equações da dimensão de sensibilidade, sua fonte de dados e algumas limitações encontradas.

Tabela 2: Fórmulas para obtenção dos indicadores de sensibilidade a partir dos MODELOS 1 e 2 .

\begin{tabular}{|c|c|c|}
\hline \multicolumn{3}{|c|}{ Índices e Fórmulas- SENSIBILIDADE } \\
\hline Índices & MODELO 1 & MODELO 2 \\
\hline $\begin{array}{l}\text { Densidade demográfica } \\
(\mathrm{DD})^{*}\end{array}$ & $\mathrm{DD}=\frac{\log \left(\frac{\mathrm{ps}}{\mathrm{as}}\right)}{\log (\mathrm{add})}$ & $\mathrm{DD}=\left(\frac{\mathrm{ps}}{\mathrm{as}}\right) /(\mathrm{add})$ \\
\hline População jovem (PIJ) & \multicolumn{2}{|c|}{$\mathrm{PIJ}=\mathrm{p} \leq 13 / \mathrm{ps}$} \\
\hline População idosa (PI) & \multicolumn{2}{|c|}{$\mathrm{PI}=\mathrm{p} \geq 65 / \mathrm{ps}$} \\
\hline População feminina (PF) & $\mathrm{PF}=\log \left(\frac{\mathrm{pf}}{\mathrm{ps}}\right) \times 10$ & $\mathrm{PF}=\left(\frac{\mathrm{pf}}{\mathrm{ps}}\right)$ \\
\hline $\begin{array}{l}\text { População analfabeta } \\
\qquad(\mathrm{PA})^{\star \star}\end{array}$ & \multicolumn{2}{|c|}{$\mathrm{PA}=\left(\frac{\mathrm{pa}}{\mathrm{ps}}\right)$} \\
\hline \multicolumn{3}{|c|}{ Indicador de Vulnerabilidade por Dimensão de Análise - SENSIBILIDADE } \\
\hline MODELO 1 & \multicolumn{2}{|c|}{ MODELO 2} \\
\hline $\mathrm{S}=5^{\Lambda}(\mathrm{DD} \times \mathrm{PJ} \times \mathrm{PI} \times \mathrm{PF} \times \mathrm{PA})$ & \multicolumn{2}{|c|}{$S=\left(\frac{D D+P J+P I+P F+P A}{5}\right)$} \\
\hline \multirow{2}{*}{\multicolumn{3}{|c|}{$\begin{array}{l}\text { *Os limites dos setores censitários foram reajustados, pois não transcorriam exatamen } \\
\text { sobre os logradouros, cobrindo ou excluindo domicílios da área total. } \\
\text { ** No censo } 2010 \text { não há dados que indiquem, diretamente a população analfabeta } \\
\text { população de cada setor (ps); área de cada setor (as); valor mais alto da densidade } \\
\text { demográfica (add). }\end{array}$}} \\
\hline & & \\
\hline \multicolumn{3}{|c|}{ Fonte: Adaptado de Murillo-Garcia et al. (2017) e Guillard-Gonçalves e Zêzere (2018). } \\
\hline
\end{tabular}

Nota-se a aplicação dos cinco índices de sensibilidade nos dois modelos, ainda que apenas dois tenham sido calculados de formas diferentes. Trata-se da densidade demográfica e da população feminina.

No caso da densidade demográfica verificou-se que a resposta a aplicação do MODELO 1 impactou a construção dos índices de sensibilidade, por terem destacado os vazios demográficos em setores com população absoluta muito baixa, como é 
possível observar nas unidades espaciais "Apiaí 32" e "Apiaí 37"1 (ANEXO 1). Neles, os índices negativos resultantes dificultaram a aplicação do SAVE nos padrões de valores entre $(0-1)$. Quanto a aplicação da densidade demográfica por meio do MODELO 02, observou-se que os 72 setores de análise apresentaram valores positivos.

Para a população feminina, os índices finais não apresentaram desvio, embora a natureza do cálculo apresentado no MODELO 1, tenha ressaltado a resposta numérica deste índice, (ANEXO 2) diferentemente do MODELO 2 com a média aritmética. Dessa maneira, observou-se que a aplicação dos índices da população feminina conforme MODELO 1, poderia superestimar sua resposta na etapa da sensibilidade final.

Destaca-se ainda, que a unidade espacial Apiaí $32\left(9,97 \mathrm{~km}^{2}\right)$ apresentou uma população absoluta de 2 pessoas, inviabilizando a aplicação dos 5 índices de interesse. Neste sentido, a unidade Apiaí $37\left(102,6 \mathrm{~km}^{2}\right)$ soma uma população absoluta de 4 pessoas, das quais uma é identificada como sendo do sexo feminino e três como de baixa instrução.

De maneira geral, trata-se de malhas espaciais com base de dados inconsistentes, causando amplo destoa mento na informação gerada. Dessa forma, os índices de analfabetismo e densidade populacional nas duas malhas espaciais e o da população feminina, apenas na malha Apiaí 37, demonstraram valores extremos e destoantes da realidade.

No caso dos índices sem representação nestas mesmas malhas setoriais (populações idosa e infanto-juvenil nos setores Apiaí 32 e 37 (ANEXOS 3 e 4) e da população feminina no setor Apiaí 32), observa-se a limitação encontrada para aplicar os 5 índices selecionados nesta dimensão de análise. Quanto aos 70 setores em que foi possível aplicar os MODELOS 1 e 2, observou-se que a quantidade de pessoas por setor e, portanto, índices de análise é bastante variada.

\footnotetext{
${ }^{1}$ nomeados dessa forma por apresentarem estes últimos dígitos como códigos de identificação do setor.
} 


\subsubsection{Exposição}

Para esta dimensão de análise utilizou-se 2 índices (população total e população temporariamente exposta), a exemplo do MODELO 1 (Tabela 3). Entretanto, a presente pesquisa inseriu o índice "ocorrência dos processos", afim de experimentar seu comportamento quando combinado com os demais.

Essa espacialização dos processos perigosos como um índice de exposição da população, envolveu, portanto, os registros das corridas de detritos e inundações bruscas deflagrados em 2014. Embora Guillard-Gonçalves e Zêzere (2018) não tenham aplicado a dimensão de exposição em seus estudos, aqui utilizou-se de médias aritméticas como orientação do MODELO 2.

Tabela 3: Fórmulas para obtenção dos indicadores de exposição a partir dos MODELOS 1 e 2.

\begin{tabular}{|c|c|c|}
\hline \multicolumn{3}{|c|}{ Índices e Fórmulas - EXPOSIÇÃo } \\
\hline Índices & MODELO 1 & MODELO 2 \\
\hline População Total (PT) & PT $=\frac{\log (\mathrm{ps})}{\log (\mathrm{pab})}$ & $(\mathrm{ps})$ \\
\hline (pab)
\end{tabular}


Diferente dos índices de sensibilidade, cujas equações eram todas simples, estes apresentam um índice composto, identificado pela equação da exposição temporária da população, e dois simples, sendo eles a população total e a ocorrência do processo. No caso do primeiro, uma limitação estrutural foi encontrada, já que a rotina da população residente, principalmente nos municípios de Itaoca e Ribeira, consiste em sua permanência diária nos mesmos espaços de convívio. A configuração de seus territórios, sobretudo no caso dos setores urbanos, apresenta uma proximidade muito grande entre os postos de trabalho, escola e postos de saúde, tornando ineficaz a variável temporal do índice composto.

Quanto a aplicação do índice, ocorrência dos processos, a limitação observada reside no valor "0" gerado em todos os setores em que não há registros da ocorrência de corridas de detritos ou inundações bruscas, totalizando 65 setores. Dessa forma, quando equacionados com os índices da população total e da exposição temporária da população pelo MODELO 1, os cálculos finais apresentam valor igual a "1", superestimando o valor do indicador final e invalidando os outros dois índices (ANEXO $5)$.

\subsubsection{Déficit de Resiliência}

Para esta dimensão de análise foram aplicados os índices: Condições de Moradia (CM), Situação da Renda (SR) e População Economicamente Ativa (PEA) (Tabela 4). Aqui foram encontradas limitações na quantificação dos domicílios atingidos, já que esta variável não existe na base de dados do IBGE, (2010) e na ausência de informações quanto as condições de moradia e situação da renda nos setores "Apiaí 32" e "Apiaí 37", em decorrência da inconsistência dos dados apresentados na dimensão de sensibilidade.

Para a aplicação do índice domicílios atingidos, buscou-se utilizar as ortofotos da EMPLASA (2010/2011), imagens do Google Earth e dados do IBGE (2010), como o número de domicílios por setor, como ferramentas de construção do índice referido. A partir daí, também a "população atingida" foi calculada. Quanto a inconsistência na base de dados das duas unidades espaciais do município de Apiaí, não foi possível obter os dados necessários. 
Tabela 4: Fórmulas para obtenção dos indicadores do déficit de resiliência.

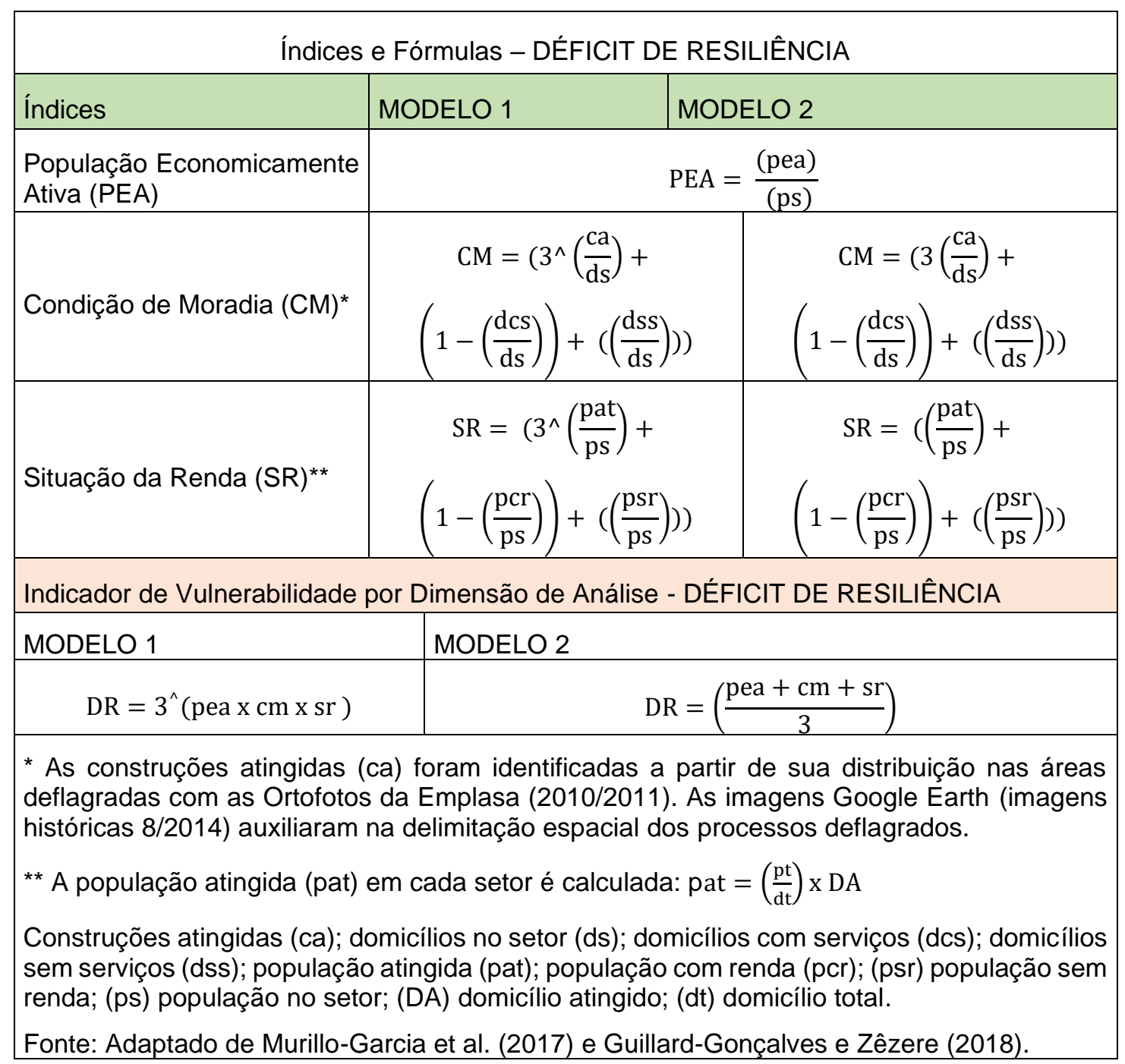




\subsection{Aplicação do método SAVE: Limitações e Redefinição da Área}

De todas as limitações encontradas, três redefiniram a aplicação dos dados em busca da construção dos índices de vulnerabilidade: (a) Inconsistência de dados, (b) rotina diária de grande parte da população e (c) abordagem conceitual aplicada sobre a vulnerabilidade.

(a) Optou-se por diminuir a quantidade de malhas espaciais, excluindo os dois setores que não ofereciam representatividade de dados. Dessa maneira, a área de estudo inicialmente composta por 72 malhas espaciais, passou para 70, distribuídas pelos 3 municípios.

(b) Observou-se que a dinâmica e modo de vida da população estudada tornou o índice, exposição temporária da população, pouco realístico, já que a mobilidade e espaços percorridos diariamente estão nos mesmos setores demográficos. Dessa maneira o índice, inicialmente caracterizado pela exposição temporária da população, tornou-se a exposição permanente da população, de modo que a variável tempo não oferecesse impacto sobre o cálculo dos indicadores de exposição final.

(c) Percebeu-se que os registros dos processos naturais corroboram de forma mais eficaz como um fator de validação da vulnerabilidade a ser alcançada ou mesmo quando busca identificar e setorizar as áreas atingidas. Assim, a dimensão final de exposição passou a contar com apenas dois índices de análise: população total e exposição permanente de população.

\subsubsection{Mapeamento das Corridas de Detritos e Inundações Bruscas}

Inicialmente mapeou-se os registros das corridas de detritos e das inundações bruscas de 2014 nos municípios de Apiaí e Itaoca. Em seguida, sobrepôs-se as malhas setoriais do censo demográfico do IBGE (2010), sobre estes registros, afim de reconhecê-los em cada malha setorial, identificando, precisamente a área atingida em cada município.

A construção do mapa das feições envolveu trabalhos de campo (abril de 2017 e outubro de 2018), a partir dos quais foi possível identificar os registros dos processos deflagrados, sobretudo o das corridas de detritos cujo impacto nas paisagens atingidas é marcante e duradouro (Figura 14). Ainda, neste processo, foram 
consultados trabalhos realizados na área deflagrada logo após o evento, como: Gramani e Mirandola (2014); Santoro (2014); Defesa Civil estadual, 2015; Brollo et al, (2015); Gramani e Arduim (2015) e Ferreira et al. (2016). A partir daí deu-se início a etapa de delimitação dos processos de interesse, desenvolvendo um inventário das corridas de detritos e das inundações bruscas. Neste processo, a ferramenta Google Earth Pro e o recurso das imagens históricas, embasaram sua construção, possibilitando uma representação bastante aproximada dos processos ocorridos no mês de janeiro. De maneira geral, o critério utilizado para a delimitação dos processos naturais em estudo foi uma análise visual das feições registradas na paisagem (WELSH, 2007).

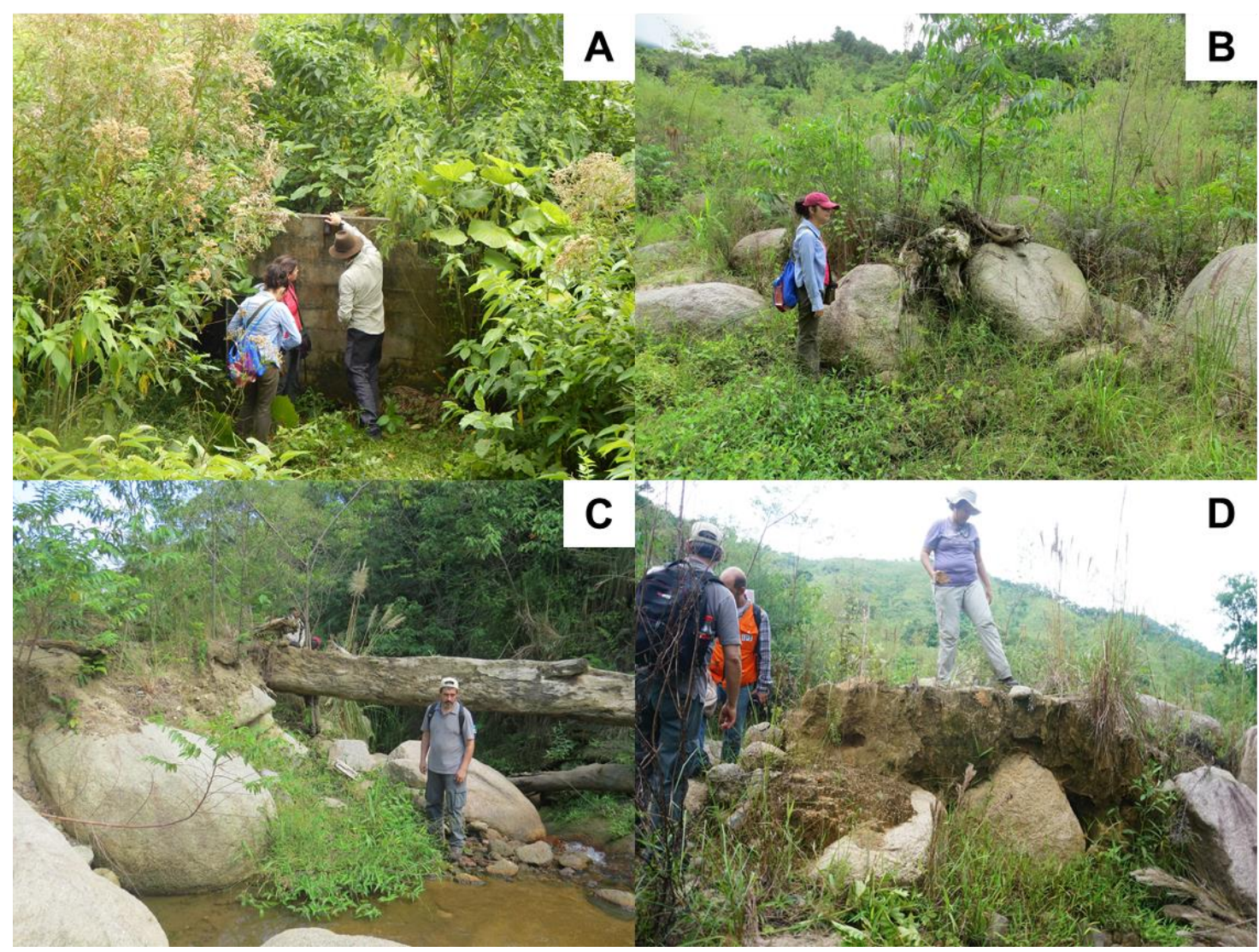

Figura 14: Observações realizadas em trabalho de campo na bacia do Rio Guarda-Mão em abril de 2017. (A) medição da altura da casa soterrada; (B) observação de blocos de tamanhos intermediários. (C) barramento natural ao longo do curso principal e (d) depósito de corridas de detritos de 2014. 
Propriamente sobre as corridas de detritos, o reconhecimento espacial se dá, a partir das características de sua morfologia. Nela, delineia-se o percurso do processo, observando os diferentes tamanhos e ausência de vegetação, combinada com a presença de sedimentos ao longo desta mesma área (WELSH, 2007). No caso da paisagem atingida em 12 de janeiro de 2014, a delimitação das corridas de detritos teve início em inclinações próximas a $30^{\circ}$, paralelas as cicatrizes de deslizamentos de terra observados. Trata-se da delimitação da etapa inicial (colapso/Impulso erosivo) do processo e envolve, de maneira segmentada, as etapas 2 e 3 das corridas de detritos, propriamente a de fluxo (erosão e deposição) até o arraste final, onde apenas a deposição de sedimentos é perceptível, já em altitudes mais baixas (Figura 15).
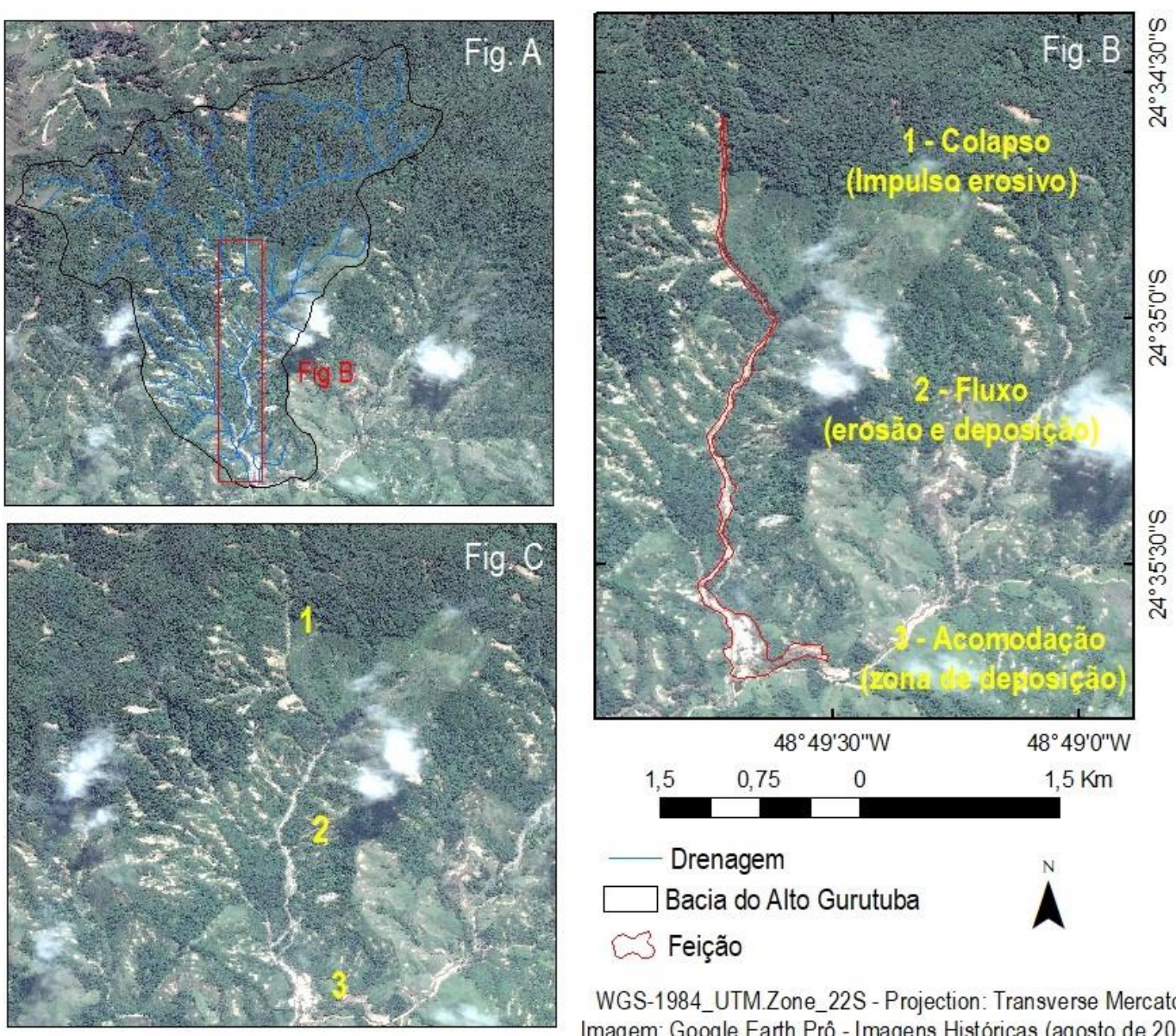

WGS-1984_UTM.Zone_22S - Projection: Transverse Mercator Imagem: Google Earth Prô - Imagens Históricas (agosto de 2014)

Figura 15: Demonstração de como a delimitação das feições de corridas de detritos foram aplicadas. Em (A) observa-se a localização do processo na bacia deflagrada, enquanto que nas figuras (B) e (C) buscou-se registrar as feições da corrida de detritos, conforme suas etapas de desenvolvimento. 
No caso das inundações bruscas, características como o alargamento de pequenos canais; presença de detritos como aporte vegetal e lama; acomodação de sedimentos, além da própria área de deposição do canal hídrico; moderada ou baixa ordenação de depósitos (WELCH, 2007), compõem os critérios de análise visual das inundações bruscas, auxiliando em sua delimitação. Nesse contexto, fotografias, imagens de satélite, relatos de moradores e profissionais acabaram por vislumbrar os locais de formação e percurso das inundações bruscas, direcionando sua delimitação. Tratou-se, sobretudo dos pontos de bloqueio por detritos naturais e artificiais (pontes), resultando nos cenários de inundação, caracterizados pelo seu grande volume de água, alargando os canais e depositando sedimentos em suas laterais, (rochas, galhos e lama) (Figura 16).
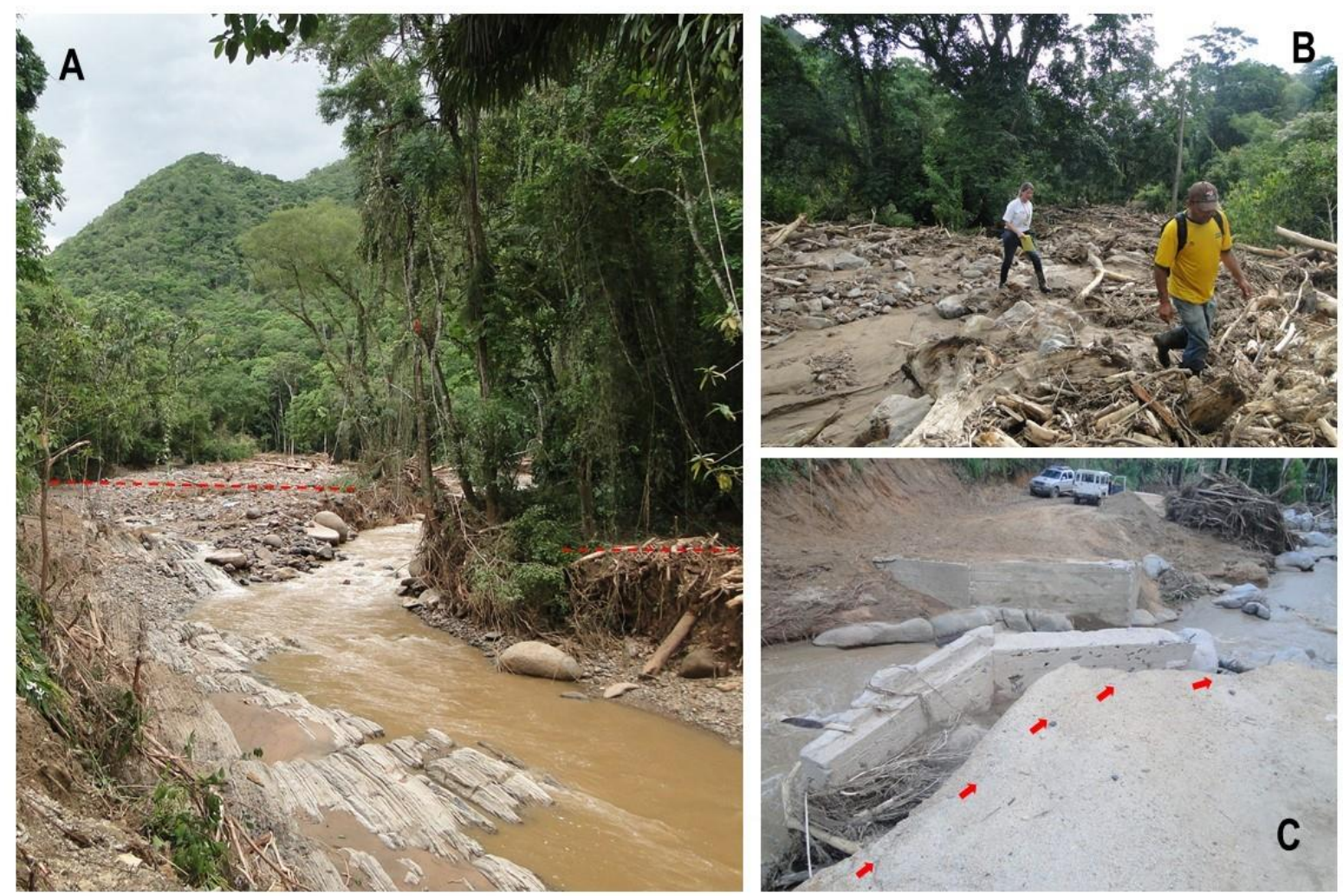

Figura 16: Características das Inundações bruscas e indicação de alguns pontos de sua delimitação, na altura dos cursos alto e médio do rio Palmital. Em (A) destaca-se o alargamento do canal durante o processo, com a deposição de detritos. Em (B) buscou-se observar a baixa ordenação dos depósitos transportados, bem como a presença do aporte vegetal. (C) Indica a direção das inundações bruscas que arrastaram a ponte do bairro do Lageado. 


\subsubsection{Cálculo dos índices de vulnerabilidade}

Para esta etapa selecionou-se dez índices que influenciam na vulnerabilidade das populações atingidas por desastres naturais, agrupados conforme as três dimensões de análise do método SAVE (sensibilidade, exposição e déficit de resiliência)

As variáveis que compõem os índices selecionados foram extraídas do censo demográfico do IBGE (2010), exceto o número de construções e as pessoas atingidas, elaboradas a partir das ortofotos da Emplasa (2010/2011) e das imagens históricas (de agosto de 2014) do Google Earth Prô. De maneira geral, a construção dos índices envolveu os dados disponíveis em 70 setores censitários (53 no município de Apiaí, 9 ao Itaoca e 8 ao município de Ribeira).

\section{Sensibilidade}

Nesta dimensão de análise dois fatores direcionaram a escolha dos cinco índices aplicados. O primeiro buscou assimilar os condicionantes sociais de maior influência na vulnerabilidade da população, enquanto que o segundo examinou sua disponibilidade para aplicação. Neste processo, selecionou-se: 1) Densidade demográfica; 2) População infanto-juvenil (até 13 anos); 3) População idosa (a partir de 65 anos de idade); 4) População feminina e 5) População analfabeta.

Para estabelecer os índices de sensibilidade selecionados, equações simples foram aplicadas (Tabela 2). Cada uma delas buscou relativizar as quantidades absolutas das populações de interesse pelo total disponível em cada setor. A este exemplo os índices da população por idade, gênero e baixa instrução foram inteiramente calculados com variáveis populacionais. No caso da primeira, ressaltase a elaboração dos perfis da população infanto-juvenil e da população idosa; seguida da população feminina e analfabeta respectivamente.

Para a densidade demográfica especificamente, destaca-se que a população absoluta de cada setor foi dividida pela extensão territorial $\mathrm{em}^{\mathrm{km}} \mathrm{km}^{2}$ de cada malha setorial, resultando em números muito elevados. Dessa forma, seus índices finais foram divididos pelo de maior densidade, afim de padronizá-los com variação entre 0 e 1. 
De maneira geral, as variáveis de cada índice aplicado encontram-se diretamente quantificadas no censo demográfico (IBGE, 2010), à exceção de três deles que precisaram ser construídos: População Infanto-juvenil e população Analfabeta e Densidade demográfica. Para a primeira utilizou-se o arquivo, Idade total, estabelecendo como população infanto-juvenil, as pessoas com idade máxima de 13 $a^{2} s^{2}$ e a segunda (População Analfabeta) foi construída utilizando dados retirados de diferentes arquivos deste mesmo censo (Equação 1).

$$
\mathrm{PA}=\left((\mathrm{PM}-\mathrm{PI})-\mathrm{P}_{\mathrm{al}}\right) \quad \text { Equação } 1
$$

Onde, $\mathrm{PA}=$ população analfabeta; $\mathrm{PM}=$ população moradora; $\mathrm{PI}=$ população infantil ( 0 a 4 anos) e $P_{a l}=$ população alfabetizada.

A Equação 1 descreve a obtenção da população com idade mínima de cinco anos e a subtração da população alfabetizada. Dessa forma, estabeleceu-se a Equação 2, que destacou a população analfabeta pela diferença entre estas duas populações:

$$
\mathrm{PA}=\mathrm{P}-\mathrm{P}_{\mathrm{al}} \quad \text { Equação } 2
$$

Onde, $(P A)$ corresponde a população analfabeta; $(P)$ população moradora e $(P a l)$ a população alfabetizada.

Quanto a elaboração da Densidade Demográfica, sua construção baseou-se em sua própria definição, envolvendo as variáveis, População Absoluta em cada setor censitário, retirada do arquivo Moradores, e o cálculo da área $\left(\mathrm{km}^{2}\right)$ das malhas espaciais através do software ArcGis 10.2 .

\footnotetext{
${ }^{2}$ No Brasil os jovens com 14 anos já podem obter carteiras de trabalho assinadas mesmo que como jovens aprendizes, iniciando sua vida profissional e abrangendo seu poder de decisão
} 


\section{Exposição}

Nesta dimensão de análise a integração entre os índices aplicados orientou a identificação das populações mais expostas, espacial e temporalmente aos danos e as perdas resultantes da ocorrência das corridas de detritos e das inundações bruscas. No total foram aplicados dois índices: (a) População total e (b) Exposição Permanente da população nas residências.

(a) Este índice de análise foi selecionado por destacar a distribuição da população dos 70 setores ocupados, conforme sua quantidade absoluta na área de estudo, embasando a exposição do perfil populacional de interesse.

b) O índice Exposição Permanente da população nas residências, volta-se à necessidade de identificar o espaço e o tempo de permanência dos perfis populacionais residentes. Nesse contexto, vale observar a escolha pelo índice, "Exposição Permanente da População" $(E P)$ ao invés da "Exposição Temporária da população" $(E T)$, como é comumente abordada pela literatura internacional e fora inicialmente pensada para esta pesquisa.

Nos municípios estudados do vale do Ribeira, sobretudo nos casos de Ribeira e Itaoca, a dinâmica sociocultural e espacial dos moradores é diferente das comunidades metropolitanas que percorrem grandes distâncias (FREIRE, AUBRECHT e WEGSCHEIDER, 2011), se ausentando dos cenários de risco por muitas horas. Nesta região, a população localiza-se próxima aos seus postos de trabalho e escolas, percorrendo, portanto, curtos trajetos diários.

Dessa forma, buscou-se compor o índice de análise com as populações que melhor representam a permanência nas residências, a partir de dois grupos, sendo um organizado por idade e outro pela condição da renda. O primeiro envolveu o agrupamento de crianças com idades entre 0 e 4 anos e de idosos, pessoas com idade mínima de 65 anos. O segundo grupo destacado envolve o total da população com idades entre 10 anos ou mais que não apresentam renda, aumentando suas horas de permanência na casa. A base de dados destes fatores foi retirada dos arquivos, Crianças idade (0 a 4 anos), Idade total e Renda, respectivamente, do censo demográfico, IBGE (2010). 


\section{Déficit de Resiliência}

A seleção dos índices da dimensão déficit de resiliência enfocou os aspectos econômicos da população, buscando apontar as condições que reduzem sua capacidade de recuperação nos cenários de risco. Nesse sentido, aplicou-se os seguintes índices: a) População economicamente ativa; b) Condição de moradia e c) Situação da Renda.

a) A seleção da população economicamente ativa como um índice de análise buscou reconhecer o contingente populacional efetivamente inserido no mercado de trabalho, escolhendo, em cada setor censitário, indivíduos com idades entre 10 anos ou mais que apresentassem renda.

b) Em condição de moradia identificou-se a quantidade de construções atingidas pelas corridas de detritos e inundações bruscas, além da infraestrutura básica, dos domicílios em cada setor de análise, por meio dos fatores: abastecimento de água e a presença de sanitários ou de banheiros com uso exclusivo por seus moradores.

No caso da elaboração do fator, construções atingidas, foi necessária a utilização das ortofotos, 2010/2011 da Emplasa ${ }^{3}$, quantificando-as de maneira mais precisa, já que a presença marcante dos detritos e sedimentos recobrindo as largas áreas afetadas, no ano de 2014, dificultaram sua visualização, através das imagens históricas do Google Earth.

Neste processo, sobrepôs-se a delimitação dos processos deflagrados sobre as construções mapeadas, destacando assim quantas foram atingidas. Contudo, quando acomodadas nos setores espaciais houve casos em que a quantidade de construções atingidas excedeu o total dos domicílios contabilizados pelo IBGE (2010). Dessa forma, identificou-se o valor percentual do número de construções atingidas, a partir dos quais calculou-se o número aproximado de domicílios atingidos (Tabela 5).

\footnotetext{
${ }^{3}$ Emplasa: (Empresa Paulista de Planejamento Metropolitano S/A) - Projeto: Mapeia São Paulo. Resolução espacial das ortofotos: Aproximadamente um metro com escala cartográfica de 1:25 000. Sistema de Compartilhamento de dados (SCD) Pedido 17850.
} 
Tabela 5: Construções e Domicílios Atingidos pelos Processos de 2014

\begin{tabular}{|c|c|c|c|c|}
\hline $\begin{array}{c}\text { Setores Censitários } \\
\text { com Construções } \\
\text { Atingidas }\end{array}$ & $\begin{array}{c}\mathrm{N}^{\circ} \text { de domicilios por } \\
\text { setor censitário, } \\
\text { (Censo demográfico, } \\
\text { BGE, 2010) }\end{array}$ & $\begin{array}{c}\mathrm{N}^{0} \text { de construções } \\
\text { atingidas } \\
\text { (Emplasa 2010/2011 e } \\
\text { Google Earth, 2014) }\end{array}$ & $\begin{array}{l}\mathrm{N}^{\circ} \text { de construções } \\
\text { atingidas, por } \\
\text { setor censitário. }\end{array}$ & $\begin{array}{c}\mathrm{N}^{\circ} \text { aproximado } \\
\text { de domicílios } \\
\text { atingidos }\end{array}$ \\
\hline Palmital & 163 & \multirow[t]{2}{*}{10} & 2 & 2 \\
\hline Palmital (1) & 95 & & 8 & 8 \\
\hline Lageado & 75 & 110 & 110 & 51 \\
\hline $\begin{array}{l}\text { Guarda- Mão e } \\
\text { Gurutuba Martins }\end{array}$ & 68 & 27 & 27 & 27 \\
\hline Itaoca Central (1) & 174 & \multirow{2}{*}{412} & 109 & 109 \\
\hline Itaoca Central & 126 & & 174 & 91 \\
\hline
\end{tabular}

Fonte: Elaborado pela autora

Quanto aos índices de infraestrutura básica de moradia, ressalta-se que sua presença nos domicílios indica o bem-estar da população, já que as condições de acesso a estes serviços impactam diretamente em sua capacidade de recuperação diante de desastres naturais. No caso do fator, abastecimento de água, denominouse dois grupos de domicílios; os que não apresentavam quaisquer formas de abastecimento de água e os que apresentavam variadas fontes, como; rede geral, poços ou nascentes, cisternas e outros. Da mesma maneira, o fator, presença de sanitários ou de banheiros com uso exclusivo por seus moradores, foi composto por dois grupos de domicílios; o primeiro com sanitários ou banheiros de uso exclusivo pelos moradores e o segundo por domicílios que não apresentavam esta condição.

c) O índice situação da renda compreende a articulação entre os seguintes fatores: 1) população atingida; 2) população com renda e 3) população sem renda. Para população atingida se considerou primeiramente a quantidade média de pessoas em cada domicílio, multiplicando-as, posteriormente pelo total de construções atingidas (Equação 4).

A população com renda e a população sem renda buscaram reforçar o perfil econômico da população em risco, tendo sido apresentados por meio da seleção de uma população economicamente ativa e outra sem renda. Dessa 
forma, normalizaram as quantidades de pessoas com acesso a renda; ambos contabilizados a partir dos dados do Arquivo Renda do censo demográfico.

$$
\mathrm{P}_{\mathrm{at}}=\left(\left(\frac{\mathrm{ps}}{\mathrm{ds}}\right)\right) \times \mathrm{DA} \quad \text { Equação } 4
$$

Onde: $P_{a t}=$ população atingida; $p s=$ total da população por setor; $d s=$ total de domicílios por setor e $D A=$ total de domicílios atingidos.

Diante do cálculo das três variáveis de análise apresentadas, ressalta-se que, suas respostas numéricas devem ser compreendidas em função do Déficit de Resiliência, envolvendo, portanto, a direção dos índices calculados (Equação 5).

$$
\text { Déficit de Resiliência }=(P E A \downarrow)+(C M \uparrow)+(S R \uparrow) \quad \text { Equação } 5
$$

No caso da PEA, os índices resultantes devem apresentar uma relação inversamente proporcional ao próprio déficit de resiliência, já que quanto menos elevados os índices da PEA, maior será o déficit de resiliência dessa população. Quanto as variáveis da Condição de Moradia e Situação da renda, sua relação é direta, exibindo, portanto, valores elevados para indicarem déficits elevados.

Dessa maneira, destaca-se os fatores, domicilios com serviços de infraestrutura básica ( $d c s$ ) e população com renda ( $p c r)$ que foram calculados com a variável "1", a fim de dirigi-los para o déficit de resiliência, colocando-os em conformidade com os fatores: domicílios atingidos e sem serviços (dss) e população atingida e sem renda (psr), respectivamente (Tabela 4).

\subsubsection{Elaboração dos Indicadores de vulnerabilidade por dimensão de análise}

Tendo em vista a elaboração dos indicadores de vulnerabilidade por dimensão de análise; a saber: a) sensibilidade, b) exposição e c) déficit de resiliência, buscouse expressar o valor de cada um dos 210 alcançados, por meio de uma equação 
matemática simples. Neste processo, utilizou-se o MODELO 02 expresso nas Tabelas 2, 3 e 4, conforme cada dimensão de análise.

a) No caso da dimensão de sensibilidade, seus índices foram somados e divididos por cinco, número total de variáveis envolvidas na busca pela compreensão da sensibilidade populacional final (Tabela 2). Neste processo, observou-se o comportamento de suas variáveis de análise ao longo dos setores aplicados.

b) Quanto a dimensão de exposição, composta por duas variáveis de análise, a elaboração de sua vulnerabilidade envolveu, a soma dos índices resultantes divididos por 2 (Tabela 3). Ressalta-se, aqui, que os indicadores alcançados devem identificar os níveis de exposição da população aos processos naturais estudados, de acordo com seu perfil etário, econômico e cultural, no contexto de sua rotina diária.

c) Para os índices do déficit de resiliência, a média aritmética envolveu três variáveis de análise (Tabela 4), que já redirecionadas passam a destacar, numericamente, o quão deficiente é a resiliência da população em estudo.

De maneira geral, cada dimensão de vulnerabilidade, apresenta a mesma direção em seus indicadores, devendo exibir números crescentes em seus resultados. A partir daí, seus valores são padronizados em indicadores de vulnerabilidade com variação entre 0 e 1. Trata-se da divisão dos números resultantes de cada um dos 70 setores aplicados, por dimensão de análise, pelos índices de maior alcance (Equação 6), caracterizando, portanto, indicadores com valor igual ou próximos de 0 como sendo de baixa vulnerabilidade, enquanto os iguais ou próximos a 1 de alta vulnerabilidade.

$$
\text { Padronização }=\frac{\text { № do índice por setor }}{\text { índice de }>N^{\circ}-\text { Índice de }<N^{0}}=(0-1) \quad \text { Equação } 6
$$

Estabelecidos os cálculos da vulnerabilidade por dimensão de análise, observouse as classificações aplicadas nos estudos que embasaram a presente pesquisa (Tabela 6), buscando compreender a melhor representação para a vulnerabilidade alcançada. Neste processo observou-se as vantagens e as limitações de cada uma, bem como sua adequação a realidade dos resultados esperados. 
Tabela 6: Modelos de Classificação para a vulnerabilidade Final

\begin{tabular}{|c|c|c|c|c|c|}
\hline Estudos & \multicolumn{5}{|c|}{ Classificações de Vulnerabilidade } \\
\hline MODELO $1^{*}$ & 0 a 0,20 & 0,21 a 0,45 & 0,46 a 0,55 & 0,56 a 0,80 & 0,81 a 1 \\
\hline MODELO $2^{* *}$ & $\begin{array}{c}>1.5 \text { Std } \\
\text { Dev. }\end{array}$ & $\begin{array}{c}0,5-1.5 \text { Std } \\
\text { Dev. }\end{array}$ & $\begin{array}{c}0,5-0,5 \text { Std. } \\
\text { Dev. }\end{array}$ & $\begin{array}{c}-1.5 \text { Std. } \\
\text { Dev. }\end{array}$ & $\begin{array}{c}<-1.5 \text { Std. } \\
\text { Dev. }\end{array}$ \\
\hline $\begin{array}{l}\text { MODELO*** } \\
\text { adotado }\end{array}$ & 0 a 0,20 & 0,21 a 0,40 & 0,41 a 0,60 & 0,61 a 0,80 & 0,81 a 1 \\
\hline \multicolumn{6}{|c|}{$\begin{array}{l}\text { *Classificação com base na divisão em partes aproximadas. } \\
\text { **Desvio Padrão como classes de análise, favorecendo a identificação dos valores extremos } \\
\text { Fonte: Adaptado de Murillo-Garcia et al. (2017) e Guillard-Gonçalves e Zêzere (2018). } \\
\text { *** Classificação com base na divisão em partes iguais }\end{array}$} \\
\hline
\end{tabular}

As classificações observadas acabam por denominar a vulnerabilidade em classes: muito baixa, baixa, média, alta e muito alta, auxiliando em uma representação que distingue os valores resultantes, por grupos visuais de análise.

Propriamente sobre a classificação do MODELO 1, a distinção das 5 classes observadas na Tabela 6 destaca a possível ausência de algumas(s) delas, a exemplo da classe com vulnerabilidade mais baixa, auxiliando os tomadores de decisão na identificação rápida dos níveis de vulnerabilidade existentes nos municípios. Nesse sentido, a descrição dos valores resultantes na escala de 0 a 1 pode auxiliar de forma mais direta, sobre planos de ação municipais em setores demográficos com maior necessidade. Dessa forma, a identificação das classes acaba por direcionar planos de ação específicos, além de tratar-se da mensuração mais aplicada para estudos de vulnerabilidade mundialmente, facilitando integração e discussão com vulnerabilidades obtidas em outros estudos.

Para a classificação do MODELO 2, a apropriação dos dados por classes de análise, não é contemplada como ocorre com o MODELO 1, já que sua classificação é pautada por meio do desvio padrão. Nesse sentido, a visualização rápida dos indicadores obtidos em cada classe de análise é dificultada, passando a exigir mais 
estudos que auxiliem a compreender a situação de classe obtida e sua conformidade com outros estudos de vulnerabilidade.

A classificação do MODELO 1 se mostra mais adequada, quando se compreende que os valores resultantes podem ser utilizados como ferramentas de ação em função da redução de risco. Além disso, facilita a padronização das classes de vulnerabilidade com as de outros mapas, como é o caso das dimensões de análise sensibilidade, exposição, déficit de resiliência, podendo torná-los compatível também com futuros mapas de risco e susceptibilidade da mesma área. Dessa forma e tendo em base a classificação descrita, adotou-se, na presente pesquisa, a distribuição dos valores resultantes em partes iguais, já que desta maneira a realidade dos valores obtidos experimentou melhor representação visual por classe de análise.

De modo geral, o maior limite da classificação pelo MODELO 1 reside na precisão numérica que diferencia as classes de análise, sobretudo na direção dos indicadores médios. Contudo, sabe-se que cada classe compreende um espectro de valores, cuja delimitação pode ser examinada, conforme a proximidade com os valores resultantes das classes mais próximas, demonstrando, portanto, o aspecto da própria dinâmica da vulnerabilidade. A este exemplo, destaca-se a transição entre as classes que se dão, predominantemente, de forma harmoniosa, passando da baixa para média, demonstrando a vulnerabilidade, efetivamente, como um processo. Dessa maneira, diante da espacialização da vulnerabilidade alcançada e de acordo com a expertise dos agentes qualificados, os limites entre as classes de vulnerabilidade não devem gerar entraves para as ações de redução de risco.

\subsubsection{Construção da vulnerabilidade final}

Estabelecidos os indicadores da sensibilidade, exposição permanente da população e do déficit de resiliência, deu-se início a conformação da vulnerabilidade final (Equação 7). Neste processo, todos os índices denotam relação de proporcionalidade direta à vulnerabilidade, já que os valores numéricos alcançados indicam a mesma direção, sendo os valores iguais ou próximos a 0 para baixa vulnerabilidade, e os valores iguais ou próximos a 1 para alta vulnerabilidade. Trata- 
se dos 70 valores finais por cada dimensão de análise, totalizando 210 índices, já padronizados em valores de 0 a 1.

$$
\mathbf{I V}=\frac{\left(\mathrm{s}+\mathrm{E}_{\mathrm{xp}}+\mathrm{Dr}\right)}{3}=\mathbf{I} \boldsymbol{V}=(0-1) \quad \text { Equação } 7
$$

Onde $=($ IV) corresponde ao indicador de vulnerabilidade; (S) a dimensão de sensibilidade; (Exp) a de exposição permanente da população e (Dr) ao déficit de resiliência.

Os indicadores provenientes das dimensões de análise foram realinhados por meio da soma e divisão das variáveis envolvidas. Neste processo, ressalta-se tratar do MODELO 2, o mesmo aplicado ao cálculo dos índices e elaboração dos indicadores por dimensão e análise. A partir daí, os indicadores da vulnerabilidade final foram padronizados em valores de 0 e 1 .

Diante do processo descrito, buscou-se analisar o comportamento de cada dimensão aplicada à vulnerabilidade final, elevando-a ou diminuindo-a. Trata-se da ação de seu aspecto múltiplo, perceptível também por meio de representações que apresentem classes de análise, já que demonstram, cartograficamente, o produto da interação entre as dimensões aplicadas.

\subsubsection{Vulnerabilidade final e o evento de 2014}

Nesta etapa da pesquisa buscou-se compreender o comportamento dos setores atingidos pelos processos de corridas de detritos e inundações bruscas em 2014, a partir dos indicadores e classes da vulnerabilidade final obtidos. Para tanto, optou-se por uma análise comparativa entre: a) Setores atingidos e b) Setores não atingidos, classificando-os respectivamente.

a) No caso dos setores atingidos, verificou-se seu percentual, diante da área de estudo como um todo, além das distâncias alcançadas pelos processos naturais em cada setor de análise. Diante de suas respostas, buscou-se compreender as classes de vulnerabilidade a que foram submetidas, identificando 0 
comportamento dos indicadores e suas dimensões na conformação da vulnerabilidade final.

b) Para os setores não atingidos identificou-se suas quantidades totais na área de estudo, bem como analisou-se o comportamento das dimensões e indicadores gerados na vulnerabilidade final, buscando caracterizar e distinguir sua condição a dos setores atingidos. 


\section{RESULTADOS}

\subsection{Mapas das corridas de detritos e inundações bruscas}

Para os registros das corridas de detritos notou-se feições concentradas nas bacias hidrográficas do rio Guarda-Mão e do rio Gurutuba, localizados em um único setor do município de Itaoca (Figura 17). Embora ambas tenham sido caracterizadas como corridas de detritos, o caso do processo deflagrado na bacia do rio Guarda-Mão, detém mais estudos e apresenta feições mais evidentes ao longo de seu percurso. Trata-se dos registros dos cordões laterais, do imbricamento dos blocos mobilizados e sua inversão granulométrica (GRAMANI e ARDUIM, 2015).

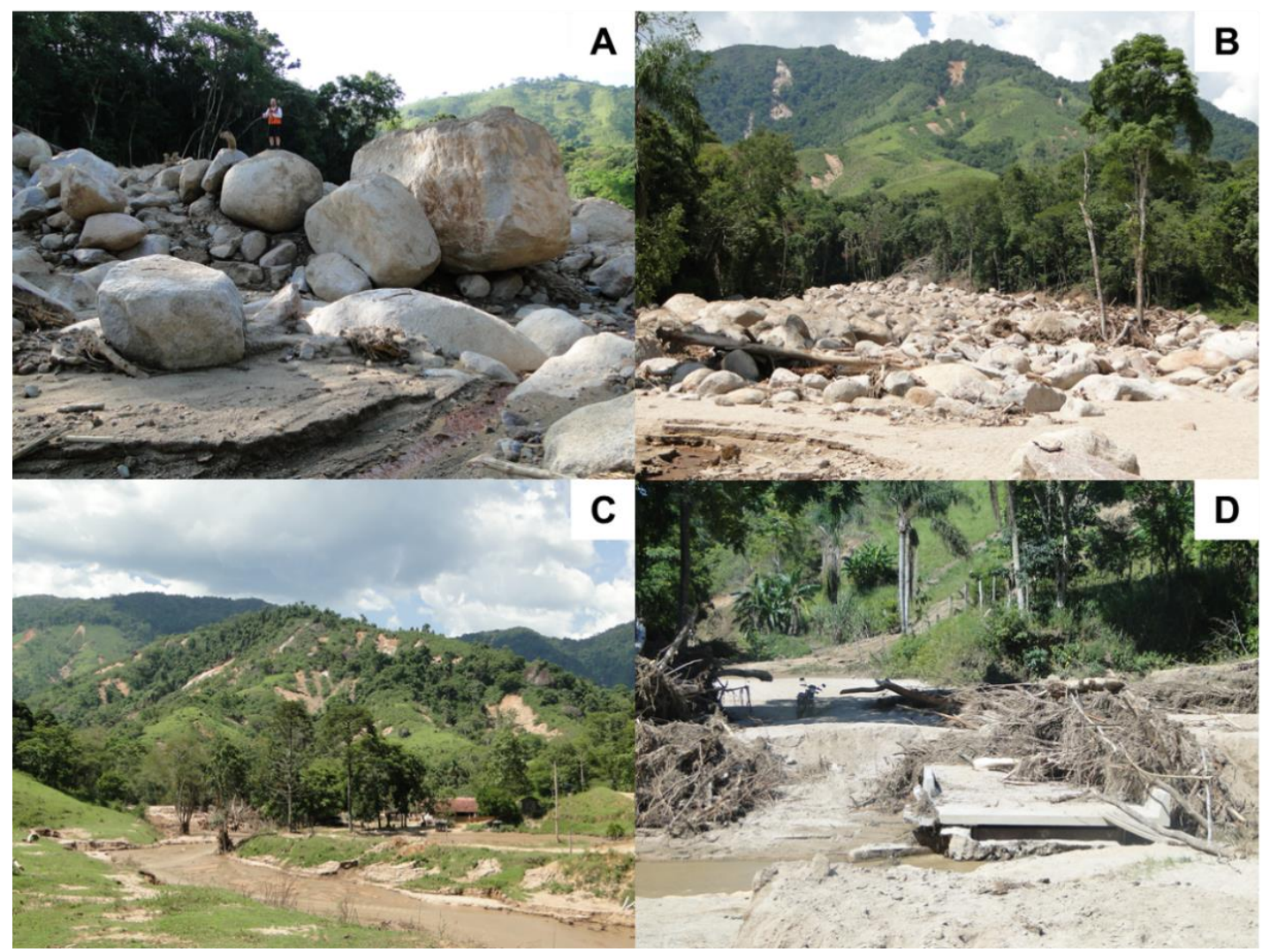

Figura 17: $(A)$ e (B) Corridas de detritos na bacia do rio Guarda- Mão. (C) e (D) Corridas de detritos e inundações bruscas na bacia do rio Gurutuba. Fonte: Marcelo F. Gramani e Prefeitura de Itaoca (2014).

No caso das inundações bruscas, destaca-se uma feição mais fluida com morfologia irregular, resultante do aumento abrupto do nível de água fluvial, em 
resposta aos barramentos por material detrítico de dimensões variadas em pontos específicos do rio Palmital (BROLLO et al. 2015).

Sobre as corridas de detritos, as áreas atingidas concentraram-se na altura do curso médio do rio, alcançando $0,40 \mathrm{~km}^{2}$ em um setor rural com $53,62 \mathrm{~km}^{2}$ no município de Itaoca. Neste processo, sua representação conferiu feições concentradas nas bacias hidrográficas do rio Guarda Mão e Gurutuba, descrevendo a dinâmica do processo. Nelas observa-se uma intensa concentração de blocos sendo mobilizados linearmente, desde suas cabeceiras até a confluência com outros rios, promovendo a interface dos blocos com grandes quantidades de sedimentos. Notase ainda que estas feições são mais acentuadas na bacia do rio Guarda - Mão, apresentando maiores dimensões e densidade de blocos, além de atingirem maior extensão que a corrida deflagrada sobre a bacia do rio Gurutuba (Figura 18).

No caso das feições representadas como inundações bruscas, destaca-se que foram deflagradas em diferentes cursos do rio Palmital, abrangendo, diretamente, quatro malhas setoriais, das quais, 1 localiza-se no município de Apiaí e 3 em Itaoca.

Para as feições registradas no alto curso do rio Palmital (Figura 19), município de Apiaí, nota-se que o processo se deu ao longo do próprio rio, ainda que em alguns pontos seus limites tenham sido expandidos com a intensa presença de sedimentos. Dessa maneira, observou-se que seu percurso se alongou por aproximadamente 7,5 $\mathrm{km}$, embora o próprio curso do rio e a densidade vegetal próxima tenham dificultado a visualização e registro das feições com maior precisão. Diante disso, ressalta-se que o setor em estudo se estende por $54,836 \mathrm{de} \mathrm{km}^{2}$ tendo sido diretamente atingido por $0,11 \mathrm{~km}^{2}$ de processo perigoso. 


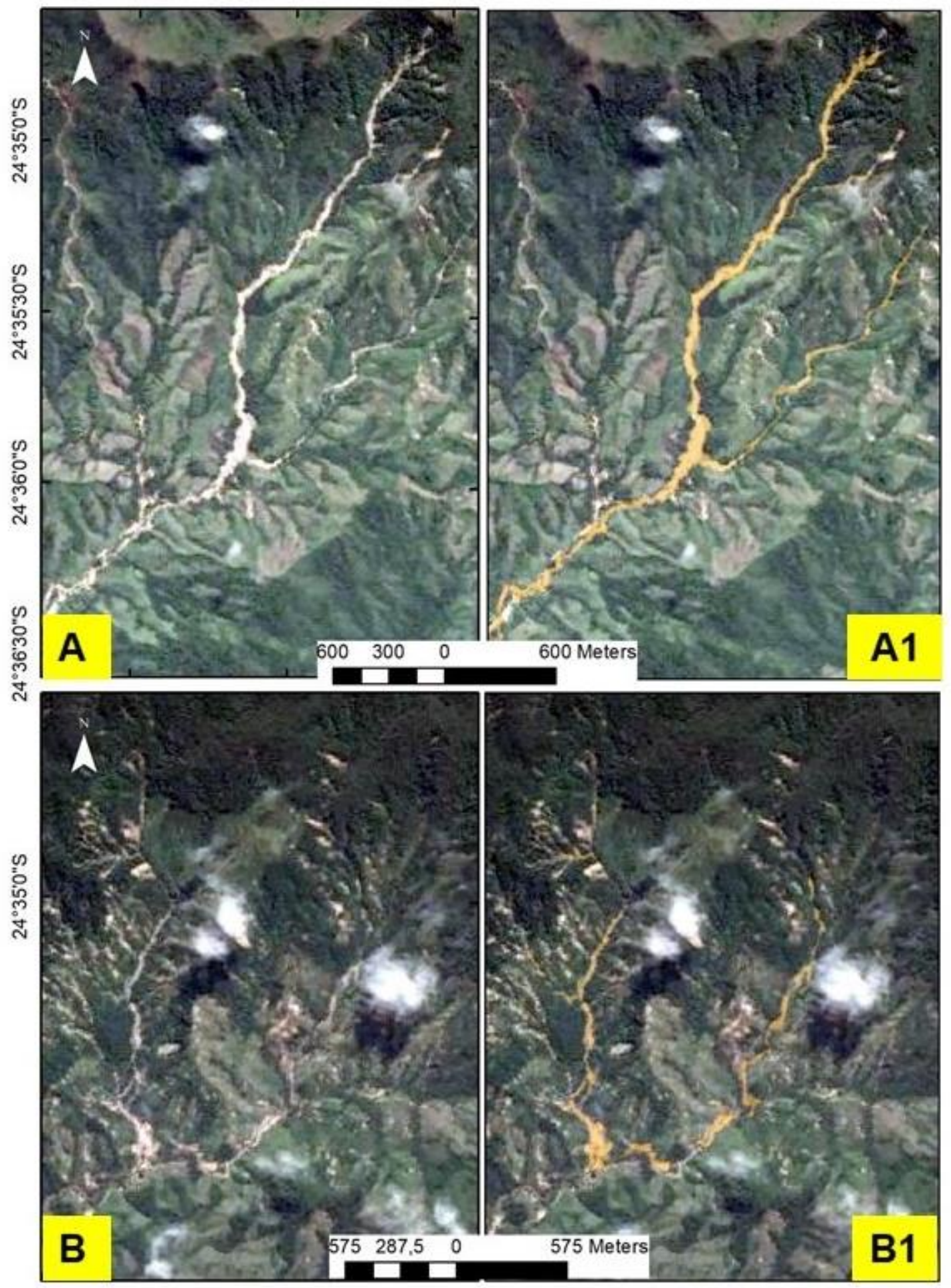

Figura 18: Corridas de Detritos no Município de Itaoca. A) Corridas de detritos atingindo a bacia hidrográfica do rio Guarda-Mão em um setor rural do município de Itaoca A1) Delimitação das corridas de detritos na bacia do rio Guarda-Mão. B) Corridas de detritos atingindo a bacia hidrográfica do rio Gurutuba no mesmo setor demográfico. B1) Delimitação das corridas de detritos na bacia do rio Gurutuba. Fonte: Imagens históricas; Google Earth (agosto, 2014). 

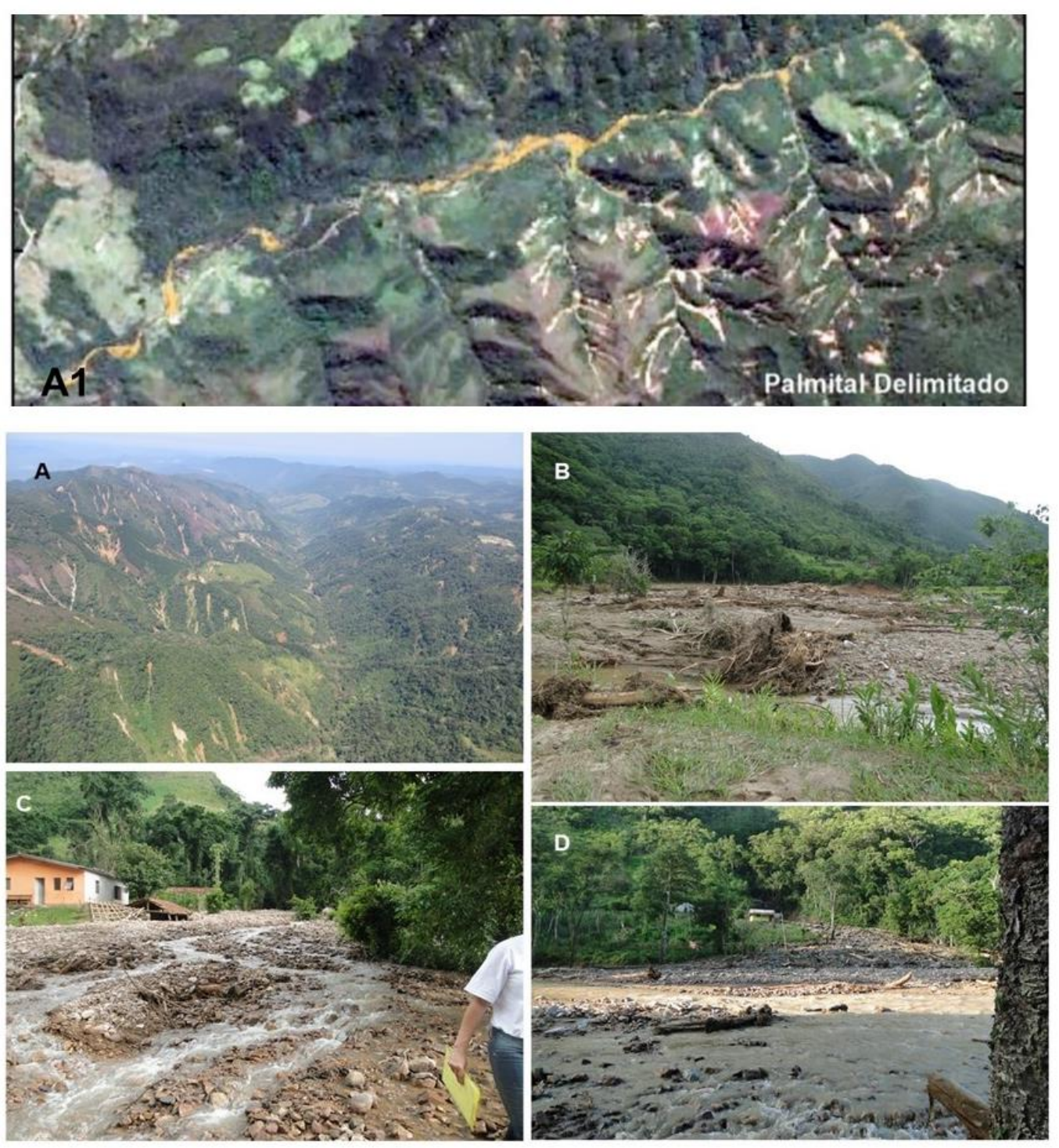

Figura 19: A) Paisagem com deflagrações de corridas de detritos no setor Palmital. Em A1) destaca-se a delimitação das inundações bruscas que atingiram o alto Palmital no município de Apiaí. Fonte: Google Earth, imagens históricas (agosto, 2014). Em B, C e D, observa-se algumas se suas características, como: acomodação de sedimentos, afora do curso do rio, além do aporte vegetal. Fotografias: Prefeitura do Município de Itaoca/Acervo, 2014. 
No caso dos cursos médio e baixo do rio Palmital, localizados no município de Itaoca, destaca-se as feições de inundações bruscas registradas no curso médio, ao longo do setor do Lajeado; segundo maior centro urbano do município de Itaoca, com extensão de 0,3741 $\mathrm{Km}^{2}$ e tendo sido atingido por $0,1169 \mathrm{Km}^{2}$ de inundação (Figura 20). No caso do curso baixo, os setores atingidos correspondem ao centro urbano da cidade, onde o setor mais atingido com $0,12 \mathrm{Km}^{2}$ de processo apresenta extensão de 0,8804 Km², configurando-se como as áreas mais afetadas em 2014 (Figura 21).

Estas inundações bruscas apresentaram o maior volume de água e alcance do material detrítico afora do curso principal do rio. Nesse contexto, observa-se o atingimento da quase totalidade dessas áreas, embora no caso do centro de Itaoca, a grande massa de detritos tenha sido dirigida para o nordeste da cidade.

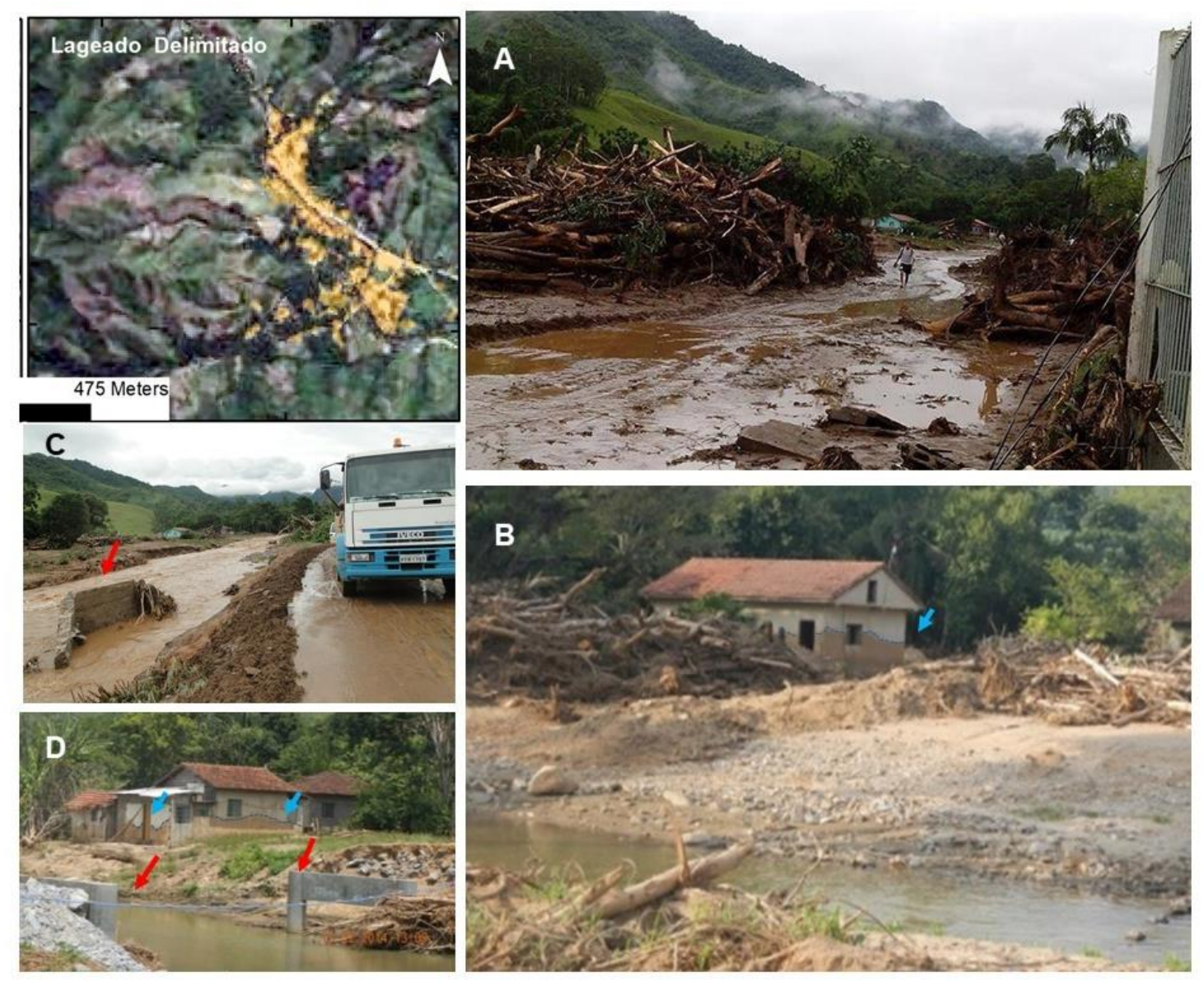

Figura 20: $E m(A)$ e $(B)$ observa-se o aspecto das inundações bruscas neste bairro. Em (C) e (D) destaca-se, respectivamente, a destruição da ponte na paisagem ainda recoberta por detritos e a construção da nova ponte. Fonte: A1: Google Earth, imagens históricas (agosto, 2014). Fotografias (A) e (C) Prefeitura do município de Itaoca/Acervo, 2014; (B) e (D) Picanço/UNICAMP, 2014. 

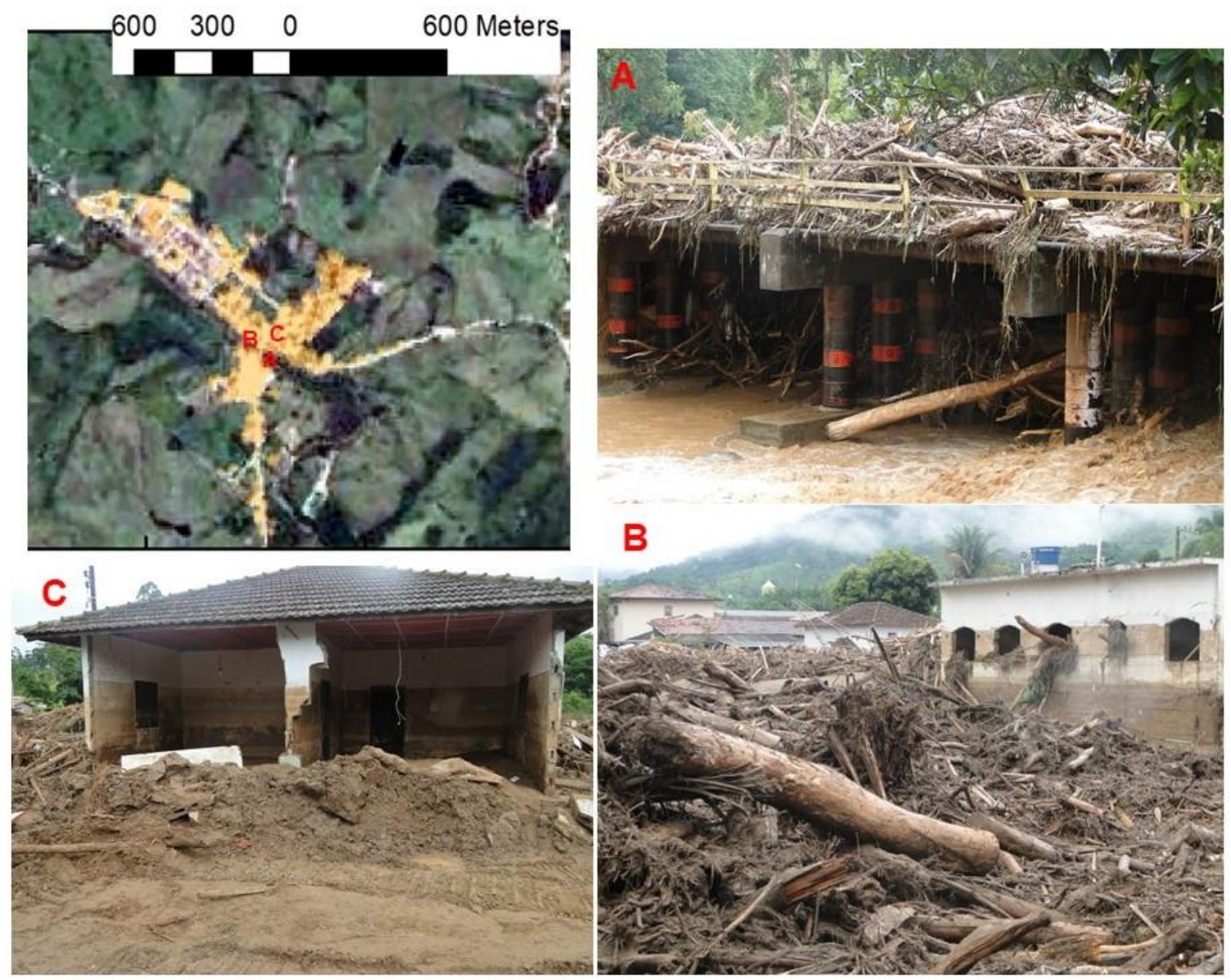

Figura 21: Impacto das inundações no centro da cidade de Itaoca. Em (A) observa-se a obstrução da ponte central principalmente por detrito vegetal e lama. Em (B) nota-se a altura a que o rio subiu depositando o material flutuante nas casas e construções próximas. Em (C) percebe-se a força da água e material transportado através do dano à estrutura construtiva. Fonte: Google Earth, imagens históricas (agosto, 2014). Fotografias: Prefeitura do município de Itaoca/Acervo, 2014.

Há ainda dois últimos setores atingidos por inundações bruscas, identificados como Palmital 1 e Itaoca Rural, por terem sido atingidos de forma indireta, pela extensão das inundações que deflagraram no alto Palmital e na cidade de Itaoca (baixo Palmital). Dessa forma, as inundações alcançaram apenas os limites das malhas setoriais com 0,02 e 0,007 $\mathrm{Km}^{2}$ de área. De modo geral, os detritos que chegaram nestas áreas caracterizam-se pelos volumes de sedimentos, desde cascalhos aos materiais mais finos, além da grande quantidade de galhos e troncos de árvores. Ressalta-se ainda, a grande quantidade de detritos urbanos que foram mobilizados pela água atingindo pessoas e bloqueando pontes e estradas. 
De maneira geral, ao combinar os 70 setores demográficos com as feições dos processos de corridas de detritos e Inundações bruscas, observou-se a concentração espacial da área perigosa a sudeste da área de estudo, atingindo, sobretudo o município de Itaoca (Figura 22). No total, sete setores foram atingidos, dentre os quais destaca-se que um concentrou as corridas de detritos registradas e os outros 6 as inundações bruscas, abrangendo os municípios de Apiaí e Itaoca. No caso de Apiaí, dois setores rurais foram atingidos no curso alto do rio Palmital, enquanto que em Itaoca 4 setores, sendo 1 rural e 3 urbanos, foram atingidos nos cursos médio e baixo.

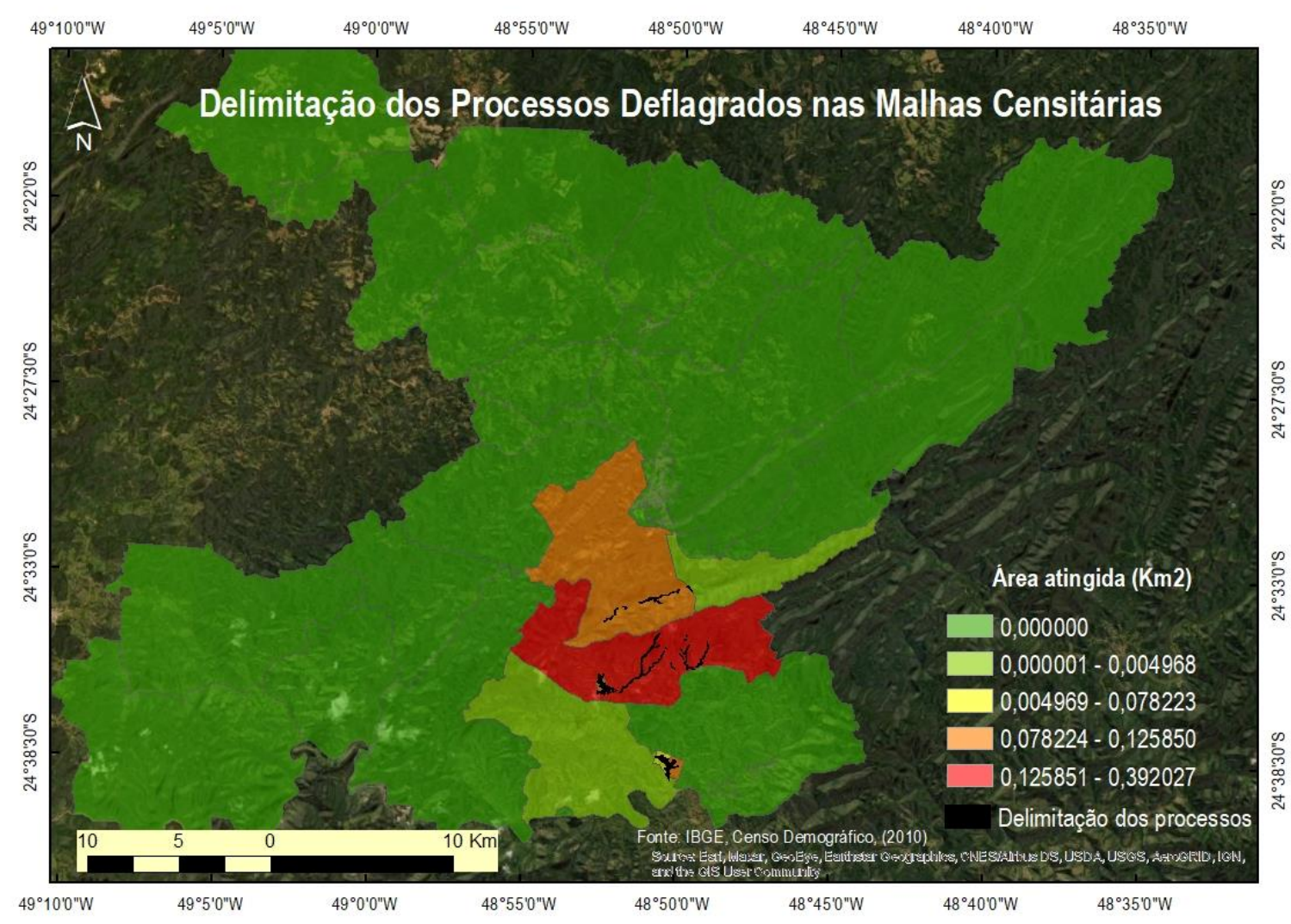

Figura 22: Distribuição e áreas atingidas pelas corridas de detritos e inundações bruscas, em cada setor demográfico. 


\subsection{Cálculo dos índices de vulnerabilidade}

\subsubsection{Sensibilidade}

Como produto dos 5 índices de sensibilidade aplicados em cada uma das 70 malhas setoriais, foram gerados 350 resultados, dentre os quais os 10 valores extremos alcançados (Figura 23). Observa-se ampla variação entre os índices máximos e mínimos alcançados, sendo a menor a população feminina que exibiu uma diferença de 0,23.

\section{Sensibilidade: Índices de análise extremos}

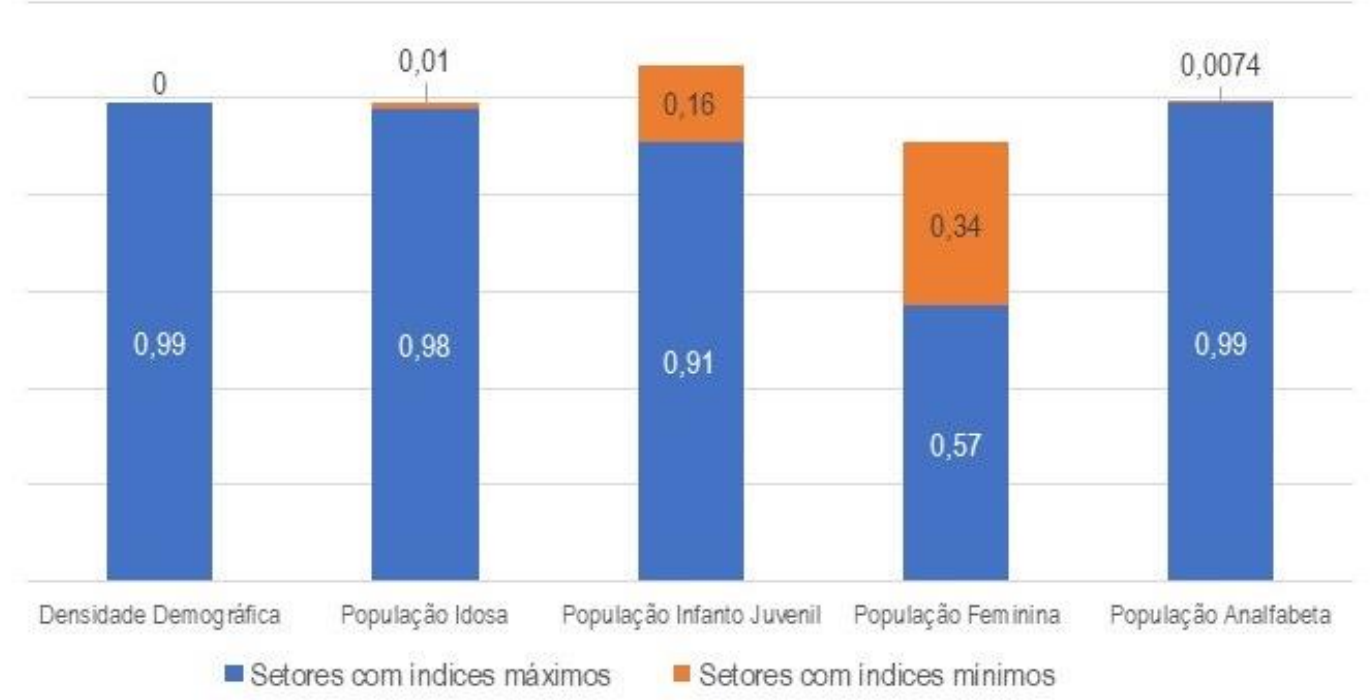

Figura 23: Observa-se os valores extremos alcançados por cada um dos cinco índices de análise aplicados. Nota-se que a densidade demográfica e população analfabeta correspondem aos índices que mais variaram; ao passo que a população feminina apresentou a menor diferença com 0,23.

Para a densidade demográfica seus valores apresentaram maior amplitude, exibindo uma variação absoluta. Pontualmente, observa-se que os índices extremos alcançados, encontram-se no município de Apiaí, onde, o valor mais baixo, 0 , corresponde, naturalmente, a um setor rural, enquanto que a densidade demográfica mais alta, 0,99, se estabelece em um setor urbano (

Figura 24). 

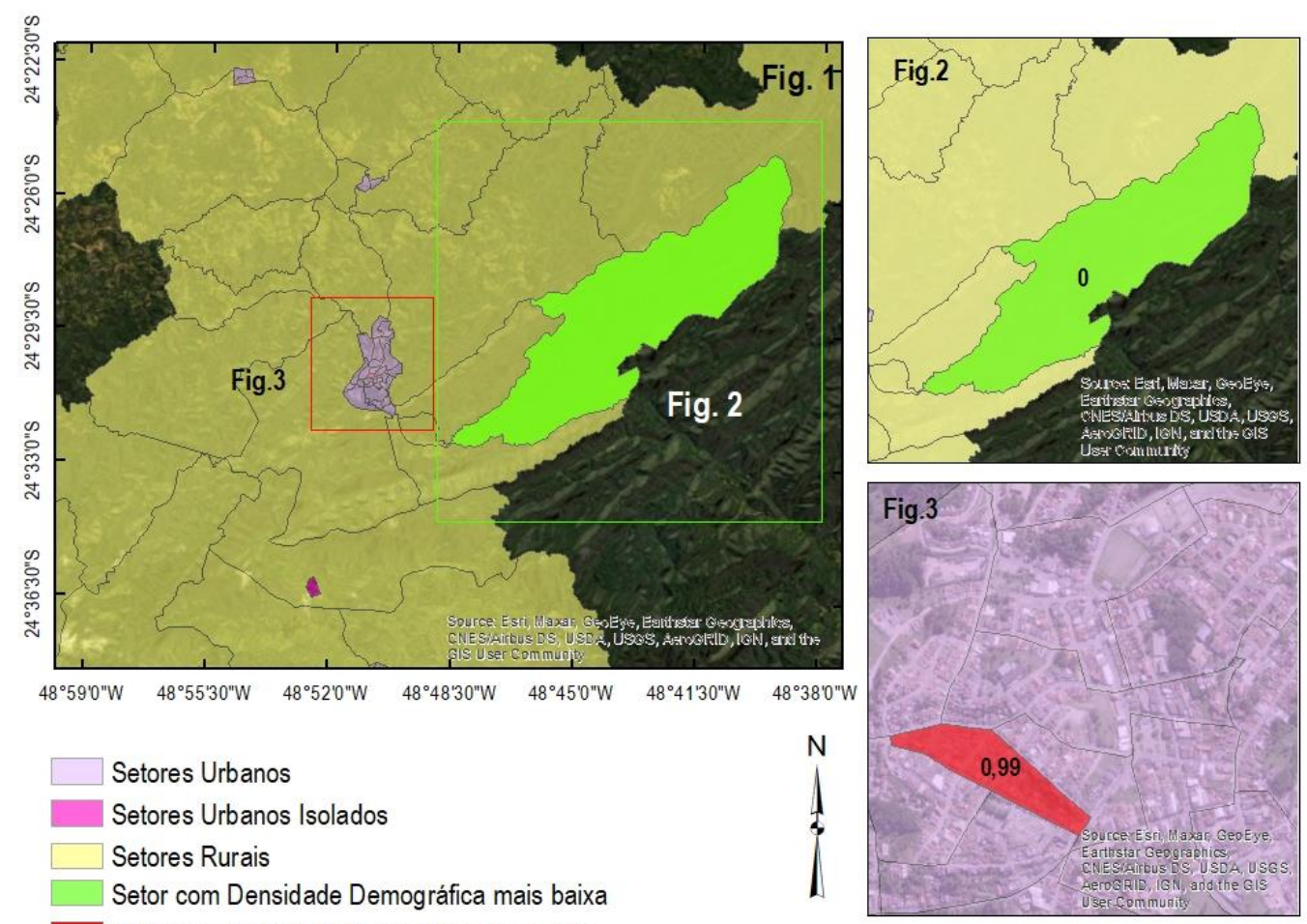

Setores Urbanos

Setores Urbanos Isolados

Setores Rurais

Setor com Densidade Demográfica mais baixa

Setor com Densidade Demográfica mais Alta

Fonte: IBGE, Censo Demográfico, (2010)

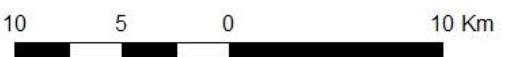

Figura 24: Localização dos índices extremos de densidade demográfica. Na Figura 2 observa-se o índice mais baixo encontrado, enquanto que na Figura 3 destaca-se o mais elevado.

Entre as populações idosa e analfabeta notou-se variação semelhante, por toda a área de estudo, embora tenha-se verificado um leve aumento entre os índices da população analfabeta. Nesse processo seus valores resultantes apresentaram correlação direta, sugerindo que a população analfabeta corresponde praticamente a população idosa nos três municípios (Figura 25). 


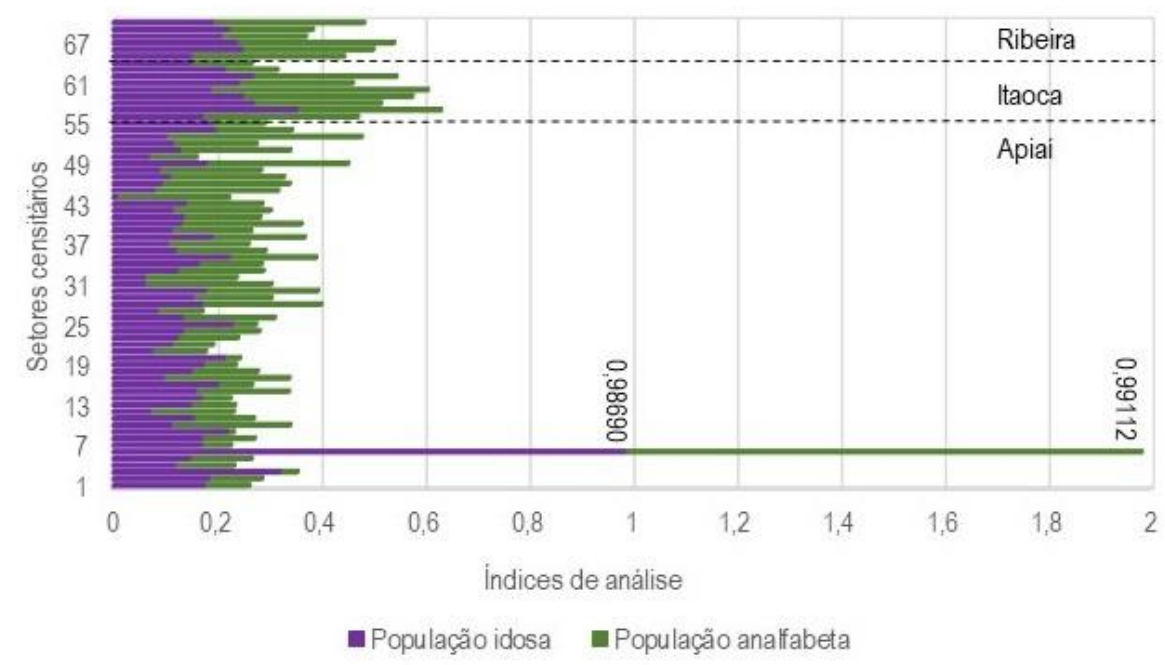

Figura 25: Correlação entre os índices de análise das populações idosa e analfabeta. Destaque para os valores mais altos alcançados.

Dessa maneira, observou-se a distribuição espacial dos índices extremos de análise que encontraram os valores mais elevados na mesma malha setorial com 0,98 de idosos e 0,99 de pessoas analfabetas (Figura 26). No caso dos índices menos elevados, os setores são diferentes, embora estejam localizados no município de Apiaí.

Quanto aos índices das populações feminina e infantojuvenil tratam-se dos valores menos elevados, embora o da população infanto-juvenil seja bastante significativo, 0,91. No caso da população feminina, o maior valor alcançado, 0,57, representa o índice de análise mais baixo, dentre os cinco apresentados (Figura 27). Contudo, eles correspondem aos que menos variaram ao longo dos 70 setores aplicados. A população feminina apresenta menor variação, 0,16 a 0,91, seguida da população feminina com, 0,34 a 0,57 (Figura 23).

A distribuição desses índices nos setores de análise aplicados, apresentaram um movimento diferente em seu comportamento, em comparação com as variáveis anteriores. No caso da população feminina, observou-se valores mais elevados nos setores urbanos, enquanto que a representação da população infantojuvenil é mais 
expressiva nos setores rurais, indicando uma desassociação entre a população feminina urbana e a natalidade (Figura 26).

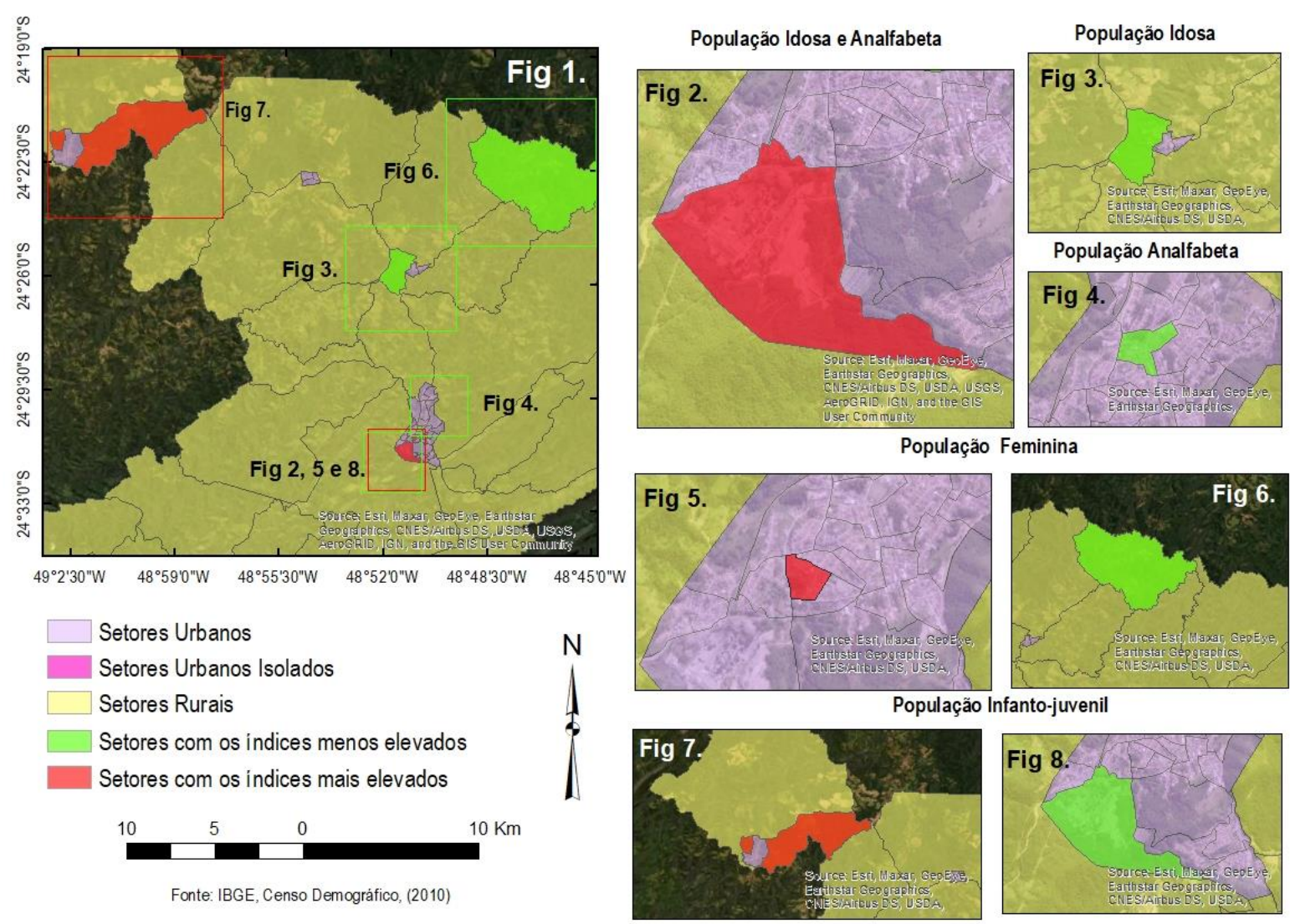

Figura 26: Distribuição espacial dos índices: população idosa, analfabeta, feminina e infantojuvenil. Nas Figuras 2, 3 e 4 observa-se a localização dos índices de análise da população idosa e analfabeta. No caso da Figura 2, destaca-se que os índices mais elevados se estabelecem no mesmo setor. Nas figuras 5 e 7 observa-se os índices mais elevados das populações feminina e infantojuvenil, enquanto que as Figuras 6 e 8 apresentam os índices menos elevados. Nota-se ainda que a população infantojuvenil mais baixa da Figura 8 localiza-se no mesmo setor em que as populações idosa e analfabeta mais elevadas se estabelecem. 


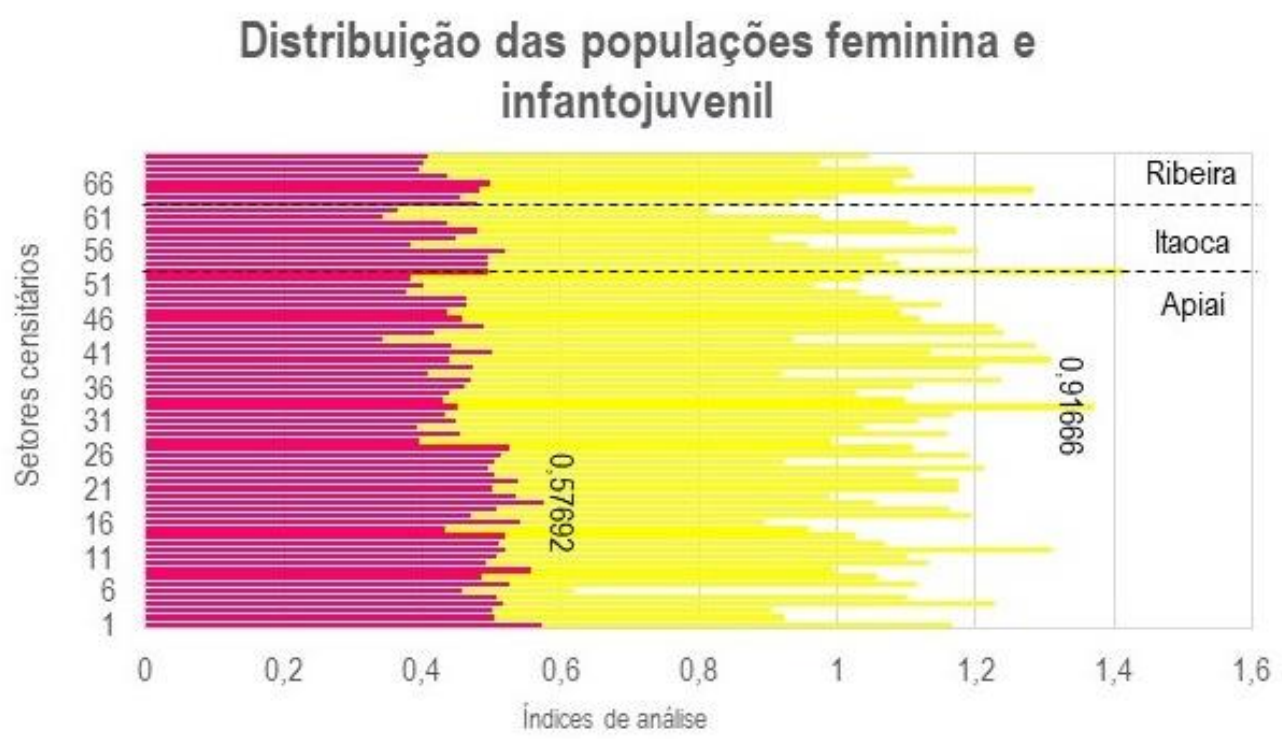

- População feminina População infantojuvenil

Figura 27: Comparação entre os índices da população feminina e Infantojuvenil nos setores de análise. Destaque para os índices mais elevados. 


\subsubsection{Exposição}

Os dois índices que compõem a dimensão de Exposição da População foram aplicados em cada um dos 70 setores demográficos, totalizando 140 índices de análise. Neste processo observou-se que a variável perfis populacionais de exposição permanente alcançou o índice de 0,692. No caso da população absoluta o índice mais elevado foi o de 0,998 (Figura 28).

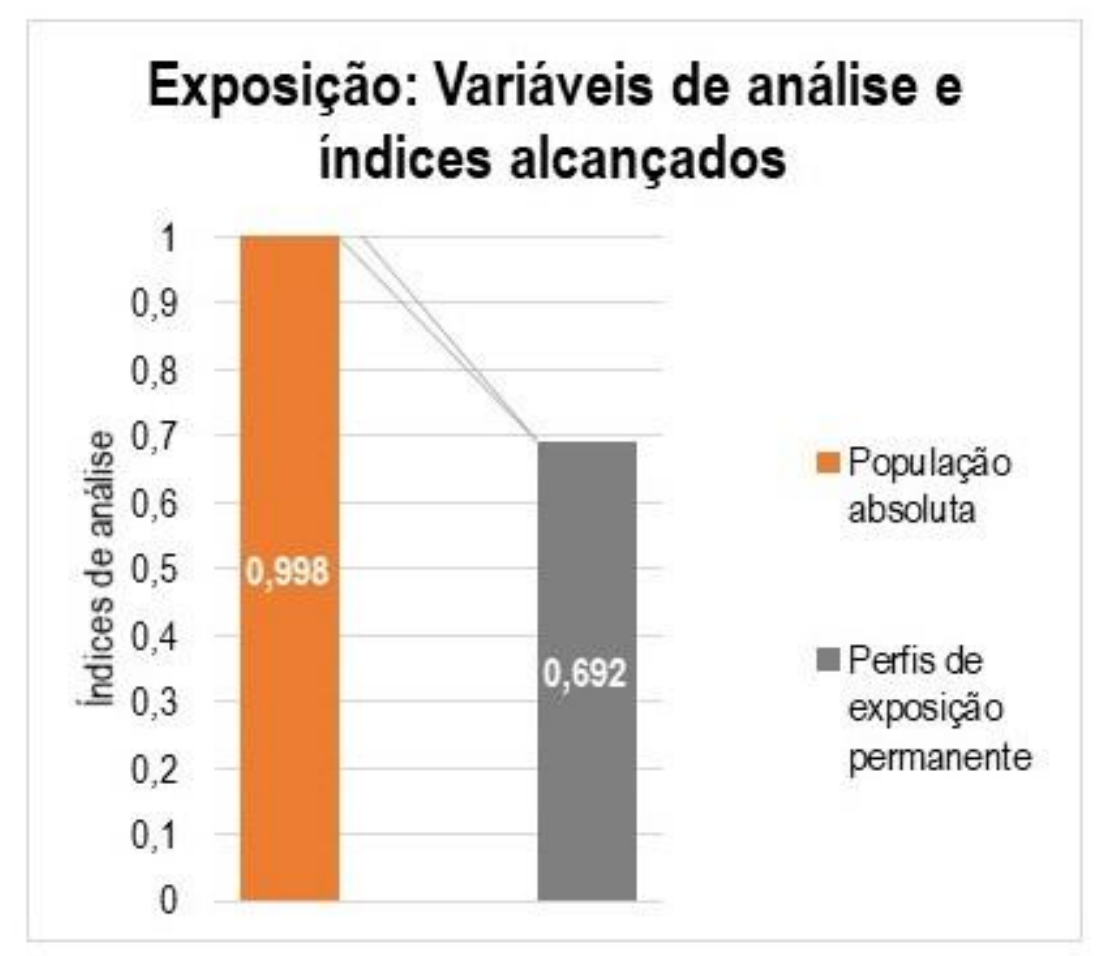

Figura 28: Índices mais elevados por variável de análise.

Dessa maneira, buscou-se observar a distribuição espacial da população residente, destacando os perfis populacionais de interesse (Figura 29). Propriamente sobre o setor de análise cuja variável população absoluta apresenta o índice mais alto alcançado,0,998, os perfis de exposição permanente exibem o índice, 0,169. No caso do setor com o índice dos perfis de exposição permanente mais elevado, 0,692, notase que sua quantidade é predominante, no setor ocupado. 
Quanto a sua amplitude, os índices dos perfis de exposição permanente não apresentaram variação, enquanto a população absoluta variou pouco; sendo elas, 0,69 e 0,94, respectivamente. Observa-se ainda que, na medida em que a quantidade de pessoas diminui, na direção dos setores rurais, verifica-se um leve aumento dos perfis de exposição permanente, embora seus índices com valores extremos tenham se estabelecido em setores urbanos (Figura 30).

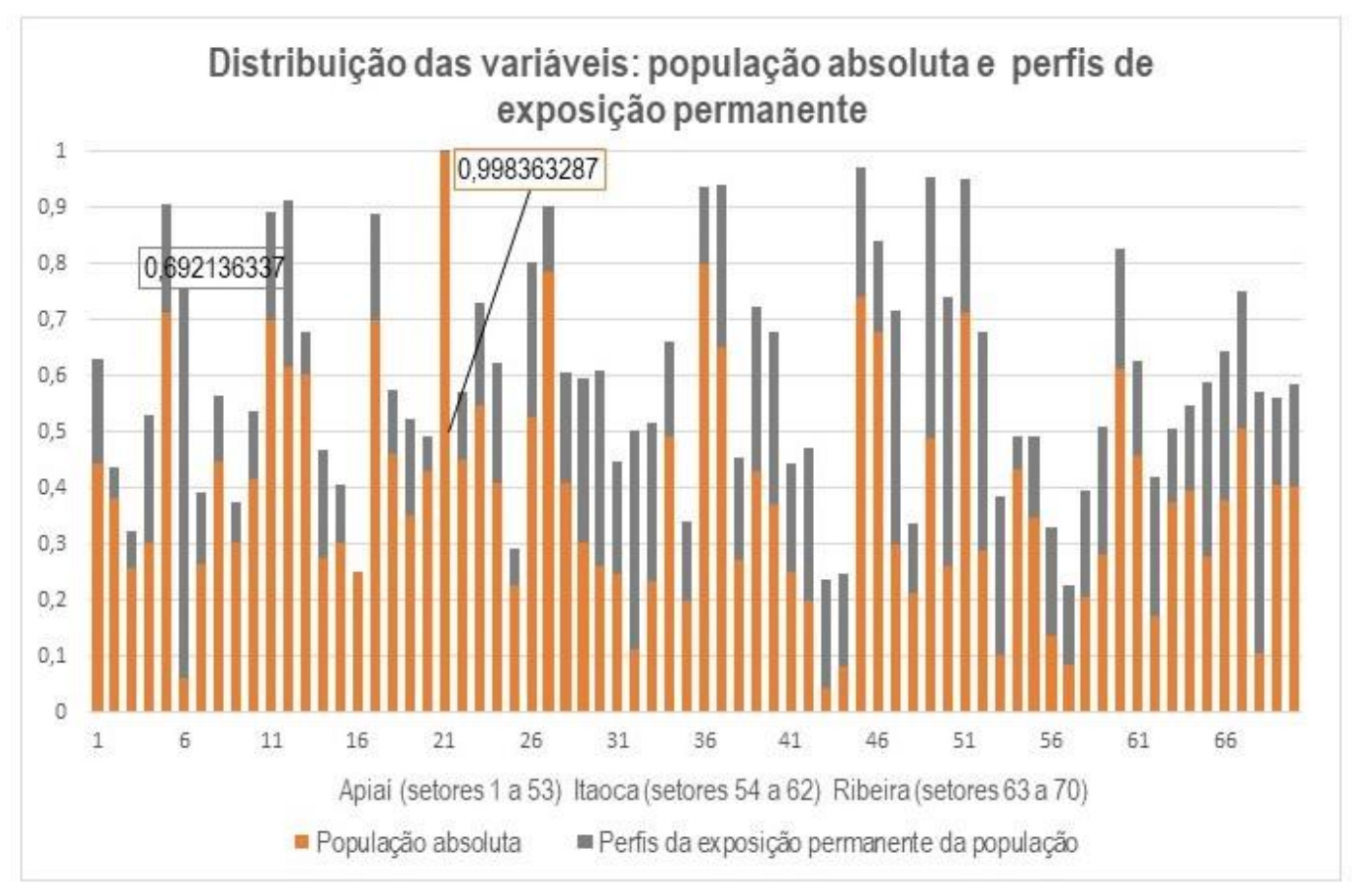

Figura 29: Observa-se a distribuição da população ao longo dos setores, por meio das variáveis população absoluta e perfis da exposição permanente, ressaltando os índices mais elevados.

Sabendo que o perfil de exposição permanente envolveu as populações idosa, infantil e sem renda (Tabela 3), buscou-se verificar a distribuição de cada uma dessas variáveis nos setores espaciais aplicados (Figura 31). Dessa forma, nota-se que os índices da população infantil (0 a 4 anos) elevam a condição de exposição populacional, seguidos da a população idosa. A primeira apresentou índices mais elevados ao longo dos setores de análise, ainda que sua variação tenha sido menor, apresentando índices que vão de 0,0,01 a 0,972. No caso da segunda, destaca-se índices extremos mais elevados, 0,01 a 0,98, apresentando, contudo, valores mais 
amenos, ao longo dos setores. Quanto a população sem renda verificou-se tratar da variável menos elevada com índices que variaram entre 0,04 e 0,75.

De maneira geral, os índices extremos concentraram-se no município de Apiaí, a exceção da população infantil, cujo setor com índice mais representativo, 0,972, localiza-se no município do Ribeira (Figura 32). Destaca-se ainda que o setor censitário em que a população infantil é mais baixa, 0,178 , corresponde ao mesmo da população idosa mais alta.
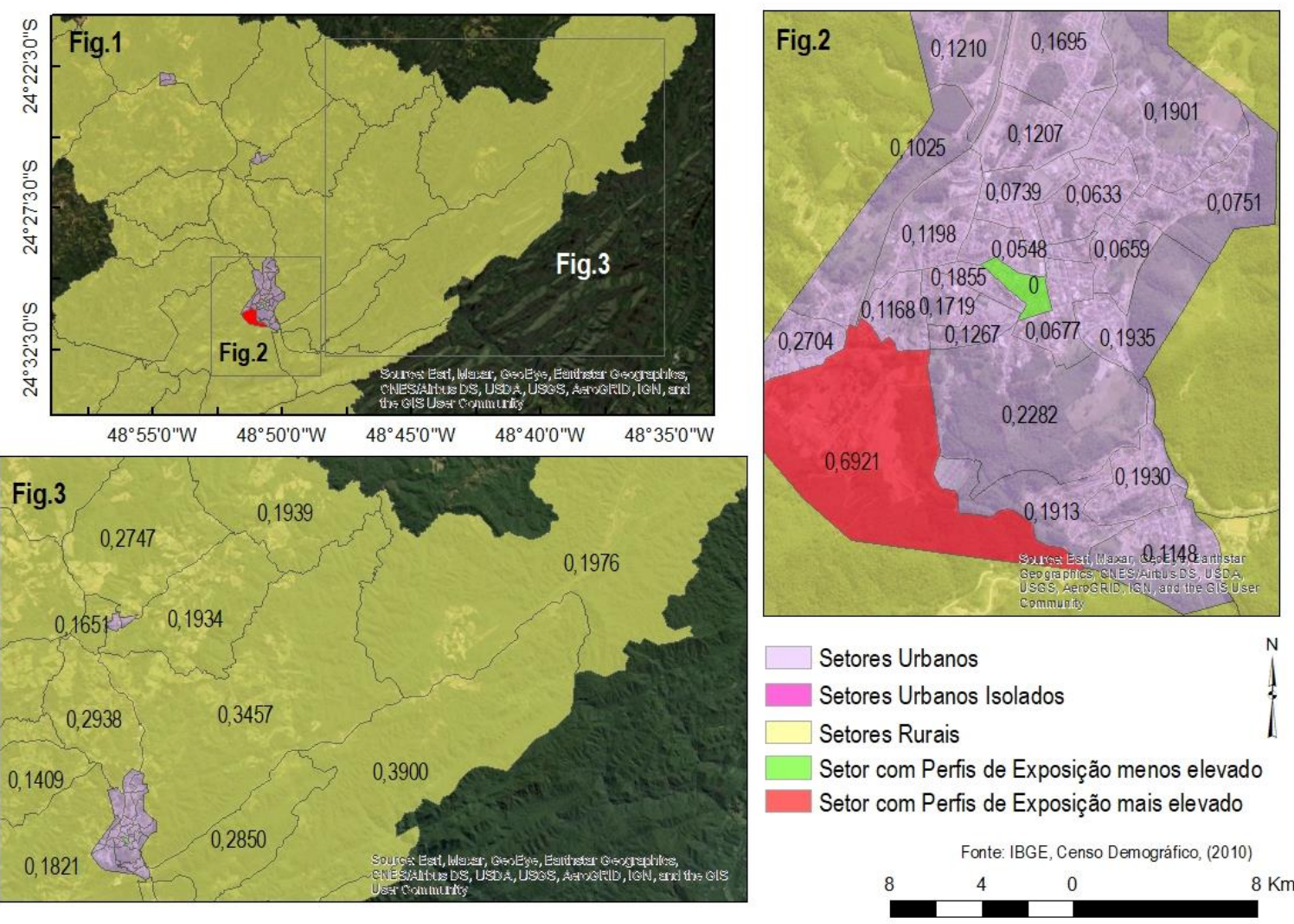

Figura 30: Distribuição espacial dos perfis de exposição permanente. Na Figura 2 observase que os índices urbanos são, relativamente, mais baixos, enquanto que na Figura 3, onde predominam os setores rurais, reúnem-se alguns dos índices mais elevados. 


\section{Distribuição dos perfis de exposição permanente}

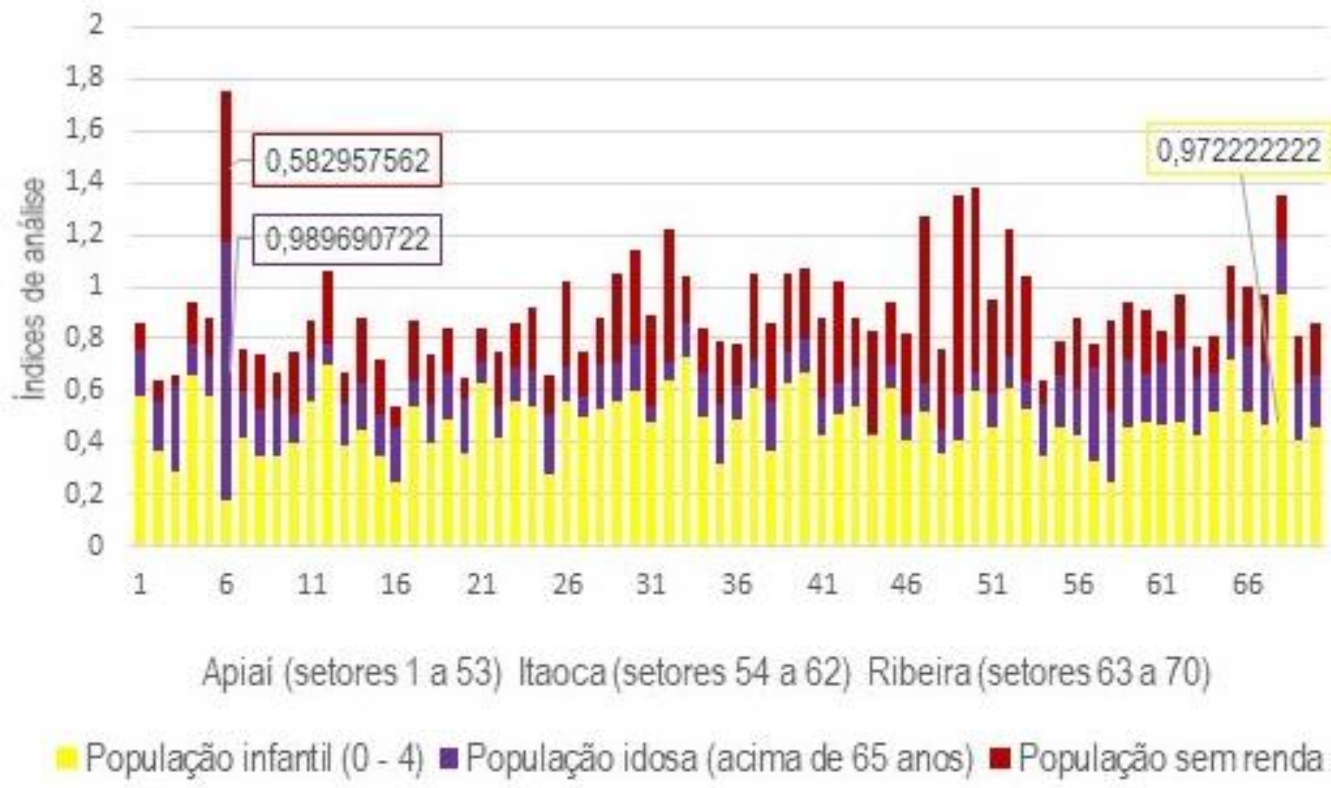

Figura 31: Distribuição dos perfis de exposição permanente da população. Destaque para os índices extremos alcançados em cada perfil de análise

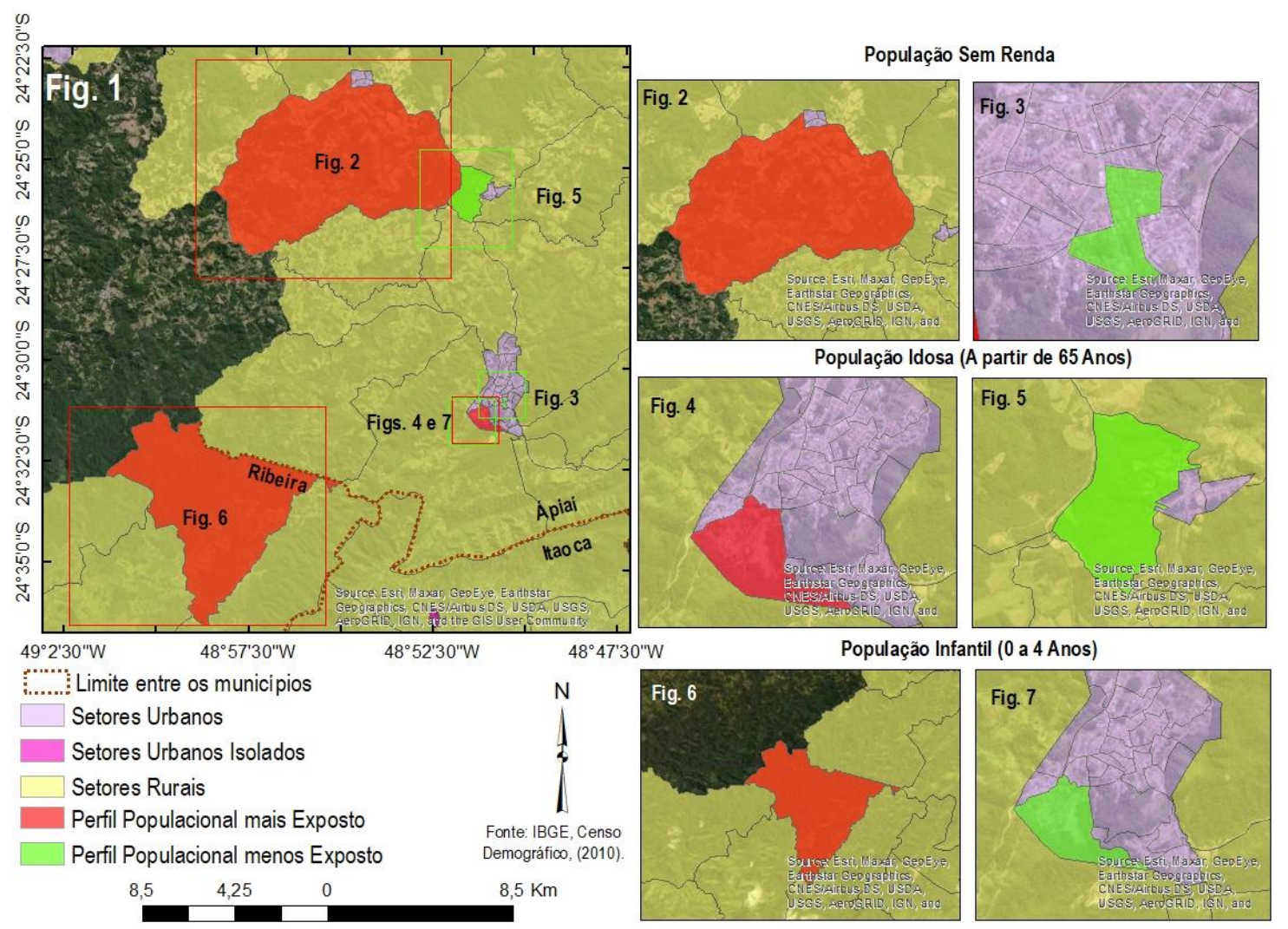

Figura 32:Localização dos perfis de exposição permanente da população na área de estudo. Destaque para os setores com índices extremos alcançados. 


\subsubsection{Déficit de Resiliência.}

No déficit de resiliência as três variáveis elaboradas foram aplicadas em 70 setores de análise, totalizando 210 índices distribuídos pelos 3 municípios estudados. De maneira geral, os valores ressaltaram como cada uma das três variáveis de análise construíram a presente dimensão (Figura 33).

Inicialmente, destaca-se a ação combinada entre os valores da $P E A$ e da situação da renda, por apresentarem índices contrastantes. Esse movimento, demonstrou que os índices da PEA, ainda que elevados, lidam com valores muito altos exibidos pela situação da renda, acabando por apontar um desarranjo na estrutura econômica da população (Figura 34).

\section{Déficit de resiliência: Variáveis de análise e valores} extremos

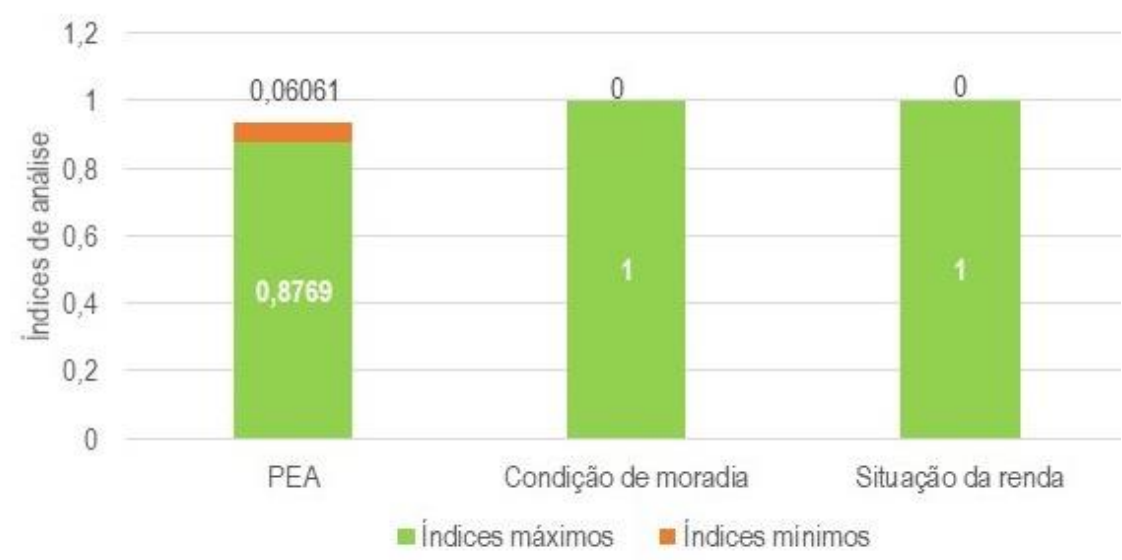

Figura 33:Observa-se os índices extremos alcançados pelas variáveis de análise que compõem o déficit de resiliência.

No caso da situação da renda, caracterizada como uma variável composta, exibiu ampla variação nos valores resultantes, ainda no âmbito dos dados relativizados (Figura 35). Nesse sentido, observa-se que o fator população atingida não apresentou qualquer elevação, já que o setor de análise com a situação da renda mais baixa não foi atingido por corrida de detritos ou inundações bruscas. Ainda neste setor, os atributos população com renda e população sem renda, os índices resultantes apresentaram elevação mínima de 0,4850. No setor com situação da renda mais elevada, destaca-se o papel da população atingida com índice de 0,6244, que somada aos atributos voltados a renda da população, configura o índice relativo de 1,6376. 
Posteriormente, ao serem padronizados em valores que correspondem aos índices delimitados entre 0 e 1, estes setores apresentaram índices iguais a 0 e 0,7163, respectivamente.

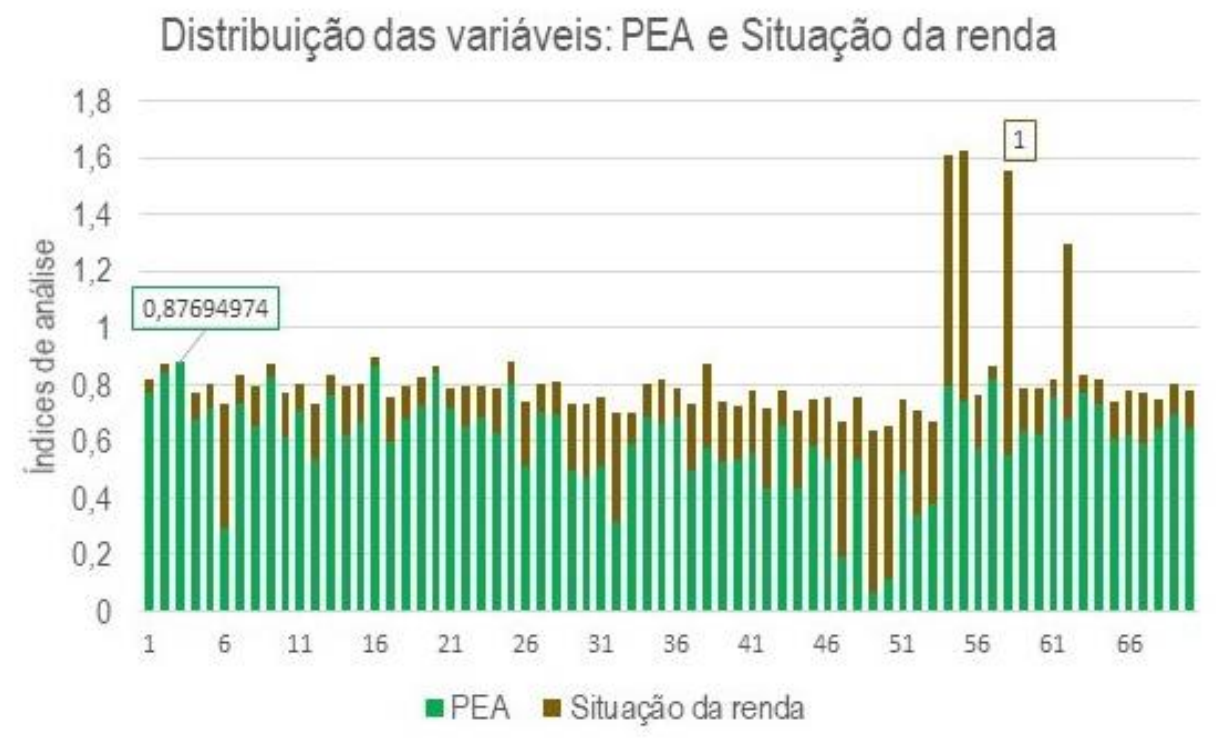

Apiai (setores 1 a 53) Itaoca (setores 54 a 62) Ribeira (setores 63 a 70)

Figura 34: Articulação entre os índices da PEA e da situação da renda em função do déficit de resiliência. Destaca-se que o setor com a PEA mais elevada, 0,8769, corresponde a situação da renda mais baixa, 0 .

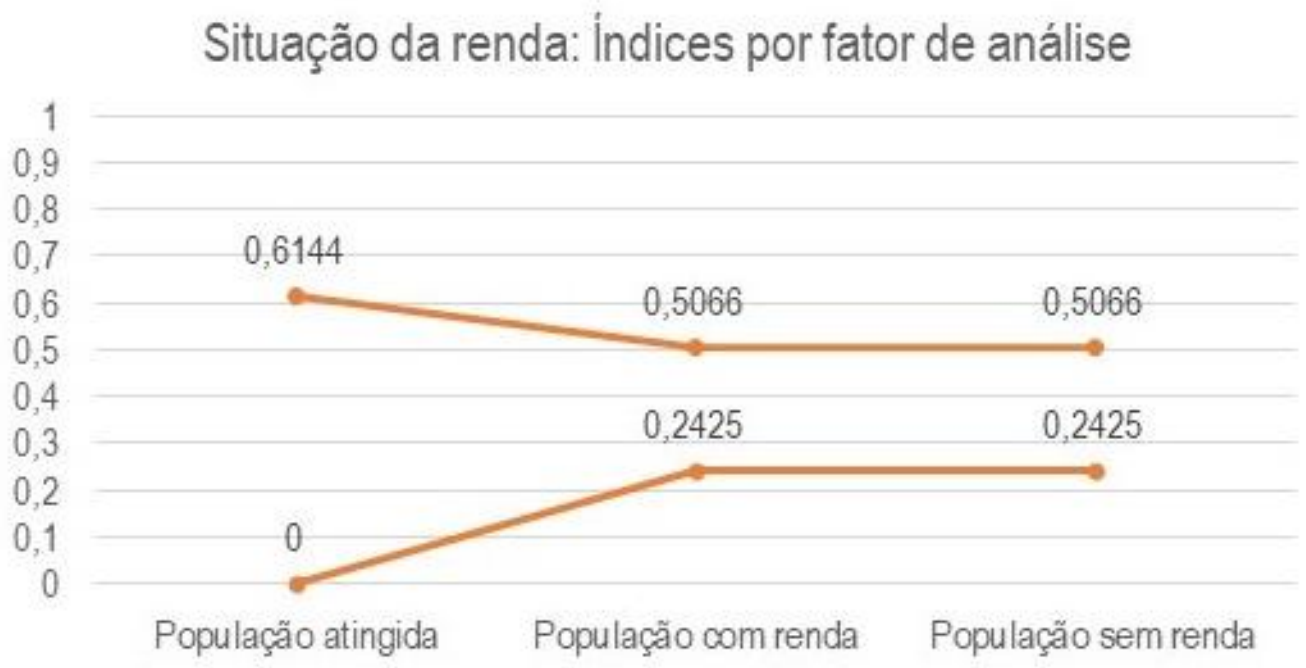

Figura 35: Destaca-se os atributos de análise que compõem a variável, situação da renda. No caso do índice mais baixo, 0,4850, observa-se a ausência de uma população atingida e os baixos valores dos perfis, população com renda e sem renda. Quanto ao setor com o indicador mais elevado, 1,6376, nota-se, a presença da população atingida, elevando o índice da situação da renda populacional. 
De maneira geral, houve uma tendência dos setores urbanos em apresentarem uma PEA mais elevada, assim como os índices mais altos da situação da renda nos setores rurais (Figura 36 ). Contudo, a quase totalidade dos setores aplicados apresentou índices elevados da situação da renda, envolvendo, por vezes, tanto os setores urbanos quanto os urbanos isolados. Nesse contexto, os setores em que se localizam os índices extremos, correspondem a 3, pois que exibem a PEA mais elevada, 0,8769 , e a situação da renda mais baixa, 0 , no mesmo setor. No caso da situação da renda mais elevada, 1, destaca-se tratar do Lageado, setor amplamente atingido pelas inundações bruscas.

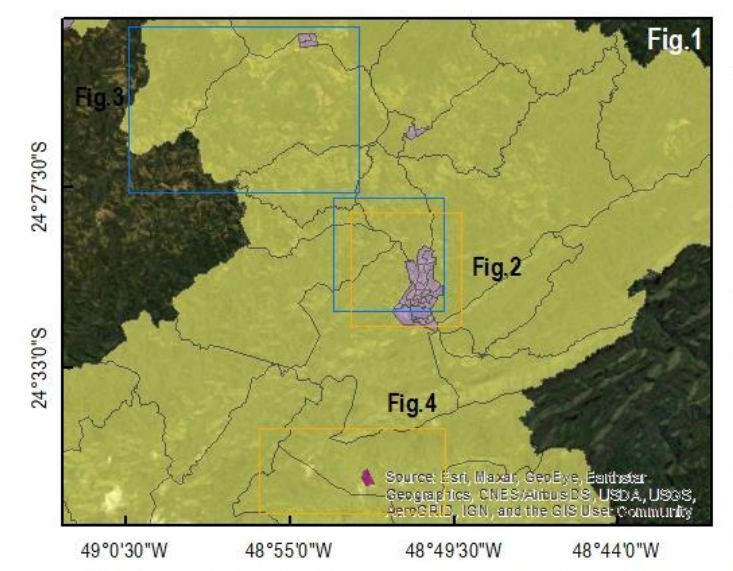

PEA: Distribuição dos indices nos setores rurais
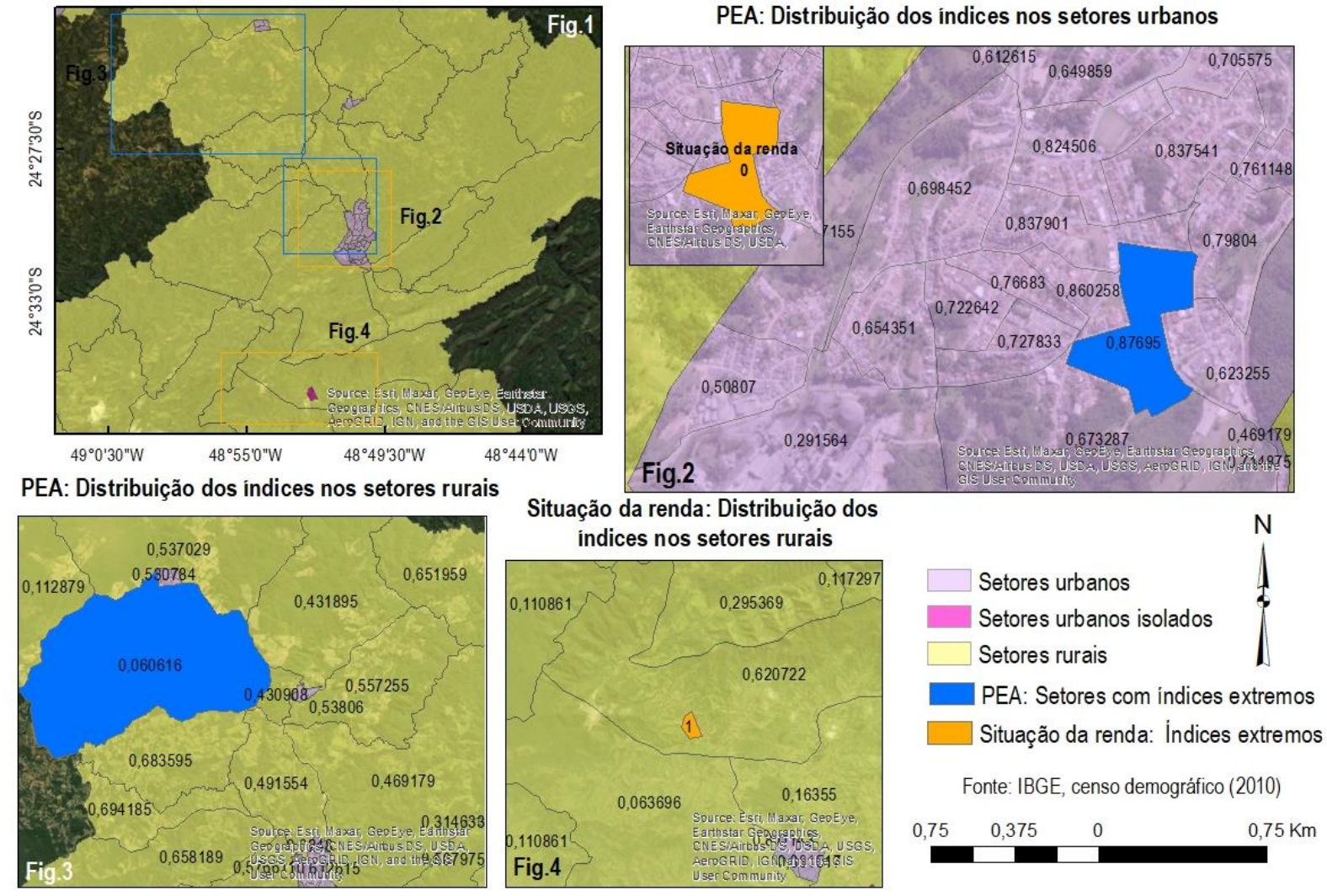

Figura 36: Distribuição dos índices da PEA e da situação da renda. Nota-se tendência de aumento dos índices da PEA nos setores urbanos e os da situação da renda nos setores rurais e urbano isolados, destacando os índices extremos dessas variáveis de análise.

Para a variável condição de moradia, observou-se que sua ação foi, igualmente marcante à da situação da renda, apresentando uma diferença absoluta entre os índices extremos alcançados (Figura 33). No caso do setor com a condição de moradia mais elevada, observa-se a baixa variação entre seus atributos de análise; 
neles destaca-se o índice de 0,3970 para os domicílios atingidos por duas corridas de detritos e 0,8382 para a soma dos domicílios com e sem serviços disponíveis (Figura 37). Quando padronizados, o índice final apresentou condição de moradia igual a 1.

No caso dos setores com índices finais da condição de moradia igual a "0", a exemplo da situação descrita na Figura 33, ressalta-se que 12 setores apresentaram esta realidade (Figura 38 ). Pontualmente, cada um deles exibe a totalidade de seus domicílios com acesso ao abastecimento de água e a existência de banheiros ou sanitários de uso exclusivo por seus moradores, além de não terem sido atingidos por corridas de detritos ou inundações bruscas em janeiro de 2014.

\section{Condição de moradia: Índices por fator de análise}

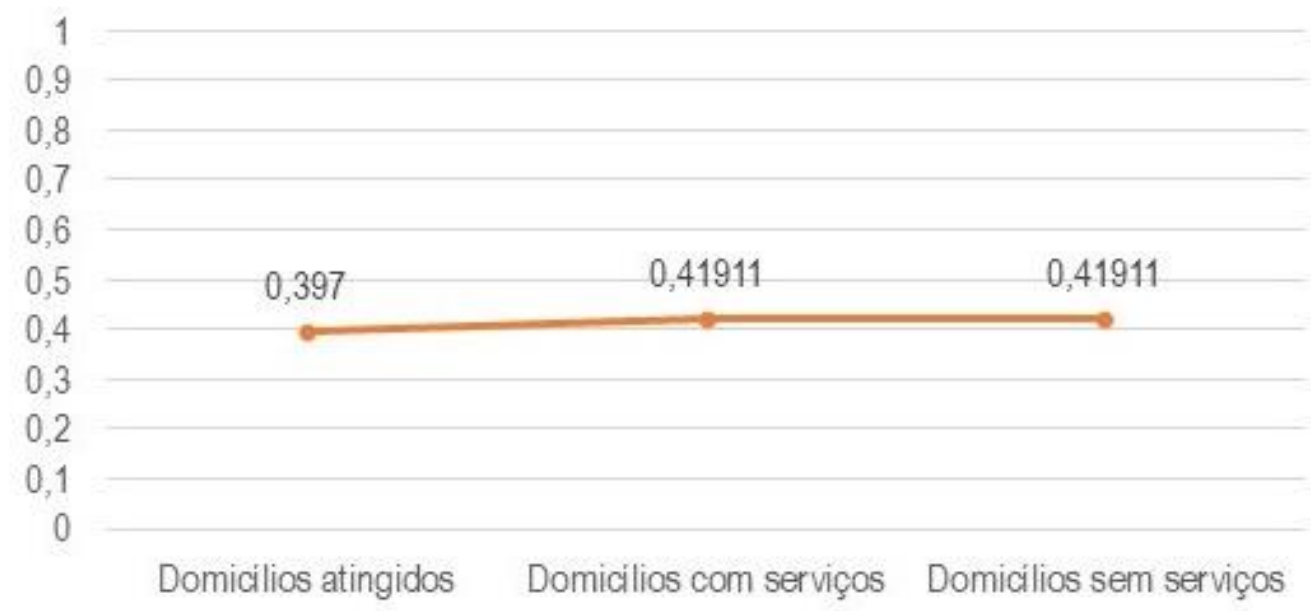

Figura 37:Destaca-se o setor com a condição de moradia mais alta, apresentando distribuição semelhante entre os fatores de análise. 

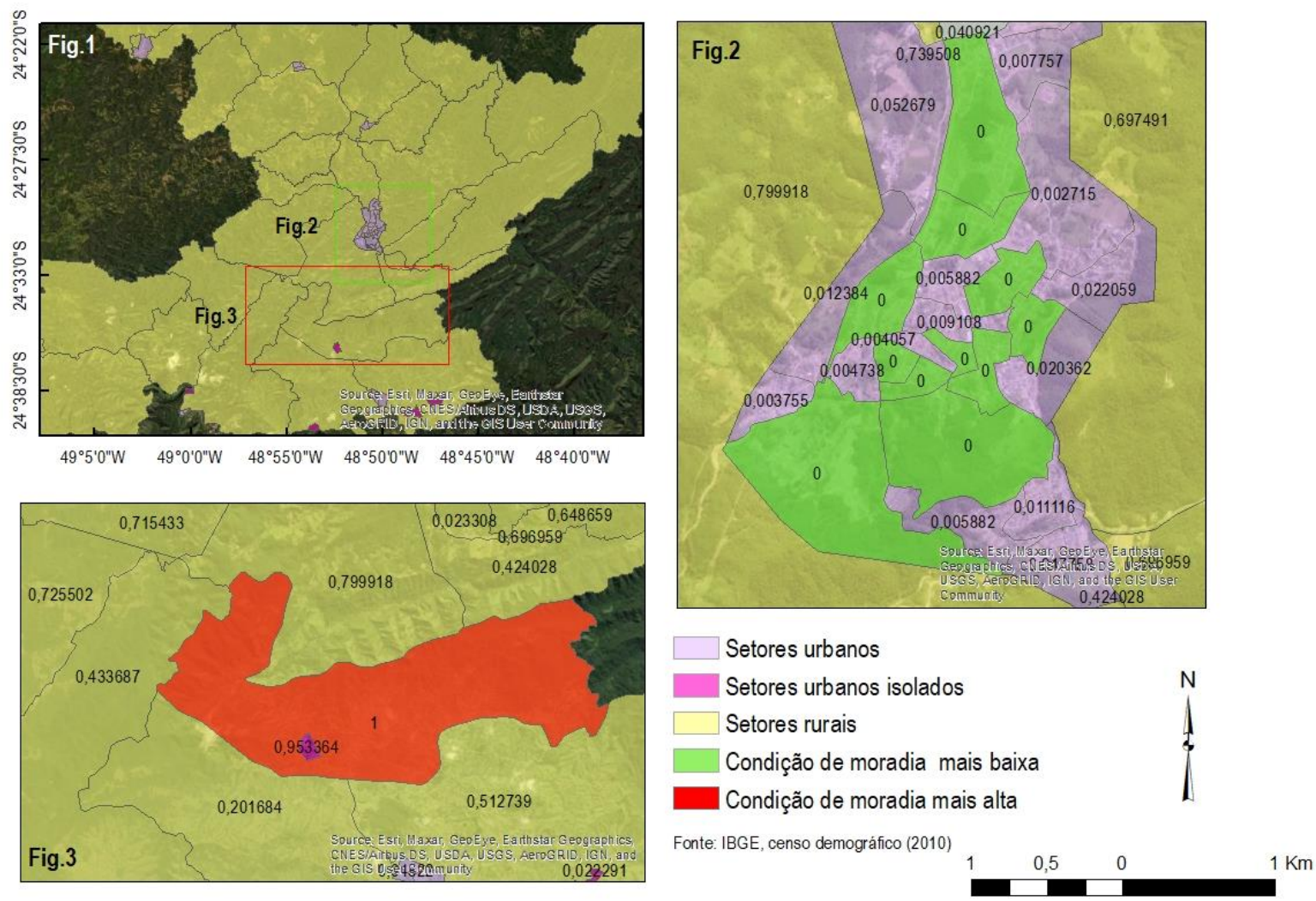

Figura 38: Distribuição dos índices da condição de moradia nos setores aplicados. Destaque para os setores com índices extremos, sendo, 0, concentrado em Apiaí com 11 dos 12 setores nesta condição e, 1, no setor rural, do Guarda-Mão e Gurutuba no município de Itaoca. 


\subsection{Elaboração dos indicadores de vulnerabilidade por dimensão de análise}

\subsubsection{Sensibilidade}

De maneira geral, os indicadores finais da sensibilidade da população, apresentaram uma amplitude de 0,5421, sendo o valor mais baixo, 0,2193 e o mais alto, 0,7614 (Figura 39). Pontualmente, observa-se que o setor com elevação mais alta compreende um grupo de setores com índices mais acentuados, dentre os setores 1 e 28 do município de Apiaí. Trata-se de setores urbanos, obedecendo a uma tendência sutil de que as sensibilidades mais altas encontram-se em setores urbanos. (Figura 40).

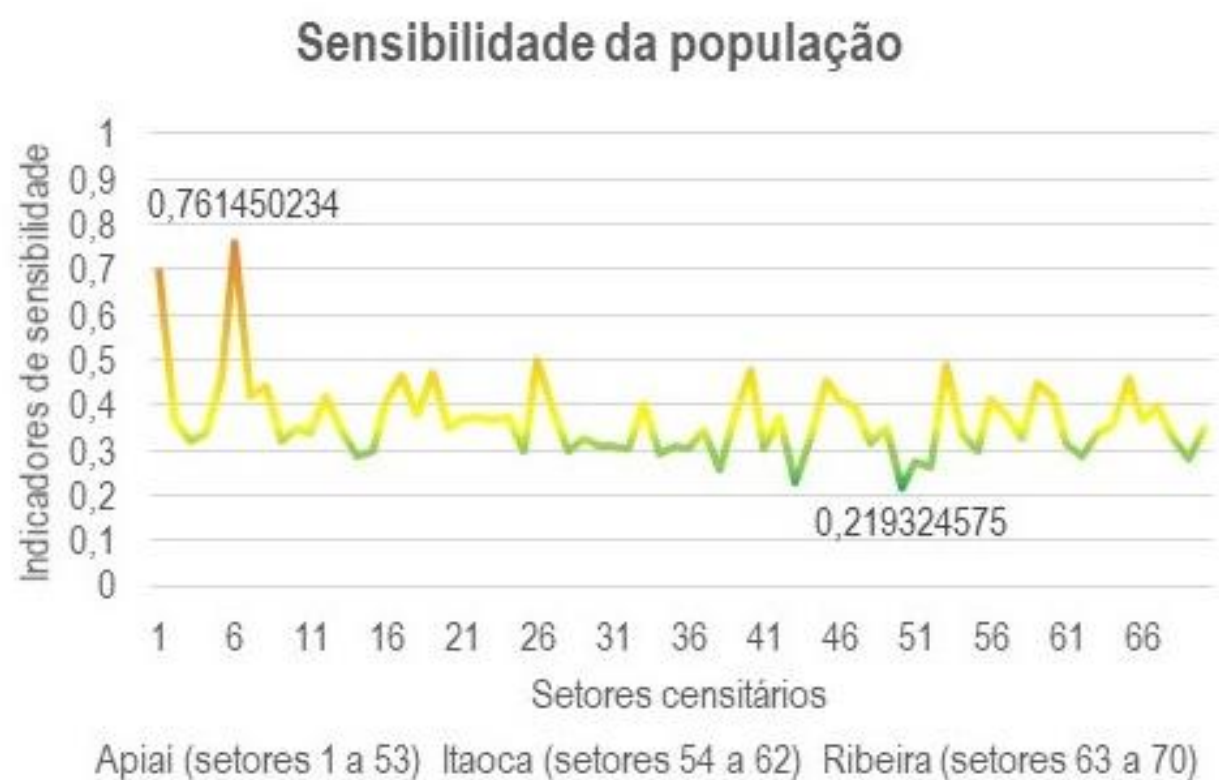

Figura 39:Observa-se a variação dos índices da dimensão de sensibilidade, destacando os casos extremos.

No caso do setor de análise com o indicador de sensibilidade mais alto, destacase o valor da população analfabeta, 0,9911, seguido da população idosa, 0,9896 e infanto-juvenil, 0,6527, corroborando para a elevação do indicador final, enquanto que os índices mais baixos foram representados pela densidade demográfica, 0,006227, e população feminina, 0,4574 (Figura 41). Quanto ao setor de análise com o indicador de sensibilidade mais baixo, 0,2193, resultou da conformação dos índices: densidade demográfica 0,0005, população analfabeta, 0,0884 e a população idosa 0,0735. 

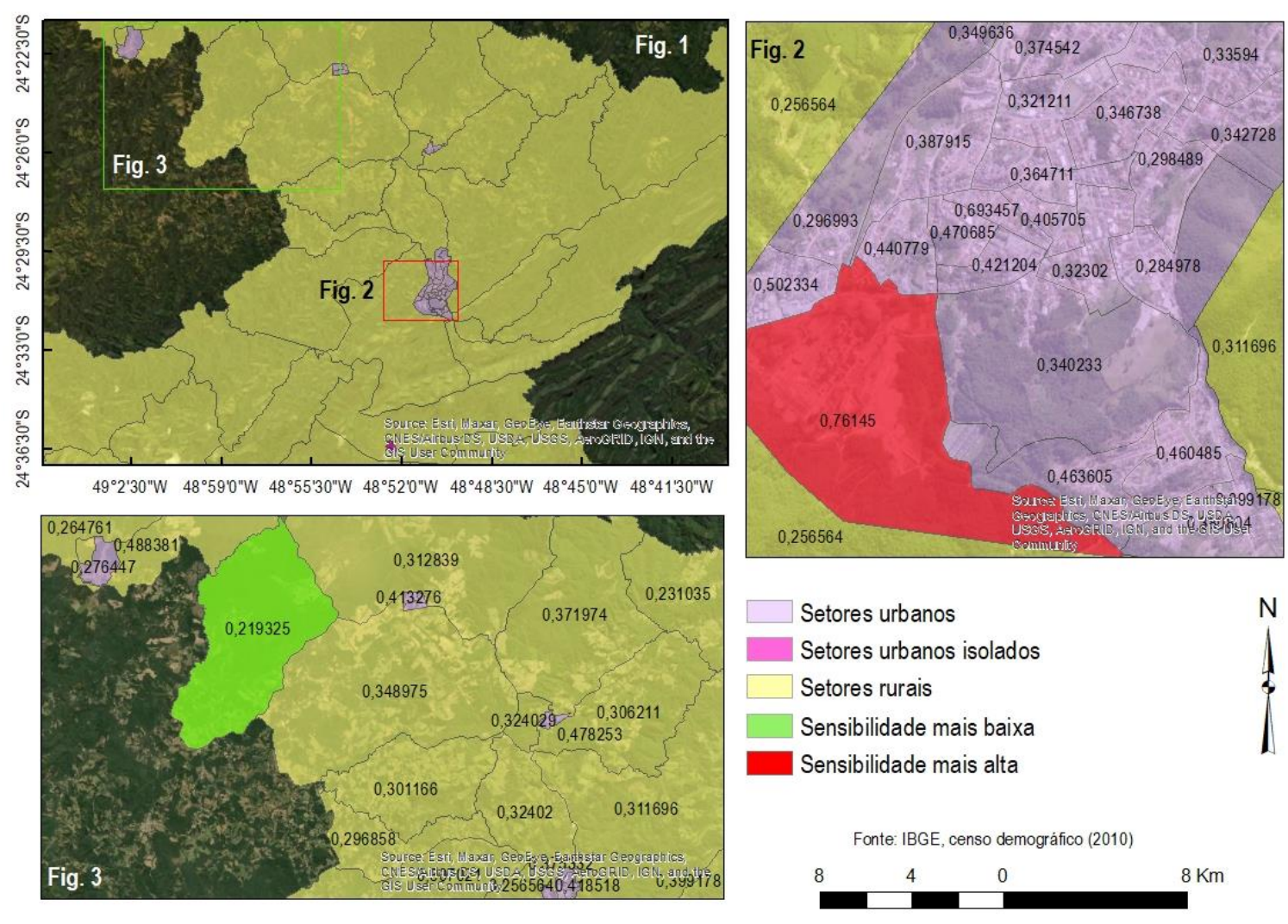

Figura 40: Registros dos indicadores finais de sensibilidade, com destaque para os valores extremos alcançados nas Figuras. 2 e 3.

Nesse processo, observou-se ampla variação entre os índices alcançados, sobretudo nas variáveis que representam o contingente com baixa instrução, no caso, a população analfabeta, além da população idosa. Observa-se o movimento contrário nos índices da densidade demográfica e população feminina, destacando valores aproximados ao longo dos 70 setores aplicados. No caso do setor com a sensibilidade mais alta, notou-se tratar do mesmo em que o índice das populações analfabeta e idosa é mais elevado (Figuras 25 e 26). Para a sensibilidade mais baixa não houve correspondência entre os setores, ainda que no caso da população idosa, trate-se, igualmente, de um espaço rural. 
Indicadores de sensibilidade: Papel das variáveis de análise

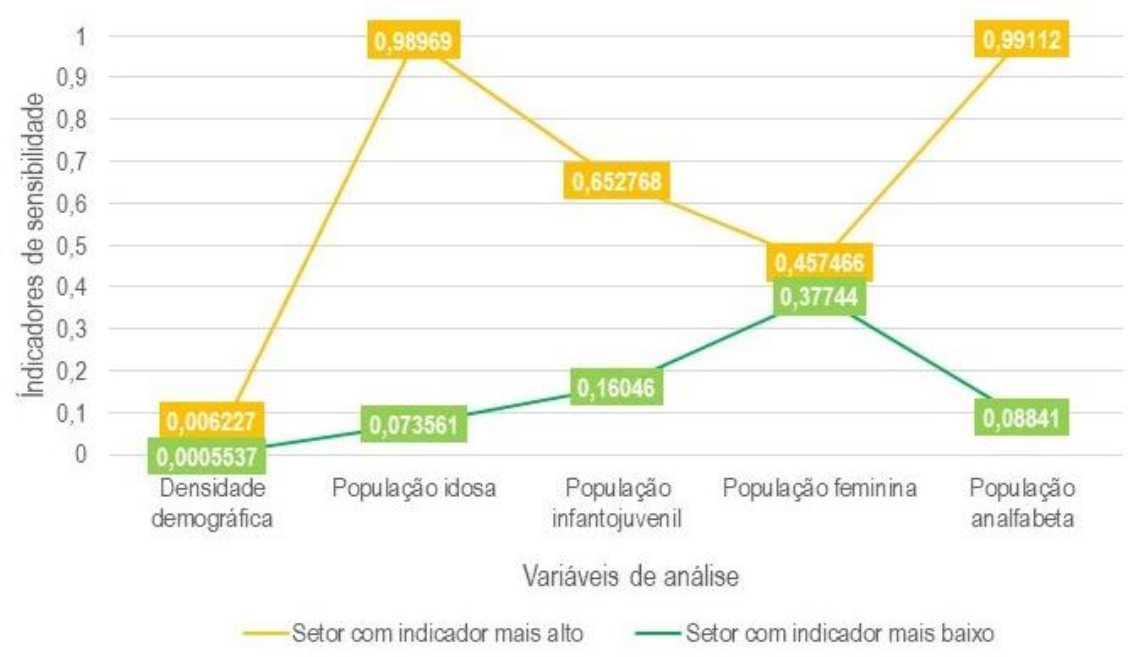

Figura 41: Distribuição das cinco variáveis de análise que compõem a sensibilidade da população nos setores com índices extremos.

Para melhor visualizar os indicadores de sensibilidade obtidos e identificar os setores com as populações mais sensíveis, buscou-se representá-los espacialmente por meio de em um mapa final de sensibilidade da população (Figura 42). Nota-se, inicialmente que a melhor condição da sensibilidade apresentada é baixa, abarcando 53 setores. Esta classe de análise envolve os setores que apresentaram índices de 0,2193 a 0,4057 , não havendo, portanto, registros de sensibilidade muito baixa ou muito alta, na área de estudo. 


\section{Sensibilidade Final da População}

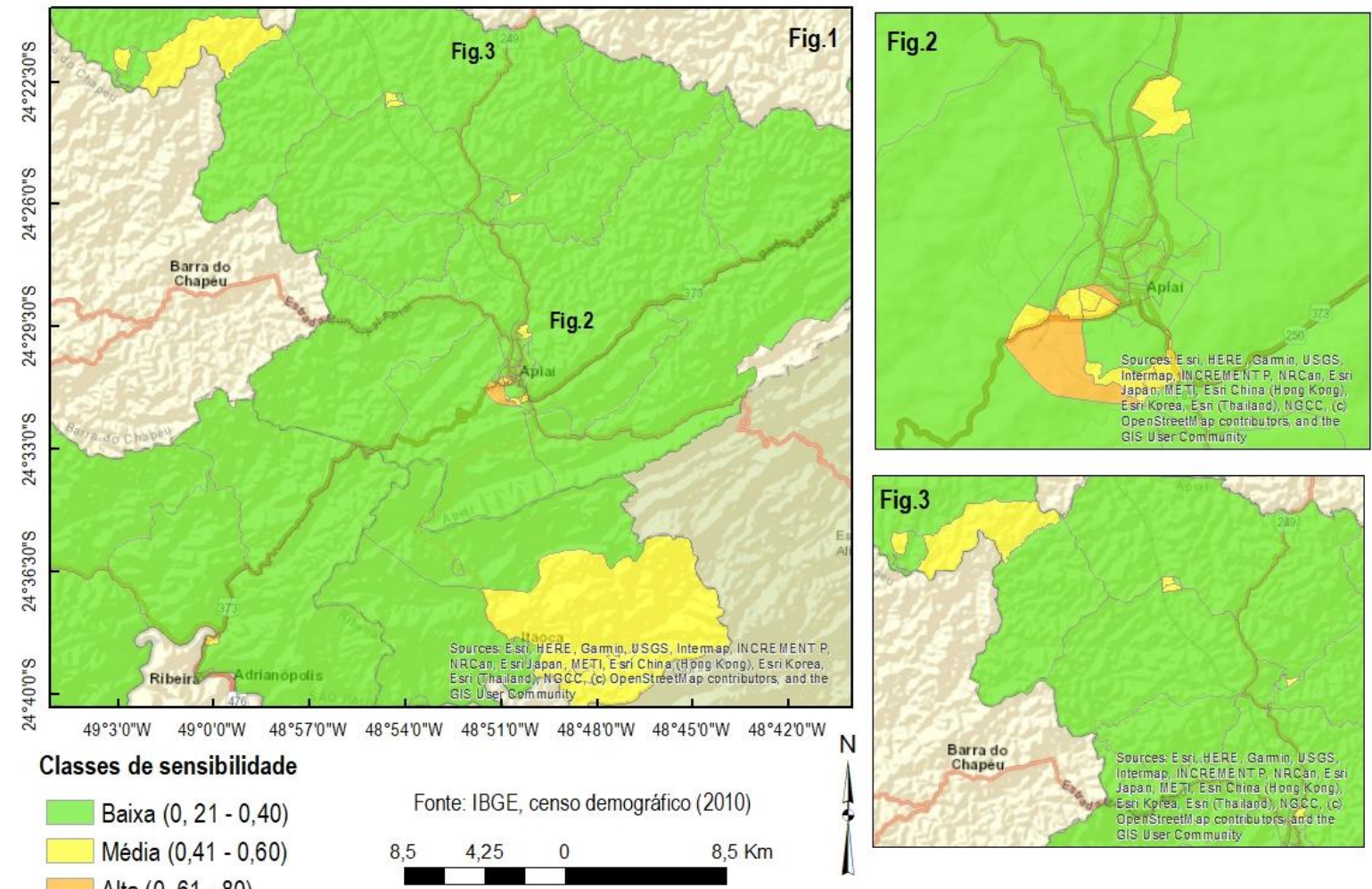

Figura 42: Mapa da Sensibilidade final da população. Destaca-se o predomínio de sensibilidade baixa, sobretudo nos setores rurais.

A sensibilidade média apresentou-se decentralizada pela área de estudo, abarcando setores rurais, urbanos e urbanos isolados. No total, foram 15 setores classificados com esta sensibilidade, apresentando índices que variaram entre, 0,4103 e 0,5023 . Quanto a classificação alta, tratou-se de uma condição acentuada em dois setores localizados no centro urbano de Apiaí; são eles, 0,6934 e 0,7614. 


\subsubsection{Exposição}

A dimensão de exposição apresentou variação de 0,7977 com indicadores que apresentaram valor de 0,0842 (mais baixo) a 0,8817 (mais alto) (Figura 43). Esta realidade é observada ao longo de toda área de estudo, fomentando cinco classes espaciais de análise.

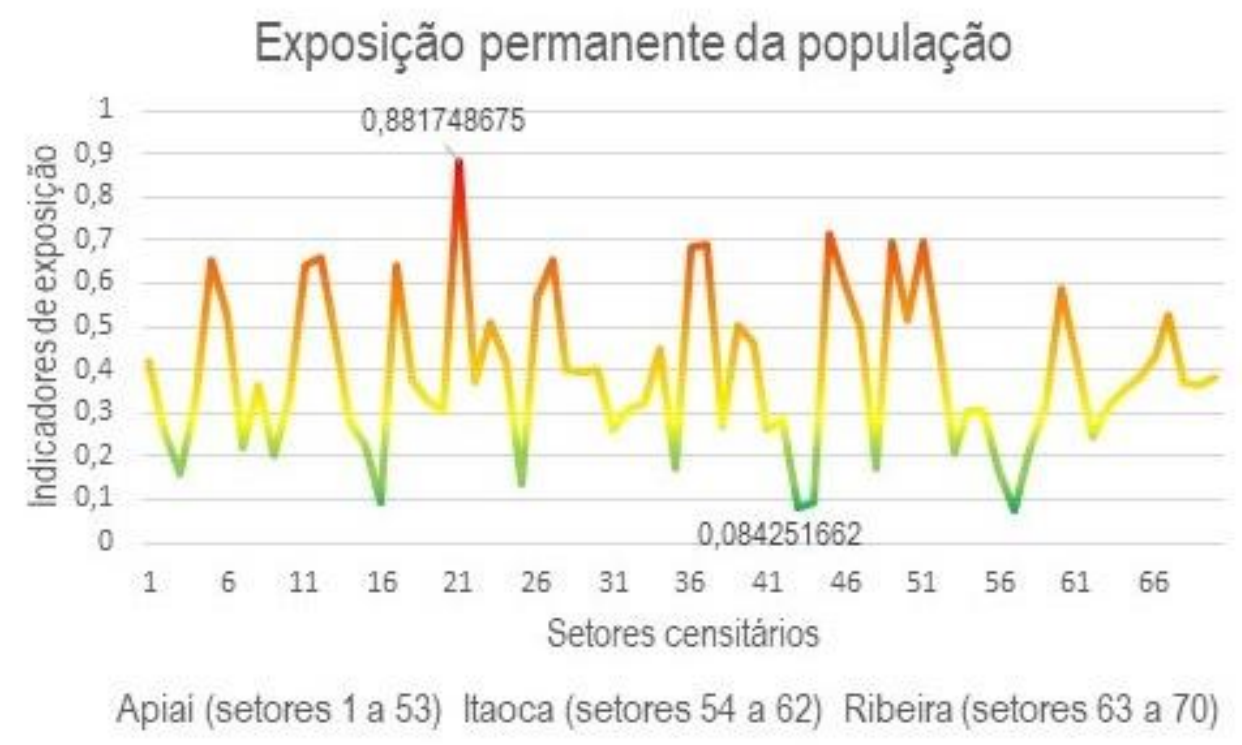

Figura 43: Indicadores da exposição permanente da população nos setores estudados. Destaque para os índices extremos.

Nesse processo o setor com indicador mais baixo, 0,08425, envolveu uma população total de 0,0425 e um perfil populacional de exposição permanente com 0,1939 . Para o indicador mais elevado, 0,8817 , exibiu-se o índice de 0,998 no caso da população total e 0,1695 , para o perfil populacional de exposição permanente (Figura 44).

Analisados conjuntamente, observa-se que a população absoluta corresponde ao fator de maior variação, 0,0425 a 0,9983, indicando, no setor com indicador mais elevado, que o setor mais populoso, não corresponde ao perfil populacional de exposição permanente. Quanto a este último, destaca-se que sua representatividade aumenta em setores menos populosos. 
Indicadores de exposição: Papel sos indices de análise

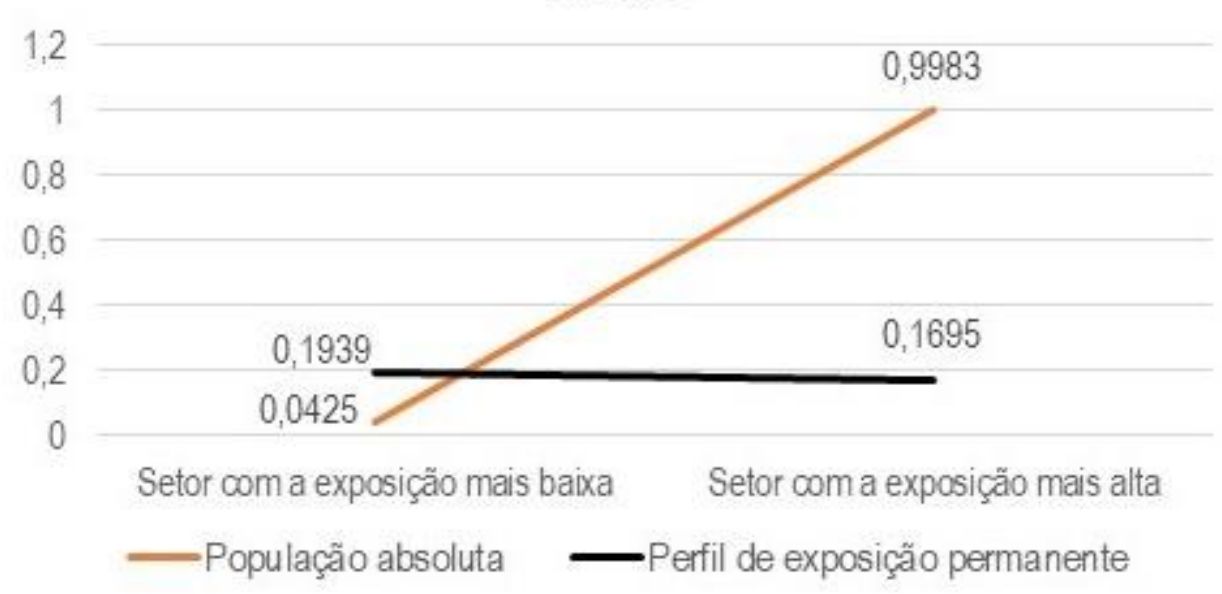

Figura 44: Nota-se que o aumento da população com perfil de exposição permanente ocorre em setores menos populosos, assim como diminui em setores mais populosos.

Por fim, o conjunto dos indicadores construídos foi representado no mapa final de exposição populacional (Figura 45). Destes 70 indicadores de exposição, 10 apresentaram exposição muito baixa, 0,0743 a 0,2028; 38 baixa, 0,2106 a 0,4020; 17 média, 0,4161 a 0,6016; 10 alta, 0,6434 a 0,7122 e 1 muito alta, 0,8817.

Dessa maneira, os setores com baixa exposição populacional foram predominantes, seguidos da classificação média. Ambas se apresentam distribuídas por toda área de estudo, envolvendo os espaços dos três municípios aplicados, tanto nos setores urbanos quanto rurais. 


\section{Exposição Final da População}
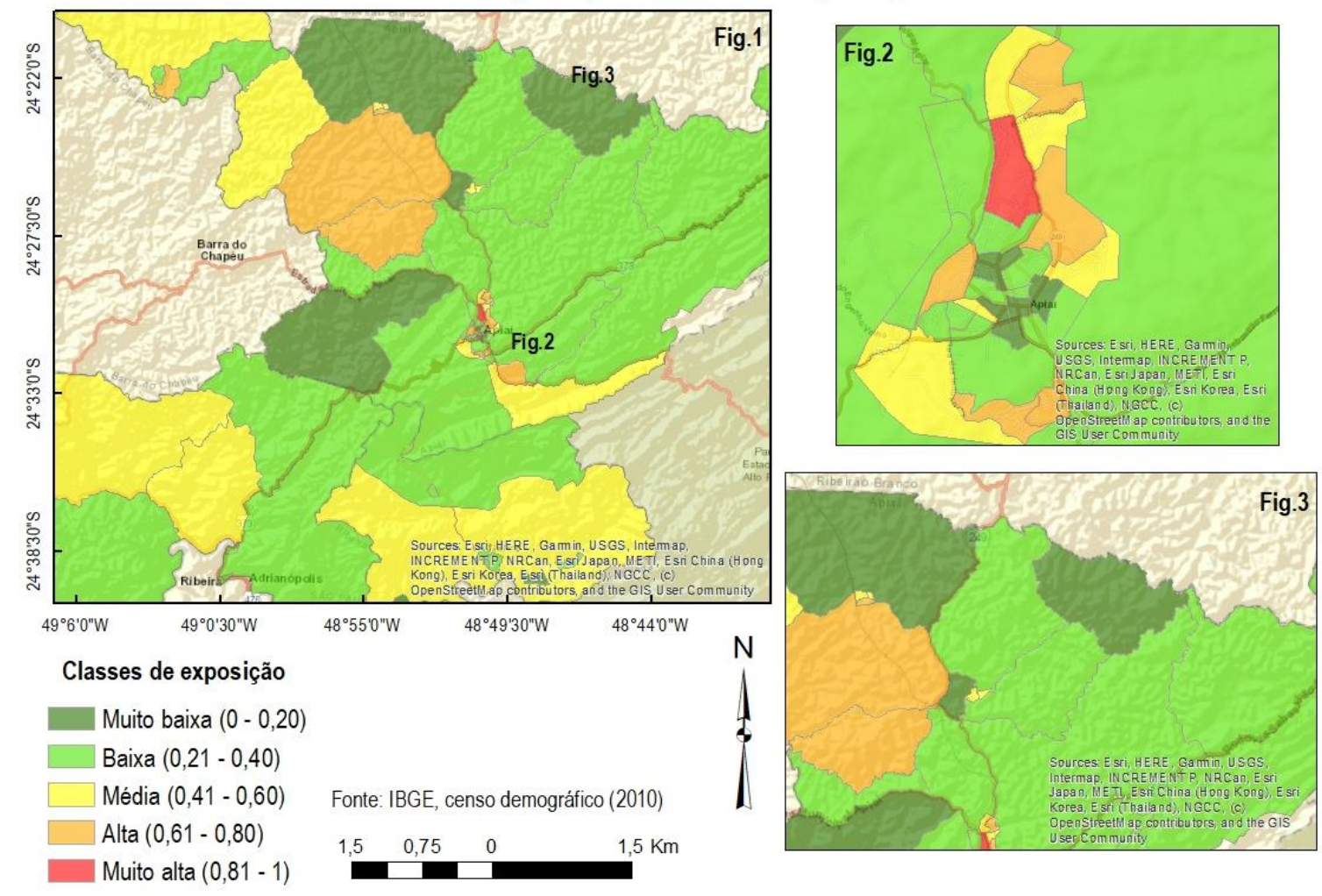

Figura 45: Distribuição espacial da população com exposição permanente

\subsubsection{Déficit de resiliência}

De maneira geral, os indicadores da dimensão do déficit de resiliência apresentaram uma variação de 0,70 com o indicador mais baixo de 0,0477 e o mais elevado igual a 0,7574 (Figura 46). Neste processo, os setores exibiram delimitações, por vezes, bem definidas, senão abruptas.

Diante da variação apresentada, a dimensão do déficit de resiliência exibiu 4 classificações de análise, indicando os setores com maior déficit nos espaços rurais dos municípios de Itaoca e Ribeira. No caso do setor com indicador de menor elevação, 0,0477, destaca-se que abrangeu os setores de estrutura urbana, notadamente observados desde o setor 1 até o 28, compondo o município de Apiaí. Para o setor com o indicador mais elevado, 0,7574, verificou-se tratar do Lageado, no município de Itaoca, atingido por inundações bruscas em janeiro de 2014 (Figura 47). 


\section{Déficit de resiliência da população}

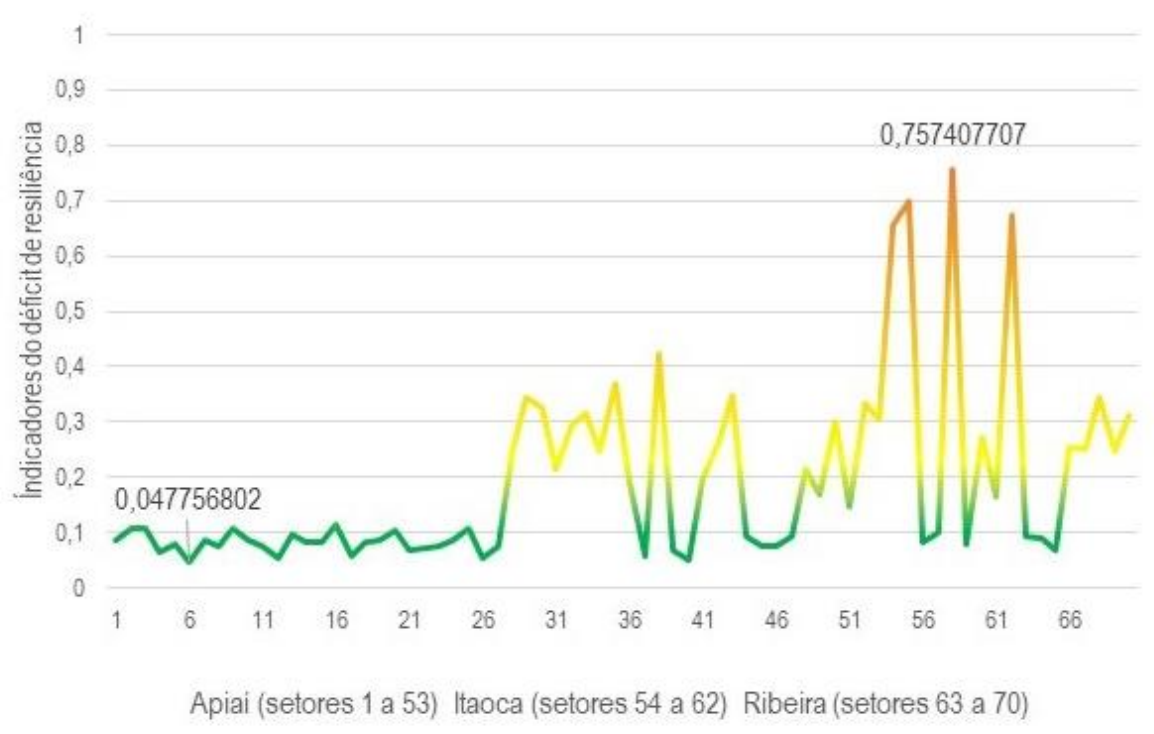

Figura 46: Variação dos indicadores do déficit de resiliência. Destaca-se os setores com os indicadores extremados, além das variações mais acintosas ao longo dos 70 setores aplicados.

Dessa maneira, observou-se como os índices dos três fatores de análise corroboraram com indicador final da resiliência. Para tanto, selecionou-se os setores com déficit de resiliência mais expressivos (Figura 48). No caso do indicador, 0,0477, o índice, 0 , exibido pela condição de moradia, acabou por diminuir o déficit de resiliência final, ainda que a combinação da baixa $P E A, 0,2915$, com a da média situação da renda, 0,4362, o tenha mantido elevado. Quanto ao setor com o déficit de resiliência mais alto, 0,7574, a situação da renda, 1, configurou-se como a principal variável, seguida da condição de moradia, 0,9533. Aqui, a PEA de 0,5531 colaborou com sua diminuição. 

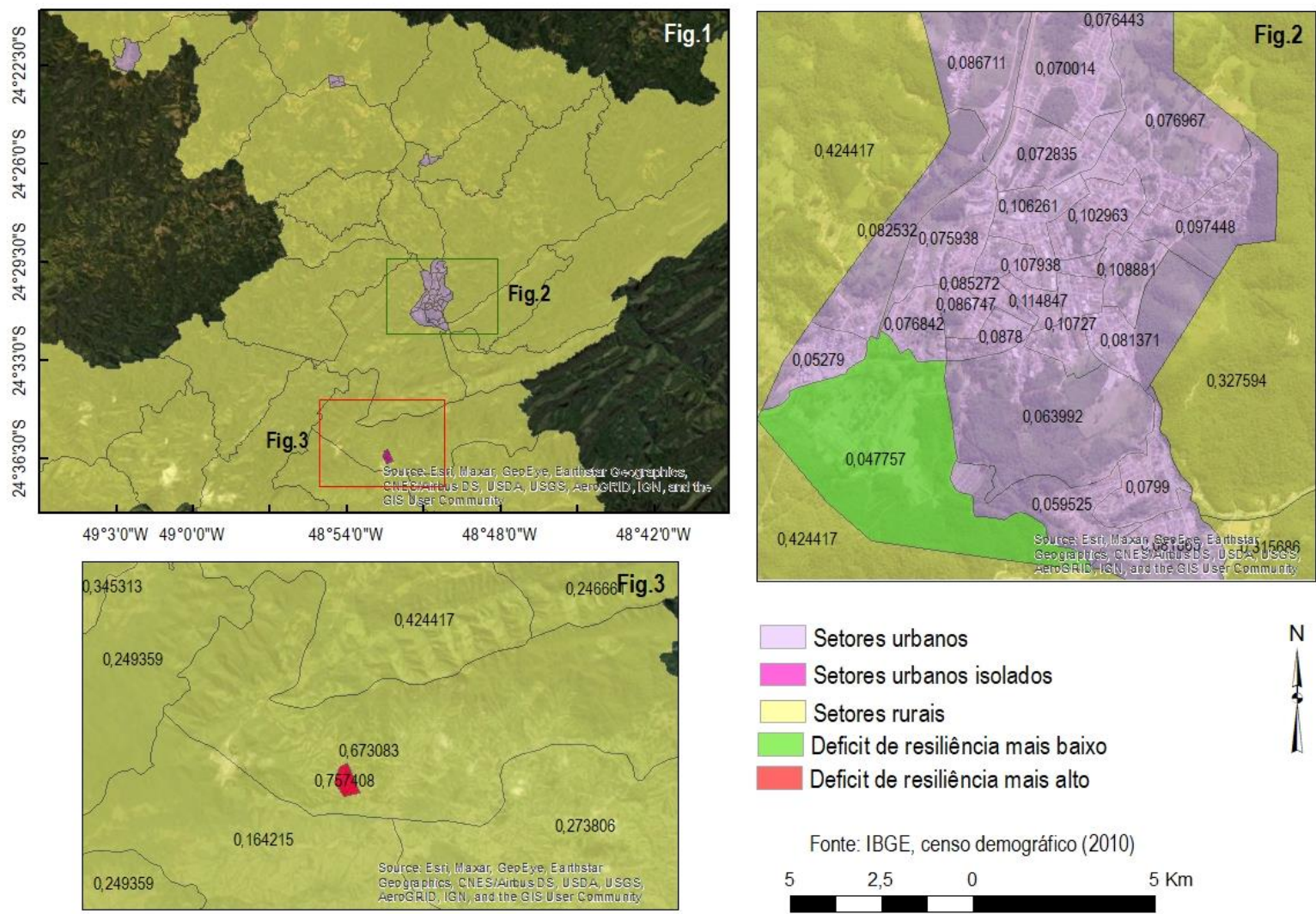

\section{Setores urbanos}

Setores urbanos isolados

Setores rurais

Deficit de resiliência mais baixo

Deficit de resiliência mais alto

Fonte: IBGE, censo demográfico (2010)

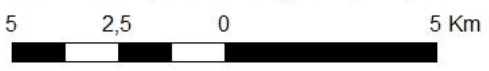

Figura 47: Indicadores do déficit de resiliência, destacando os setores com indicadores extremos.

\section{Déficit de resiliência: Papel das variáveis de análise}

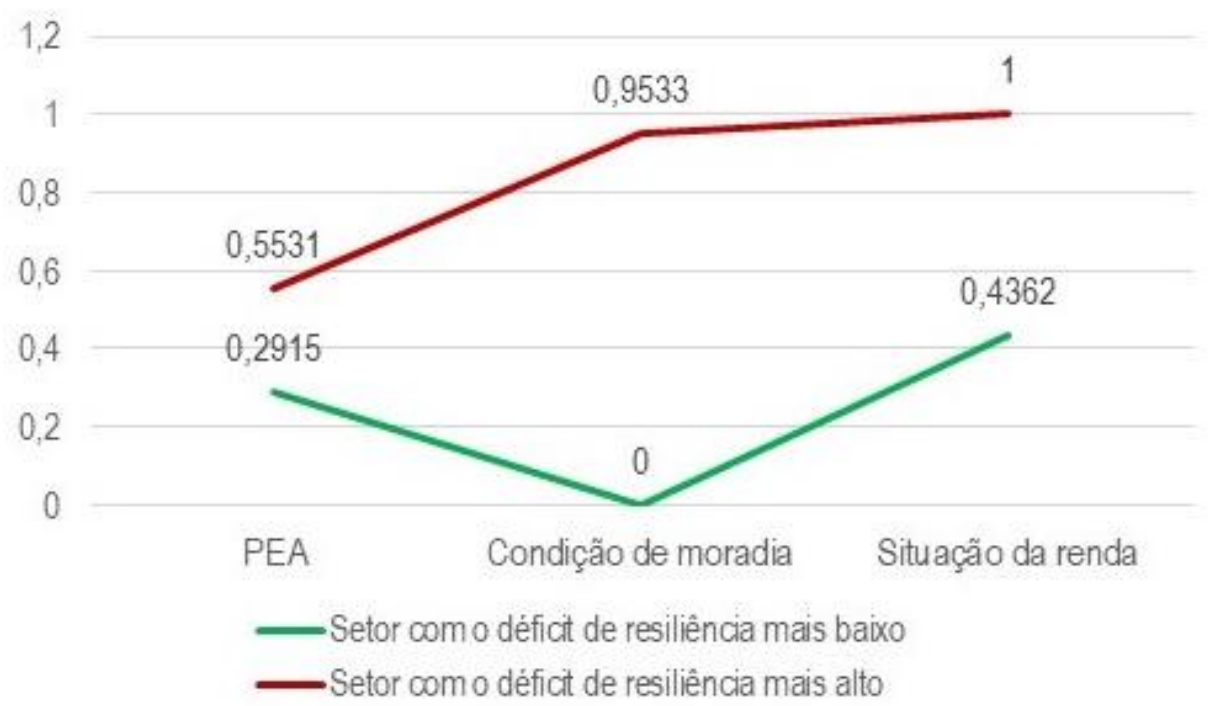

Figura 48: Observação das variáveis de análise nos setores com indicadores finais extremos. No setor com o indicador do déficit de resiliência mais baixo 0,0477, o índice da condição de moradia, foi determinante. No caso do setor com o indicador mais elevado 0,7574 , tratou-se da situação da renda seguida da condição de moradia. 
Por fim, a distribuição espacial dos 70 indicadores de análise aplicados alcançou 4 classes de déficit de resiliência, representando a ampla variação demonstrada nesta dimensão (Figura 49). Propriamente sobre cada classe, observa-se, inicialmente, a predominância de indicadores com déficits de resiliência muito baixos, 0,0477 a 0,1978 . Os 45 setores com esta classificação concentram-se, sobretudo em espaços urbanos não atingidos por corridas de detritos ou inundações bruscas. A segunda classe com maior número de setores, 20, é a baixa com índices que variaram de 0,2142 a 0,3688 . Apenas um setor apresentou classificação média com índice de 0,4244 e 4 setores foram classificados com o déficit de resiliência alto, 0,6571 0,7574 . Dessa maneira, destaca-se que estes últimos 4 setores, além do classificado como de déficit médio, foram atingidos por corridas de detritos ou inundações bruscas. Neste caso, observa-se sua concentração nos limites entre os municípios de Apiaí e Itaoca.

Déficit de Resiliência Final da População
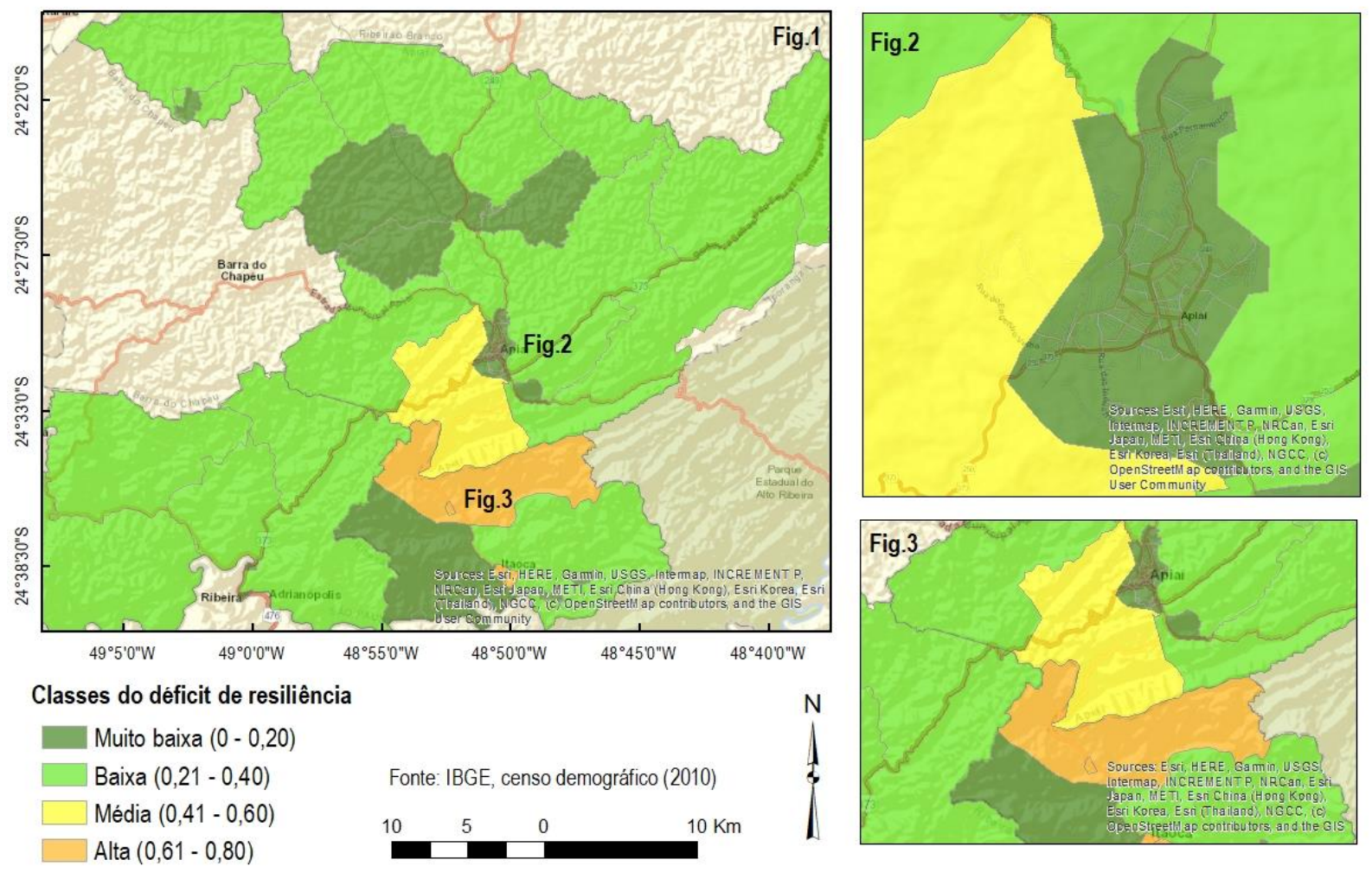

Figura 49: Classificação dos indicadores finais na dimensão do déficit de resiliência. 


\subsection{Vulnerabilidade Final}

A vulnerabilidade final apresentou uma variação de, 0,6186, já que os índices extremos alcançados foram 0,2117 e 0,8303 (Figura 50). Dessa maneira, observa-se a formação de 4 classes de análise, destacando a ausência de indicadores muito baixos.

De maneira geral, trata-se de 17 setores com vulnerabilidade baixa, 0,2117 0,4028; 27 média, 0,4131 a 0,6096; 24 alta, 0,6106 a 0,8090 e 2 setores com vulnerabilidade muito alta, 0,8179 a 0,8303. (Figura 51). Neste contexto, observou-se que estas últimas se localizam na região central do município de Apiaí.

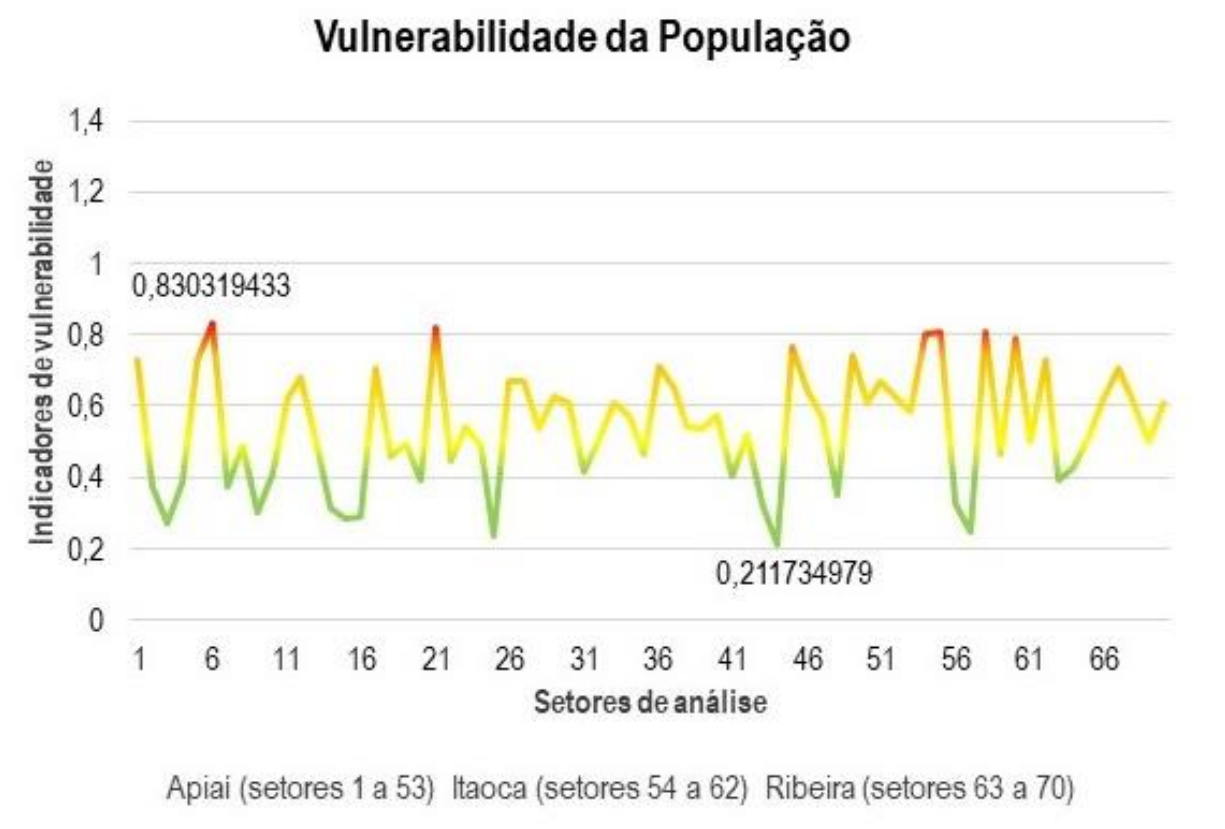

Figura 50: Variação dos indicadores da vulnerabilidade final. 


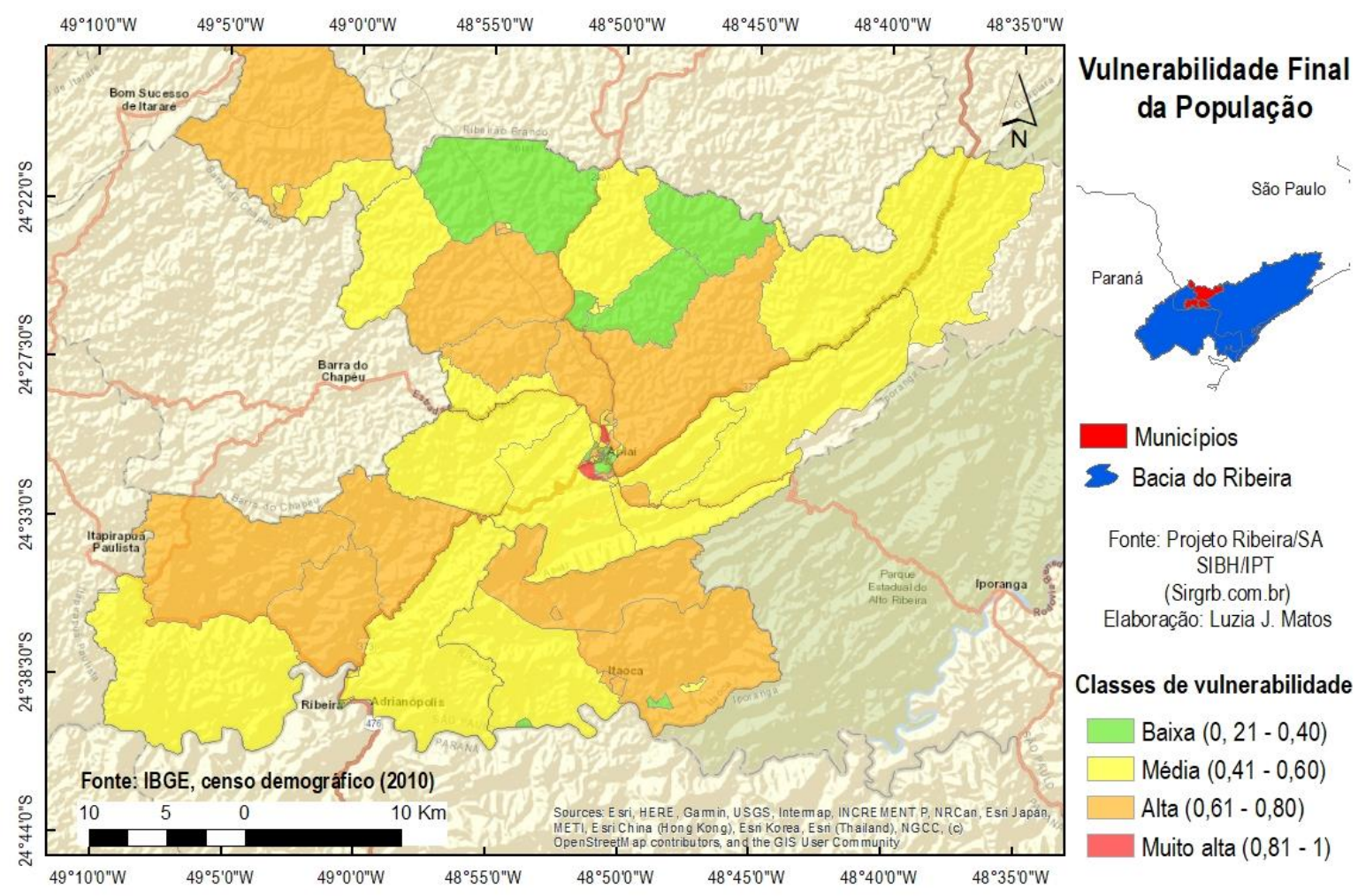

Figura 51: Vulnerabilidade final e distribuição das classes de análise.

No caso do valor mais elevado, 0,8303, situado em Apiaí, observa-se tratar de um setor com infraestrutura urbana central, cuja configuração final de análise resultou da combinação de elevados indicadores de exposição e de sensibilidade, sendo o déficit de resiliência menos expressivo (Figura 52). Neste contexto, a dimensão de sensibilidade apresentou o índice, 0,7614, destacando o papel das populações analfabeta e idosa que totalizaram 0,99 e 0,98, respectivamente. Em seguida, a dimensão de exposição permanente da população, apresentou o indicador médio de 0,5254 e os relevantes números da população idosa, 0,9896 e sem renda, 0,5829.

A dimensão do déficit de resiliência, 0,0775, estimulada sobretudo pelo índice da condição de moradia (0), contribuiu para a diminuição da vulnerabilidade apresentando domicílios com abastecimento de água e existência de banheiros ou sanitários com uso exclusivo pelos moradores, além de não terem sido atingidos por corridas de detritos ou inundações bruscas (Figura 53). 

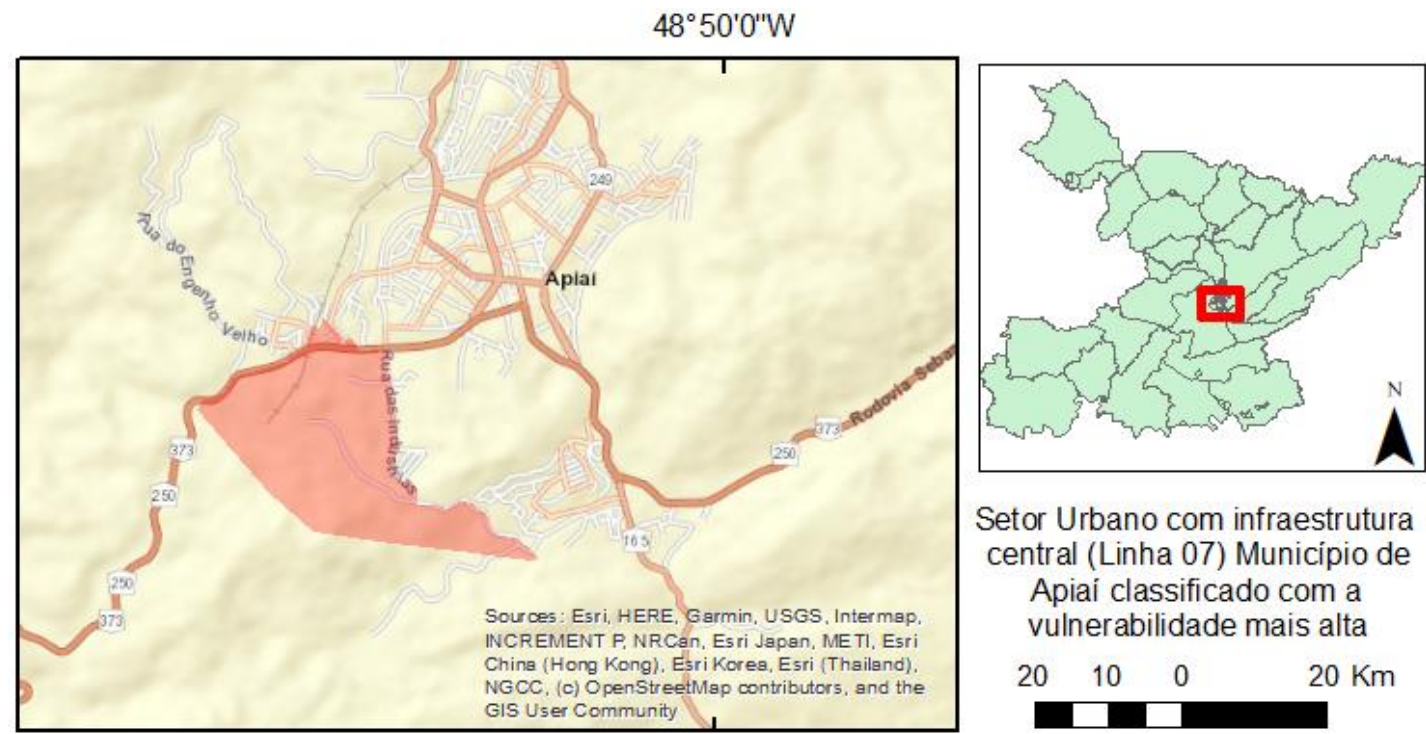

Setor Urbano com infraestrutura central (Linha 07) Municipio de Apiai classificado com a vulnerabilidade mais alta

$20 \quad 10 \quad 0 \quad 20 \mathrm{Km}$

Figura 52: Localização do setor demográfico com a maior vulnerabilidade alcançada.

$$
\begin{aligned}
& \text { Vulnerabilidade Final } \\
& \mathrm{VF}=\text { Sensibilidade }+ \text { Exposiçầ + Déficit de Resiliência/3 } \\
& \mathrm{VF}=\frac{(0,761450234)+(0,525404796)}{3}+\frac{+(0,07756802)}{3}=0,444870611 \\
& \text { Indicador da Vulnerabilidade Final = 0, } 830319433 \\
& \text { Exp }=P a b+P \text { erfil } E x / 2 \\
& \operatorname{Exp}=\frac{(0,033446712)+(0,692136337)}{2 \downarrow}= \\
& \text { (Descrição: Perfil de } \\
& \text { Exposição Permanente da População) } \\
& \text { Crianças + Idosos + } \\
& \mathrm{Ep}=(0,1781)+(0,9896)+0,5829=0,5209 \\
& \text { Índice da Exposição = }
\end{aligned}
$$

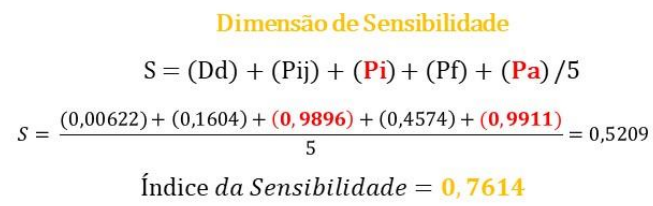$$
\text { Dimensão de Sensibilidade }
$$

Figura 53: Indicadores do setor demográfico com a maior vulnerabilidade alcançada.

Para o setor demográfico com o indicador de vulnerabilidade mais baixo, 0,2117, ressalta-se tratar de um setor rural no município de Apiaí (Figura 53). Nele, o processo de vulnerabilidade se deu com indicadores mais elevados na dimensão de sensibilidade ,0,3240, impulsionados, sobretudo pela concentração da população infanto-juvenil, 0,9214. Em seguida, as dimensões do déficit de resiliência, 0,09261, e de exposição, 0,09239 contribuíram para a diminuição do indicador final, 
apresentando, respectivamente, baixos índices da condição de moradia, 0,1307 e da população idosa, 0,0103, na variável exposição permanente (Figura 54).
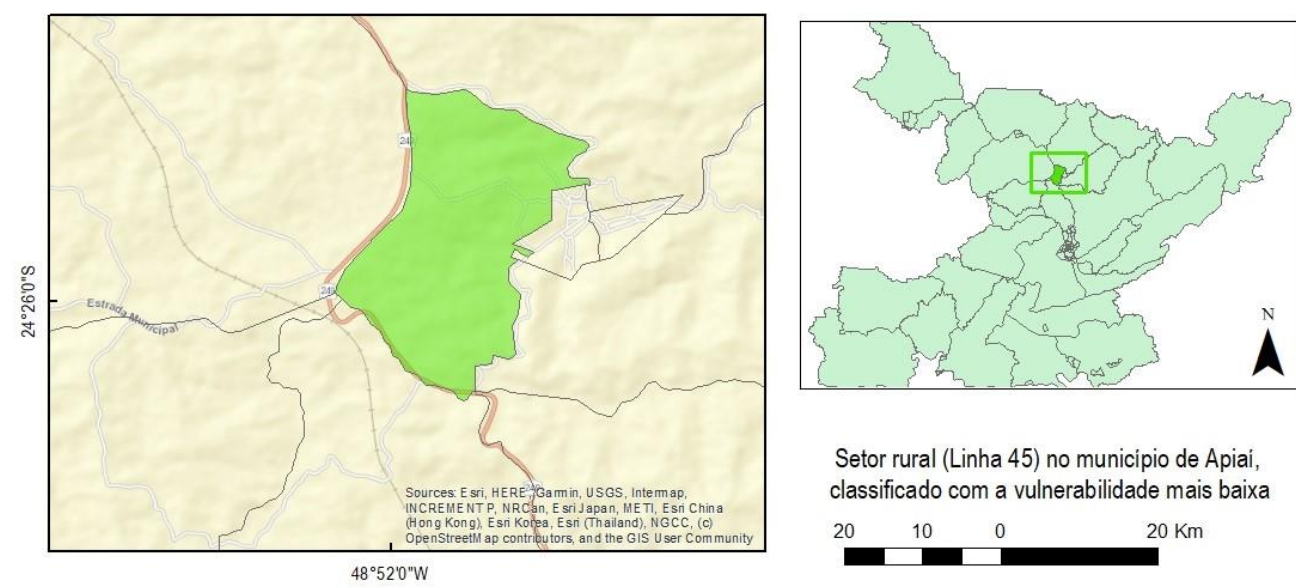

Setor rural (Linha 45) no municipio de Apiai, classificado com a vulnerabilidade mais baixa

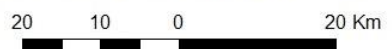

Figura 54: Localização do setor demográfico com a menor vulnerabilidade alcançada.

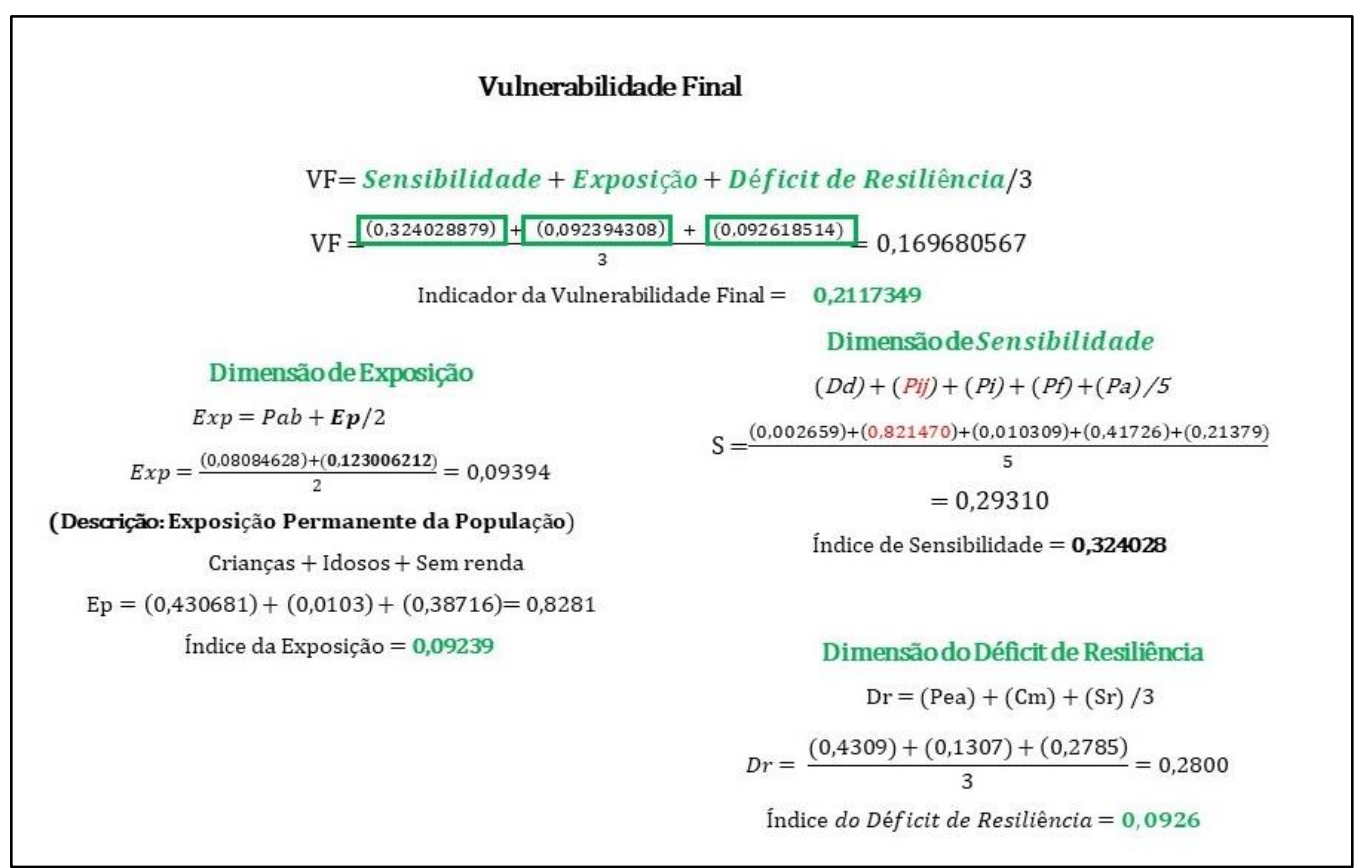

Figura 55: Indicadores do setor demográfico com a menor vulnerabilidade alcançada. 


\subsection{Vulnerabilidade Final e o Evento de 2014}

Em relação à vulnerabilidade final, considerando as corridas de detritos e as inundações bruscas deflagradas em 2014, 63 setores demográficos não foram atingidos por estes processos ( $90 \%$ do total dos setores). Entretanto, observa-se nestes, setores não atingidos, a presença das classes de vulnerabilidade mais elevadas (muito alta, alta, média e baixa) (Figura 56). Dos 7 setores atingidos, um corresponde ao das corridas de detritos (Guarda-Mão/ Gurutuba) e 6 ao das inundações bruscas (Lageado, Palmital, Itaoca Central, Itaoca Central 1, Palmital 1, Itaoca rural). Ao final, foram classificados como de vulnerabilidade alta (Guarda-Mão/ Gurutuba, Lageado, Itaoca Central e Itaoca central 1) e vulnerabilidade média (Palmital, Palmital 1, Itaoca rural) (Erro! Fonte de referência não encontrada.).
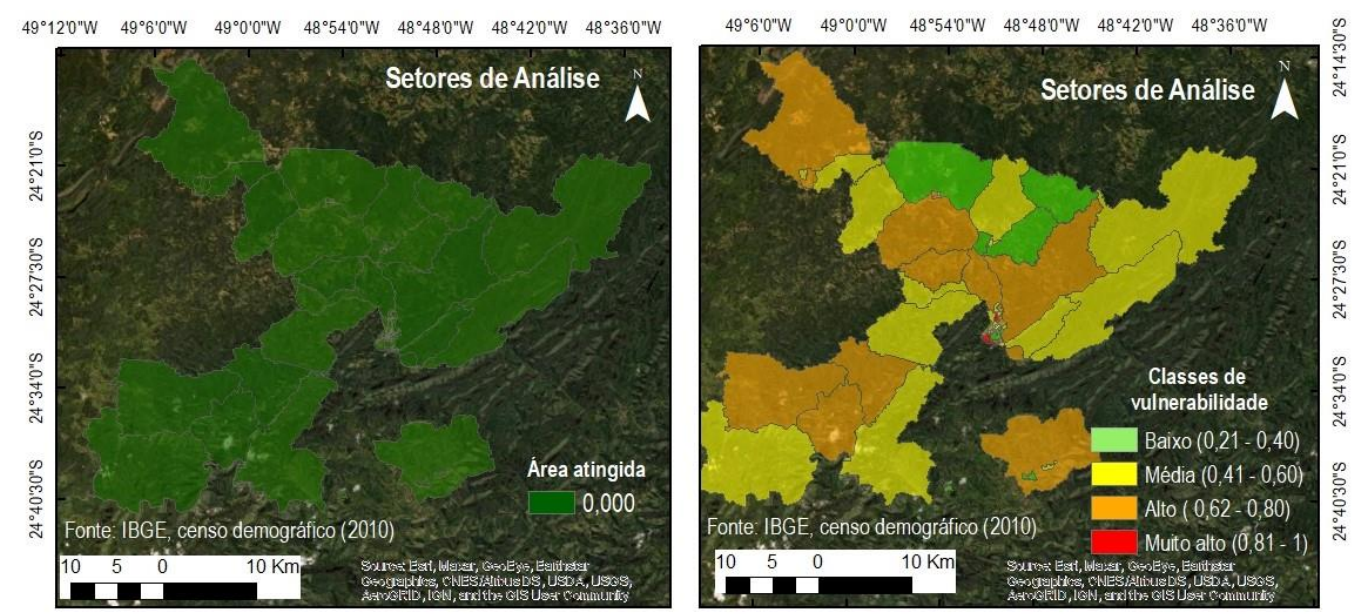

Figura 56: Setores não atingidos e a vulnerabilidade final destes setores.
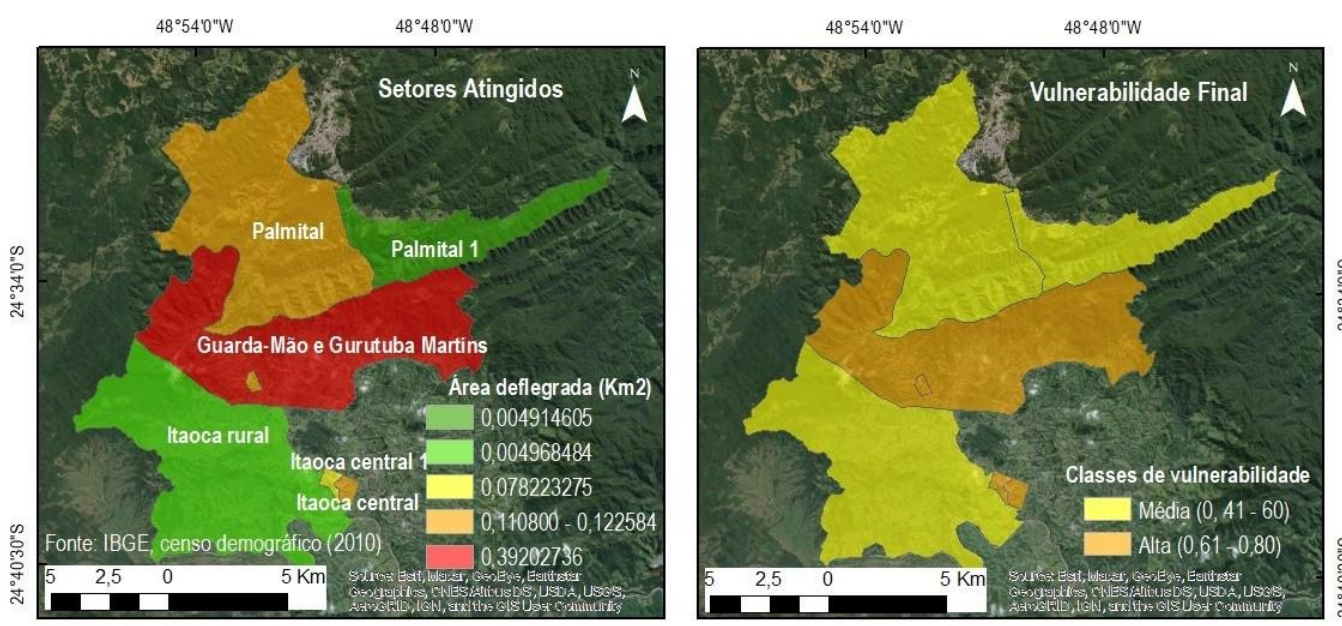

Figura 57: Setores atingidos e a vulnerabilidade final destes setores. 
Em relação aos setores de vulnerabilidade média, destacam-se os espaços do Palmital, Palmital 1 e Itaoca rural atingidos por inundações bruscas. No caso do primeiro, a classificação da vulnerabilidade média não foi acompanhada de uma área amplamente deflagrada. Nesse setor, apenas $0,2 \%$ de seu território foi acometido por inundações bruscas, ainda que o processo natural tenha sido o terceiro maior, em área deflagrada (Tabelas 7). Seu déficit de resiliência foi bastante expressivo com índice de 0,42 e os domicílios e população atingidos, apresentaram os percentuais de $7,5 \%$ e $8,4 \%$ (Figura 19). Para os setores Palmital 1 e Itaoca rural observou-se tratar de pequenas extensões do processo natural avançando para o setor mais próximo. No caso do Itaoca rural, a área deflagrada abrangeu menos de $0,01 \%$ de seus limites, sem atingir, portanto, qualquer domicílio ou pessoa.

Tabela 7: Classes de Vulnerabilidade e os Processos Naturais em Apiaí e Itaoca.

\begin{tabular}{|c|c|c|c|c|c|c|c|c|c|}
\hline \multirow{2}{*}{\multicolumn{2}{|c|}{ Vulnerabilidade/Setores (VA) }} & \multicolumn{3}{|c|}{ Índices/Indicadores } & \multicolumn{5}{|c|}{$\begin{array}{l}\text { Dimensões de Análise. Destaque para } \\
\text { os fatores diretamente relacionados ao } \\
\text { impacto com os processos naturais no } \\
\text { Déficit de Resiliência }\end{array}$} \\
\hline & & Ordem & $\begin{array}{l}A A \\
(\%)\end{array}$ & $\begin{array}{l}\text { Área do } \\
\text { processo } \\
(\mathrm{Km} 2)\end{array}$ & $\mathbf{s}$ & Exp & $\mathrm{Dr}$ & $\begin{array}{l}\text { DA } \\
\text { (\%) }\end{array}$ & $\begin{array}{l}\text { PA } \\
\text { (\%) }\end{array}$ \\
\hline \multirow{4}{*}{ 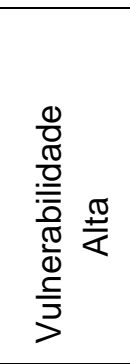 } & $\begin{array}{c}\text { Guarda-Mão/ Gurutuba } \\
(0,728270659)\end{array}$ & $1^{*}$ & 0,73 & 0,39202736 & 0,28 & 0,24 & 0,67 & 39,7 & 39,7 \\
\hline & $\begin{array}{c}\text { Lageado } \\
(0,809031943)\end{array}$ & 2 & 31,2 & 0,116933725 & 0,32 & 0,22 & 0,75 & 68 & 62,4 \\
\hline & $\begin{array}{l}\text { Itaoca Central } \\
(0,805353252)\end{array}$ & 1 & 14,2 & 0,125849775 & 0,29 & 0,30 & 0,70 & 72,2 & 66,9 \\
\hline & $\begin{array}{c}\text { Itaoca Central } 1 \\
(0,802545724)\end{array}$ & 4 & 12 & 0,078223275 & 0,33 & 0,30 & 0,65 & 62,4 & 64,1 \\
\hline \multirow{3}{*}{ 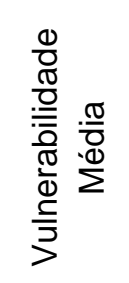 } & $\begin{array}{c}\text { Palmital } \\
(0,542325591)\end{array}$ & 3 & 0,20 & 0,110800017 & 0,25 & 0,26 & 0,42 & 7,5 & 8,4 \\
\hline & $\begin{array}{c}\text { Palmital 1 } \\
(0,571072982)\end{array}$ & 5 & 0,025 & 0,004968484 & 0,29 & 0,44 & 0,24 & 1,2 & 1,0 \\
\hline & $\begin{array}{c}\text { Itaoca rural } \\
(0,500215105)\end{array}$ & 6 & 0,0091 & 0,004914605 & 0,31 & 0,41 & 0,16 & 0 & 0 \\
\hline
\end{tabular}

Legenda: Vulnerabilidade Alcançada (VA); Área Atingida (AA); Sensibilidade (S); Exposição (Exp); Déficit de Resiliência (Dr); Domicílios Atingidos (DA) População Atingida (PA). * Atingido por corridas de detritos. 
O mesmo ocorreu com o Palmital 1, atingido pela extensão de alcance das inundações bruscas deflagradas diretamente no interior do setor Palmital; nele, o alcance das inundações chegou a apenas $0,02 \%$ de seu território, tendo atingido $1,2 \%$ dos domicílios e 1,0\% de sua população (Tabela 7).

Para os setores classificados com a vulnerabilidade alta, destacam-se Lageado, Palmital, Itaoca central e Itaoca central 1 atingidos por inundações bruscas e o setor Guarda-Mão/Gurutuba atingido por corridas de detritos.

O setor Lageado apresentou tanto a vulnerabilidade mais alta, dentre os atingidos por inundações bruscas, quanto a maior área com $31 \%$ de território deflagrado (Erro! Fonte de referência não encontrada.). Quanto ao impacto deste índice na relação evento deflagrado e vulnerabilidade alcançada, observou-se que embora este tenha sido atingido pela segunda maior extensão do processo natural, isso não correspondeu a uma diminuição dos índices de vulnerabilidade. Seu déficit de resiliência configurou-se como o maior dos 70 setores aplicados, com índice final de 0,75 , apresentando, dentre outros fatores, o número de domicílios e pessoas atingidas que corresponderam a 68 e $62,4 \%$, respectivamente.

Destaca-se ainda o caso do setor Itaoca central classificado com a segunda vulnerabilidade mais alta, dentre os atingidos, mesmo tendo sido acometido pela maior extensão de inundações bruscas (Tabela 7). Nele, o total da área deflagrada correspondeu a $14 \%$ do território. Seu déficit de resiliência foi de 0,70 , elevado, sobretudo pelos percentuais dos domicílios e a população atingidos, com $72,2 \%$ e $66,9 \%$ respectivamente (Figura 21 ).

Por fim, observa-se o Itaoca central 1, terceiro setor mais atingido pelas inundações deflagradas, destoando da classificação obtida no mapa da vulnerabilidade final com 0,8025 (Tabela 7). Neste setor, caracterizado como urbano de infraestrutura central, as inundações bruscas alcançaram 12\% (AA) da área de seu território, atingindo $62,4 \%$ dos domicílios e $64,1 \%$ da população total do setor. Tratase do único setor urbano em que a população superou a quantidade de domicílios atingidos. Observa-se ainda que a dimensão do déficit de resiliência foi a mais relevante para esta configuração final $(0,65)$, seguida da sensibilidade $(0,33)$ e da exposição permanente da população $(0,30)$.

No caso do setor Guarda-Mão/Gurutuba atingido principalmente por corridas de detritos, notou-se que, embora seu território tenha sido atingido em menos de $1 \%$, o 
número de domicílios e de pessoas atingidas corresponde igualmente a 39,7\% (Tabela 7), podendo indicar que o percurso das corridas de detritos e suas características de intensidade e tempo, limitam as chances de salvamento das pessoas residentes.

De maneira geral, observou-se que a vulnerabilidade final não foi pautada pela abrangência das áreas deflagradas. Estas, por sua vez, demonstraram correspondência com os percentuais de domicílios e população atingidos. Dessa forma, sugere-se que as classes de vulnerabilidade alcançadas responderam às diferentes condições físicas e sociais apresentadas em cada um dos setores; a exemplo de sua própria situação de urbanidade ou ruralidade, envolvendo, portanto fatores como a densidade demográfica ou ainda, sua extensão territorial (Figura 58).

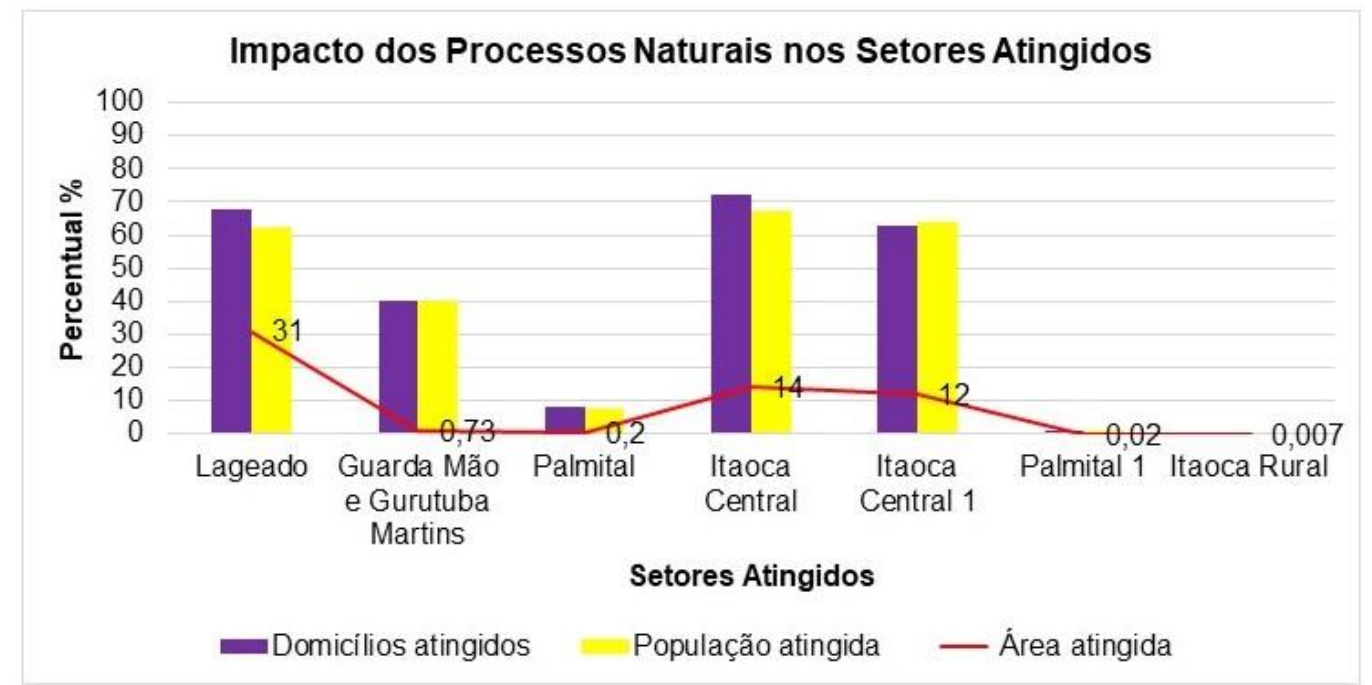

Figura 58: Elementos de risco atingidos e processos naturais deflagrados

No caso dos setores não atingidos a variação entre seus indicadores chegou a 0,70 , produto da diferença entre os índices extremos do déficit de resiliência. Sendo o índice, 0,368873606, o mais alto encontrado, correspondente a um setor rural no município de Apiaí, enquanto o menor, 0,047756802, caracteriza um setor urbano do município de Apiaí. No caso deste último, destaca-se que se trata também do menor déficit de resiliência dos 70 setores aplicados. Quanto aos setores atingidos a variação entre os índices extremos foi de 0,59 tendo observado que o maior índice foi também o máximo alcançado nos 70 setores aplicados e localiza-se no Lageado, setor 
urbano isolado no município de Itaoca, enquanto que o menor corresponde ao setor Itaoca rural com índice de 0,164215372.

Nesta etapa, observou-se que as duas situações apresentaram variações semelhantes, resultando em uma diferença de 0,27 . Inicialmente, esta amplitude entre os déficits de resiliência das duas situações, demonstra um padrão entre elas, corroborando com a razoabilidade da vulnerabilidade final obtida. Contudo, a diferença de 0,59 encontrada nos setores atingidos é muito alta, para uma área setorial que corresponde a apenas $11,1 \%$ dos setores não atingidos.

Dessa forma, examinou-se especificamente a situação dos setores atingidos, afim de identificar o quanto de seu déficit de resiliência correspondeu diretamente ao impacto com os processos naturais (Figura 59). Para tanto, analisou-se os fatores domicílios e população atingida, calculados com base no índice final do próprio déficit de resiliência. Neste contexto, verificou-se que o impacto dos processos naturais sobre os domicílios e população atingida variou amplamente, tendo alcançado 56,08\% no setor Itaoca central 1. Dessa forma, infere-se que a elevação dos indicadores do déficit de resiliência, não é suficiente para elevar a vulnerabilidade do setor à extremidade.

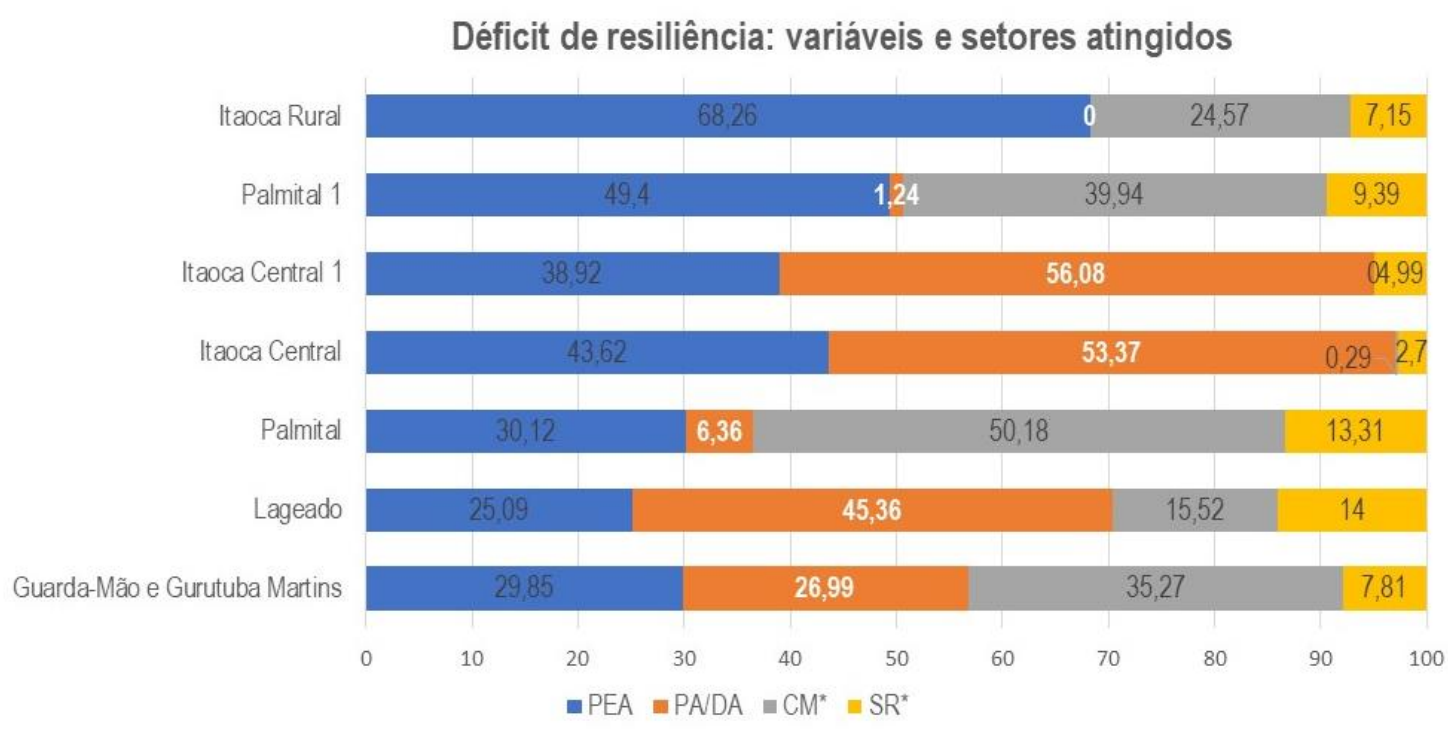

Figura 59: Observa-se o impacto nos domicílios e população atingida na dimensão do déficit de resiliência. Legenda: (PEA) População Economicamente Ativa, (PA) População Atingida (DA) Domicílios Atingidos; (CM) Condição de Moradia e (SR) Situação da Renda. 


\section{DISCUSSÕES}

A aplicação do método SAVE no alto vale do Ribeira resultou em indicadores de vulnerabilidade, predominantemente médios e altos com movimentos que refletem a estrutura apresentada nas dimensões de sensibilidade, exposição e déficit de resiliência. Nesse contexto, foram observadas seis associações ( $A, B, C, D, E$ e F), explicando a formação da vulnerabilidade final (Tabela ). De maneira geral, notou-se como a ação combinada entre essas dimensões explicaram as classes de vulnerabilidade geradas.

Todos os setores aplicados exibiram o padrão de movimento A e F, envolvendo, propriamente, a interação entre as dimensões de sensibilidade e déficit de resiliência (Figura 60). Nela, a sensibilidade exibiu indicadores elevados, quando os do déficit de resiliência apresentaram valores mais baixos, conformando nas vulnerabilidades mais próximas de "1" em setores de infraestrutura urbana e "0" nos rurais. Dessa mesma forma, quando os indicadores de sensibilidade apresentaram valores mais baixos que os do déficit de resiliência, a vulnerabilidade final aproximou-se de "1" nos setores de infraestrutura rural e de "0" nos urbanos. Em meio a essa estrutura, percebeu-se que a dimensão de exposição permanente da população agiu de forma combinada, ora com a sensibilidade, ora com o déficit de resiliência.

Tabela 8: Associações entre as dimensões de análise e suas características

\begin{tabular}{|c|c|c|c|c|c|c|c|c|}
\hline & \multicolumn{3}{|c|}{ Associações } & \multirow{2}{*}{ 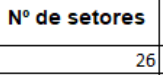 } & \multirow{2}{*}{$\begin{array}{c}\text { Infraestrutura dos setores, características } \\
19 \text { urbanos centrais; } 4 \text { rurais; } 3 \text { urbano isolados }\end{array}$} & \multirow{2}{*}{\begin{tabular}{c|} 
Classes de Vulnerabilidade \\
1 Muito Alta, 1 alta; 12 média e 12 baixa \\
\end{tabular}} & \multirow{2}{*}{$\begin{array}{c}\text { Situação } \\
\text { não atingidos }\end{array}$} & \multirow{2}{*}{\begin{tabular}{|c|} 
Municípios \\
Apiaí, Itaoca, Ribeira \\
\end{tabular}} \\
\hline A & s & $\operatorname{Exp}$ & $\mathrm{Dr}$ & & & & & \\
\hline B & s & $\mathrm{Dr}$ & Exp & 6 & 1 urbano central; 4 rurais; 1 urbano isolado & 1 média; 5 baixa & não atingidos & Apiaí, Itaoca \\
\hline c & $\operatorname{Exp}$ & $\mathrm{s}$ & $\mathrm{Dr}$ & 27 & 12 urbanos centrais; 15 rurais & 1 muito alta; 15 altas; 11 média & 2 atingidos & Apiaí, Itaoca, Ribeira \\
\hline D & Exp & Dr & $\mathrm{s}$ & 5 & 5 rurais & 1 média; 4 alta & não atingidos & Apiaí, Ribeira \\
\hline E & $\mathrm{Dr}$ & $\mathrm{s}$ & Exp & 5 & 1 urbano central; 3 rurais; 1 isolado urbano & 3 Alta; 2 média & 4 Atingidos & Apiaí e Itaoca \\
\hline $\mathrm{F}$ & $\mathrm{Dr}$ & $\operatorname{Exp}$ & $\mathrm{s}$ & 1 & 1 Urbano & 1 Alta & 1 atingido & Itaoca \\
\hline & \multicolumn{3}{|c|}{5 associações } & Total: 70 Setores & 37 Urbanos Centrais; 5 Urbanos Isolados; 28 Rurais & 2 Muito alta; 24 alta; 27 média e 17 baixa & 7 atingidos & 3 municípios \\
\hline
\end{tabular}

Legenda: $\mathrm{S}=$ Sensibilidade; Exp = Exposição do perfil populacional; $\mathrm{Dr}=$ Déficit de resiliência. 


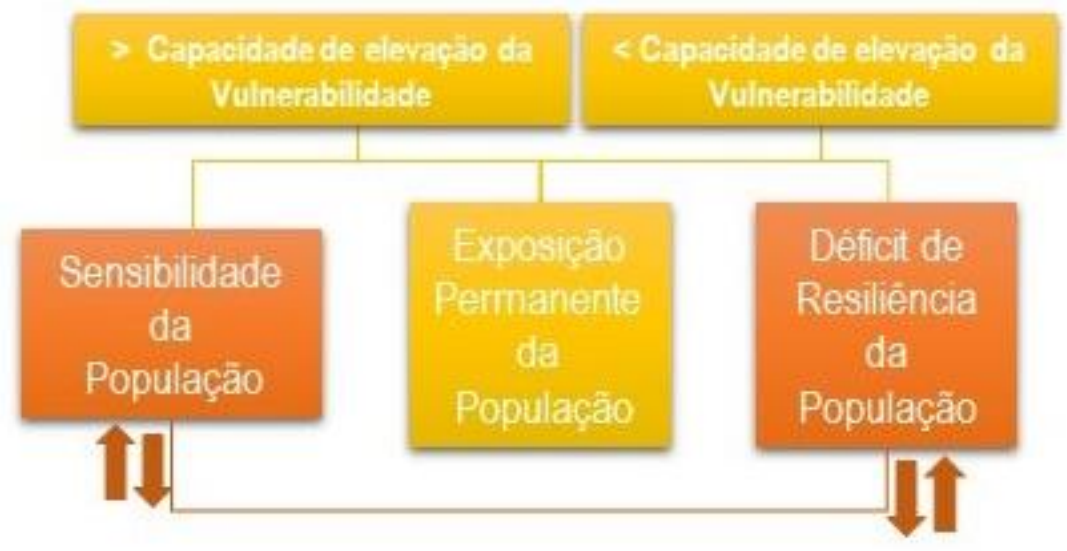

Figura 60: Organograma esquemático demonstrando a ação combinada entre as dimensões de análise em função da vulnerabilidade final.

Os casos mais evidentes foram observados em 27 setores, dos quais, a associação A se estabeleceu em 26 setores, predominantemente urbanos. Neles notou-se a maior capacidade de elevação da vulnerabilidade, chegando a classe mais alta, 0,8303. $\mathbf{F}$ exibiu 1 setor urbano com capacidade reduzida de elevação da vulnerabilidade à sua extremidade. No caso deste setor, especificamente, observa-se tratar de um cenário crítico, já que, tendo sido atingido por processos naturais, apresentou elevação da dimensão do déficit de resiliência, sobre a da sensibilidade em um setor urbano, no caso, o Itaoca central, amplamente atingido por inundações bruscas.

Propriamente em B, C, D e E destacam-se as variações da dimensão de exposição e seu impacto na estrutura da vulnerabilidade final. Dessa maneira, observou-se 32 casos em que a exposição é a variável dominante, expressos nas associações $C$ e D. Em B e E ela corresponde a dimensão de menor relevância, descrita em 11 setores aplicados.

Em C e D a dimensão de exposição exibiu a maior quantidade de setores com indicadores altos, elevando a capacidade da vulnerabilidade a seu extremo. A associação $C$ demonstrou a aproximação da exposição com a sensibilidade em 27 setores de análise. Deles, 16 (10 urbanos) apresentaram classes de vulnerabilidade alta, incluindo a muito alta, que se configurou no segundo setor com a vulnerabilidade mais elevada, 08179, dentre os 70 aplicados. Para os setores com classificação média, dentre eles, 6 de infraestrutura rural, observa-se uma diminuição dos 
indicadores no setor. Em D a exposição se aproximou mais diretamente dos indicadores do déficit de resiliência em 5 setores. Neste caso, a dimensão de exposição corresponde ao fator mais elevado de análise e envolveu apenas setores rurais, apresentando uma classe de vulnerabilidade média e 4 altas.

Nas associações B e E em que a dimensão de exposição apresentou os indicadores mais baixos, a capacidade de elevação da vulnerabilidade parece reduzida, embora, no caso das associações em "E", esse movimento apresente as perturbações com a deflagrações diretas em 4 desses setores. $\mathrm{Na}$ associação $\mathrm{B}$, observou-se a formulação de 6 setores, sendo 5 de vulnerabilidade baixa e apenas 1 média. $\mathrm{Na} \mathrm{E}$, atenta-se para a situação dos 4 setores atingidos pelas inundações bruscas e corridas de detritos na cidade de Itaoca e Apiaí. Trata-se do Palmital com vulnerabilidade média e do Lageado, Itaoca central 1 e Guarda-Mão e Gurutuba classificadas com a vulnerabilidade alta. Ainda sobre esta associação, o único setor não atingido, apresentou o menor valor 0,4657 , classificado como de vulnerabilidade média. Dessa maneira, a elevação do déficit de resiliência sobre os de sensibilidade, mais diretamente, reflete o impacto do processo natural sobre a estrutura de vulnerabilidade. A combinação dessa dinâmica, com os baixos indicadores da população permanentemente exposta, conformou a vulnerabilidade desses setores em alta e média.

Em uma abordagem mais geral, Welle e Birkmann (2015) e Almeida, Welle e Birkmann (2016), afirmam que a vulnerabilidade de uma sociedade ou país não corresponde a exposição populacional aos processos naturais. Dessa maneira, concluiu-se que a exposição, como um dos aspectos múltiplos da vulnerabilidade, apresenta influência direta em sua estrutura. Nesse contexto, observou-se que, quanto mais elevados os indicadores de exposição, maior será a capacidade de elevação da vulnerabilidade a índices extremos. Quanto mais baixos seus indicadores, menor será essa condição (Figura 61). 


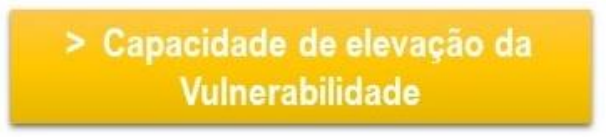

A

Sensibilidade, Exposição e

Déficit de Resiliência

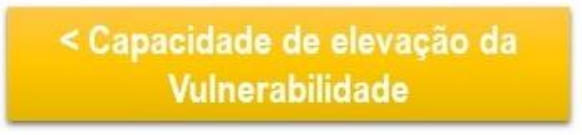

$\mathbf{F}$

Déficit de Resiliência,

ou Exposição e Sensibilidade

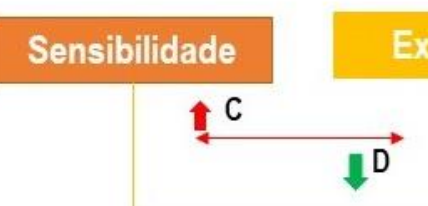

cposiçâc

Déficit de

Resiliência

B!

\section{$\mathrm{TE}$}

As setas indicam os movimentos da Vulnerabilidade Final

Figura 61: Movimentos da dimensão de exposição e seu impacto na vulnerabilidade final.

A luz das aplicações descritas, e mecanismos demonstrados, remonta-se a leitura de que a construção do processo de vulnerabilidade, antecede a deflagração dos processos naturais. Nesse contexto, Cardona (2004) assevera que a vulnerabilidade pode ser definida como um fator de risco interno a um elemento ou sistema expostos a um processo natural, correspondendo, portanto, a sua predisposição intrínseca a ser afetada ou a estar susceptível ao dano.

Os resultados desta pesquisa mostraram que as deflagrações dos processos geomorfológicos naturais em janeiro de 2014, não poderiam destoar, de forma extrema, a condição da vulnerabilidade nos 70 setores aplicados, sobretudo os 63 que não foram atingidos diretamente. Nesse contexto, observa-se também certo grau de independência entre a vulnerabilidade estabelecida e os impactos dos processos naturais.

Para as áreas diretamente atingidas, constatou-se que embora os dados referentes as perdas e os danos interajam de forma direta com a vulnerabilidade estabelecida, eles não foram decisivos para as classificações extremas. Dos 5 setores atingidos diretamente, apenas 2, sendo 1 urbano central e 1 urbano isolado na cidade de Itaoca exibiram uma resposta mais pronunciada sobre os setores. Contudo, ressalta-se a ação dos baixos indicadores de exposição, observados na associação E, dificultando a elevação da vulnerabilidade aos índices extremos. 
Nos demais setores, a elevação do déficit de resiliência a partir dos fatores população e domicílios atingidos não foi suficiente para elevar a condição de vulnerabilidade a extremidade. A esse exemplo, destaca-se a situação do setor do Guarda Mão e Gurutuba Martins, que mesmo tendo sido atingido por duas corridas de detritos, obteve classificação de vulnerabilidade alta e não muito alta. Trata-se da associação $\mathrm{E}$ demonstrando maior distanciamento entre os indicadores do déficit de resiliência com os de exposição, diminuindo a capacidade de elevação da vulnerabilidade. As perdas e danos neste setor foram extremamente altas, contudo, a desassociação direta entre a sensibilidade e a exposição apresentada salvaguarda a classificação da vulnerabilidade alta obtida.

Dessa maneira, examina-se que a vulnerabilidade corresponde a uma estrutura que favorecerá a elevação ou diminuição dos graus de perdas e danos, sem, contudo, constringi-los às classes de vulnerabilidade aplicadas.

A este exemplo, Murillo-Garcia et al. (2017) citam o caso de Cuauneutla de La Paz que mesmo tendo sido atingida por deslizamentos de terra com baixa magnitude, em 1999, alcançou um grau de perda extremamente alto. Tratando-se de pequena área agrícola com população de baixa renda e residências de estrutura simples, infere-se tratar de uma área rural com elevados indicadores de déficit de resiliência. Destaca-se ainda, o caso da área central da cidade de Pahuatlàn, México, por ter sido atingida pelos deslizamentos rotacionais de 2005 de baixa e média magnitude, sem, causar, portanto, danos diretos ou perdas fatais a sua população. Nessa área, contudo, a classificação de vulnerabilidade obtida foi a alta. Segundo os autores, tratou-se do status econômico da cidade com a presença do palácio do governo e modo de vida da população, que a definiram.

Nesse contexto, Ciurean et al. (2016) indicam que a vulnerabilidade e as taxas de perdas estimadas exibem maiores incertezas, conforme a escala aplicada. Nesse estudo, avaliou-se a vulnerabilidade das construções atingidas pelas corridas de detritos nos alpes italianos ocidental, estimando também seu grau de perda em escalas local e regional. Seus resultados apontaram para maiores diferenças entre a vulnerabilidade obtida e as taxas de perdas em escala regional.

De maneira geral, verificou-se na presente pesquisa que a combinação das dimensões, exposição, sensibilidade e déficit de resiliência, assim como, 
sensibilidade, exposição e déficit de resiliência, corresponderam as associações que mais interferiram na construção da vulnerabilidade final da população no alto vale do Ribeira. Dos 70 setores aplicados, 53 apresentaram essa estrutura, os 17 restantes exibiram suas variações.

Dessa maneira, as classes predominantes alcançadas caracterizaram-se como sendo média e alta, distribuídas, respectivamente em 38,57\% e 34,28\%. As classificações baixas e muito altas corresponderam a 24,28\% e 2,85\% e não houve classificação muito baixa da vulnerabilidade. Em Murillo Garcia et al. (2017), observou-se maior variação entre os indicadores, com a apresentação das cinco classes de vulnerabilidade, alcançando situações de muito baixa a muito alta vulnerabilidade. Dentre elas, a classe de vulnerabilidade alta foi predominante com $55 \%$ da área.

Em Guillard-Gonçalves e Zêzere (2018) organizou-se dois mapas finais da vulnerabilidade, separando a vulnerabilidade física da social. No caso dessa última, seus resultados foram mais baixos, destacando a ampla variação entre as densidades demográficas no município. Quanto à vulnerabilidade física, seu grau foi elevado, acompanhando o aumento da magnitude dos deslizamentos de terra.

Por fim, a condição da vulnerabilidade alcançada no período entre 2010 e 2014 variou entre as classes muito alta, alta, média e baixa, principalmente pela ação da exposição populacional, que ao se aproximar da sensibilidade alcançou a vulnerabilidade máxima. Nos casos em que ela se aproximou do déficit de resiliência a vulnerabilidade variou entre baixa, média e alta. Destacando os setores atingidos, verificou-se que os 5 dos 7 casos, incluindo o acometido por corridas de detritos, aplicam-se ao segundo caso com vulnerabilidades altas e médias.

Diante da estrutura apresentada, notou-se que a representação do mapa de vulnerabilidade final exibiu apenas uma das classificações possíveis. Com base nela e na compreensão de como as associações entre as dimensões de análise foram encadeadas, buscou-se representá-la em uma nova perspectiva espacial.

A similaridade e o padrão dos casos analisados em C, A e D, e E, F e B, caracterizaram dois grandes grupos de vulnerabilidade, cuja movimentação do processo se pautou na capacidade de alcance da vulnerabilidade extrema (Figura 62). 


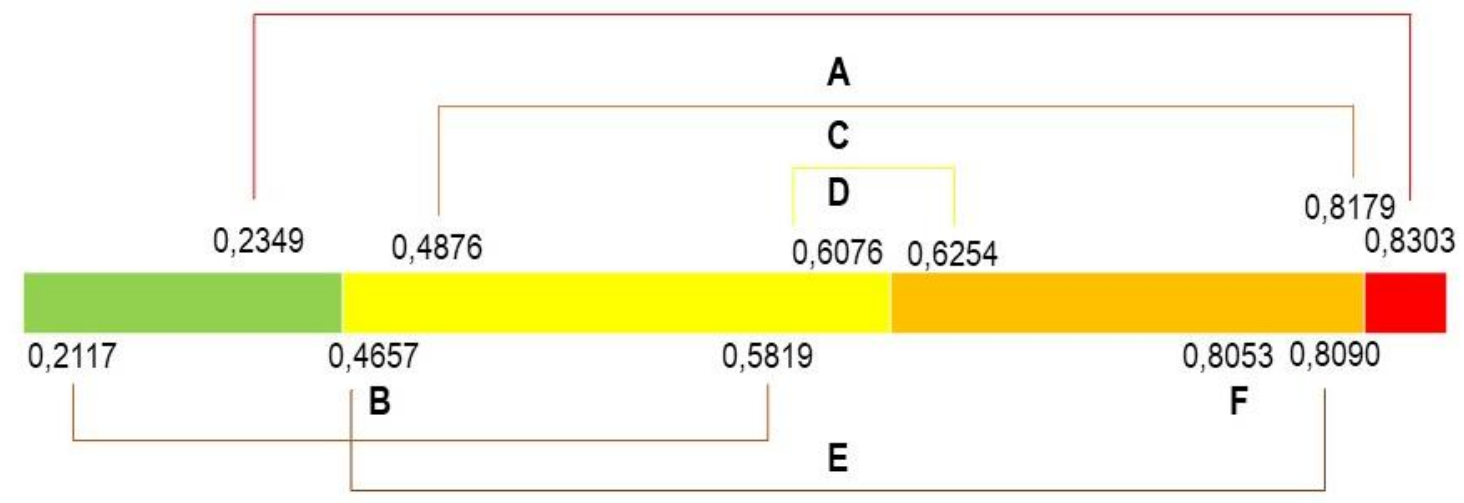

Figura 62: A paleta de cores no centro da figura representa a primeira classificação aplicada, indicando $2,85 \%$ da área com vulnerabilidade muito alta, 34,28\% alta e 38,57\% média e $24,28 \%$ baixa. Em seu entorno observa-se as extensões e indicadores máximos e mínimos de cada uma das 6 associações que interferiram na vulnerabilidade final.

As associações entre A, C e D, nessa ordem, abarcam os setores que apresentam maior capacidade de elevação da vulnerabilidade a extremidade. Tratase de 58 setores nessa condição, com apenas 2 deles atingidos por inundações bruscas em 2014 (Figura 63). No caso da E, F e B, envolvem os setores com menor capacidade de elevação da vulnerabilidade ao extremo. Nelas, propriamente E e F representam os casos de 5 setores atingidos, pelos processos naturais estudados, compondo os 6 setores sob essa classificação. De maneira geral, a Figura 63 demonstra, espacialmente, como o movimento das dimensões de análise interferiram na elaboração da vulnerabilidade final no período de 2010 e 2014 nos municípios de Apiaí, Ribeira e Itaoca. A compreensão da estrutura que embasou esse movimento, sugere que outros cenários de risco possam apresentar condições semelhantes. 


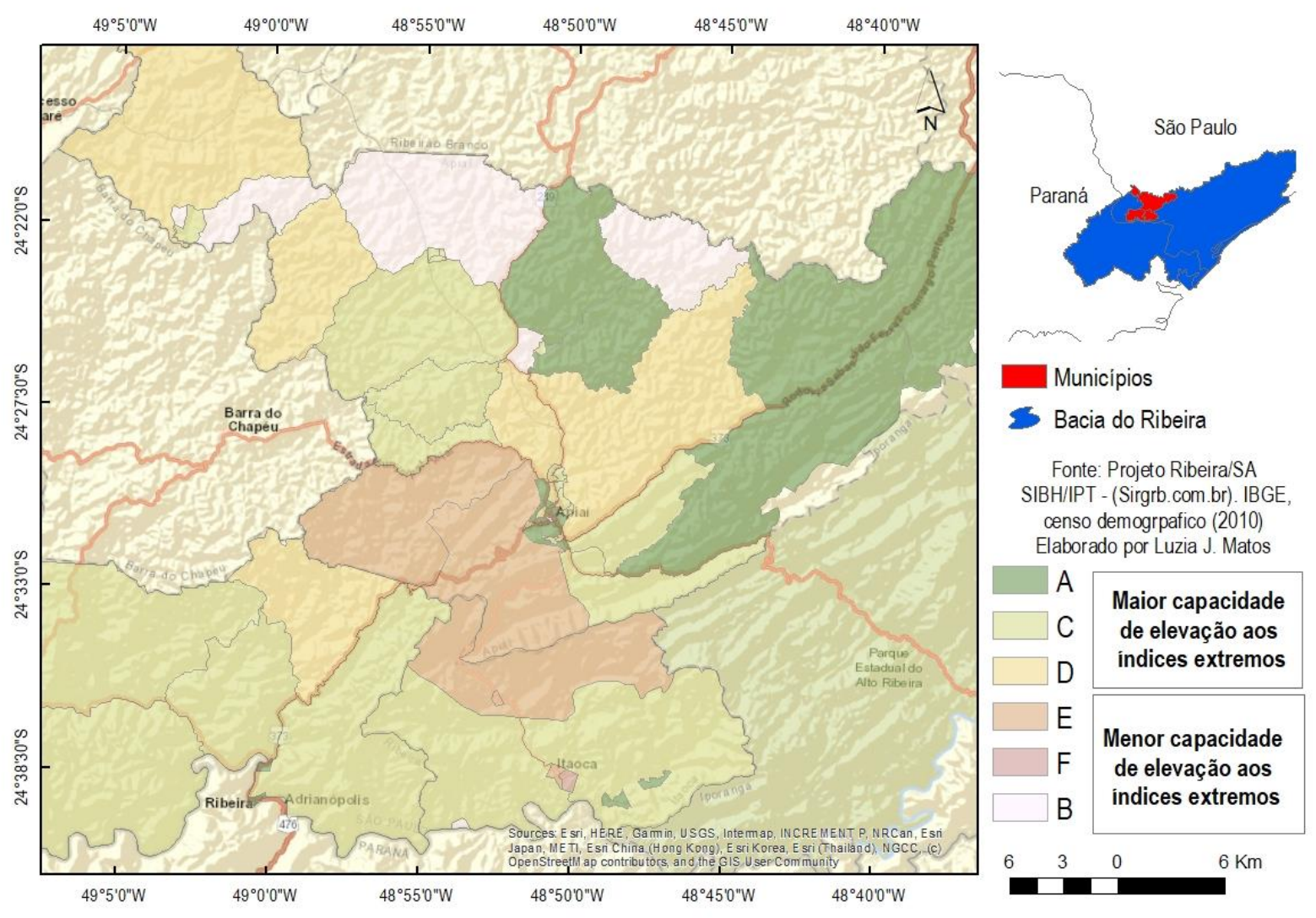

Figura 63: Mapa da estrutura que embasa a vulnerabilidade final. 


\section{CONSIDERAÇÕES FINAIS}

O presente estudo concluiu que a condição da vulnerabilidade alcançada pelos setores de análise, no período entre 2010 e 2014 variou entre baixa e muito alta com o predomínio das classes média e da alta vulnerabilidade. Observou-se ainda, que, assim como em outros trabalhos, essas classes não foram definidas pela magnitude do processo natural. De modo geral, o impacto dos processos naturais sobre os setores atingidos, reforçaram a compreensão de que a vulnerabilidade final não depende da deflagração dos processos naturais e que sua interação não é, necessariamente, linear.

Nesse processo, verificou-se que a vulnerabilidade final resultou da combinação das diferentes associações entre as dimensões de análise, elevando-a e diminuindoa. Dessa maneira, destaca-se que quando a dimensão de exposição se aproxima da sensibilidade a vulnerabilidade tende a aumentar, chegando a alcançar valores extremos. Quando a exposição se aproxima do déficit de resiliência, a capacidade de elevação da vulnerabilidade aos índices extremos diminui. Nesse contexto, evidenciou-se como a deflagração das corridas de detritos e inundações bruscas impactaram a estrutura da vulnerabilidade alcançada em cada setor. Destaca-se ainda, que nenhuma dimensão de análise foi capaz de definir, unicamente, a vulnerabilidade final.

De maneira geral, a representação desse mecanismo exibe a estrutura que elaborou na vulnerabilidade final, sugerindo a aplicabilidade do modelo em outras áreas de risco. Assim, a estrutura do modelo SAVE possibilita a criação de diferentes representações espaciais, de modo que as instituições e agentes capacitados possam avaliar o melhor produto em seus planos de ação, sobretudo os voltados a redução ou controle das perdas e danos nas áreas de risco.

Finalizando, as maiores limitações observadas na presente pesquisa apontam para a generalização das informações no setor, pois que, a visualização dos mapas e análises setoriais levam a crer que toda a população setorial está vulnerável da mesma forma. A segunda limitação se refere ao uso dos dados de pesquisa do censo demográfico como única ou principal fonte de dados, pois que para o estudo de um processo dinâmico como o da vulnerabilidade, o intervalo de 10 anos para a observação dos dados é problemático. 
No âmbito do método SAVE a maior limitação encontrada refere-se à subjetividade dos dados de entrada, gerando incertezas nos resultados finais. Por outro lado, sua grande vantagem reside na capacidade de gerar representações espaciais mais realísticas, capazes de demonstrar a estrutura do processo da vulnerabilidade nos resultados alcançados. 


\section{REFERÊNCIAS BIBLIOGRÁFICAS}

ALEXANDER, D. (1993) Natural Disasters, Chapman e Hall, New York, 7 p.

ALMEIDA, Q, L. WELLE, J. BIRKMANN, J (2016) - Disaster Risk Indicators in Brazil: A proposal based on the world risk index. International Journal of Disaster Risk Reduction. Vol 17, p. 251-272.

AUBRECHT, C. FUCHS, S. NEUHOLD, C. (2013) Spatio-Temporal aspects and dimensions in integrated disaster risk management. Springer, Natural. Hazards Original Paper p. $1205-1216$.

AUGUSTO FILHO, O. (1993) - O estudo das corridas de massa em regiões serranas tropicais: um exemplo de aplicação no Município de Ubatuba, SP. Congr. Bras.Geol.Eng., 7, Poços de Caldas. ABGE. V 2, p. 63-70.

AVELAR, A.S., COELHO NETO, A.N., LACERDA, W.A., BECKER, L.B., MENDONÇA., M.B. (2011) Mechanisms on the Recent Catastrophic Landslides in Mountainous Range of Rio de Janeiro, Brazil. In: The Second World Landslide Forum, Roma, p 1-5.

BIGARELLA, J. J., BECKER, R.D. (1975). Catastrophic events in the Tubarão area. In International Symposium on the Quaternary Southern Brazil, Boletim Paranaense de Geociências, vol. 33, p. 200-206.

BIRKMANN, J. (2006). Measuring Vulnerability to promote disaster-resilient societies: Conceptual frameworks and definitions. In J. Birkmann (Ed.), Measuring vulnerability to natural disasters - United Nations University Press. p. 09-54).

BIRKMANN, J. (2007). Risk and Vulnerability indicators at different scales: Applicability, Usefulness and Policy implications. Elsevier - Environmental Hazards. 7. P. 20-31.

BIRKMANN, J. CARDONA, O.D, CARRÊNO, M.L, BARBAT, A.M, PELLING M, SCHNEIDERBAUER S, KIENBERGER M, KEILER M, ALEXANSER D, ZELI P, WELLE T (2013). Framing Vulnerability, Risk and Societal Responses: The MOVE framework. Natural Hazards 67:193 - 211p.

BROLLO, M. J.; SANTORO, J.; PENTEADO, D. R.; FERNANDES DA SILVA, P. C.; RIBEIRO, R. R. Itaoca (SP) (2015): Histórico de acidentes e desastres relacionados a perigos geológicos. $14^{\circ}$ Simpósio de Geologia do Sudeste. Campos do Jordão - SP: $1-5$.

CANNON, H, S., KIKHAM, M. R., PARISE, M. (2001) Wildfire-related debris-flow initiation processes, Storm King Mountain, Colorado. Geomorphology, Vol.39 Elsevier - p. 171-188.

CANNON, T. (2008) Vulnerability, "innocent" dasasters and the imperative of cultural understanding. Disaster Prevention Management. 17 (3) p. 350-357. 
CARDONA, D. O (2004) The need for rethinking the concepts of vulnerability and risk from a Holistic Perspective: A necessary review and criticism for effective risk management. In Bankoff, G. Frerks and D. Hilhorst, (Eds), MappingVulnerability: Disasters, development and people, London: Earthscan, p. 1-17.

CHEN, N. SH, ZHOU, W, YANG, CH. L, HU, G. SG, GAO, Y. CH, HAN, D. (2010) The processes and Mechanism of failure and debris flow initiation for gravel soil with different clay content. Geomorphology 121 - Elsevier: DOI: 10.1016/J. geomorph. 2010.04.017. p. 222-230.

CIUREAN, R. L, HUSSIN, H., WESTEN, C, J. (2016) Multi-scale debris flow vulnerability assessment and direct loss estimation of building in the Eastern. Natural Hazards, DOI: 10.1007/s11069-116-2612-6. Springer, 28 p.

CONWAY, F.S. DECALNE, A. BALME, R.M. MURRAY, B. J. TOWNER, C.M. (2010) A new approach to estimating hazard posed by debris flows in the Westfjords of Iceland. Geomorphology - Elsevier. DOI: 10.1016/J. geomorfology. 2009.08.015. p. 556-572.

CRUZ, O. (1974). A Serra do Mar e planície na área de Caraguatatuba- contribuição à geomorfologia litorânea tropical. Série Teses e Monografias, 11, IGEOG/USP: 181 p.

DEFESA CIVIL DO ESTADO DE SÃO PAULO (2015). Defesa Civil continua atuando em Itaoca. São Paulo - http://www.saopaulo.sp.gov.br. Último acesso em 29/11/2017.

DEMUTH, J. L, MORSS, E. R, LAZO, K. J. LAZO (2016) The Effects of Past Hurricane Experiences on Evacuation Intentions through Risk Perception and Efficacy Beliefs: A Mediation Analysis. American Metheorologycal Society; DOI: 10.1175/WCAS-D-150074.1; Vol 8 -327-344p.

EM-DAT- The Internacional Disaster Database. General Classification. Disponível em: http://www.emmat.be/classification. Acesso em -7/11/2017.

Empresa Paulista de Planejamento Metropolitano S/A - (EMPLASA). Projeto: Mapeia São Paulo - Ortofotos 2010/2011. Sistema de Compartilhamento de Dados (SCD).

FERREIRA, C. J., ROSSINI-PENTEADO, D. BROLLO, M. J. (2016) Debris flow hazard and susceptibility zonation in small watersheds in Itaoca municipality, São Paulo state, Brazil. In: Landslides and Engineered Slopes. Experience, Theory and Practice Aversa et al. (Eds) Associazione Geotecnica Italiana, Rome, Italy, ISBN 978-1-13802988-0, p. $893-900$.

FREIRE, S. AUBRECHT, C. WEGSSCHEIDER, S. (2011) Spatio-Temporal Population Distribution and Evacuation Modeling for Improving Tsunami Risk Assessment in the Lisbon Metropolitan Area. International Symposium on Geo-Information (Gi4DM), Antaya, 3-8 Maio de 2011; 6p.

FUCHS, S. (2009) Susceptibility versus resilience to mountain in Austria - paradigms of vulnerability revisited, Nat. Hazards Earth Syst. Sci., 9, 337-352p. 
FUCHS, S. KUHLICKE C, VOLKER, M (2011). Editorial for the especial issue: Vulnerability to natural hazards - the challenge of integration. Natural Hazards. 58:609 $-619 p$.

FUNDAÇÃO SISTEMA ESTADUAL DE ANÁLISE DE DADOS, SEADE (2015) Portal de estatísticas do estado de São Paulo. Municípios do alto vale do Ribeira, Itaoca, Apiaí e Ribeira. http://www.seade.gov.br. Último acesso em Junho de 2020.

GRAMANI, M. F. (2001) Caracterização geológico-geotécnica das corridas de detritos (Debris flows) no Brasil, em comparação com alguns casos internacionais. Dissertação (Mestrado) - Departamento de Engenharia de Estruturas e Fundações Escola Politécnica da Universidade de São Paulo. São Paulo, p 135 - 225.

GRAMANI, M. F. KANJI, M. A. (2001). Inventário e Análise das Corridas de Detritos no Brasil. $3^{\circ}$ Congresso Brasileiro Estabilidade de Encostas (COBRAE), ABMS, Rio de Janeiro, 53-60.

GRAMANI, M. F.; ARDUIN, D. H. (2015) Morfologia da drenagem dos depósitos de debris flow em Itaoca, São Paulo. In: $15^{\circ}$ Congresso Brasileiro de Geologia de Engenharia e Ambiental (CBGE), Bento Gonçalves (RS) ISBN: 078-85-7270-069. Anais, 10, p.

GRAMANI, M. F.; MIRANDOLA, F. A (2014) A corrida de massa no córrego GuardaMão, município de Itaoca (SP): Impacto e observações de campo. In: Desastres em 2014 no Sudeste. São Paulo, ABGE, Associação Brasileira de Geologia de Engenharia e Ambiental, São Paulo, p 28-36.

GUIDICINI, G, C. M. NIEBLE, (1976). Estabilidade de Taludes Naturais e de Escavação. São Paulo. p. 09-27.

GUILLARD-GONÇALVES, C. ZÊZERE, L.J. (2018) Combining Social Vulnerability and Physical Vulnerability to Analyse Landslide Risk at the Municipal Scale. Geosciences, 8, DOI: 10.3390. 294p.

HAAS, T, DENSMORE, A. L, STOFFEL, M, SUWA, H, IMAIZUMI, F, BALLESTEROSCÁNOVAS, J.A, WASKLEWICZ, T (2018) Avulsions and the spatio-temporal evolution of debris-flow fans. Earth-Science Reviews, https://doi.org/10.1016/j.earscirev.2017.11.007 - 177, P53-75.

HOLLESTEIN, K (2005) Reconsidering the risk assessment concept: Standardizing the impact description as a building block for vulnerability assessment. Natural Hazards and Earth System Sciences, v 5 - p. 301-307

INSTITUTO BRASILEIRO DE GEOGRAFIA E ESTATÍSTICA (IBGE). Censo Demográfico (2010). Disponível em http://www.ibge.gov.br/censo2010/. Último acesso em 23/02/2020.

INSTITUTO DE PESQUISAS TECNOLÓGICAS (1987) - Estudo das instabilizações de encostas da Serra do Mar na região de Cubatão objetivando a caracterização do fenômeno "corrida de lama" e a prevenção de seus efeitos. Relatório № 25065/87. 
INSTITUTO DE PESQUISAS TECNOLÓGICAS, (2002). Reconhecimento, Caracterização e Monitoramento de locais potencialmente sujeitos a instabilizações na serra do mar na área de influência dos diversos sistemas de captação e abastecimento de água de tratamento de esgoto, Estado de São Paulo. SCT. Relatório $N^{\circ} 59123 / 02$.

JAKOB. M, STEIN. D, ULMI. M. (2012) Vulnerability of buildings to debris flow impact. Natural Hazards: DOI 10.1007/S11069-011-0007-Vol 2. p. 241-261.

JORNAL REGIONAL, VALE DO RIBEIRA, (2011) Força das águas: Eldorado sofre a segunda maior enchente da história. Disponível em: http://regionaljornal.blogspot.com/2011/08/forca-das-aguas-eldorado-sofresegunda.html. Último acesso em abril de 2020.

KANJI, A. M; GRAMANI, F. M (2001) Metodologia para Determinação da Suscetibilidade a Corridas de Detritos em Pequenas Bacias Hidrográficas. In: 3a Conferência Brasileira de Estabilidade de Encostas (COBRAE), Rio de Janeiro, 8 p.

KANJI, M. A. MASSAD, F. CRUZ, T. P. (2003) Debris Flows in areas of residual soils: Occurrence and characteristics, P. 1-8.

KAPPES, M. S, PAPATHOMA-KÖLE, M. K, (2012). Assessing physical vulnerability for multi- hazards using an indicator-based methodology. Elsevier - Applied Geography vol.32, Wien - Austria. p 577-590.

LARSEN, C. M., WIECZOREK, F. G., EATON, S. L., MORGAN, A. B., SIERRA, T. H. (2001) Venezuelan Debris Flow and Flash Flood Disaster of 1999 Studied. In: Eos/ AGU (American Geophysical Union) Vol. 82, No. 47, EON, DOI: 10.1029/01E000335 - P. $572-573$.

LIMA, F. I., FERNANDES, F. N., VARGAS JUNIOR, A.E, (2020). Análise morfométrica em bacias afetadas por fluxos de detritos na região serrana do Rio de Janeiro. Revista $\begin{array}{llllll}\text { Brasileira de Geomorfologia, V } & \left.\text { 21, } \mathrm{n}^{\circ} \quad 2020\right) \text {. }\end{array}$ ISSN://dx.doi.org/10.20502/rdg.v2i2.1515. p 400-419.

LOPES, E. S. S, (2006). Modelagem Espacial Dinâmica em Sistema de Informação Geográfica: Uma Aplicação ao Estudo de Movimentos de Massa em Uma Região da Serra do Mar Paulista. Tese de doutorado. Universidade Estadual Paulista, Rio Claro, p. 314.

MANCEBO, O. (2001) Apiaí: do sertão à Civilização: História Regional - Apiaí no Alto Ribeira e Arredores. Editora - Ômega, São Paulo - SP, 01-4106 - 279p.

MARCHI, L. AND TECCA, R.P. (2006) Some Observations on the use of data from Historical Documents in Debris Flow studies. Nat. Hazards - Springer p. 301-320.

MATOS, L. J., VIEIRA. B.C, FERREIRA. C. J. (2017) Avaliação da Vulnerabilidade das Construções às Corridas de Detritos por meio do método PTVA (Papathoma Tsunami Vulnerability Assessment). Boletim Paulista de Geografia, ISSN 2447-0945, Vol. 97, p.42-65. 
MEIS, M. R. M \& SILVA, J.X. (1968) Considerações geomorfológicas a propósito dos movimentos de massa ocorridos no Rio de Janeiro, Rev. Bras. Geografia, ano 30, n. $1, \mathrm{p} 55-73$.

MELLO, C, S. I., BETTENCOURT, S. J (1998) Geologia e gênese das mineralizações associadas ao maciço itaoca, Vale do Ribeira, SP e PR. Revista Brasileira de Geociencias, Vol 28 (3) - p. 269-284.

MICHELL, J, K. (1989) "Urban metabolism and disaster vulnerability in an era" In: Schellhhuber, H. J. and Wenzel, V Schel In:. (Eds), Earth System Analystics: Interacting Science for Sustainability, Springer, Berlin and Heidelberg, p 359-77.

MURILLO-GARCIA, F. ROSSI, M. FIORUCCI, F. ALCÀNTARA-AYALA, I (2017). Population Landslide Vulnerability Evaluation: The Case of the Indigenous Population of Pahuatlán-Puabla, México. Engireering Geology for Society - 14: (7) 1241-1261. DOI: 10.1007S11629-016-4179-9.

NAKAZAWA, V.A.; CERRI, L.E.S. (1990) - Os escorregamentos ocorridos em Petrópolis - RJ em fevereiro de 1988: ações emergenciais. In: Simpósio LatinoAmericano sobre Risco Geológico Urbano, I, 1990, Atas/ABGE, p.325-333.

NEUMAYER, E, PLÜMPER, T (2007) The gendered nature of natural disasters: the impact of catastrophic events on the gender gap in life expectancy, 1981-2002. Anais da Associação dos Geógrafos Americanos, 97(3). DOI: 10.1111/j.14678306.2007.00563.x - 551-566p.

ORGANIZAÇÃO DAS NAÇÕES UNIDAS (ONU) - ISDP (2009) Terminology on disaster risk reduction. United Nations, Geneva, Switzerland, Maio, 2009 p. 30.

PAPATHOMA, K, M., NEUHÄUSER, B., RATZINGER, K.,WENZEL, H., \& DOMINEY, $\mathrm{H}$, D. (2007). Elements at risk as a framework for assessing the vulnerability of communities to landslides. Natural Hazards and Earth System Sciences, 7, 765 e 779.

PAPATHOMA. M and HOWES D. (2003). Tsunami vulnerability assessment and its implications for coastal hazard analysis and disaster management planning, Gulf of Corinth, Greece. Natural Hazards and Earth System Sciences, 3, European Geosciences Union. p. 733-747.

PELLERIN, J., DUARTE, G. M., SCHEIBE, L. F., MENDONÇA. M., BUSS, M. D., MONTEIRO, M. A. (1996) "Timbé do Sul - Jacinto Machado: Avaliação preliminar da extensão da catástrofe de 23-24/12/95". Revista GEOSUL, Florianópolis., v 12, nº 23 , p. $71-86-1^{\circ}$ Semestre de 1997.

PETRI, S. e SUGUIO, K. (1971) Características granulométricas dos materiais de escorregamentos de Caraguatatuba, São Paulo, como subsídio para o estudo da sedimentação neocenozóica do sudeste brasileiro. Anais 25ํㅡㄹ Congresso Brasileiro de Geologia. São Paulo, Vol. 1 ed. 2o - p. 70-82.

PORTILLA, M., CHEVALIER, G., HÜRLIMANN, M., (2010). Description and analysis of the debris flows occurred during 2008 in the Eastern Pyrenees. Natural Hazards Earth Syst. Sci. DOI: 10,1635-1645,2020. p. 1636-1645. 
PREFEITURA MUNICIPAL DE ITAOCA. - Fundo Social da prefeitura: Registros Históricos/fotografias dos processos naturais deflagrados em janeiro de 2014.

PROGRAMA DAS NAÇÕES UNIDAS PARA DESENVOLVIMENTO (PNUD) - Brasil (2010) Índice de Desenvolvimento Humano Municipal (IDHM) https://www.br.undp.org/content/brazil/pt/home.html. Último acesso em Junho de 2020.

ROMARIS, A, D (1996) Aspectos da Vegetação do Brasil. 2ª edição, São Paulo, CDU: 581.526(081), 60p.

ROSS, J. L. S.; MOROZ, I. C. (1997) Mapa Geomorfológico do Estado de São Paulo. Laboratório de Geomorfologia. São Paulo: Departamento de Geografia - FFLCH USP/Laboratório de Cartografia Geotécnica - Geologia Aplicada - IPT/FAPESP (Fundação do Amparo à Pesquisa do Estado de São Paulo). (Mapas e Relatórios).

ROSS, S, L. J. (2002) A Morfogênese da Bacia do Ribeira do Iguape e os Sistemas Ambientais. GEOUSP - Espaço e Tempo, São Paulo, nº 12, p.21-46.

RUFAT, S. TATE, E. BURTON, G. C, MAROOF, S. A (2015). Social Vulnerability to Floods: Review of case studies and implications for Measurement. International Journal of Disaster Risk Reduction, 14: 470-486.

SANTI. P.M, HEWITT. D. F, VANDINE. E, BARILLAS, C. Debris-flow impact, vulnerability, and response. Natural Hazards - DOI 10.1007/s11069-010-9576-8 - p. 371- 402, 2011.

SANTORO, J. (2014) Atendimento emergencial no município de Itaoca (SP) In: Desastres de 2014 Na região Sudeste do Brasil. São Paulo /ABGE/ p.22-27.

SELBY, M. J. (1993). Mass Wasting of soils In: Hillsope: Materials \& process. New York, Publisher: Oxford University Press. USA. 2 editions. 480 p.

SOETERS, R., VAN WESTEN, C.J. (1996) Slope Instability Recognition Analysis and Zonation. In: Turner K.T. and Schuster, R.L., Eds., Landslides: Investigation and Mitigation, Special Report No. 247, Transportation Research Board National Research Council, Washington DC, p.129-177.

SOUZA, L. A., SOBREIRA, F. G. (2014) Guia para elaboração de cartas geotécnicas de aptidão à urbanização frente aos desastres naturais. Brasília (DF) $1^{\circ} \mathrm{Ed}$. ISBN: 978-85-917793-0-7 - P. 68

STINY, P. J. (1997). Debris Flows: An attempted monograph with particular reference to the conditions in the Tyrolean Alps. EBA Engineering Consultants Ltd., Vancouver, British Columbia. p.105.

TAKAHASHI, T. (2007) "Debris flow: Mechanics, Prediction and Countermeasures", Taylor and Francis Group, Londres 448p.

TERASSI, M, P, B. e GALVANI, E. (2017) O Efeito Orográfico da Serra do Mar e o Potencial Erosivo das Chuvas nas Bacias Hidrográficas do Ribeira e Litorânea - 
Paraná. Revista Brasileira de Climatologia. Ano 13 - Vol. 21. ISSN: 2237-8642. 327$345 p$.

TURNER, IIBL, KASPERSON, R.E, MATSONE, P.A, McCARTHY, J.J, CORELL, R.W, (2003) A framework for Vulnerability Analysis in Sustainability Science. PNAS 100 (14): 8074-8079P.

UNDRO, (1984). Disaster Prevention and Mitigation: A compendium of current knowledge. UN, New York.

VANDINE, D. F. (1996) "Debris flow control structures for forest engineering", Ministry of Forests Research Program, Victoria, British Columbia, Canadá, 68 p.

VIEIRA, B. C.; VIEIRA, A.C.F.: FERNANDES, N.F,; AMARAL, CP. Estudo comparativo dos movimentos de massa ocorridos em Fevereiro de 1996 nas bacias do Quitite e do papagaio (RJ): uma abordagem Geomorfológica. In: 2nd Panam. Symp. Landslides, $2^{\mathrm{a}}$ COBRAE, proceedings, 1997.p. 165-544.

WEICHSELGARTNER, J. (2001) Disaster mitigation: the concept of vulnerability revisited. In: Disaster Prevention and Management, Vol 10. Number 2, p.85-94.

WEINMEISTER, W. H. (2007) Integrated Debris Flow Disaster Mitigation: A comprehensive Method for Debris Flow Disaster Mitigation. Journal of Mountain Science. Vol. 4 No 4 p. 293-308.http://jms.imde.ac.cn

WELLE, J. BIRKMANN, J (2015) - The world Risk Index - an approach to asses vulnerability on a global scale. Extreme Events, Vol 2. 34p. International Journal of Disaster Risk Reduction. Vol 17 - DOI: 10.1142/S2345737615500037. p. 251-272.

WELSH, A (2007). Deliniating debris-flows hazards on alluvial fans in the Coronandel and Kaimai regions, New Zeland, using GIS. Tese em Geociências - Universidade de Canterbury, 203 p.

WEN, C. L, TING, C. T, CHI, H. H. (2012) Building Vulnerability to debris flows in Taiwan: a preliminary study. Springer - Nat. Hazards - Original Paper. p. 2107-2128.

WOLLE, C. M. e CARVALHO, C. S (1994). Taludes Naturais. In F. F. Falconi and A. N. Jr. (eds), Solos do litoral de São Paulo. Associação Brasileira de Mecânica de Solos Núcleo Regional de São Paulo - ABMS, São Paulo, pp. 180-203.

YI WU, C. (2003) "Numerical Modelling on the motion and deposition behaviors of debris flow”, Dissertação de Mestrado - Escola de Engenharia Civil, NCKU, Tailândia. 
ANEXO 1: Densidade da população (Dimensão de Sensibilidade)

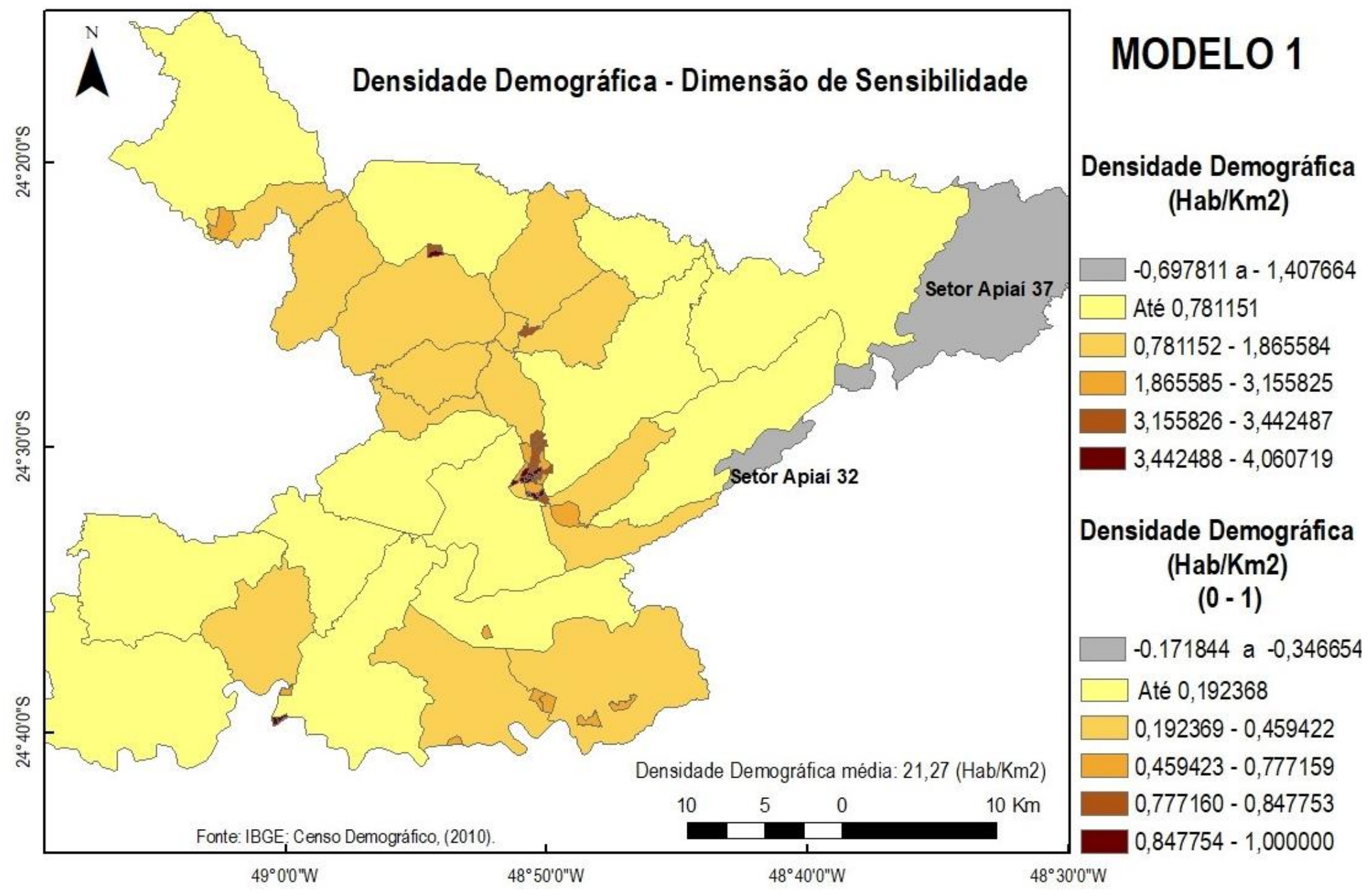


ANEXO 2: População Feminina (Dimensão de Sensibilidade)

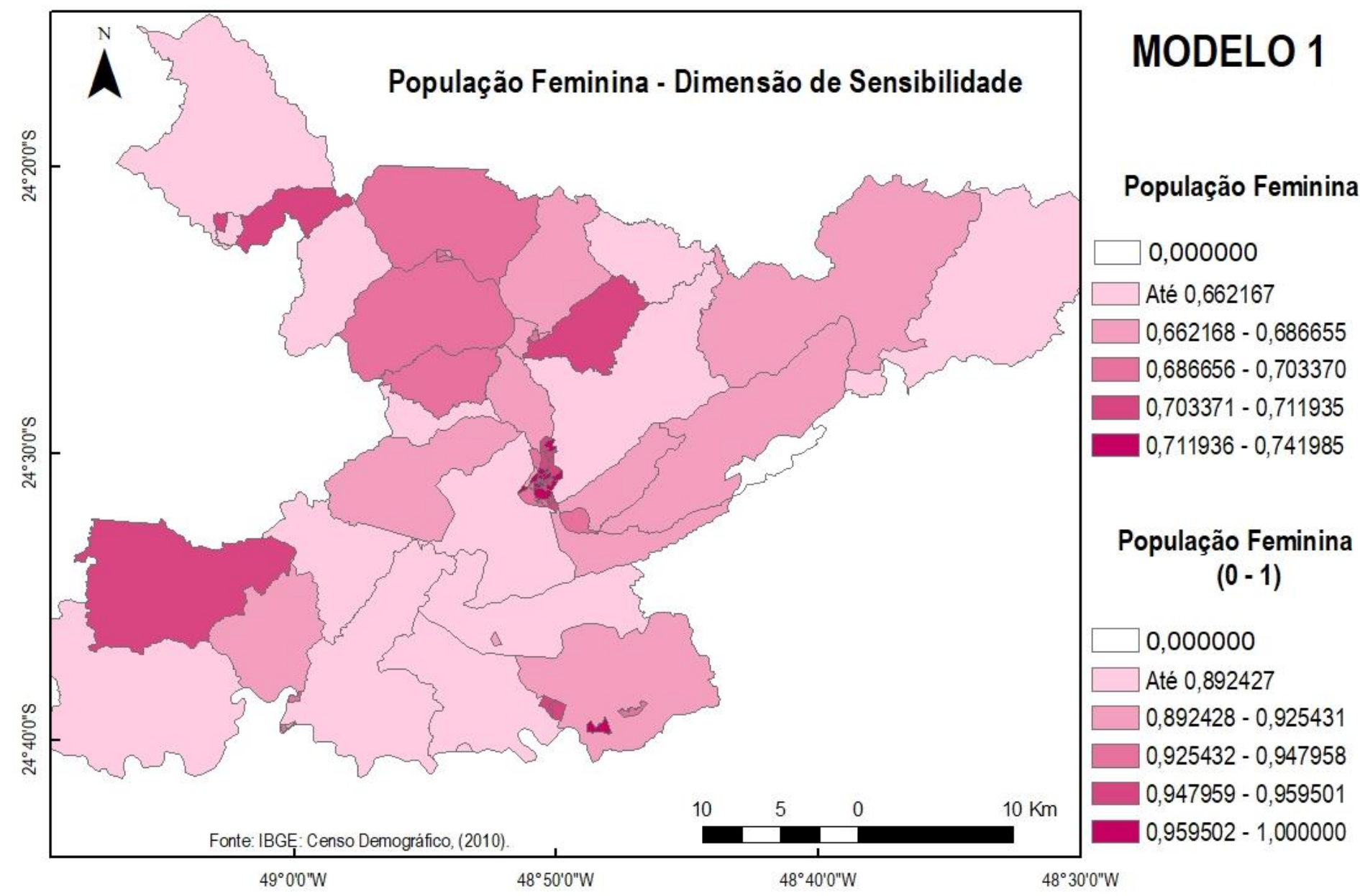


ANEXO 3: População Infanto-Juvenil (Dimensão de Sensibilidade)

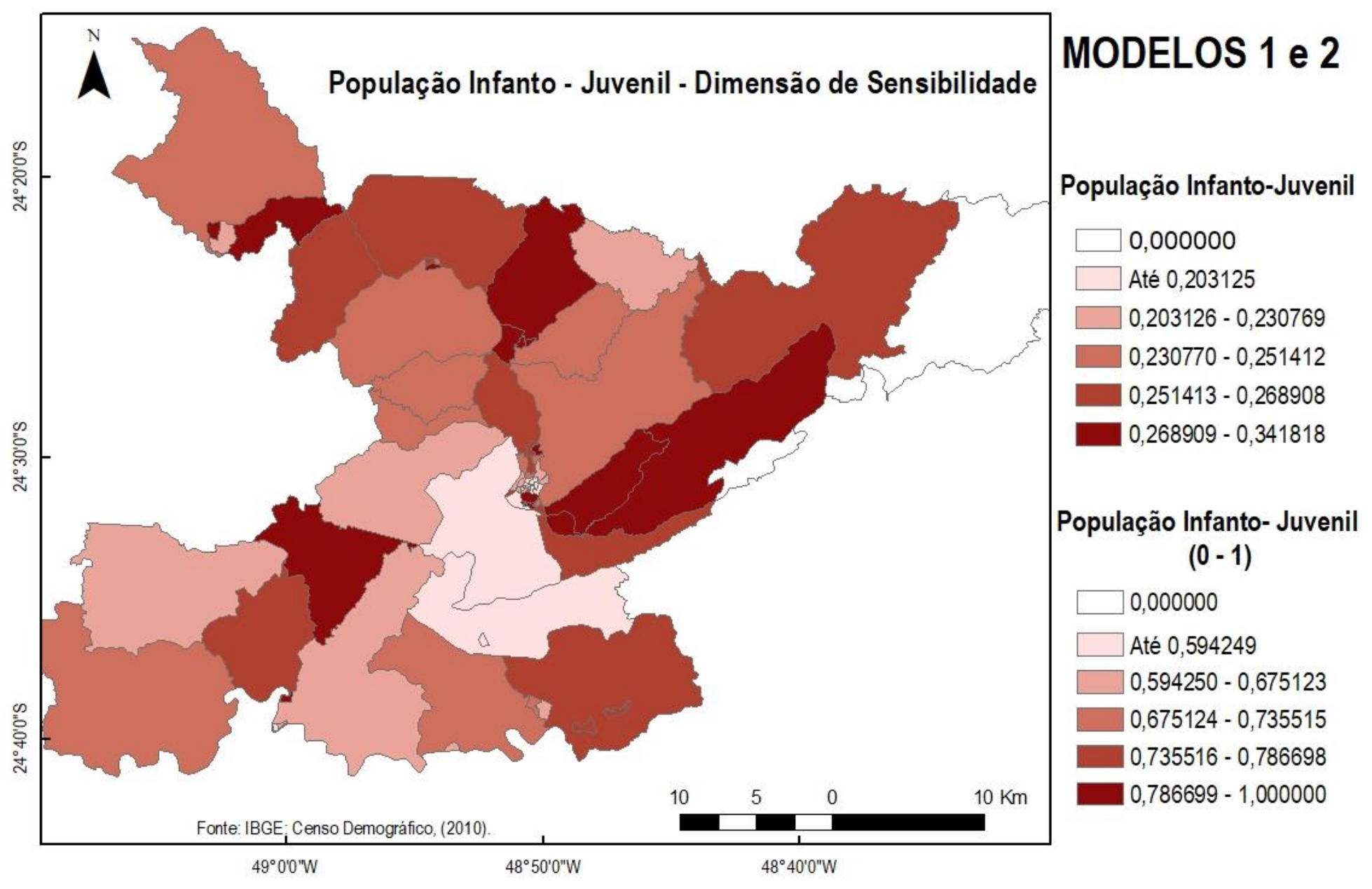


ANEXO 4: População Idosa (Dimensão de Sensibilidade)

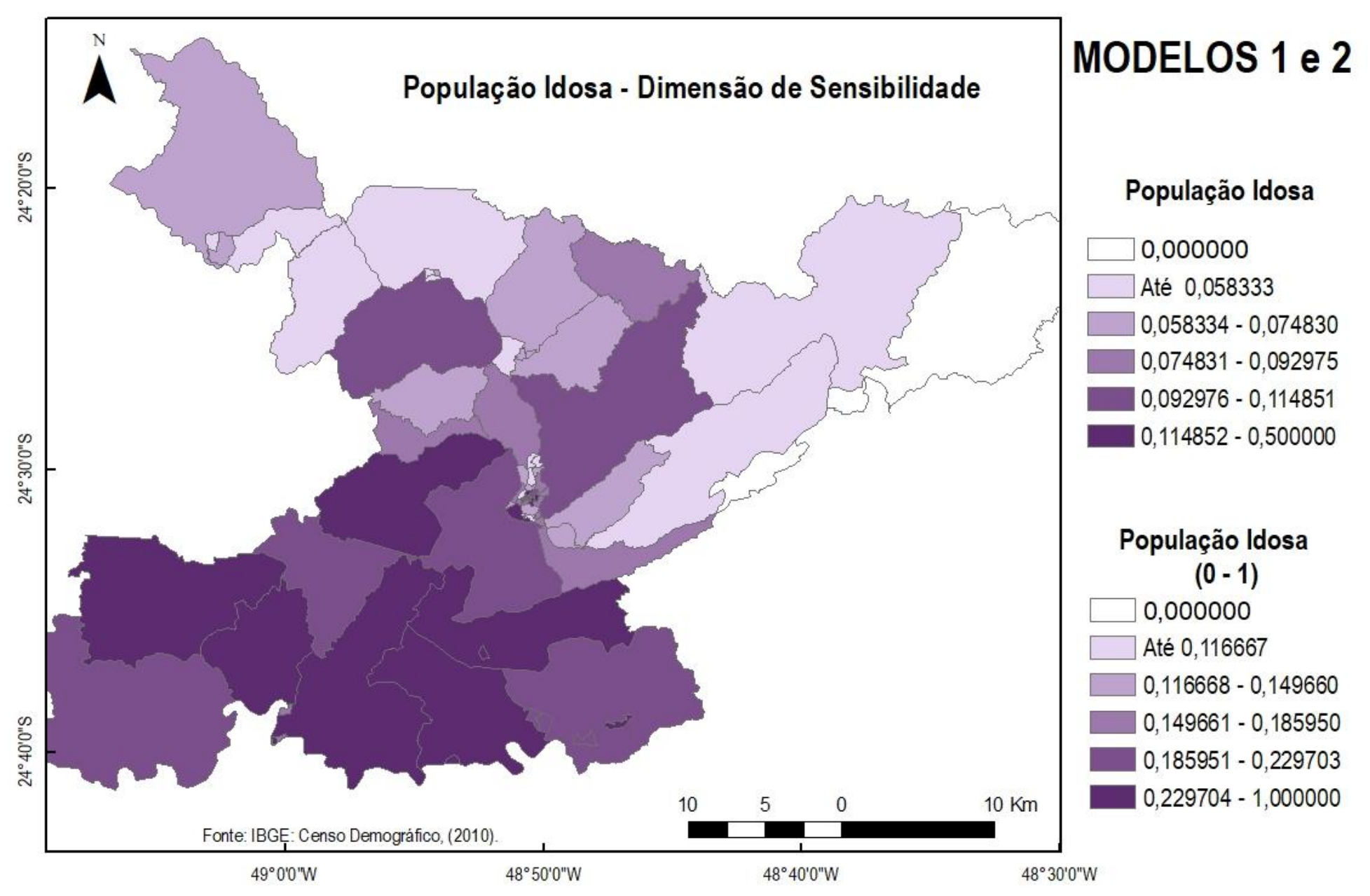


ANEXO 5: Exposição Final da População - MODELO 1

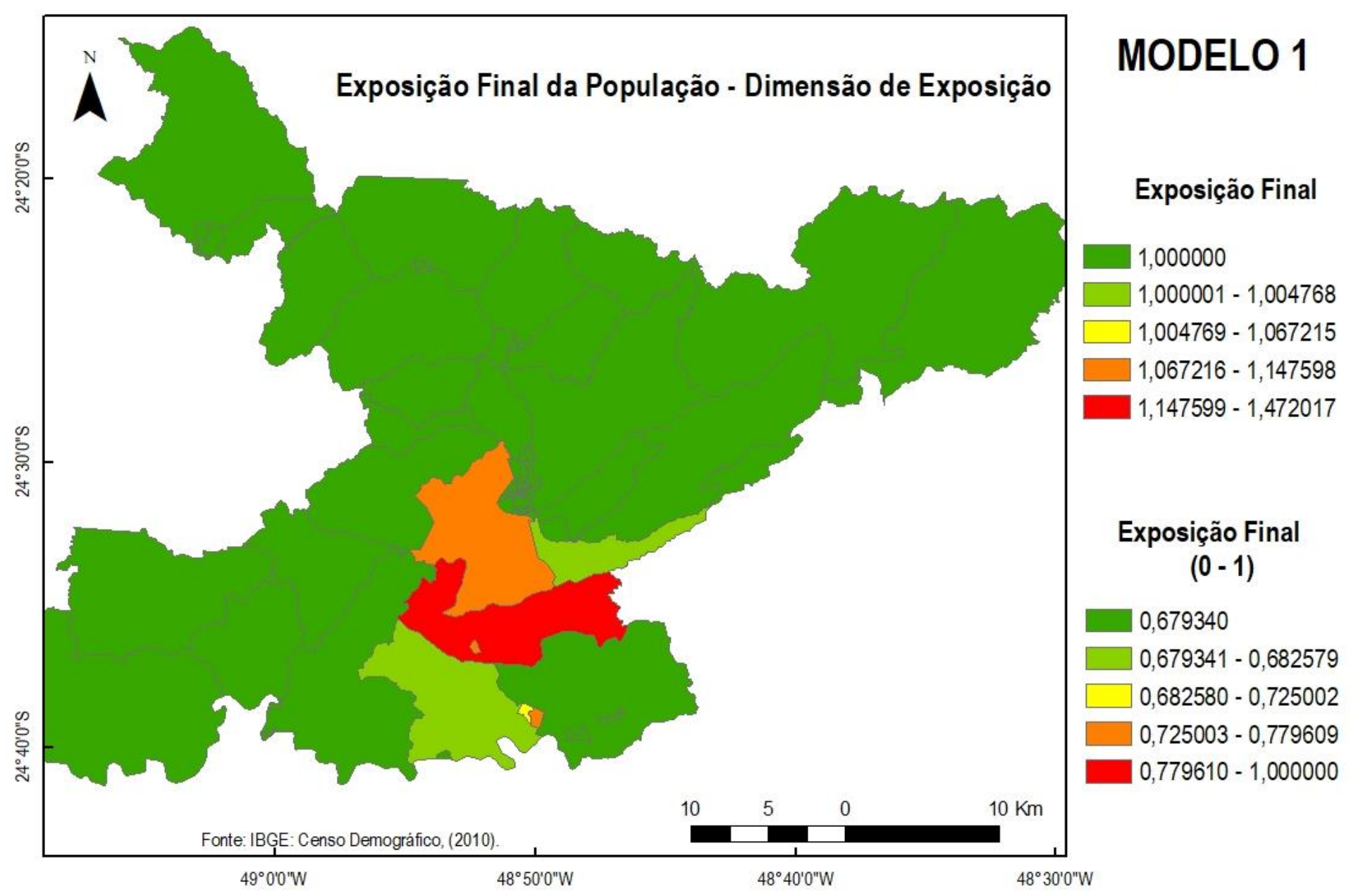

